\author{
Monograph \\ urn:lsid:zoobank.org:pub:FE4ED74A-3FE6-4CA6-A116-CB3AF46826F7
}

\title{
Systematic revision of Platevindex Baker, 1938 (Gastropoda: Euthyneura: Onchidiidae)
}

\section{Tricia C. GOULDING ${ }^{1}$, Adam J. BOURKE ${ }^{2}$, Joseph COMENDADOR ${ }^{3}$, Munawar KHALIL ${ }^{4}$, Ngo Xuan QUANG ${ }^{5}$, Shau Hwai TAN ${ }^{6}$, Siong Kiat TAN ${ }^{7}$ \& Benoît DAYRAT ${ }^{8, *}$}

${ }^{1,8}$ Department of Biology, Pennsylvania State University, University Park, PA 16802, USA.

${ }^{1}$ Current address: Smithsonian Institution, National Museum of Natural History, PO Box 37012, MRC 163, Washington, DC, 20013, USA.

${ }^{2}$ College of Engineering, Information Technology and the Environment,

Charles Darwin University, Ellengowan Dr., Casuarina, NT 0810, Australia.

${ }^{3}$ National Museum of the Philippines, Taft Ave., Ermita, Manila, 1000 Metro Manila, Philippines.

${ }^{4}$ Department of Marine Science, Faculty of Agriculture, Universitas Malikussaleh,

Reuleut Main Campus, Kecamatan Muara Batu, North Aceh, Aceh, 24355, Indonesia.

${ }^{5}$ Institute of Tropical Biology, Vietnam Academy of Science and Technology,

85 Tran Quoc Toan Street, District 3, Ho Chi Minh City, Vietnam.

${ }^{5}$ Graduate University of Science and Technology, Vietnam Academy of Science and Technology, 18 Hoang Quoc Viet, Cau Giay, Hanoi, Vietnam.

${ }^{6}$ Centre for Marine and Coastal Studies, Universiti Sains Malaysia, 11800 Minden Penang, Malaysia.

${ }^{6}$ Marine Science Laboratory, School of Biological Sciences,

Universiti Sains Malaysia, 11800 Minden Penang, Malaysia.

${ }^{7}$ Lee Kong Chian Natural History Museum, 2 Conservatory Dr,

National University of Singapore, 117377, Singapore.

*Corresponding author: bad25@psu.edu

${ }^{1}$ Email: tc.goulding@gmail.com

${ }^{2}$ Email: adamjohn.bourke@gmail.com

${ }^{3}$ Email: joseph.comendador@gmail.com

르ail:khalil@unimal.ac.id

5Email: ngoxuanq@gmail.com

${ }^{6}$ Email: aileen@usm.my

${ }^{7}$ Email: nhmtsk@nus.edu.sg

\footnotetext{
${ }^{1}$ urn:1sid:zoobank.org:author:6009A165-E73E-4124-96C6-C143FC51B18F

${ }^{2}$ urn:lsid:zoobank.org:author:AAF38199-57BF-4E7E-A888-468A9B01720C

${ }^{3}$ urn:1sid:zoobank.org:author:0EAAEF74-7E54-47BA-9A3A-D3A4ED40AD85

${ }^{4}$ urn:lsid:zoobank.org:author:6D38234D-0DE1-4CDE-9F7E-603070C9B27D

${ }^{5}$ urn:lsid:zoobank.org:author:AD2EB983-517E-435A-BEDB-B51BC442D42C

${ }^{6}$ urn:Isid:zoobank.org:author:6E9B8F28-EFCC-42F1-A7C4-3957C92995AA

${ }^{7}$ urn:lsid:zoobank.org:author:1BFA4D8E-30CE-4DC4-A6C2-64E0281996DF

${ }^{8}$ urn:1sid:zoobank.org:author:192B0AF4-A4B0-4129-8422-DEF8D0FB4A45
} 


\begin{abstract}
In the Indo-West Pacific, intertidal slugs of the genus Platevindex Baker, 1938 are common in mangrove forests, where they typically live on the roots and trunks of mangrove trees. These slugs are easily distinguished from most onchidiids by their hard notum and narrow foot, but despite their large size and abundance, species diversity and geographic distributions have remained a mystery. With the aid of new collections from across the entire Indo-West Pacific, the taxonomy of Platevindex is revised using an integrative approach (natural history field observations, re-examination of type specimens, mitochondrial and nuclear DNA sequences, and comparative anatomy). In this monograph, nine species of Platevindex are recognized, including one new to science: P. amboinae (Plate, 1893), P. applanatus (Simroth, 1920) comb. nov., P. aptei Goulding \& Dayrat sp. nov., P. burnupi (Collinge, 1902) comb. nov., P. coriaceus (Semper, 1880), P. latus (Plate, 1893), P. luteus (Semper, 1880), P. martensi (Plate, 1893) and $P$. tigrinus (Stoliczka, 1869) comb. nov. Five species names are recognized as junior synonyms, four of which are new, and two Platevindex names are regarded as nomina dubia. One new subspecies is also recognized: P. coriaceus darwinensis Goulding \& Dayrat subsp. nov. Most species were previously known only from the type material and many new geographic records are provided across the Indo-West Pacific, from South Africa to the West Pacific (Japan, New Ireland and New Caledonia).
\end{abstract}

Keywords. Biodiversity, Indo-West Pacific, integrative taxonomy, revisionary systematics, South-East Asia.

Goulding T.C., Bourke A., Comendador J., Khalil M., Quang N.X., Tan S.H., Tan S.K. \& Dayrat B. 2021. Systematic revision of Platevindex Baker, 1938 (Gastropoda: Euthyneura: Onchidiidae). European Journal of Taxonomy 737: 1-133. https://doi.org/10.5852/ejt.2021.737.1259

\title{
Table of Contents
}

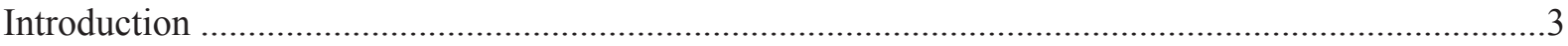

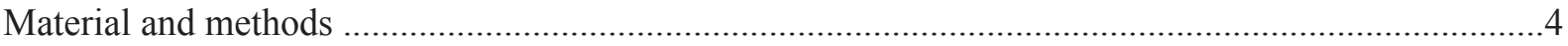

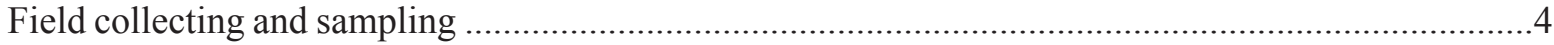

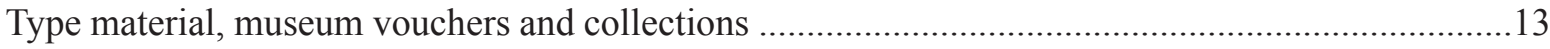

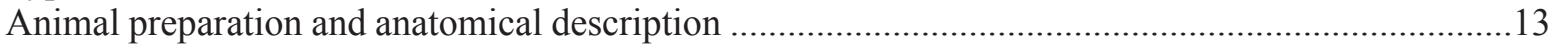

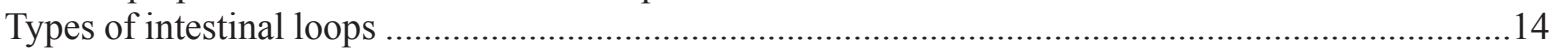

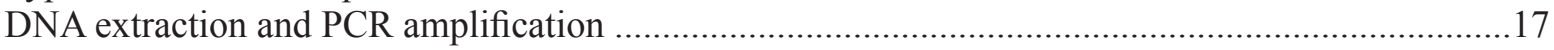

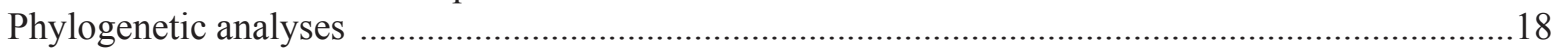

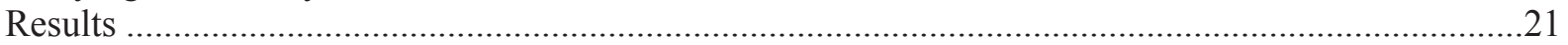

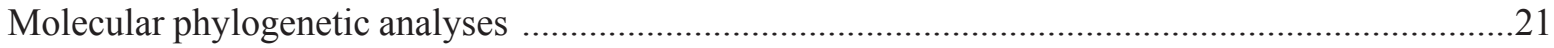

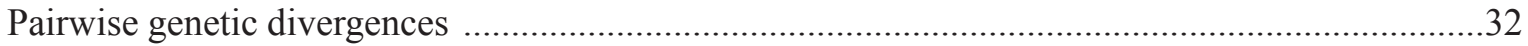

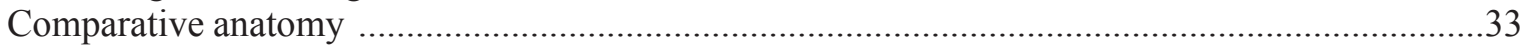

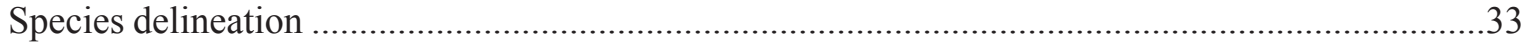

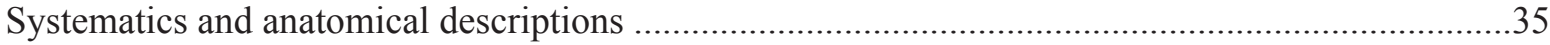

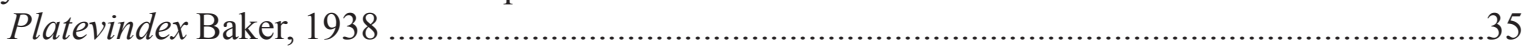

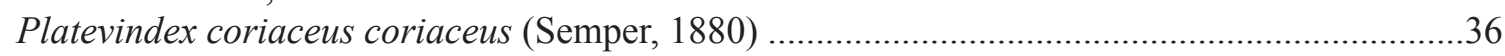

Platevindex coriaceus darwinensis Goulding \& Dayrat subsp. nov. ...........................................56

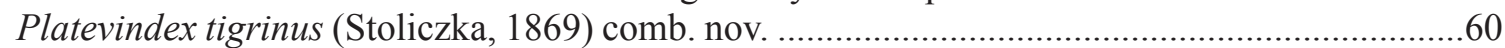

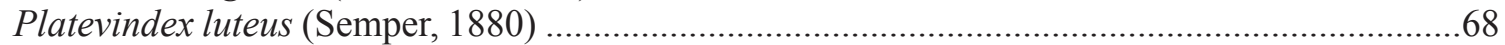

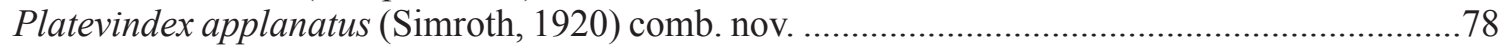

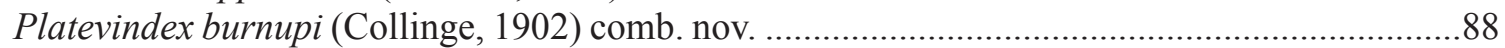

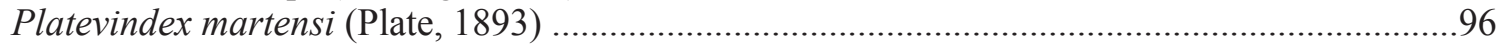

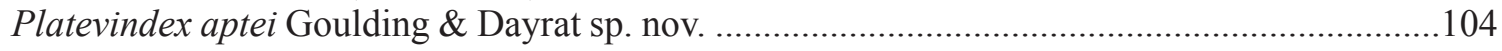

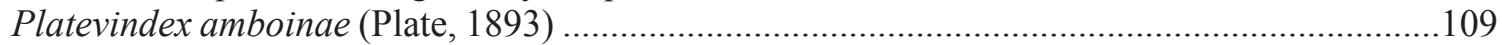

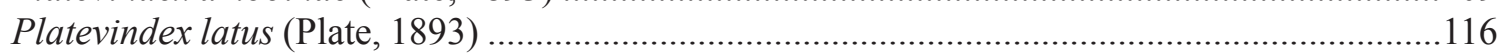

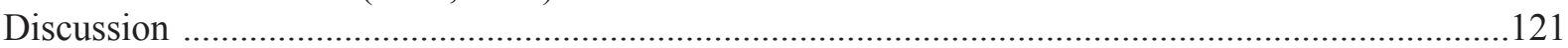

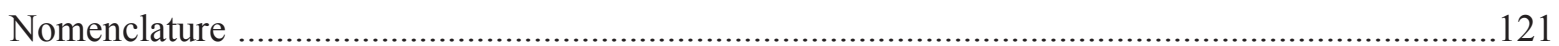




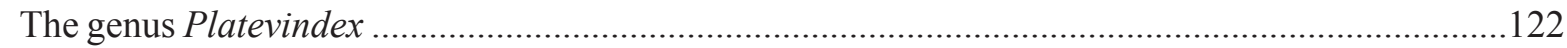

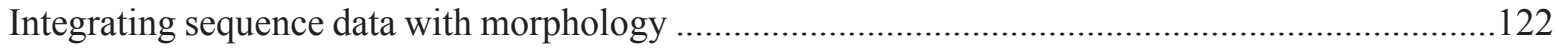

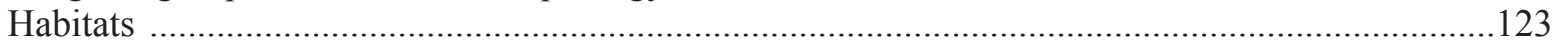

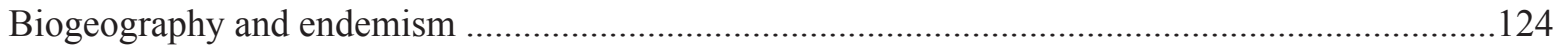

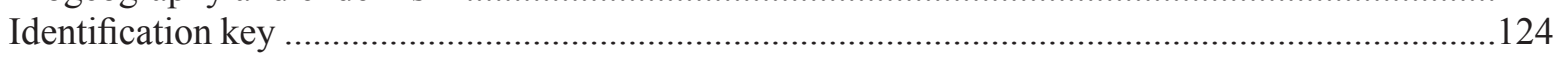

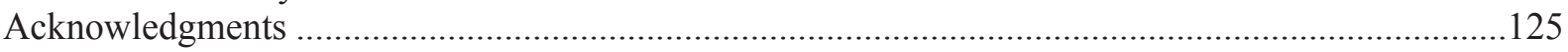

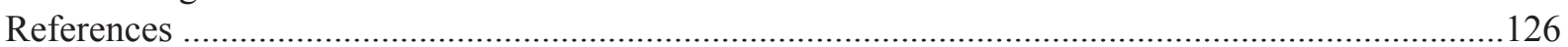

\section{Introduction}

In the tropics and subtropics, mangrove forests are home to a diverse array of invertebrates, fish and birds, and provide important ecosystem services (Dorenbosch et al. 2005; Lee 2008; Luther \& Greenberg 2009; Vo et al. 2012). Mangrove forests were once widespread across South-East Asia, but forest coverage has declined substantially since the beginning of the $21^{\text {st }}$ century due to land reclamation for development, agriculture, aquaculture and logging (Spalding et al. 1997; Valiela et al. 2001; Long et al. 2014; Richards \& Friess 2016). These forests are further threatened by rising sea levels due to climate change (Lovelock et al. 2015). Mangroves host much higher plant and animal diversity in the tropical Indo-West Pacific than in the Americas (Ellison et al. 1999; Hoeksema 2007), but this diversity remains poorly known, especially for invertebrates. As a dominant component of mangrove ecosystems, molluscs play an important role in food webs through nutrient cycling (Kristensen et al. 2008) and serve as prey for other molluscs, crustaceans and fish (Hill 1976; Hughes 1984; Cannicci et al. 1998; Tan \& Oh 2002). In order to conserve healthy mangrove ecosystems, it is imperative to understand the diversity, biogeography and natural history of mangrove molluscs.

Even though onchidiid slugs are one of the dominant groups of gastropods in the mangrove forests of South-East Asia and Australia, they have often been overlooked in surveys of mangrove invertebrates. This is likely due to their camouflage with mud and tree bark, but also because many species, even from different genera, are extremely difficult to distinguish (e.g., slugs of the genera Paromoionchis Dayrat \& Goulding, 2019 and Laspionchis Dayrat \& Goulding, 2019; Dayrat et al. 2019a, 2019b). Some of the challenges with onchidiid taxonomy are those that taxonomists often face: few specimens from mangroves available in museum collections, type material often destroyed or lost, and difficulty in identifying informative characters (Dayrat 2009). In spite of those difficulties, the taxonomy of the onchidiids is being revised systematically, genus by genus, based on an unprecedented effort in collecting fresh material worldwide (Dayrat et al. 2016, 2017, 2018, 2019a, 2019b, 2019c, 2019d, 2020; Dayrat \& Goulding 2017; Goulding et al. 2018a, 2018b, 2018c).

The genus Onchidium Buchannan, 1800, which previously was used by default for many unrelated onchidiid species in the Indo-West Pacific, has been shown to include only four species restricted to mangroves (Dayrat et al. 2016, 2019d). Three genera have been described over the last few years for species formerly included in the genus Onchidium as well as species newly discovered; these include Wallaconchis Goulding \& Dayrat, 2018, found in sandy mangroves and coral rubble (Goulding et al. 2018b), Marmaronchis Dayrat \& Goulding, 2018, found on rocky shores (Dayrat et al. 2018) and Paromoionchis from muddy mangrove forests (Dayrat et al. 2019a). Three additional genera of mangrove onchidiids were described based entirely on new species: Melayonchis Dayrat \& Goulding, 2017 (Dayrat et al. 2017, 2019c), Laspionchis (Dayrat et al. 2019b), and Alionchis Goulding \& Dayrat, 2018 (Goulding et al. 2018). Two other existing genera of onchidiids associated with mangroves have also been revised: Onchidina Semper, 1882 (Dayrat \& Goulding 2017) and Peronina Plate, 1893 (Goulding et al. 2018c). Platevindex Baker, 1938, one of the most diverse onchidiid genera, is revised here, with numerous new geographic records that reveal the broad distributions of most species. Most Platevindex slugs live on wood in muddy mangrove forests, either on the roots and trunks of mangrove trees or on logs, and they are generally abundant in estuarine mangrove forests. 
Platevindex slugs can easily be recognized in the field due to their dorso-ventrally flattened body, their hard notum and their narrow foot (usually less than one third of the total width). Unlike other mangrove onchidiids, Platevindex slugs were recognized early on as distinct from other onchidiids and were first classified in the genus Oncis Plate, 1893. However, this name is a junior objective synonym of Onchis Férussac, 1822 (see our remarks on the generic name), and the valid generic name for the genus revised here is Platevindex, established by Baker (1938) with Onchidium coriaceum Semper, 1880 as the type species, by original designation. The diversity of Platevindex is revised using an integrative approach based on fresh material from the entire Indo-West Pacific (including most type localities of existing species names), a re-examination of all onchidiid type specimens available, a review of all original descriptions, and species delineations combining comparative anatomy, mitochondrial (COI and 16S) and nuclear (ITS2, 28S and H3) DNA sequences. Because the taxonomy of Platevindex has never been revised, the anatomy of many of the species is described in detail here for the first time (most original descriptions were brief and based on few specimens) and many new geographical records are provided (most species were known only from their type localities).

Nine species are recognized in Platevindex, one of which was undescribed: P. amboinae (Plate, 1893) comb. nov., P. applanatus (Simroth, 1920) comb. nov., P. aptei Goulding \& Dayrat sp. nov., P. burnupi (Collinge, 1902) comb. nov., P. coriaceus (Semper, 1880), P. latus (Plate, 1893) comb. nov., P. luteus (Semper, 1880) comb. nov., P. martensi (Plate, 1893) comb. nov. and P. tigrinus (Stoliczka, 1869) comb. nov. One new subspecies is also described here: P. coriaceus darwinensis Goulding \& Dayrat subsp. nov.

\section{Material and methods}

\section{Field collecting and sampling}

All specimens used in this study were collected by at least one of the authors, with the exception of 14 specimens from Papua New Guinea (Madang and Kavieng), Vanuatu, and New Caledonia collected during expeditions led by Philippe Bouchet and borrowed from the Muséum national d'histoire naturelle, 5 specimens from South Africa collected by Mary Cole and borrowed from the East London Museum, South Africa, 3 specimens of P. latus from the Zoologisches Museum Hamburg, 28 specimens of $P$. coriaceus from the Western Australian Museum, as well as the many type specimens borrowed from various institutions. Collecting parties were led by Benoît Dayrat in the Andaman Islands and West Bengal (India), Brunei, Malaysia, Northern Territory (Australia), the Philippines and Singapore, by Tricia Goulding in Queensland (Australia), Madagascar, Mauritius, Maharashtra and Tamil Nadu (India) and Vietnam, and by Munawar Khalil in Indonesia.

Specimens were collected by hand at low tide. GPS coordinates are available for all stations. At each site, photographs were taken to document the habitat (e.g., dense or open mangrove forest, sediment type, plant species) as well as the exact microhabitats where specimens were collected (e.g., mud surface, tree trunk, old $\log$ ). In the field, specimens were individually numbered and photographed. At each site, individuals were chosen to represent variation in color and size. A notum piece was cut from most specimens for DNA extractions (in 95\% ethanol) so that each DNA sequence corresponds to a particular preserved specimen and a series of field photographs. After those cuts for DNA extractions, animals were relaxed in magnesium chloride $\left(\mathrm{MgCl}_{2}\right)$ for approximately 24 hours and then preserved in $70 \%$ ethanol for comparative anatomy. Relaxed specimens from Sumatra, Sulawesi and Queensland were fixed in formalin prior to being transferred into $70 \%$ ethanol.

In total, 229 specimens of Platevindex are included in this study, not counting the many type specimens of existing nominal species. DNA sequences are provided for 184 specimens of Platevindex (Table 1). Specimens with no DNA sequences are marked in the list of material examined as "[no DNA]" or with a number in brackets (i.e. "[\#1]") if the specimen is illustrated. Specimens with no DNA sequences include 


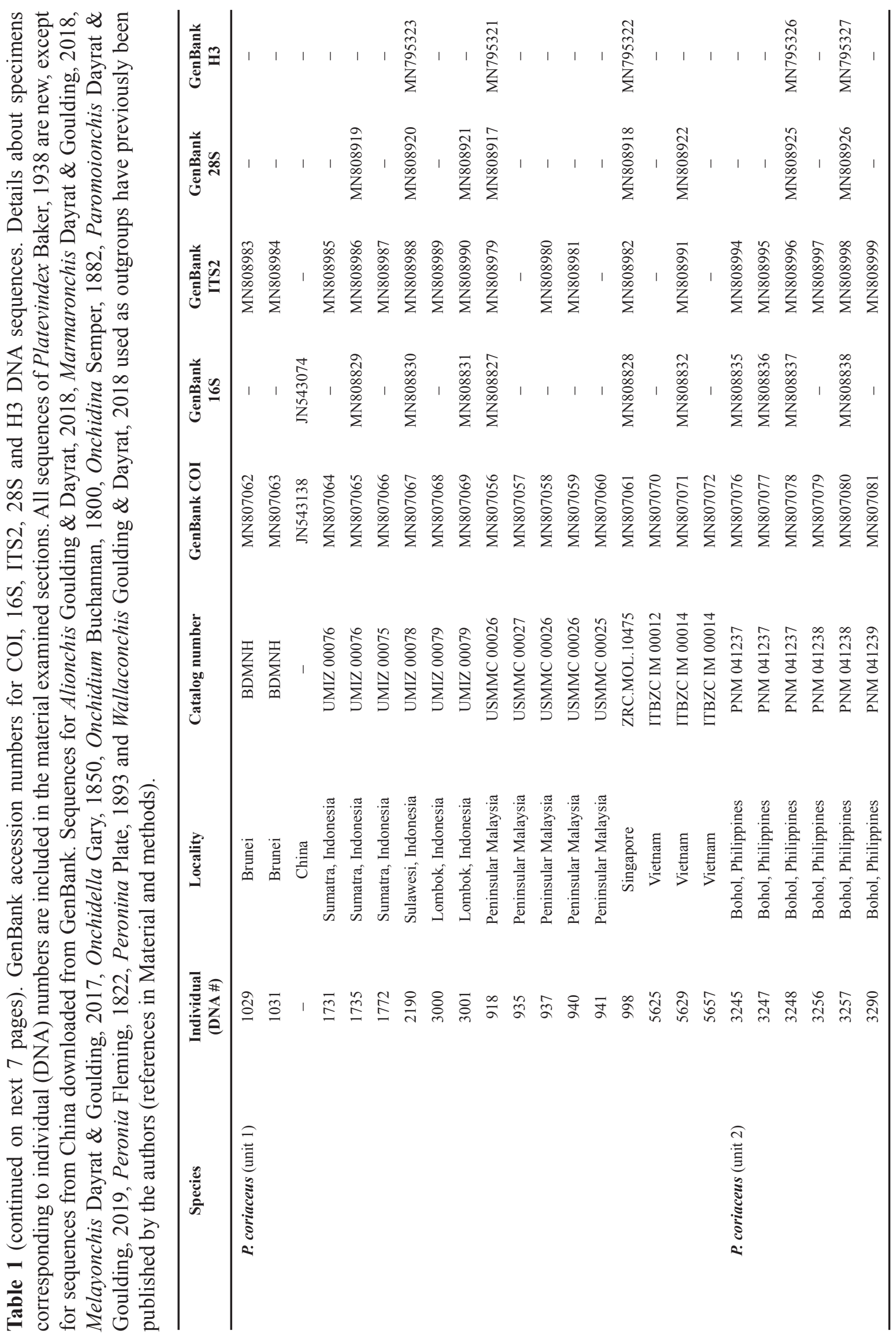




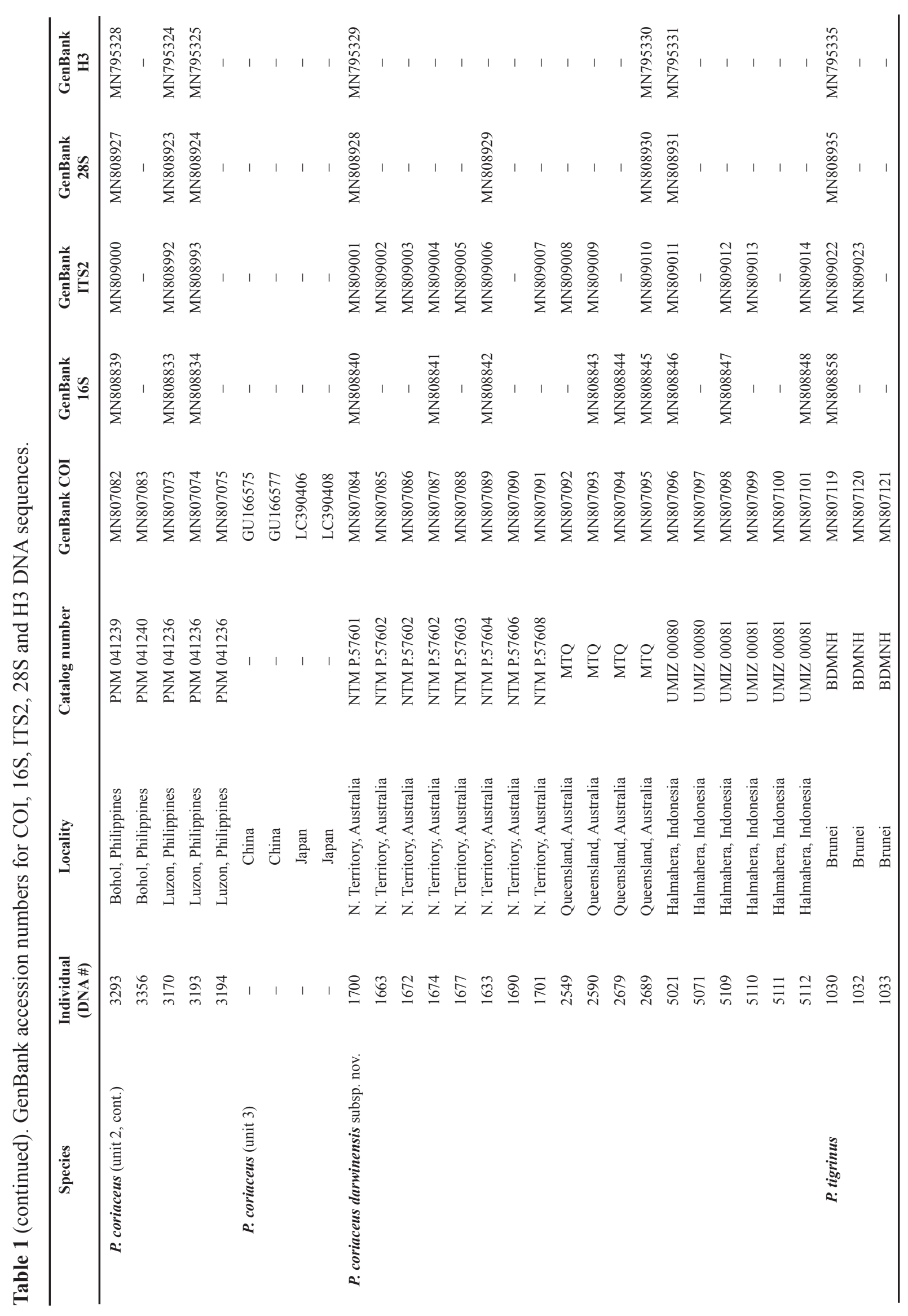




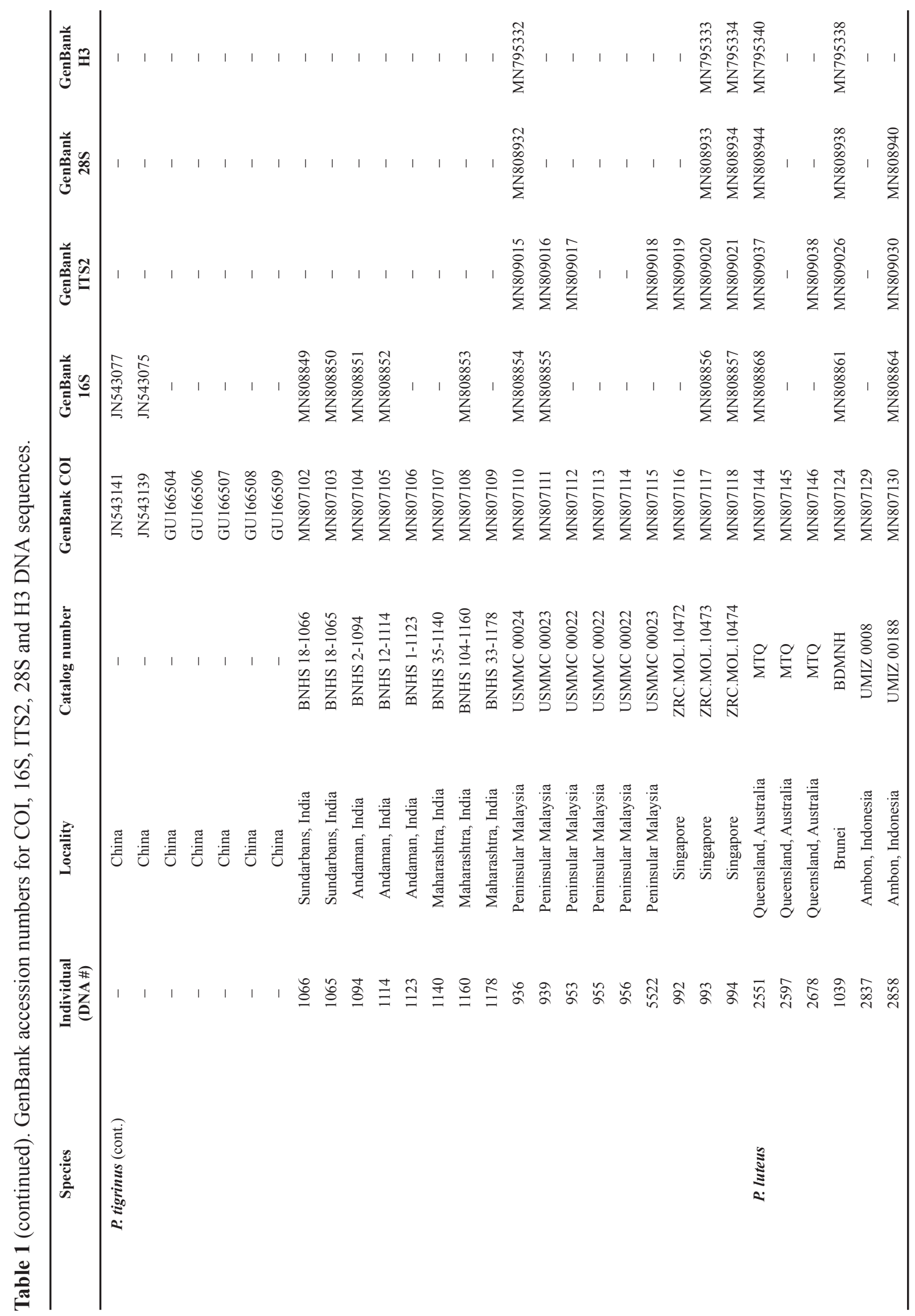




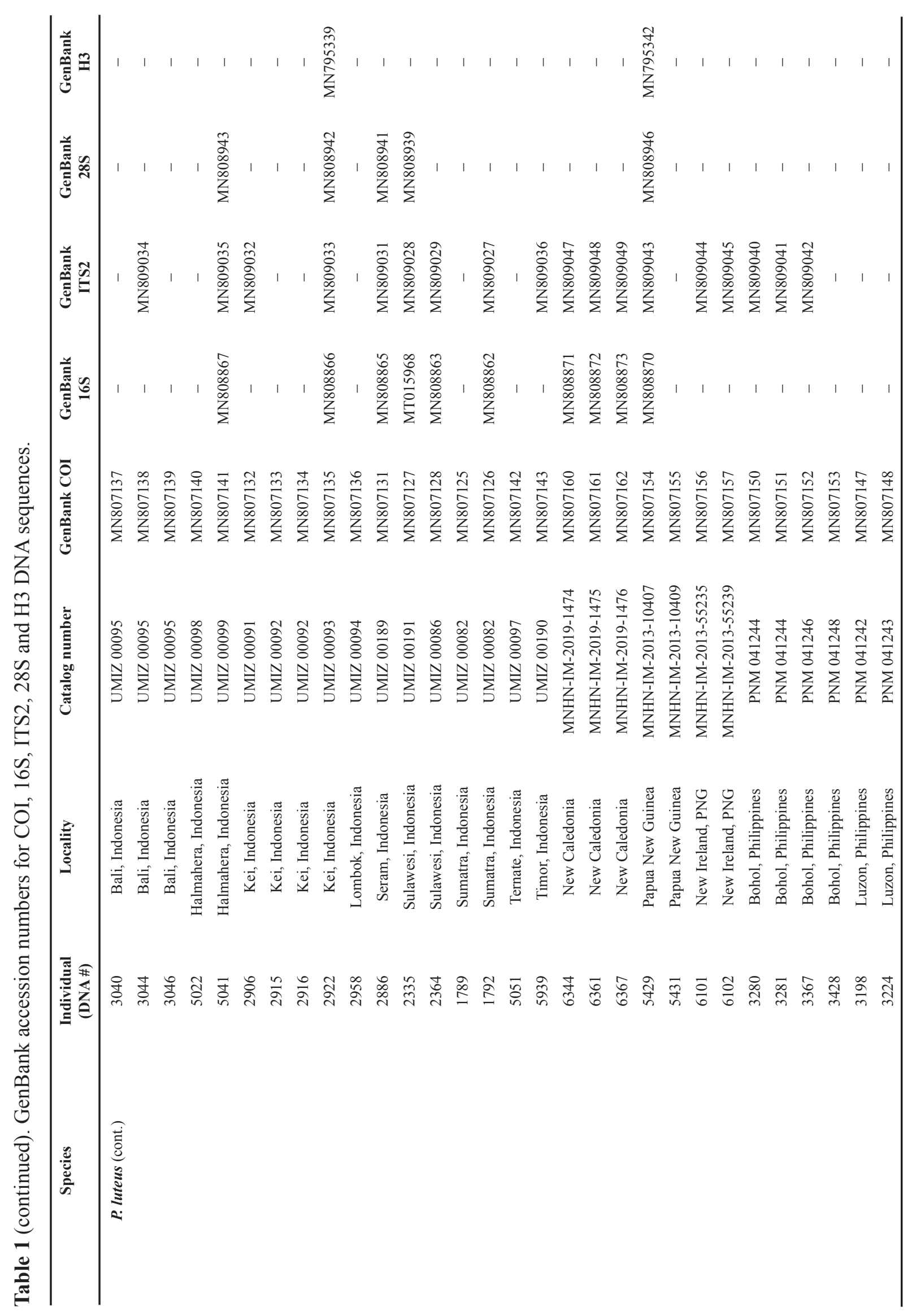




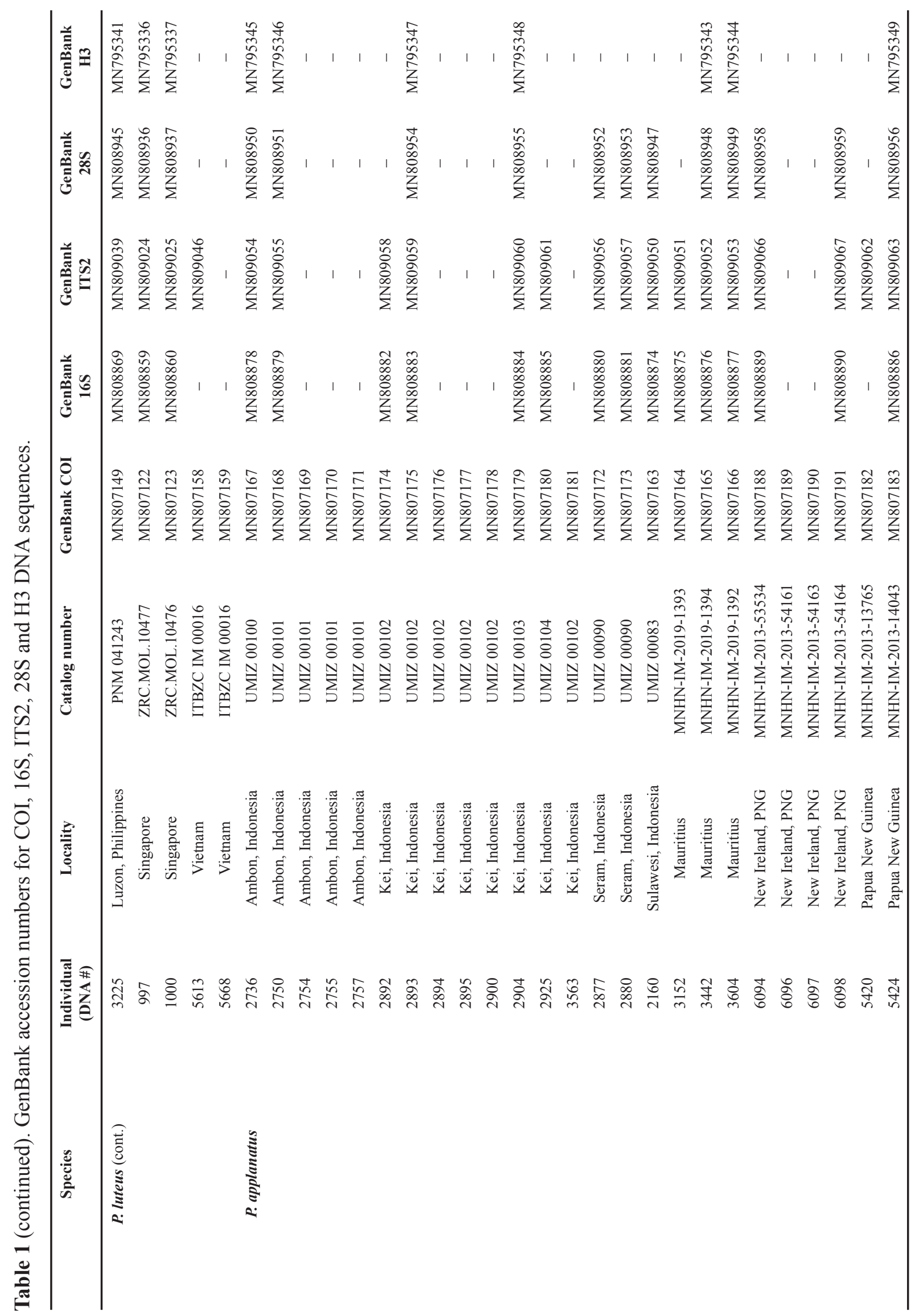




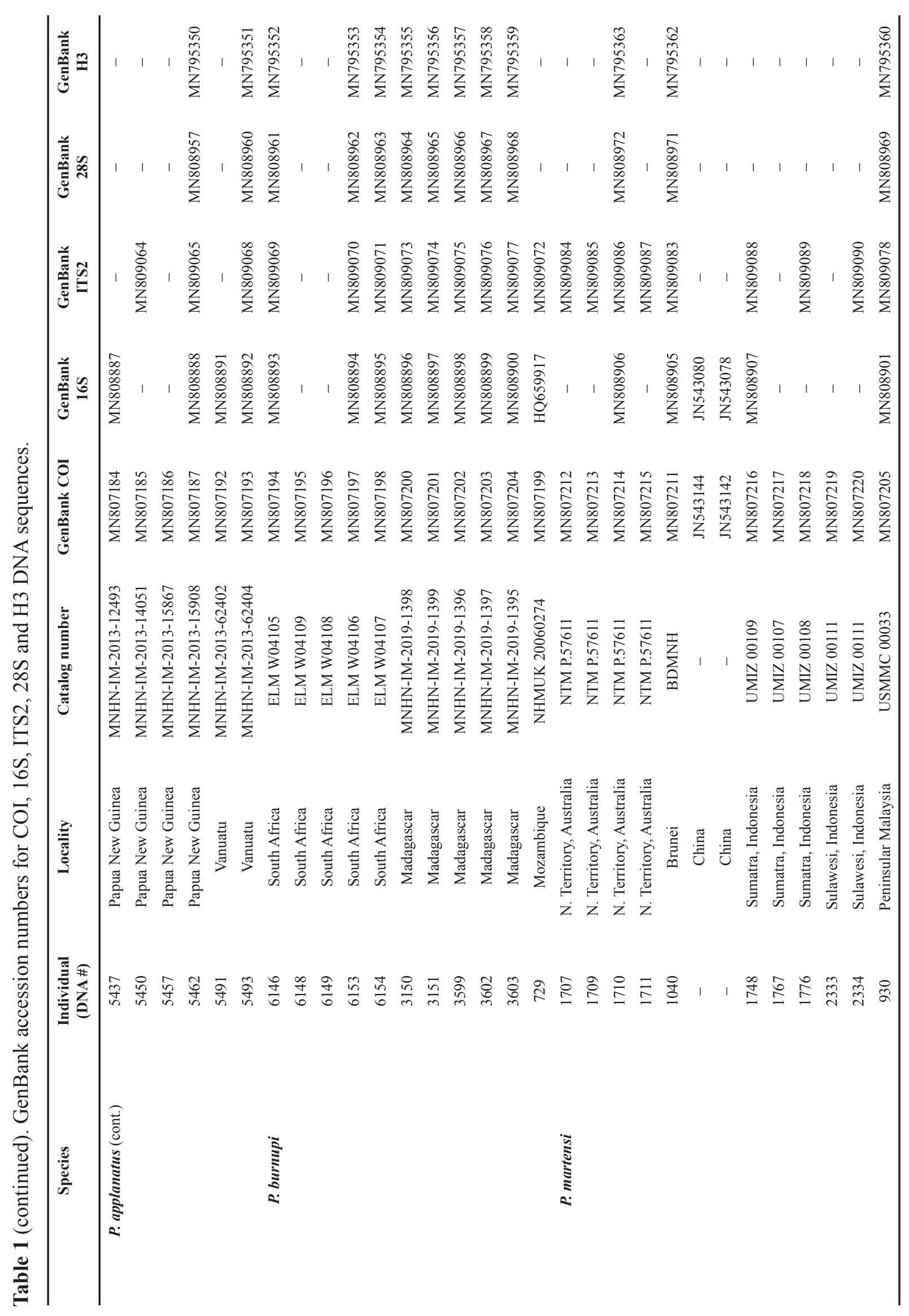




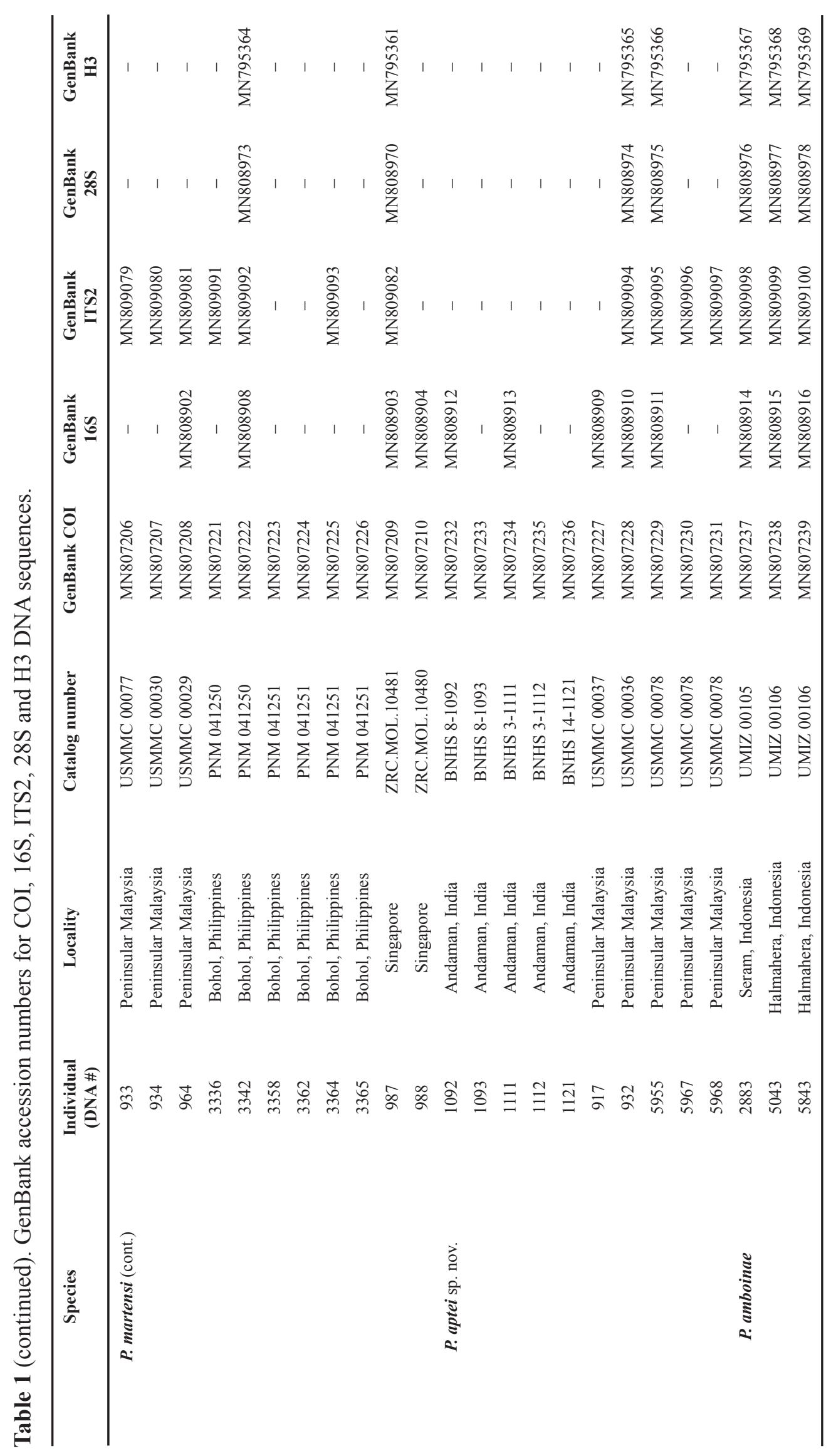




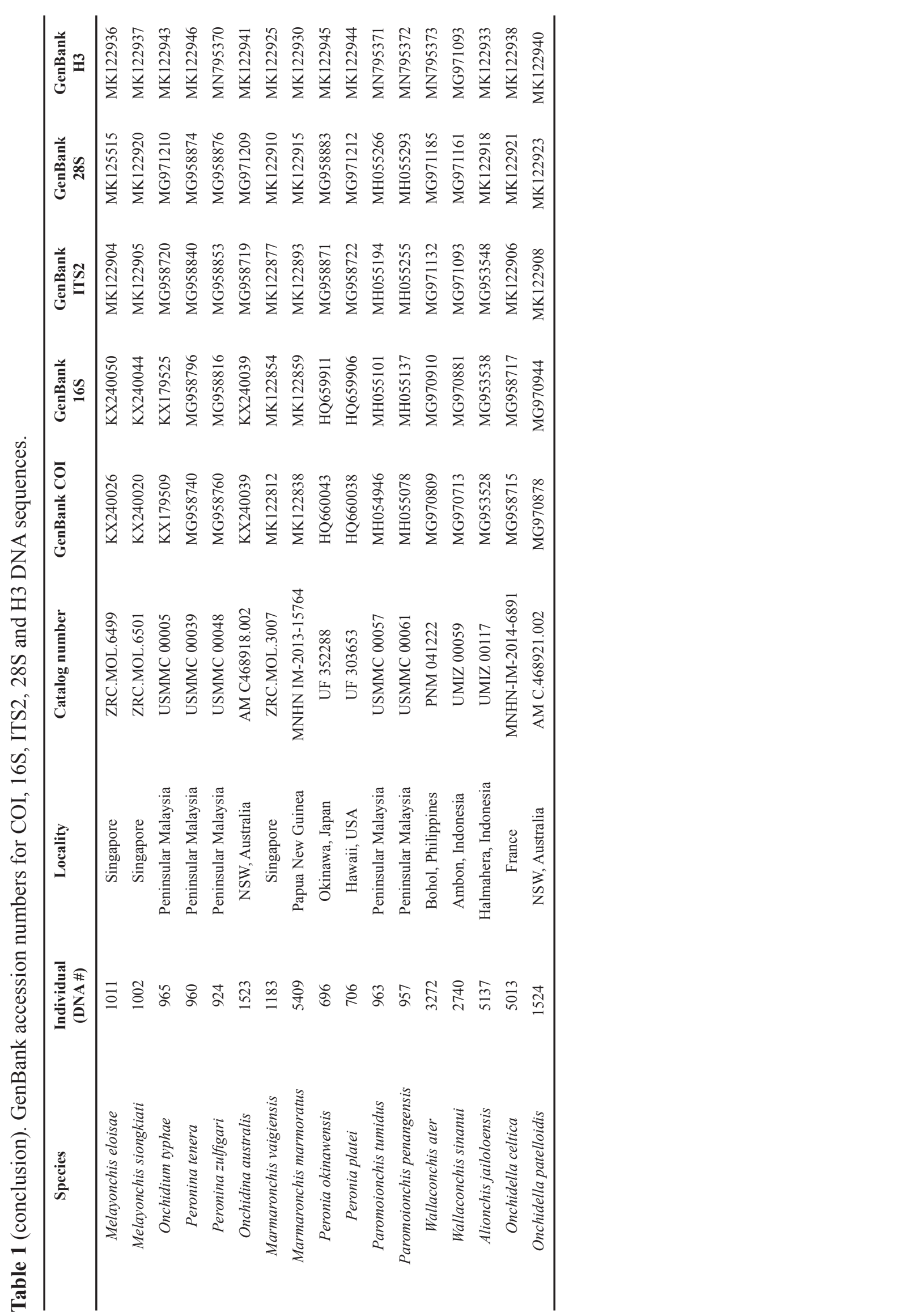


material collected by the authors and which could be confidently identified based on their anatomy: P. coriaceus darwinensis subsp. nov. (3 specs), P. tigrinus (2 specs), P. martensi (5 specs) and P. aptei sp. nov. (4 specs). Specimens with no DNA sequences also include old, non-type material from museum collections which could not be sequenced: $P$. latus (3 specs) and $P$. coriaceus ( 28 specs). DNA sequences could not be obtained from the old type specimens of existing nominal species.

\section{Type material, museum vouchers and collections}

All the types available for the Onchidiidae were examined in the context of a taxonomic revision of all onchidiid genera (types were borrowed on loan, except for a few which could not be exported and were examined by the last author during visits to museum collections). Several species of Platevindex were originally described based on a single specimen. In the case of syntypes, it was often necessary to designate a lectotype in order to clarify the application of species names. Fresh material was used for DNA sequencing, comparative anatomy and natural history observations. Individual DNA extraction numbers are indicated on phylogenetic trees, in the lists of material examined, as well as in figure captions (DNA extraction numbers are in square brackets). Animal sizes are based on the maximum length and width of specimens when preserved, and are indicated in millimeters (as length/width).

All specimens freshly collected were deposited as vouchers in institutions in the countries where they were collected, except for specimens from Mauritius and Madagascar deposited at the MNHN. Acronyms of collections are:

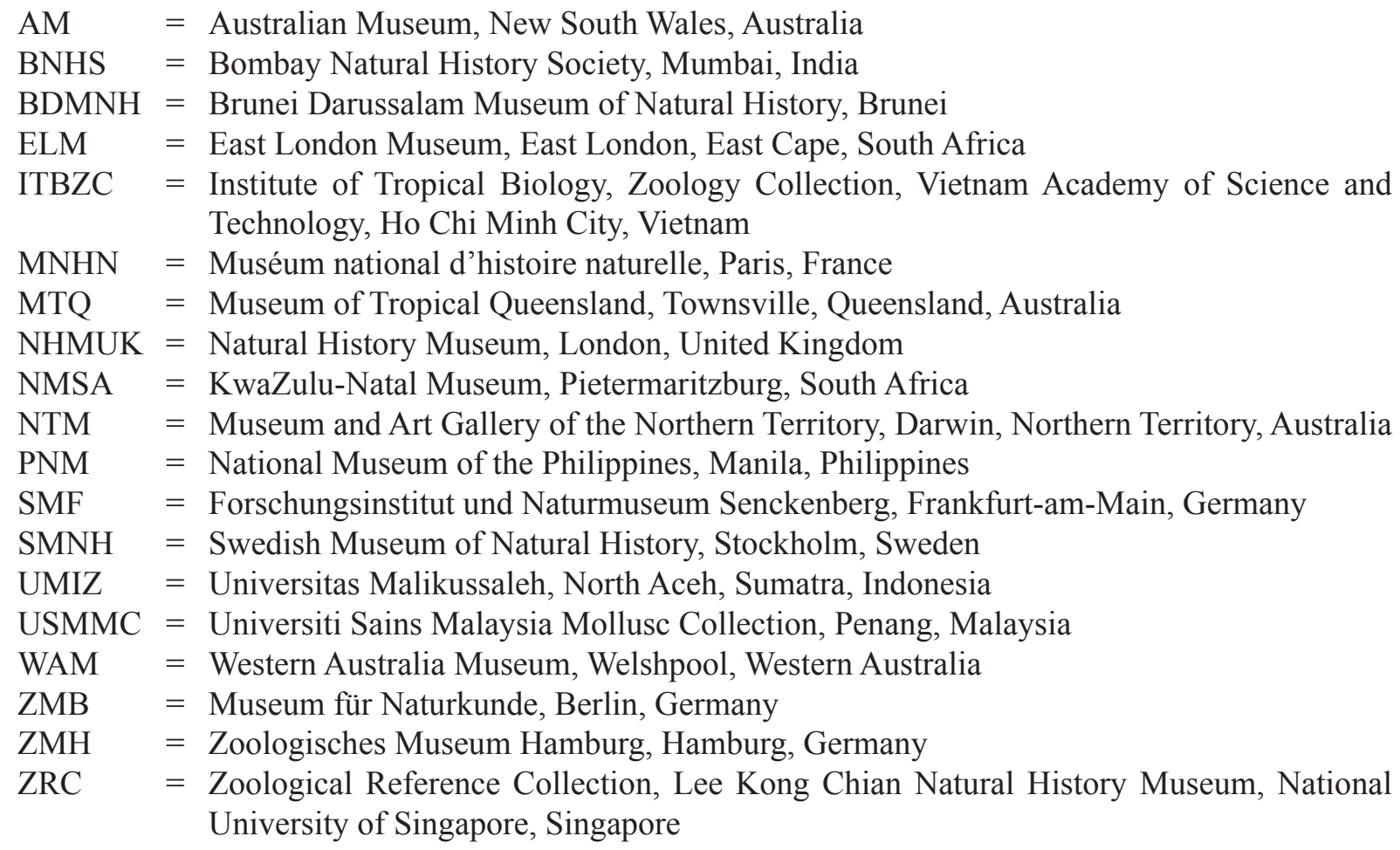

\section{Animal preparation and anatomical description}

Both the external morphology and the internal anatomy were examined under a dissecting microscope and drawn with a camera lucida. In addition, organs were prepared for scanning electron microscopy (SEM). Radulae were cleaned in $10 \% \mathrm{NaOH}$ for a week, rinsed in distilled water, sputter-coated with goldpalladium and examined by SEM. Soft parts (penis and penial hooks) were dehydrated in $95 \%$ ethanol and critical point dried before coating. Radulae and the male parts were extracted from 3 specimens per species. Radulae and male parts were extracted from additional specimens in the three species with 
Table 2. Types of intestinal loops in species of Platevindex Baker, 1938.

\begin{tabular}{|c|c|c|c|c|c|}
\hline \multirow{2}{*}{ Taxon } & \multicolumn{2}{|c|}{ Type I } & \multirow{2}{*}{$\begin{array}{c}\text { Type II } \\
\text { 6-9 o'clock }\end{array}$} & \multicolumn{2}{|c|}{ Type III } \\
\hline & $12-3$ o'clock & 3-6 o'clock & & 12-3 o'clock & 3-6 o'clock \\
\hline P. applanatus & $\checkmark(1$ to 2$)$ & & & & \\
\hline P. luteus & & $\checkmark(3$ to 6$)$ & $\checkmark(6$ to 8$)$ & & \\
\hline P. burnupi & & & $\checkmark(\sim 7)$ & & \\
\hline P. coriaceus coriaceus (unit \#1) & & & $\checkmark(6$ to 9$)$ & & \\
\hline P. coriaceus coriaceus (unit \#2) & & & $\checkmark(7$ to 9$)$ & & \\
\hline P. coriaceus darwinensis subsp. nov. & & & $\checkmark(6$ to 8$)$ & & \\
\hline P. tigrinus & & & $\checkmark(6$ to 9$)$ & & \\
\hline P. martensi & & & $\checkmark(6$ to 9$)$ & & \\
\hline P. aptei sp. nov. & & & $\checkmark(7$ to 9$)$ & & \\
\hline P. amboinae & & & & $\checkmark(1$ to 3$)$ & $\checkmark(\sim 6)$ \\
\hline P. latus & & & & $\checkmark(12$ to 2$)$ & \\
\hline
\end{tabular}

high intraspecific genetic diversity: 9 specimens of $P$. coriaceus (3 for $P$. coriaceus coriaceus unit \#1, 3 for unit \#2 and 3 for $P$. coriaceus darwinensis subsp. nov.), 9 specimens of $P$. applanatus (including 3 specimens from Mauritius) and 5 specimens of $P$. burnupi. Exceptionally, only 2 radulae were extracted for $P$. latus, as only a few specimens of this species are known in museum collections. Specimens were dissected from across the geographic distribution of each species, including 22 specimens of $P$. coriaceus coriaceus, 11 specimens of $P$. coriaceus darwinensis subsp. nov., 8 specimens of $P$. tigrinus, 21 specimens of $P$. luteus, 17 specimens of $P$. applanatus, 6 specimens of $P$. burnupi, 16 specimens of P. martensi, 6 specimens of $P$. aptei sp. nov., 4 specimens of $P$. amboinae and 3 specimens of $P$. latus. The number of dorsal eyes was counted in all specimens examined.

The anatomy of $P$. coriaceus, the type species, is fully detailed. The written description of the many anatomical features that are virtually identical between species (nervous system, heart, etc.) is given only for the type species to avoid repeating the information eight times. Thus, any feature that is only mentioned for $P$. coriaceus is identical in the other eight species. As expected, differences between species are mostly found in the male copulatory apparatus, which is described and illustrated in detail for each species.

\section{Types of intestinal loops}

In onchidiid slugs, the types of intestinal loops are based on the dorsal pattern of the intestine. Plate (1893: pl. 8, figs 29-32) first distinguished four types of intestinal loops (types I to IV) and Labbé (1934: 178, fig. 3) later added a type V. The intestinal types I, II and III are found in Platevindex (Figs 1-3, Table 2). It is necessary to define intestinal types clearly because they have often been confused. For that purpose, three different sections are recognized in intestinal loops and colored differently (Dayrat et al. 2019b, 2019c, 2019d, 2020): a clockwise loop is colored in blue, a counterclockwise loop in yellow, and a transitional loop between them in green (Figs 1-3).

The intestine first appears dorsally on the right side. In a type I (Fig. 1), the intestine starts by forming a clockwise (blue) loop. This clockwise loop does not form a full circle and soon transitions into a counterclockwise (yellow) loop. As a result, the transitional (green) loop between clockwise and counterclockwise loops is oriented to the right, typically at 3 o'clock (horizontal red arrow, Fig. 1A-B). In intestinal loops of type I, the transitional (green) loop is oriented to the right, but not always at 3 o'clock: it can vary from an orientation close to 12 o'clock (Fig. 1C) all the way down to an orientation at 6 o'clock (Fig. 1D). However, the intraspecific variation is usually limited to a range of 
approximately $90^{\circ}$ around a mean axis (i.e., $45^{\circ}$ on either side of the mean axis). In Platevindex, a type I with a transitional loop oriented between 12 and 3 o'clock is found only in P. applanatus (Fig. 1C, Table 2) and a type I with a transitional loop oriented between 3 and 6 o'clock is found only in P. luteus (Fig. 1B, D, Table 2).

In a type II (Fig. 2), the clockwise (blue) loop is longer and rotates more than in a type I. As a result, the transitional (green) loop is oriented to the left, typically at 9 o'clock (horizontal red arrow, Fig. 2A-C). However, because of intraspecific variation, the transitional loop is not always oriented at 9 o'clock. A type II with a transitional loop oriented between 6 and 9 o'clock is found in six species of Platevindex (Fig. 2B-H, Table 2): P. aptei sp. nov., P. burnupi, P. coriaceus, P. luteus, P. martensi and P. tigrinus. The intraspecific variation of the intestinal loops in $P$. luteus is unusually high (Figs $1 \mathrm{~B}, \mathrm{D}$, $2 \mathrm{E}$ ): the orientation of its transitional loop covers a range of nearly $180^{\circ}$, between 3 o'clock (type I) and 8 o'clock (type II).

In a type III (Fig. 3), the clockwise (blue) loop is longer and rotates more than in a type II. As a result, the transitional (green) loop is oriented to the right, typically at 3 o'clock (horizontal red arrow, Fig. 3A). However, as in types I and II, there is some individual variation (Fig. 3). In Platevindex, two closelyrelated species are characterized by intestinal loops of type III (Tables 2, 4): P. amboinae and P. latus. In P. amboinae, the orientation of the transitional loop covers a range of nearly $180^{\circ}$ (Fig. 3C-E). A type III with a transitional loop oriented between 12 and 2 o'clock is found in P. latus (Fig. 3B), but the limited variability in the orientation of the transition loop in P. latus may be due to limited sampling (see the remarks on that species).

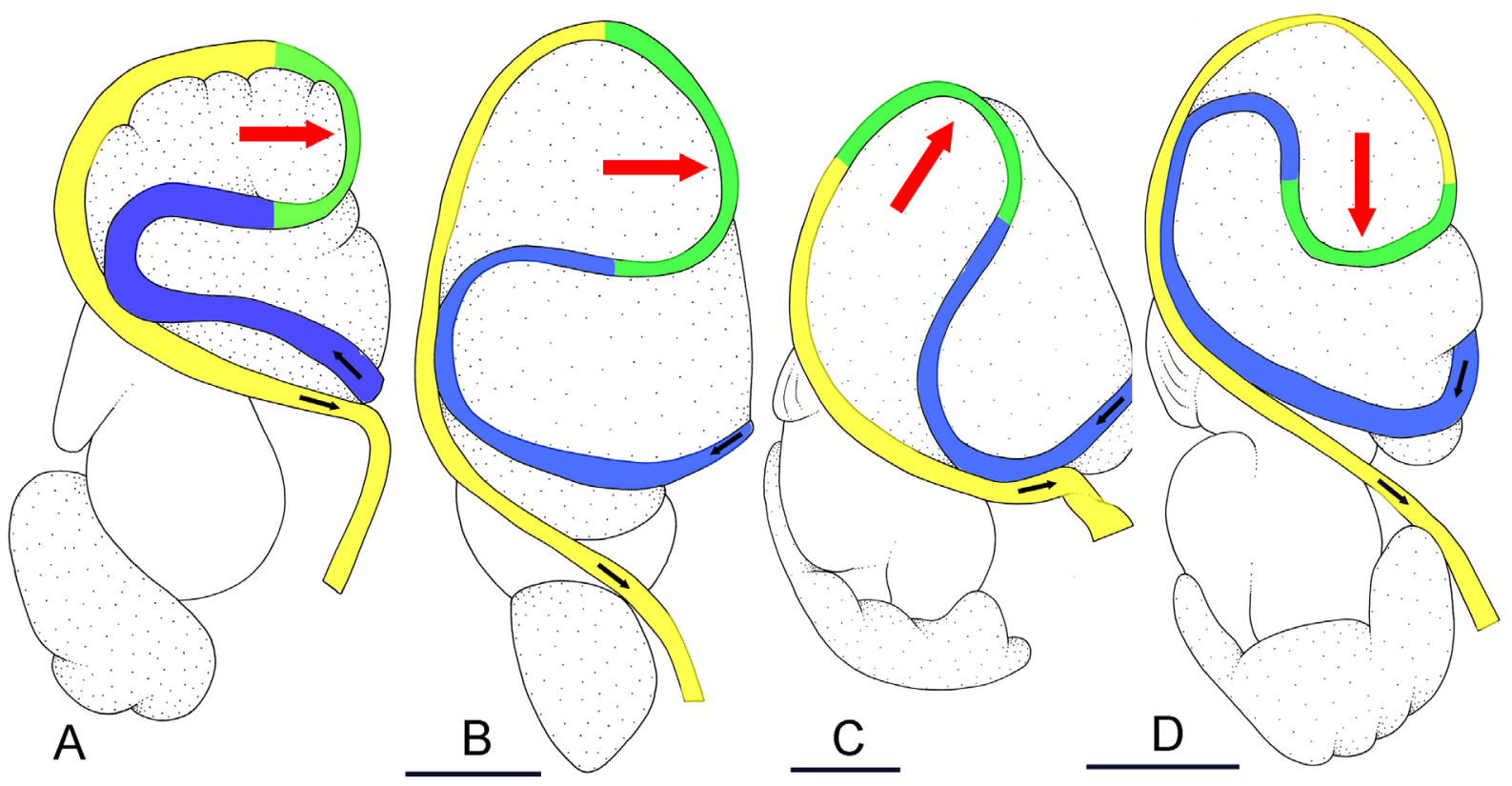

Fig. 1. Intestinal loops of type I. Small black arrows show the direction of the intestinal transport. The clockwise loop is in blue. The counterclockwise loop is in yellow. The transitional loop (between clockwise and counterclockwise loops) is in green. Red arrows indicate the orientation of the transitional loop. A. Type I (as defined by Plate 1893), with a transitional loop oriented at 3 o'clock, redrawn from Plate (1893: pl. 8, fig. 29). B. Type I, with a transitional loop oriented at 3 o'clock, Platevindex luteus (Semper, 1880) [5613] (ITBZC IM 00016), Vietnam. C. Type I, with a transitional loop oriented at 1 o'clock, P. applanatus (Simroth, 1920) [5420] (MNHN IM-2013-13765), Papua New Guinea. D. Type I, with a transitional loop oriented at 6 o'clock, P. luteus [2837] (UMIZ 00089), Ambon, Indonesia. Scale bars: $\mathrm{B}-\mathrm{C}=2 \mathrm{~mm}$; $\mathrm{D}=3 \mathrm{~mm}$. 


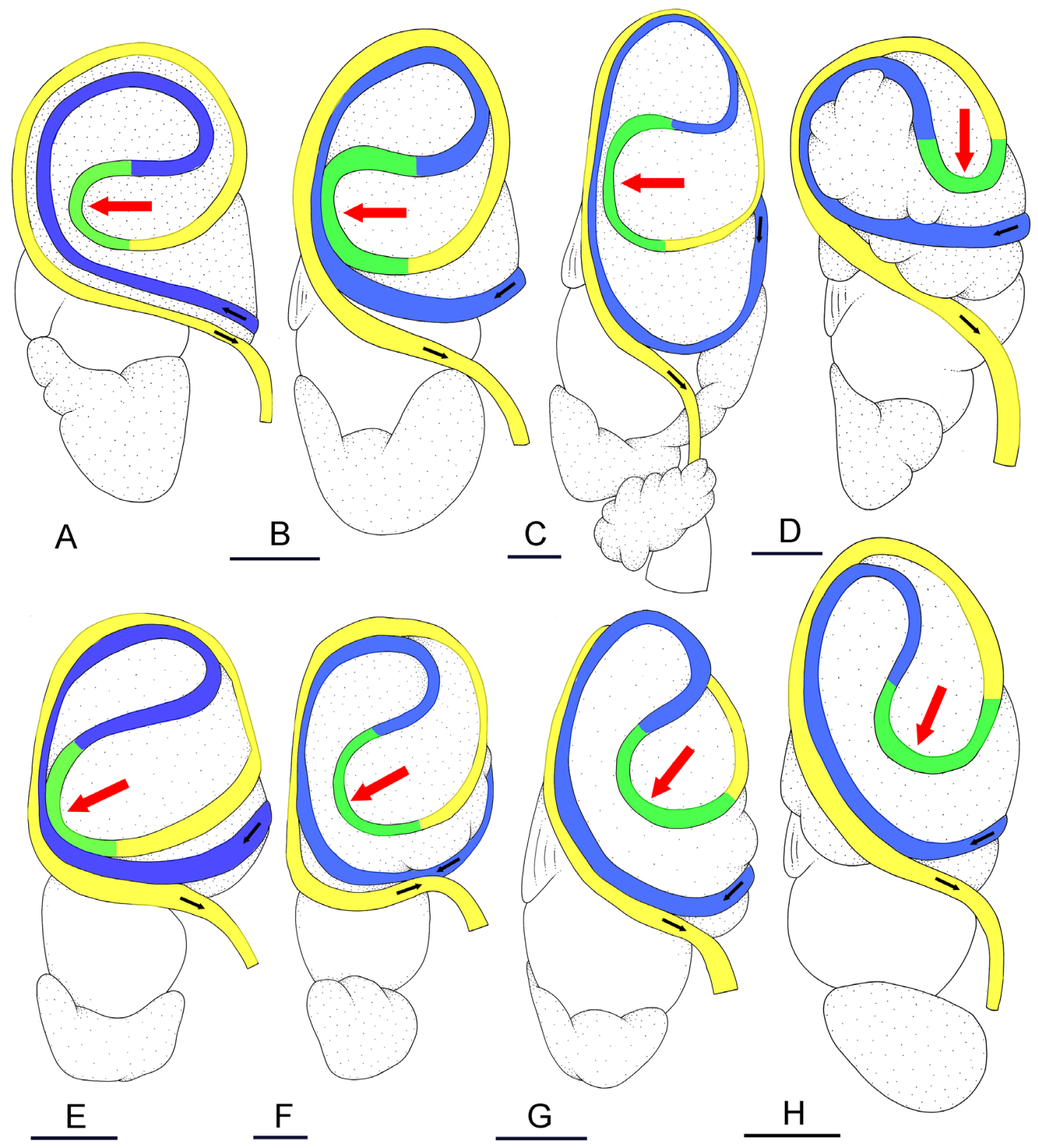

Fig. 2. Intestinal loops of type II. Small black arrows show the direction of the intestinal transport. The clockwise loop is in blue. The counterclockwise loop is in yellow. The transitional loop (between clockwise and counterclockwise loops) is in green. Red arrows indicate the orientation of the transitional loop. A. Type II (as defined by Plate 1893), with a transitional loop oriented at 9 o'clock, redrawn from Plate (1893: pl. 8, fig. 31). B. Type II, with a transitional loop oriented at 9 o'clock, Platevindex coriaceus coriaceus (Semper, 1880) unit \#2 [3170] (PNM 041236), Luzon, Philippines. C. Type II, with a transitional loop oriented at 9 o'clock, P. martensi (Plate, 1893) [2333] (UMIZ 00111), Sulawesi, Indonesia. D. Type II, with a transitional loop oriented at 6 o'clock, P. martensi [964] (USMMC 00029), Peninsular Malaysia. E. Type II, with a transitional loop oriented at 8 o'clock, P. luteus (Semper, 1880) [3367] (PNM 041246), Bohol, Philippines. F. Type II, with a transitional loop oriented at 8 o'clock, P. aptei Goulding \& Dayrat sp. nov., [5955] (USMMC 00078), Peninsular Malaysia. G. Type II, with a transitional loop oriented at 7 o'clock, P. burnupi (Collinge, 1902) [3150] (MNHN-IM-2019-1398), Madagascar. H. Type II, with a transitional loop oriented at 7 o'clock, $P$. coriaceus coriaceus unit \#2 [3256] (PNM 041238), Bohol, Philippines. Scale bars: B-H = 2 mm. 


\section{DNA extraction and PCR amplification}

DNA was extracted using a phenol-chloroform extraction protocol with cetyltrimethyl-ammonium bromide (CTAB). Portions of two mitochondrial genes (COI and 16S) and three nuclear loci (ITS2, $28 \mathrm{~S}$ and $\mathrm{H} 3$ ) were amplified. The cytochrome oxidase I region (COI) was amplified using the universal primers (all primers indicated as 5'-3'): LCO1490 GGT CAA CAA ATC ATA AAG ATA TTG G, and HCO2198 TAA ACT TCA GGG TGA CCA AAR AAY CA (Folmer et al. 1994), except in P. luteus, for which modified Folmer primers were used: jgLCO1490 TIT CIA CIA AYC AYA ARG AYA TTG G, and jgHCO2198 TAI ACY TCI GGR TGI CCR AAR AAY CA (Geller et al. 2013). Other universal primers used for 16S, ITS2, 28S and H3 were: 16Sar CGC CTG TTT ATC AAA AAC AT

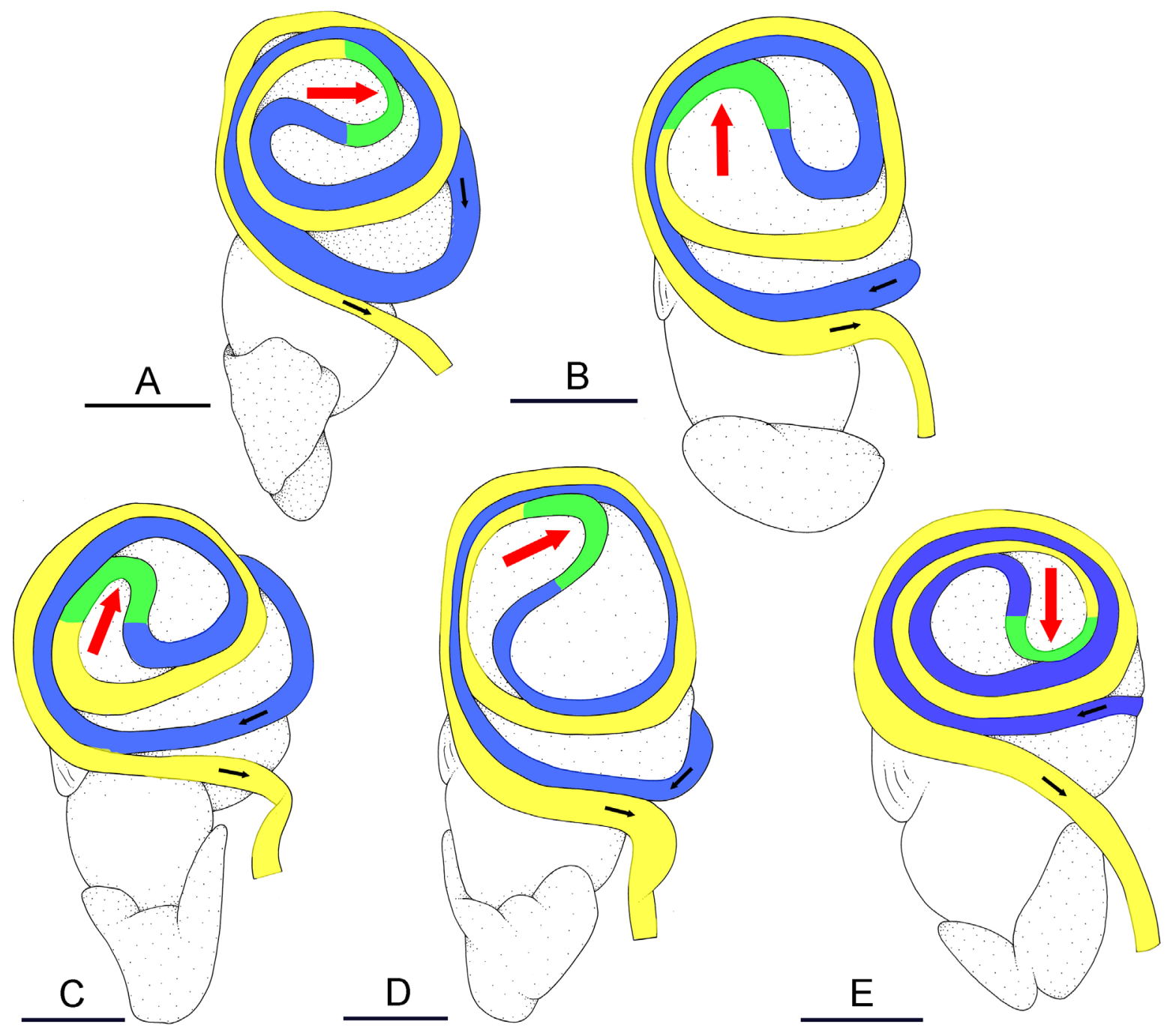

Fig. 3. Intestinal loops of type III. Small black arrows show the direction of the intestinal transport. The clockwise loop is in blue. The counterclockwise loop is in yellow. The transitional loop (between clockwise and counterclockwise loops) is in green. Red arrows indicate the orientation of the transitional loop. A. Type III, with a transitional loop oriented at 3 o'clock, Onchidium stuxbergi (Westerlund, 1883) (from Dayrat et al. 2016: fig. 11b). B. Type III, with a transitional loop oriented at 12 o'clock, Platevindex latus (Plate, 1893) (ZMH 27511, \#1), Papua New Guinea. C. Type III, with a transitional loop oriented at 1 o'clock, P. amboinae (Plate, 1893), lectotype (ZMB/Moll 11621a), Ambon, Indonesia. D. Type III, with a transitional loop oriented at 2 o'clock, P. amboinae [2883] (UMIZ 00105), Seram, Indonesia. E. Type III, with a transitional loop oriented at 6 o'clock, $P$. amboinae (SMF 333602, \#1), Sulawesi, Indonesia. Scale bars: A-B $=5 \mathrm{~mm} ; \mathrm{C}-\mathrm{E}=4 \mathrm{~mm}$. 
(Palumbi 1996), 16S 972R CCG GTC TGA ACT CAG ATC ATG T (Dayrat et al. 2011), ITS2-LSU1 CTAGCTGCGAGAATTAATGTGA, ITS2-LSU-3 ACTTTCCCTCACGGTACTTG (Wade \& Mordan 2000), 28SC1 ACC CGC TGA ATT TAA GCA T (Hassouna et al. 1984), 28SD3 GAC GAT CGA TTT GCA CGT CA (Vonnemann et al. 2005), H3F ATG GCT CGT ACC AAG CAG ACV GC and H3R ATA TCC TTR GGC ATR ATR GTG AC (Colgan et al. 2000). PCRs for COI and 16S were each done in a total reaction volume of $25 \mu \mathrm{l}$ containing $15.8 \mu \mathrm{l}$ of water, $2.5 \mu \mathrm{l}$ of $10 \times$ PCR buffer, $1.5 \mu \mathrm{l}$ of $25 \mathrm{mM}$ $\mathrm{MgCl}_{2}, 0.5 \mu \mathrm{l}$ of each $10 \mu \mathrm{M}$ primer, $2 \mu \mathrm{l}$ of dNTP mixture, $0.2 \mu \mathrm{l}$ (1 unit) of TaKaRa Taq (Clontech, Cat No. R001A), $1 \mu \mathrm{l}$ of $20 \mathrm{ng} / \mu \mathrm{l}$ template DNA and $1 \mu \mathrm{l}$ of $100 \times$ BSA (bovine serum albumin). PCRs for ITS2 used the reagents in the same amounts as for COI and 16S, except that water was reduced to $14.8 \mu \mathrm{l}$, the amount of $100 \times$ BSA was increased to $2 \mu \mathrm{l}$ and the amount of template DNA reduced to $0.5 \mu \mathrm{l}$. PCRs for $28 \mathrm{~S}$ contained $14.3 \mu \mathrm{l}$ of water, $0.5 \mu \mathrm{l}$ of $10 \times$ PCR buffer, $5 \mu \mathrm{l}$ of Q solution (QIAGEN, ID: 201203), $0.5 \mu \mathrm{l}$ of each $10 \mu \mathrm{M}$ primer, $1 \mu \mathrm{l}$ of dNTPs, $0.2 \mu \mathrm{l}$ (1 unit) of TaKaRa Taq and $0.5 \mu \mathrm{l}$ of $20 \mathrm{ng} / \mu \mathrm{l}$ template DNA. PCR reactions for $\mathrm{H} 3$ were done in $25 \mu \mathrm{l}$ reactions containing $14.8 \mu \mathrm{l}$ of water, $2.5 \mu \mathrm{l}$ of $10 \times$ PCR buffer, $1.5 \mu \mathrm{l}$ of $25 \mathrm{mM} \mathrm{MgCl}, 0.5 \mu \mathrm{l}$ of each $10 \mu \mathrm{M}$ primer, $2 \mu 1$ of dNTP mixture, $0.2 \mu \mathrm{l}$ (1 unit) of TaKaRa Taq, $2 \mu \mathrm{l}$ of $100 \times \mathrm{BSA}$ and $1 \mu \mathrm{l}$ of $20 \mathrm{ng} / \mu \mathrm{l}$ template DNA. The thermoprofile used for COI and $16 \mathrm{~S}$ was: $5 \mathrm{~min}$ at $94^{\circ} \mathrm{C} ; 30$ cycles of $40 \mathrm{~s}$ at $94^{\circ} \mathrm{C}, 1 \mathrm{~min}$ at $46^{\circ} \mathrm{C}$ and $1 \mathrm{~min}$ at $72^{\circ} \mathrm{C}$; and $10 \mathrm{~min}$ at $72^{\circ} \mathrm{C}$. The ITS2 thermoprofile was: $1 \mathrm{~min}$ at $96^{\circ} \mathrm{C} ; 35$ cycles of $30 \mathrm{~s}$ at $94^{\circ} \mathrm{C}, 30 \mathrm{~s}$ at $50^{\circ} \mathrm{C}$ and $1 \mathrm{~min}$ at $72^{\circ} \mathrm{C}$; and a final extension of $10 \mathrm{~min}$ at $72^{\circ} \mathrm{C}$. The $28 \mathrm{~S}$ thermoprofile was: $4 \mathrm{~min}$ at $94^{\circ} \mathrm{C}$; 38 cycles of $30 \mathrm{~s}$ at $94^{\circ} \mathrm{C}, 50 \mathrm{~s}$ at $52^{\circ} \mathrm{C}$ and $2 \min 30 \mathrm{~s}$ at $72^{\circ} \mathrm{C}$; and $10 \mathrm{~min}$ at $72^{\circ} \mathrm{C}$. The $\mathrm{H} 3$ thermoprofile was: $5 \mathrm{~min}$ at $93^{\circ} \mathrm{C} ; 30$ cycles of $1 \mathrm{~min}$ at $93^{\circ} \mathrm{C}, 2 \mathrm{~min}$ at $55^{\circ} \mathrm{C}$ and $1 \mathrm{~min}$ at $73^{\circ} \mathrm{C}$; and a final extension of $10 \mathrm{~min}$ at $73^{\circ} \mathrm{C}$. Sequenced fragments represented approximately $680 \mathrm{bp}(\mathrm{COI}), 530 \mathrm{bp}(16 \mathrm{~S}), 650 \mathrm{bp}$ (ITS2, including parts of 5.8S and 28S), $1000 \mathrm{bp}(28 \mathrm{~S})$ and $340 \mathrm{bp}(\mathrm{H} 3)$.

\section{Phylogenetic analyses}

Chromatograms were consulted to resolve rare ambiguous base calls. Consensus sequences for $28 \mathrm{~S}$ and (when necessary) ITS2 were produced by aligning forward and reverse sequences in Geneious ver. 9.1.8 (Kearse et al. 2012). Alignments of COI and 28S sequences were each obtained using MUSCLE in MEGA 7 (Kumar et al. 2016). 16S and ITS2 sequences were aligned separately using MAFFT ver. 7 (Katoh et al. 2002). The iterative refinement method E-INS-I was selected for sequences with multiple conserved domains and long gaps. COI DNA sequences were also translated into amino acid sequences in MEGA using the invertebrate mitochondrial genetic code to check for the presence of stop codons (no stop codon was found).

DNA sequences for 184 specimens were submitted to GenBank and vouchers deposited in museum collections (Table 1). All sequences of Platevindex in this study are new, with the exception of 14 previously published sequences from China and Japan, which were downloaded from GenBank. Seventeen onchidiid species were selected as outgroups representing other onchidiid genera. All outgroup sequences are from our recent taxonomic studies (Dayrat et al. 2011, 2016, 2017, 2018, 2019a, 2019b, 2019c, 2019d; Dayrat \& Goulding 2017; Goulding et al. 2018a, 2018b, 2018c): Alionchis jailoloensis Goulding \& Dayrat, 2018, Marmaronchis marmoratus (Lesson, 1831), Marmaronchis vaigiensis (Quoy \& Gaimard, 1825), Melayonchis eloisae Dayrat, 2017, Melayonchis siongkiati Dayrat \& Goulding, 2017, Onchidella celtica (Cuvier in Audouin \& Milne-Edwards, 1832), Onchidella nigricans (Quoy \& Gaimard, 1832), Onchidina australis (Semper, 1880), Onchidium typhae Buchannan, 1800, Paromoionchis penangensis Dayrat \& Goulding, 2019, Paromoionchis tumidus (Semper, 1880), Peronia platei (Hoffmann, 1928), Peronia okinawensis Dayrat \& Goulding, 2020, Peronina tenera (Stoliczka, 1869), Peronina zulfigari Goulding \& Dayrat, 2018, Wallaconchis ater (Lesson, 1831) and Wallaconchis sinanui Goulding \& Dayrat, 2018.

The ends of each alignment were trimmed. The concatenated mitochondrial alignment included 1047 nucleotide positions: 609 (COI) and 438 (16S). The concatenated nuclear alignment included 1768 
positions: 758 (ITS2, including gaps) and 1010 (28S, including gaps) - the insertion of gaps in nuclear alignments is largely due to the comparison with outgroups. The alignment of $\mathrm{H} 3$, used in the partitioned multi-locus analysis, included 294 positions.

DNA sequences were used to test species limits within Platevindex, relationships between species, as well as the monophyly of Platevindex. Mitochondrial and nuclear sequences were first analyzed independently to determine whether different markers yielded different results. Then, mitochondrial and nuclear sequences were concatenated and analyzed using partitions. So, in total, five sets of phylogenetic analyses were performed (the number of individuals for each analysis does not include the outgroups): 1) maximum likelihood and Bayesian analyses with just COI sequences, performed with 198 individuals; 2) maximum likelihood and Bayesian analyses with concatenated COI and $16 \mathrm{~S}$ sequences, performed with 96 individuals; 3) maximum parsimony analyses with ITS2 sequences, performed with 46 unique haplotypes representing 122 individuals; 4) maximum parsimony analyses with concatenated ITS2 and 28S sequences, performed with 62 individuals; and 5) maximum likelihood and Bayesian analysis of partitioned COI (all 3 codons partitioned separately), 16S, ITS2, 28S and H3 sequences, performed with 62 individuals.

Prior to phylogenetic analyses, the best-fitting evolutionary model was selected using the Model Selection option from Topali ver. 2.5 (Milne et al. 2004). Maximum likelihood analyses for mitochondrial COI and 16S were performed using PhyML (Guindon \& Gascuel 2003) and Bayesian analyses were performed using MrBayes ver. 3.1.2 (Ronquist \& Huelsenbeck 2003), both implemented in Topali. Node support in maximum likelihood analyses was evaluated using bootstrapping with 100 replicates; here, bootstrap values greater than $70 \%$ are considered moderately supported, and greater than $95 \%$ are considered highly supported (Soltis \& Soltis 2003). Bayesian analyses were performed with five simultaneous runs of $1.5 \times 10^{6}$ generations each, sample frequency of 100 and burn-in of $25 \%$; posterior probabilities, or PP, were also calculated. Posterior probabilities greater than 0.95 are considered highly supported. Topali did not detect any issue with respect to convergence. Analyses of the internal transcribed spacer (ITS2) were carried out using maximum parsimony conducted in PAUP ver. 4.0 (Swofford 2002), with gaps coded as a $5^{\text {th }}$ character state. Although both indels and shared nucleotide positions in nuclear sequences are informative for phylogenetic inference, indel characters are less likely to be homoplastic than nucleotide positions and are informative for phylogenetic analyses (Lloyd \& Calder 1991; Simmons et al. 2001; Ashkenazy et al.2014). Including indels in phylogenetic analyses has been shown to increase support for phylogenetic relationships (Nagy et al. 2012; Yuri et al. 2013). One hundred bootstrap replicates were conducted using a full heuristic search. Maximum likelihood analyses of partitioned loci were conducted in RAxML ver. 7.2.8 (Stamatakis 2014) using the General Time Reversible+Gamma $(\mathrm{GTR}+\mathrm{G})$ model as implemented in Geneious ver. 9.1.8 (Kearse et al. 2012). Node support was evaluated using bootstrapping with 100 replicates. For the Bayesian partitioned analyses, the best-fit model of nucleotide substitution was identified for each sequence partition by means of user-defined partition schemes evaluated with the corrected Akaike information criterion (AICc) in PartitionFinder ver. 2.1.1 (Lanfear et al.2012). Six partitions were designated in the analyses: each codon position of COI partitioned separately, 16S, ITS2, 28S and H3. Bayesian analyses of partitioned data were performed in MrBayes ver. 3.2.6 on the CIPRES Science Gateway (Miller et al. 2010). Each MrBayes run consisted of four simultaneous runs of $10^{7}$ generations each, sample frequency of 500, burn-in of $25 \%$. Quality and ESS values (effective sampling size) of each run were checked in Tracer ver. 1.7 (Rambaut et al. 2018). All analyses were run several times and yielded similar results.

Pairwise p-distances between individual COI sequences were calculated in MEGA 7 (Kumar et al. 2016). Automatic Barcode Gap Discovery (Puillandre et al. 2011) was used to delimit molecular units based on the presence of a barcode gap in genetic divergence. Pairwise genetic distances summarized for each molecular unit delimited with the barcode gap analysis (ABGD) are presented in Table 3. 

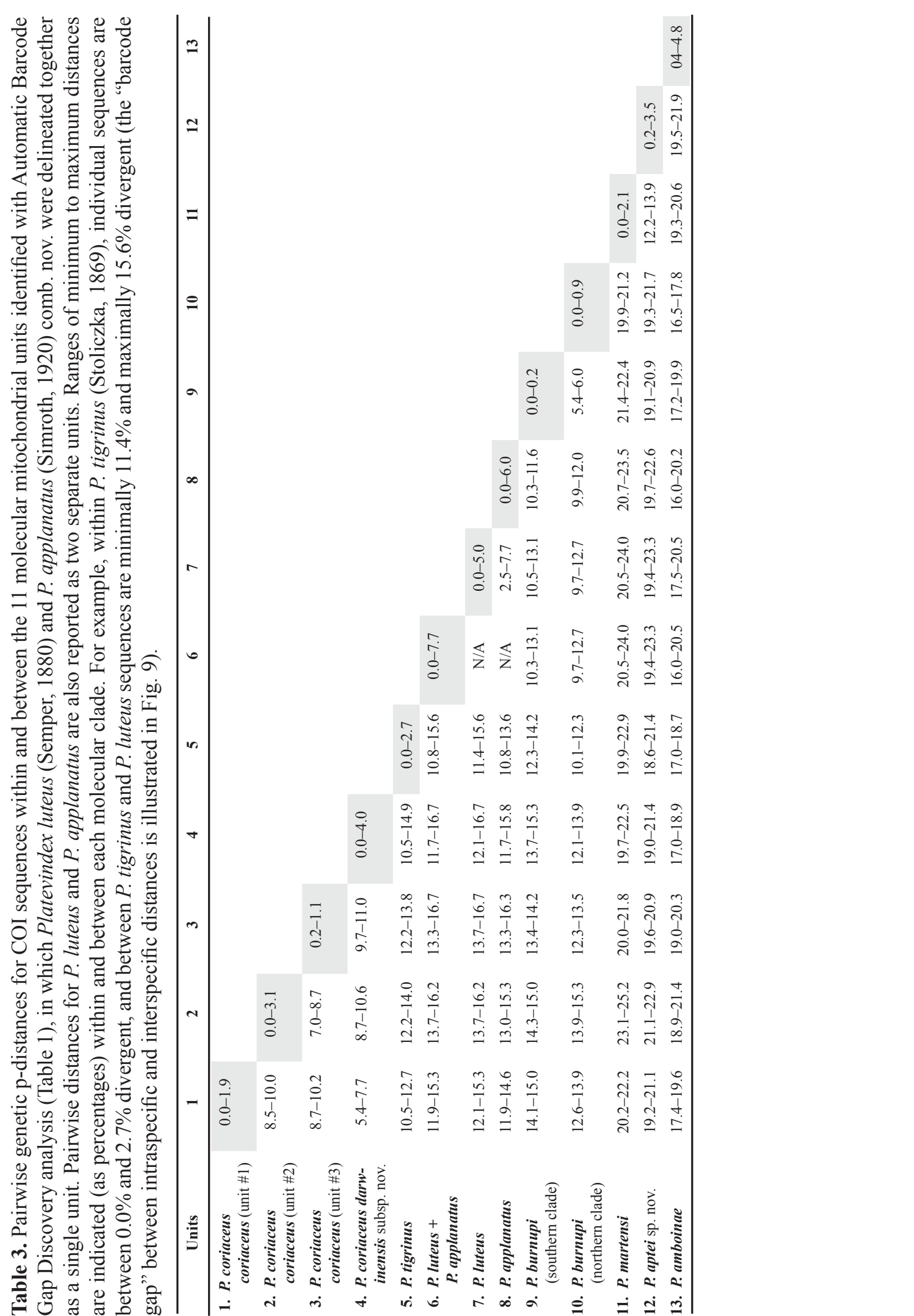

总宗言家这

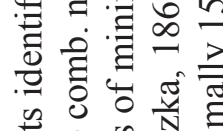

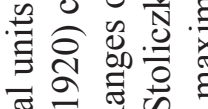

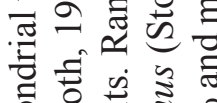

营

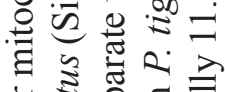

䒕

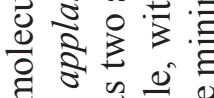

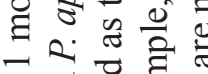

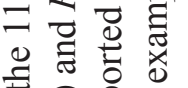

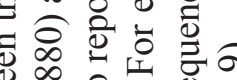

in

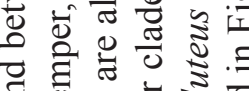

ब

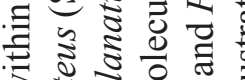

उ इ

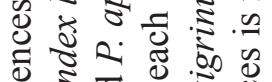

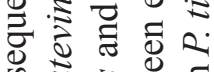

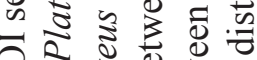

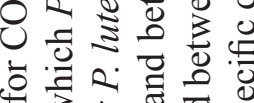

๖.

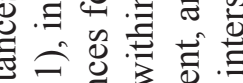

可

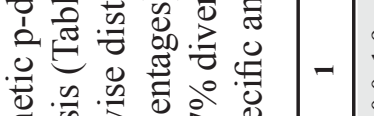

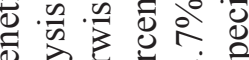

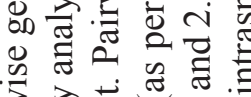

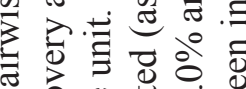

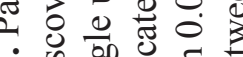

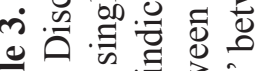

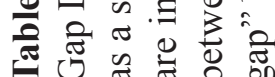




\section{Results}

\section{Molecular phylogenetic analyses}

The number of parsimony-informative sites in our alignments is reported without outgroups; thus, the number of sites is smaller than the number of sites in the alignments used for phylogenetic analyses (because outgroup sequences add many sites to the alignments). The ITS2 alignment includes 77 parsimony-informative sites out of 699 sites. The $28 \mathrm{~S}$ alignment includes 20 parsimony-informative sites out of 986 sites. The best substitution model for mitochondrial loci was the GTR+G+I model, while the best substitution model for nuclear loci was $\mathrm{HKY}+\mathrm{G}$ as determined by Topali. For partitioned analyses in MrBayes, the best substitution models selected for COI were GTR+G+I for the first codon position, GTR $+\mathrm{I}$ for the second position and GTR $+\mathrm{G}$ for the third position. The best fit model for $16 \mathrm{~S}$, ITS2, 28S and H3 as determined by PartitionFinder was GTR $+\mathrm{G}+\mathrm{I}$, implemented separately for each locus. For partitioned RAxML analyses, a GTR model is used by default, but the GTR $+\mathrm{G}+\mathrm{I}$ search option was used to incorporate substitution rate heterogeneity and estimate the proportion of invariable sites for the same partitions used in the Bayesian analysis.

The monophyly of Platevindex is strongly supported in the partitioned multi-locus analysis (PP 0.96, bootstrap 87\%, Fig. 4), as well as in analyses including nuclear sequences (Figs 5-6). Analyses of mitochondrial DNA sequences (COI, 16S) yield a similar topology for the deeper nodes (including the monophyly of Platevindex) but with lower support (Figs 7-8).

Seven well-supported clades in the partitioned analysis provide the foundation for Platevindex species relationships (clades labeled A to G, Fig. 4). That P. amboinae (clade B) is distantly related to all other Platevindex (clade A) is also recovered in the nuclear analyses (Figs 5-6) and is not contradicted by mitochondrial analyses (Figs 7-8). Clade B includes only P. amboinae in molecular analyses, but P. latus (for which no fresh material was available) likely belongs to clade B as well, because it shares several distinctive features with P. amboinae (Table 4). Clade A includes two clades (Fig. 4): clade D (P. aptei sp. nov. and P. martensi) and clade C (all Platevindex except $P$. amboinae, $P$. martensi, and $P$. aptei sp. nov.). The monophyly of clade D is strongly supported in all analyses (Figs 4-8), which is in agreement with morphology because both $P$. martensi and $P$. aptei sp. nov. share several distinctive features (Table 4). The monophyly of clade $\mathrm{C}$ is recovered in mitochondrial analyses of COI and 16S (Fig. 8) but is poorly supported (Figs 6-7) or unresolved (Fig. 5) in other analyses. Morphologically, clade C includes all the Platevindex species with dorsal eyes that are not close to the edge $(>2 \mathrm{~mm})$ of the notum (Table 4), which could be a synapomorphy or a symplesiomorphy. Clade C includes two clades (Fig. 4): clade E (P. burnupi, P. applanatus, and P. luteus) and clade F (P. coriaceus and P. tigrinus). Clade E is unresolved in both nuclear analyses (Figs 5-6) and mitochondrial maximum likelihood analyses (Figs 7-8) but is supported in the Bayesian analysis of COI and 16S (Fig. 8, PP 1). Support for clade F is lower than for other clades but it is recovered in most analyses: in the partitioned analysis with all five markers (PP 0.7, bootstrap 64\%, Fig. 4), in the nuclear analysis of ITS2 and 28S (bootstrap 57\%, Fig. 6), as well as in the mitochondrial analysis of COI and $16 \mathrm{~S}$ (bootstrap 51\%, Fig. 8); it only is not recovered in the COI analyses, which is expected given that COI is much less useful for deeper nodes (Fig. 7). Although the monophyly of clade $\mathrm{F}$ (P. tigrinus and P. coriaceus) is not strongly supported by molecular data, both species are externally indistinguishable and share many anatomical features. Finally, clade $\mathrm{E}$ includes clade G (P. applanatus and P. luteus), which is sister taxon to P. burnupi (Fig. 4). Clade G is strongly supported in the combined, partitioned analyses (PP 1, bootstrap 100\%, Fig. 4) as well as in the mitochondrial analyses (PP 0.99, bootstrap 91\%, Fig.7; PP 1, bootstrap 99\%, Fig. 8).

The monophyly of the eight species recognized here is well supported in the partitioned analysis with all five markers (Fig. 4). The monophyly of the ninth species, P. latus, could not be tested because no fresh material was available. These eight species are also supported in nuclear maximum parsimony analyses 


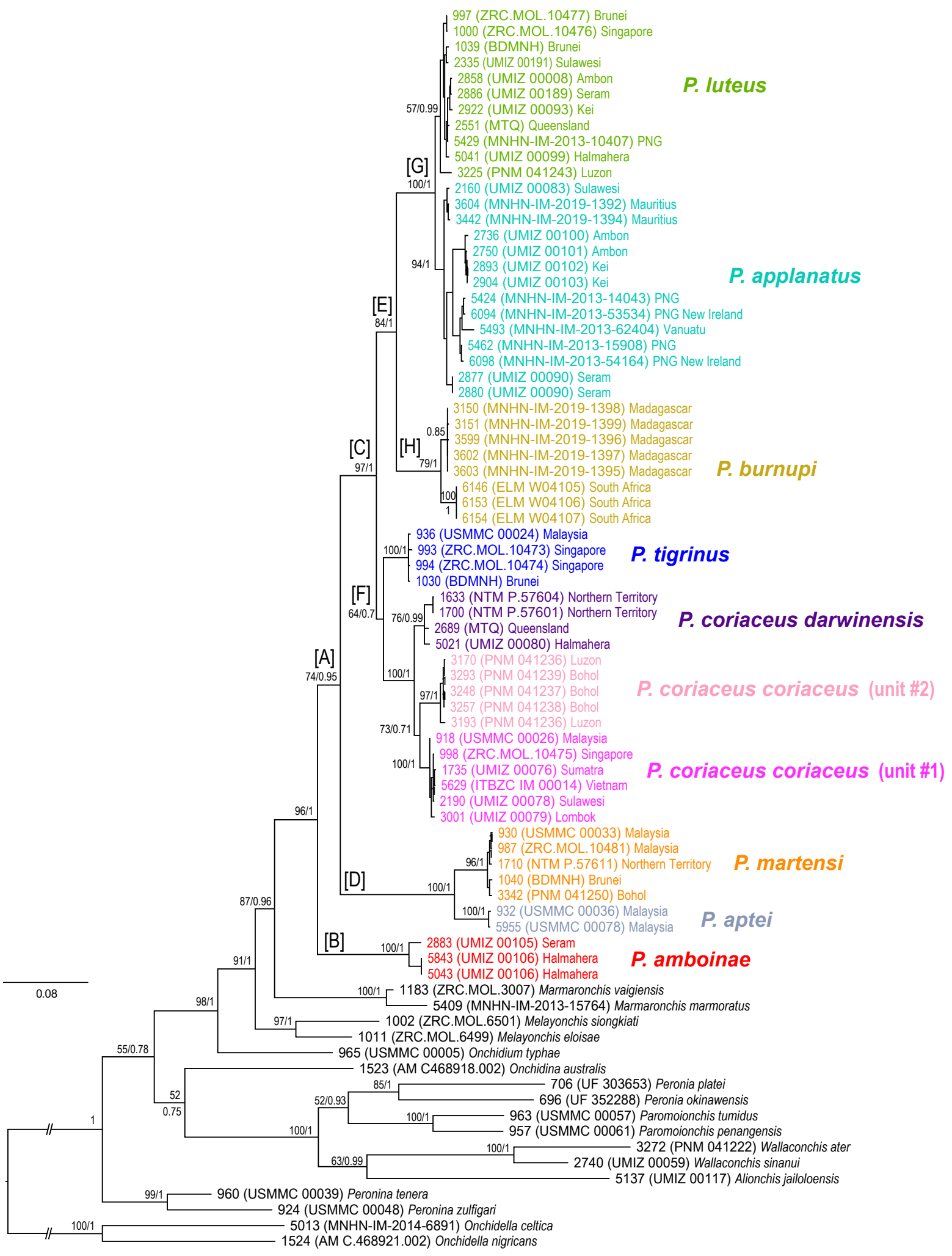

Fig. 4. Phylogenetic relationships of species of Platevindex based on partitioned COI, 16S, ITS2 and 28S sequences. Support values are reported above each branch with bootstrap values (maximum likelihood) listed first, followed by posterior probabilities (Bayesian analysis). 


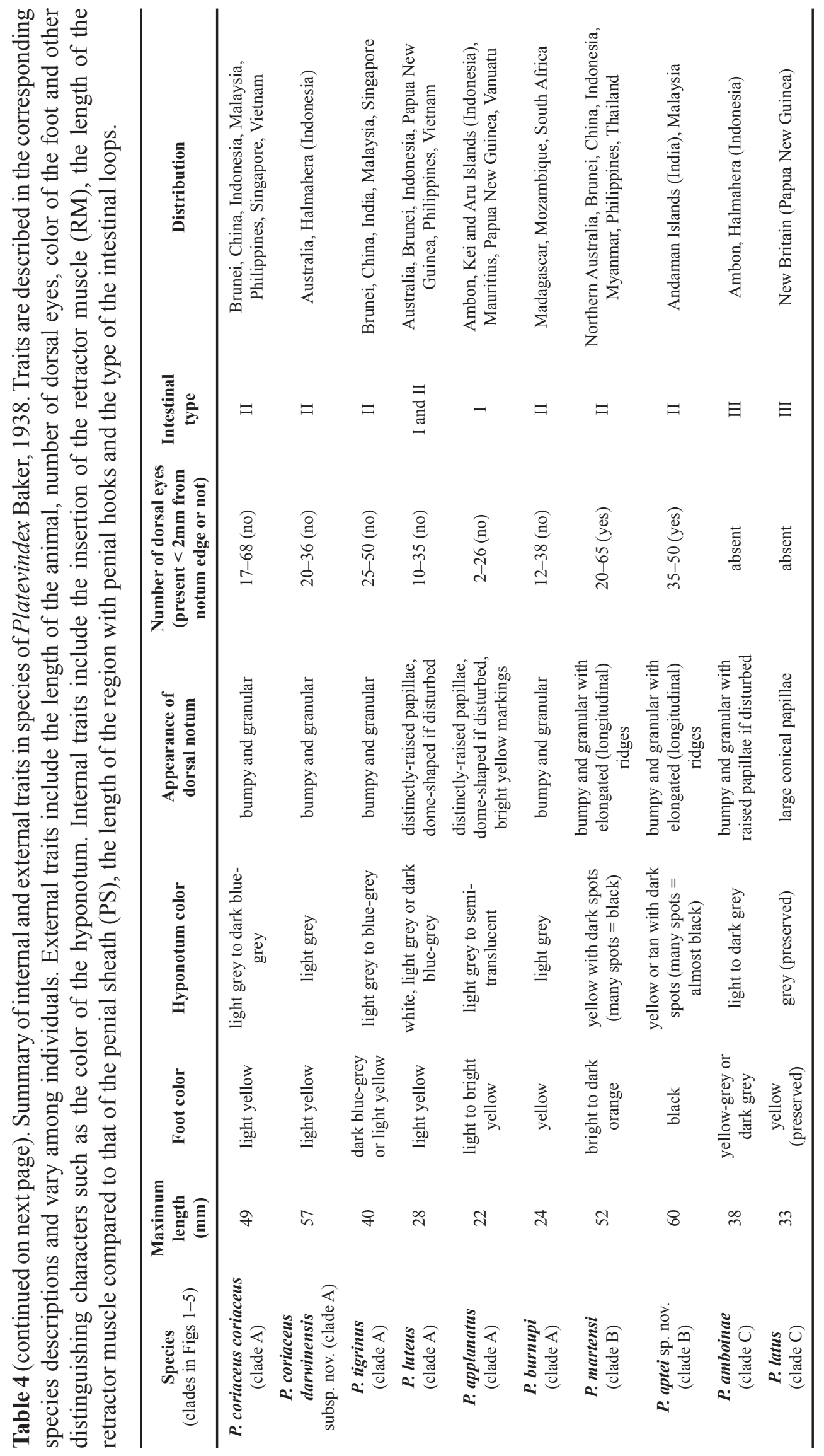




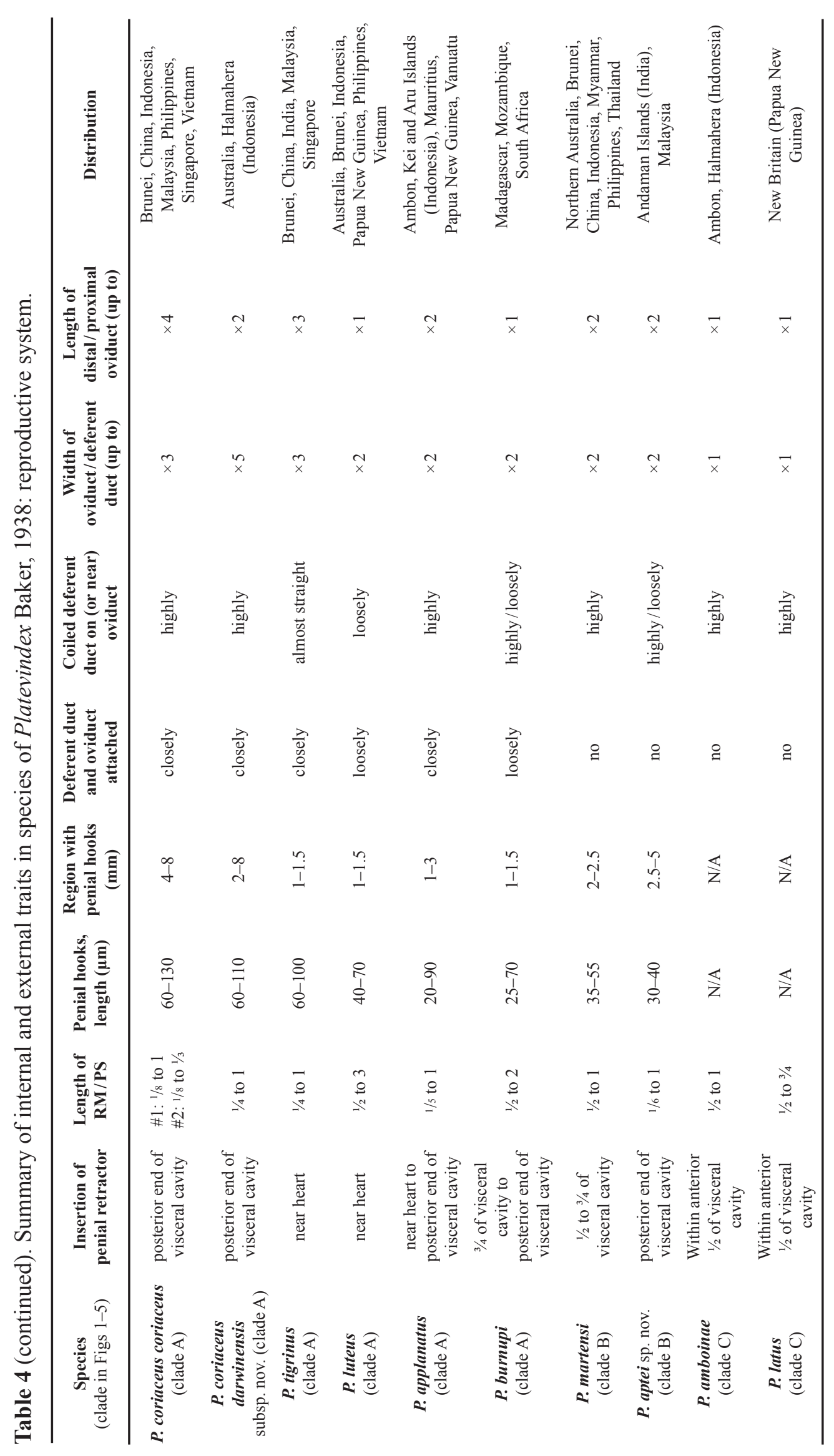




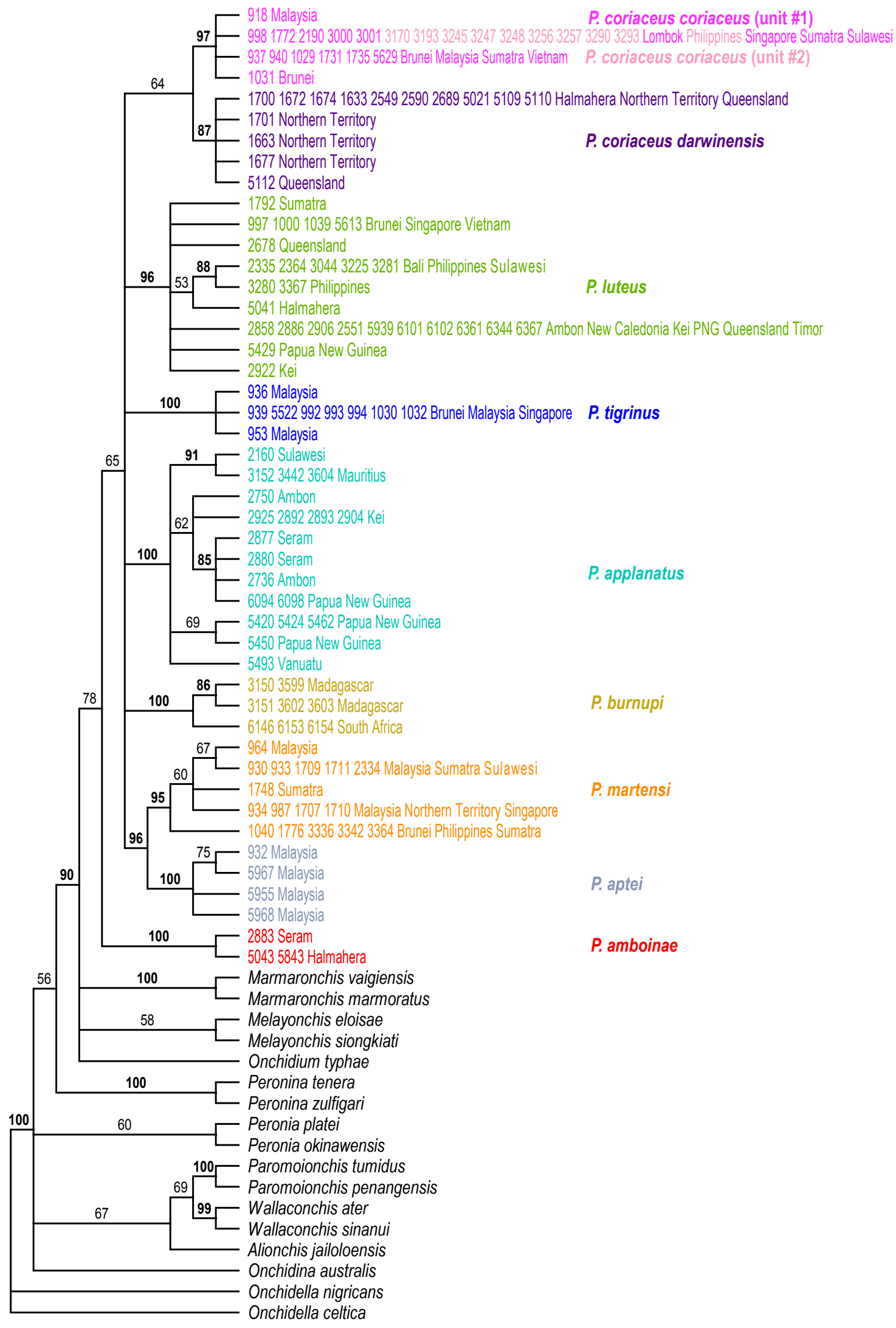

Fig. 5. Maximum parsimony consensus tree of species of Platevindex based on unique ITS2 haplotypes. Numbers above the branches are bootstrap values. 


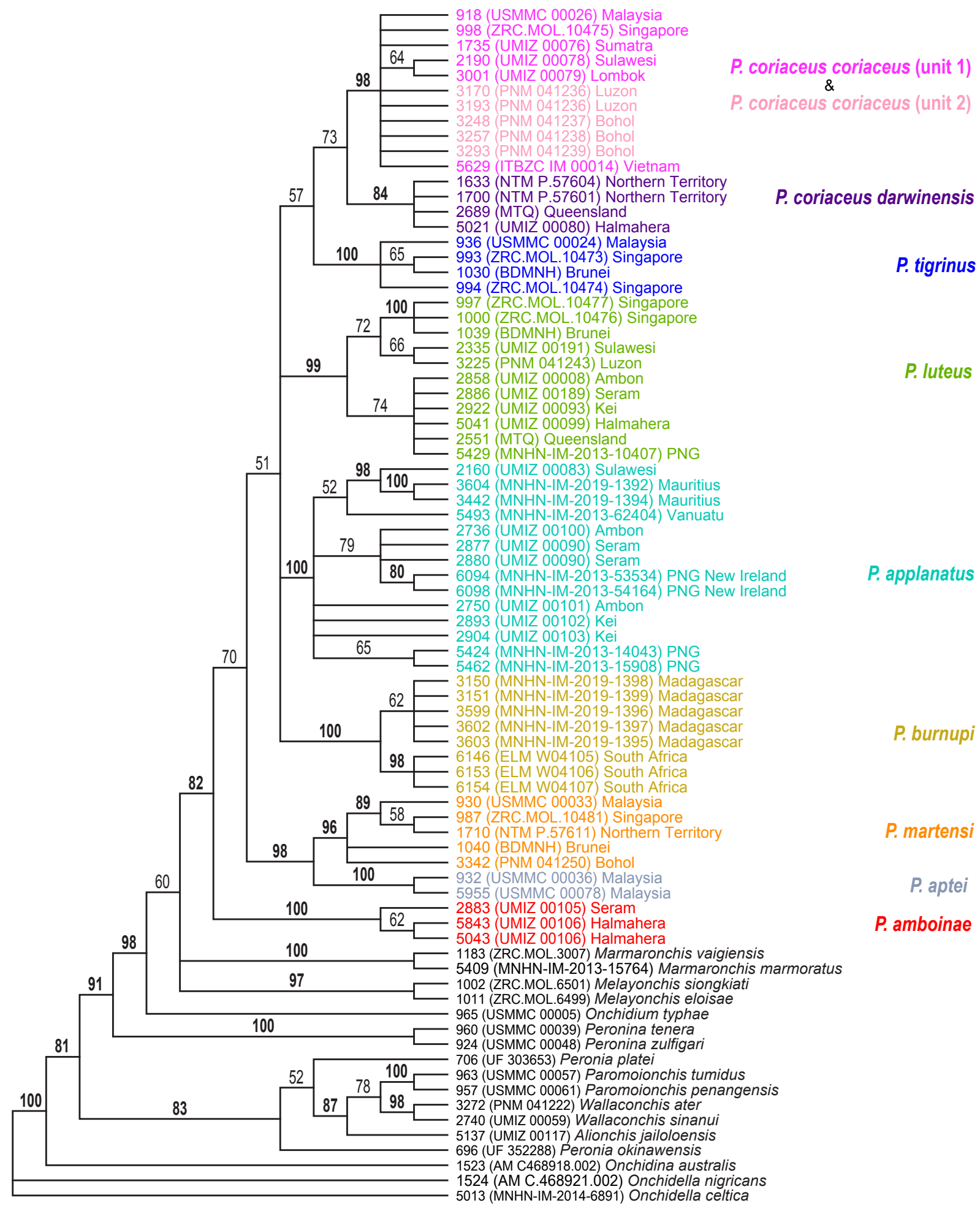

Fig. 6. Maximum parsimony consensus tree of species of Platevindex based on ITS2 and 28S sequences. Numbers above the branches are bootstrap values. 


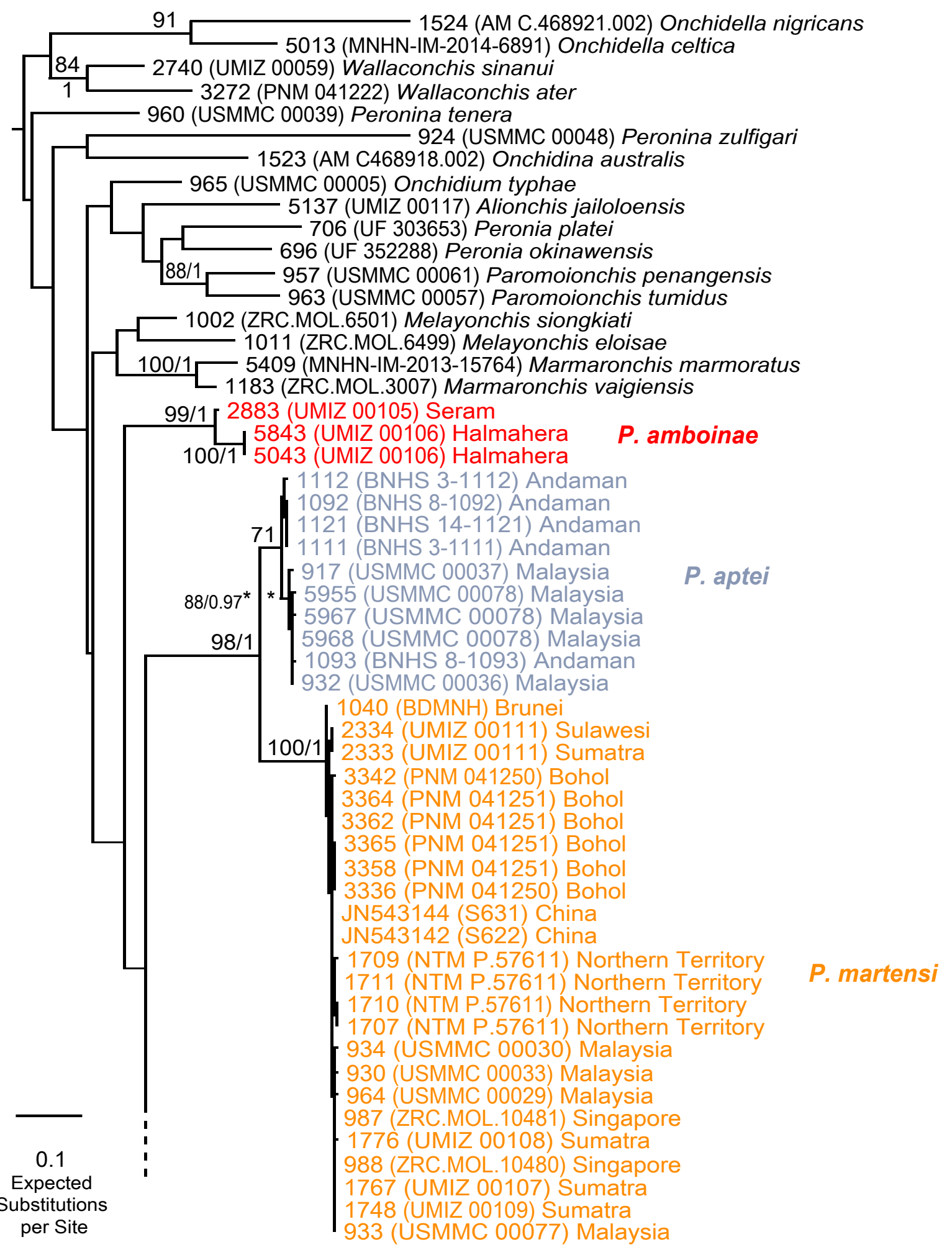

Fig. 7 (part 1 of 3). Phylogenetic tree based on COI sequences for 195 individuals (plus outgroups). Only bootstrap values $>60 \%$ (maximum likelihood) and posterior probabilities $>0.9$ (Bayesian analysis) are indicated. Some outgroups sequences are from previous studies (Dayrat et al. 2011a, 2016, 2017, 2018, 2019a, 2019b, 2019c, 2019d; Goulding et al. 2018a, 2018b, 2018c). Information on specimens can be found in the lists of material examined and in Table 1. All sequences of specimens of Platevindex are new, except sequences obtained from GenBank for specimens from China. 


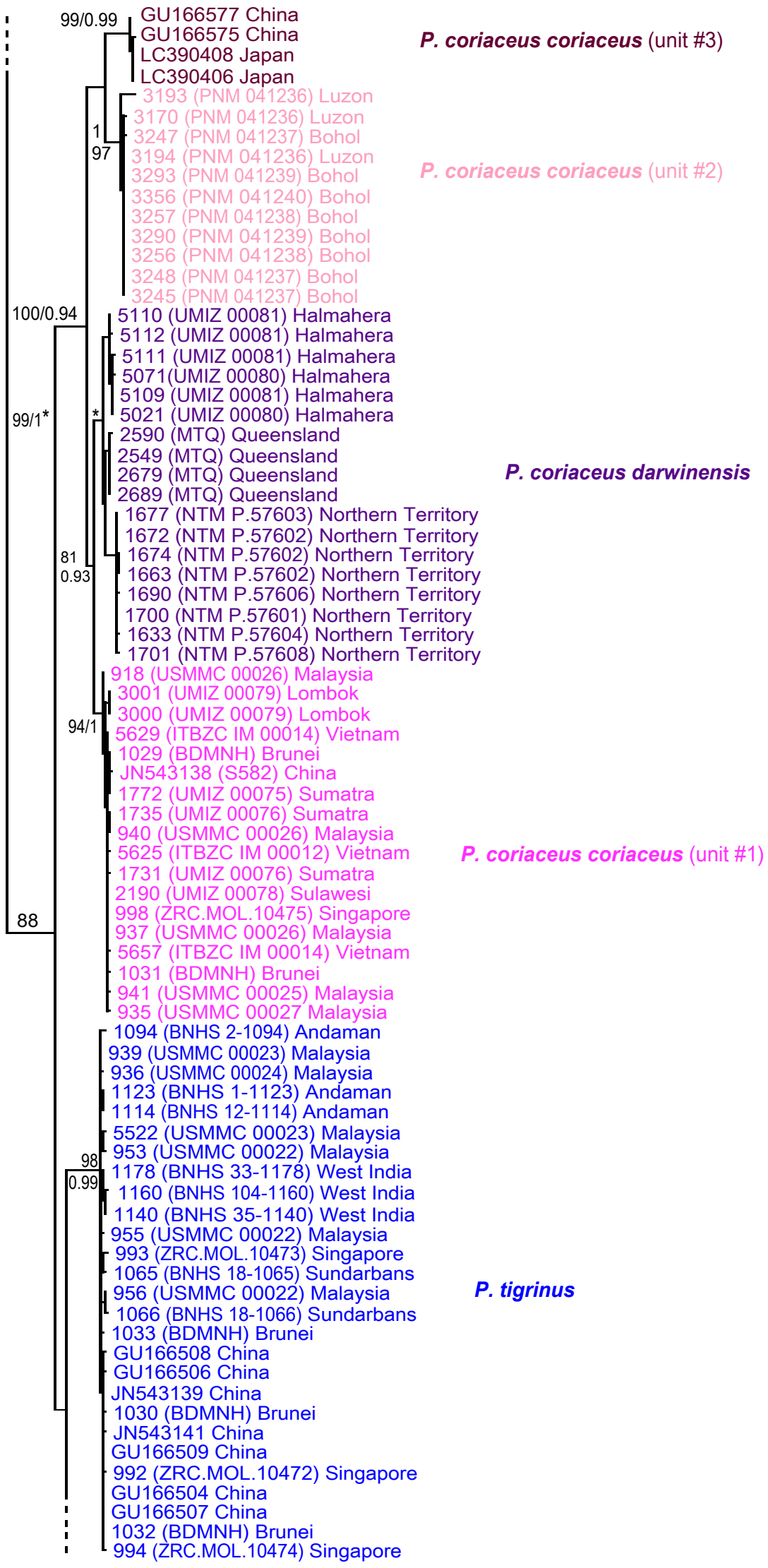

Fig. 7 (part 2 of 3). Phylogenetic tree based on COI sequences for 195 individuals (plus outgroups). 


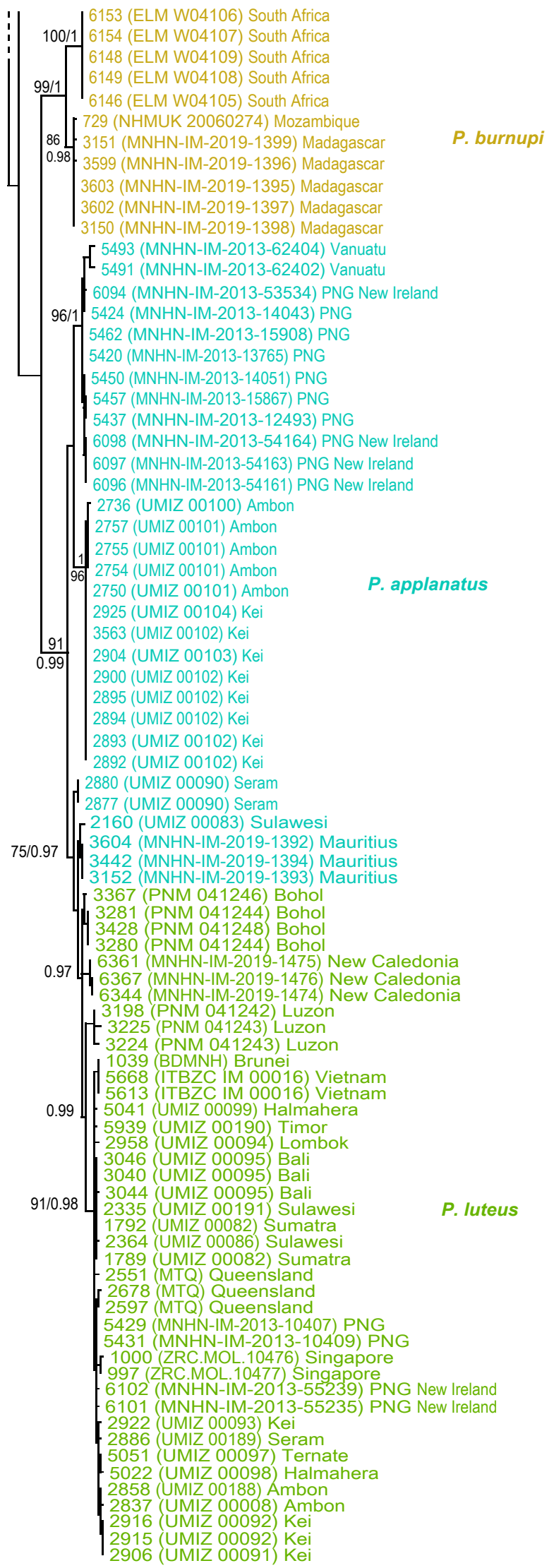

Fig. 7 (part 3 of 3). Phylogenetic tree based on COI sequences for 195 individuals (plus outgroups). 


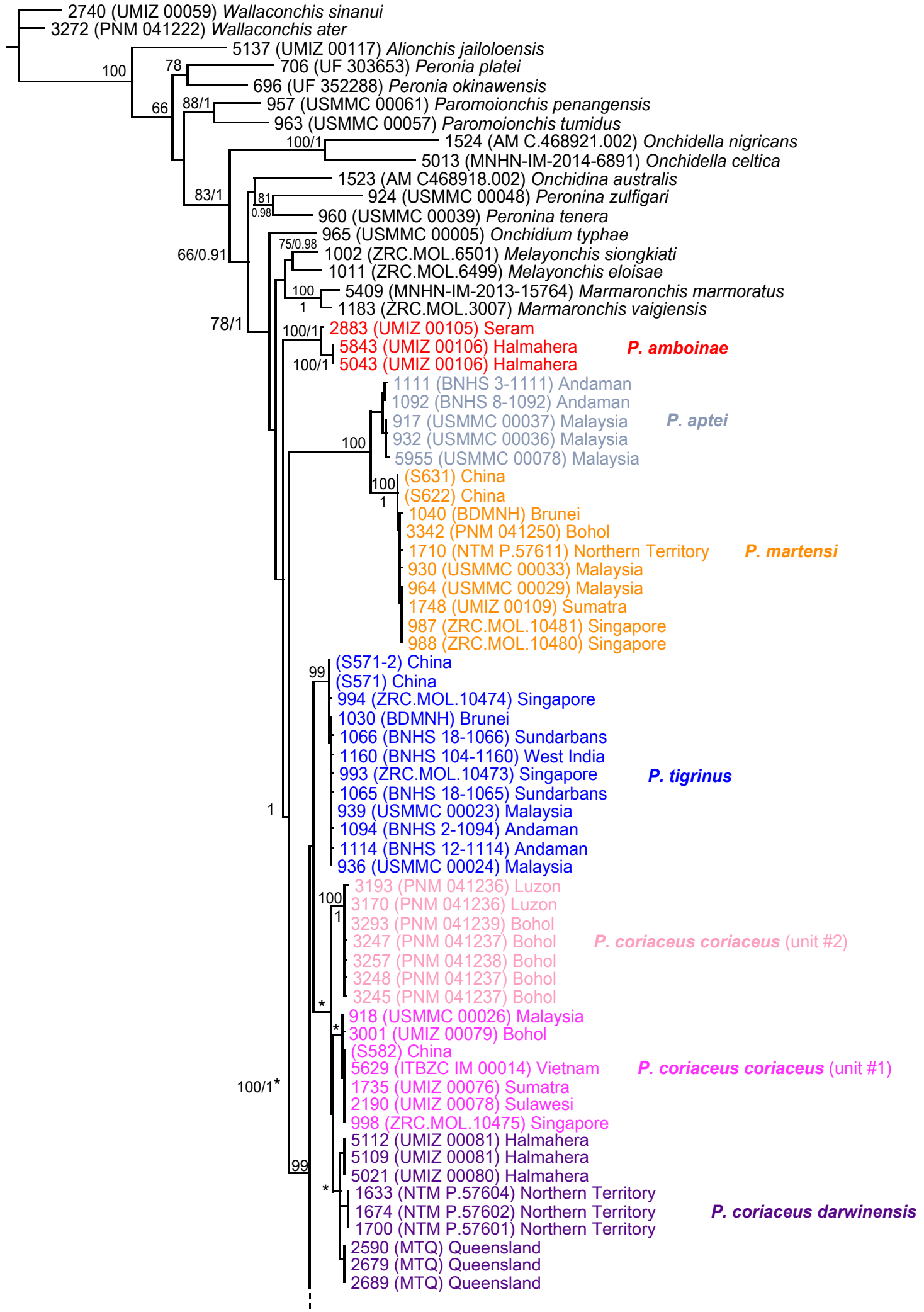

Fig. 8 (part 1 of 2). Phylogenetic tree of species of Platevindex based on mitochondrial COI and 16S sequences. Support values are reported above each branch with bootstrap values (maximum likelihood analysis) followed by posterior probabilities (Bayesian analysis); only values $>60 \%$ and $>0.9$, respectively, are indicated. 
(Figs 5-6). Overall, mitochondrial data show remarkable congruence with nuclear data regarding species limits. Trees from mitochondrial analyses (Figs 7-8) only differ with respect to P. luteus and P. applanatus, two species which are well supported in the combined partitioned analyses (Fig. 4) as well as in the nuclear analyses (Figs 5-6). Based on mitochondrial sequences, individuals of $P$. applanatus from Mauritius ([3152], [3442], 3604]), Seram ([2877], [2880]), and Sulawesi ([2160]) are sistergroup to P. luteus. As a result, P. luteus is nested within P. applanatus (Figs 7-8) and P. applanatus is paraphyletic based on mitochondrial DNA. Unlike nuclear DNA, mitochondrial loci are uniparentally inherited and do not undergo recombination. Thus, mitochondrial DNA can introgress from one species into another as a linked block following hybridization and backcrossing (Smith 1992; Funk \& Omland

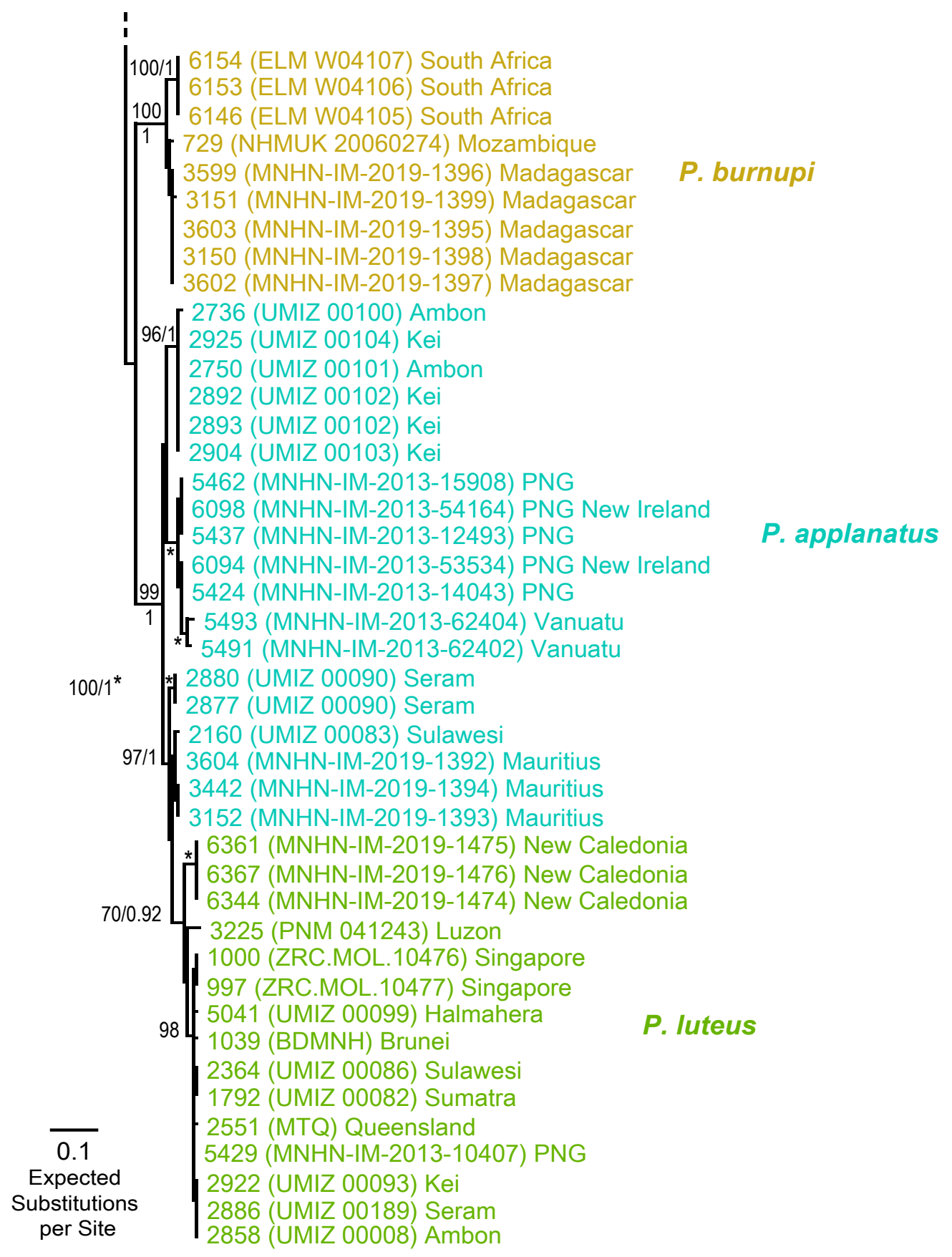

Fig. 8 (part 2 of 2). Phylogenetic tree of species of Platevindex based on mitochondrial COI and 16S sequences. 
2003). Platevindex luteus and P. applanatus are regarded as distinct species (see 'Species delineation' below) because they differ anatomically and the two groups are genetically divergent clades based on nuclear DNA data (Figs 5-6). The incongruence between mitochondrial and nuclear data is addressed in the discussion.

Four clades are recovered in the species $P$. coriaceus based on mitochondrial COI sequences (Fig. 7): these four least-inclusive, monophyletic, mitochondrial units are referred to as units \#1, \#2, \#3 and \#4. Units \#1 and \#2 are not recovered as distinct clades with nuclear data (i.e., specimens from unit \#1 and unit \#2 cluster together in a single clade) and the reciprocal monophyly of the mitochondrial unit \#4 is confirmed with nuclear data (Figs 5-6); mitochondrial unit \#3 (China and Japan) is only represented in $\mathrm{COI}$ analyses because no $16 \mathrm{~S}$ sequences and no nuclear sequences were available in GenBank for those individuals. The reciprocal monophyly between unit \#4 and all other units in nuclear analyses and the fact that the specimens from unit \#4 differ slightly from the rest of the species both serve to recognize two subspecies within P. coriaceus: $P$. coriaceus coriaceus (units \#1,\#2 and \#3) and P. coriaceus darwinensis subsp. nov. (unit \#4). The three units in P. coriaceus coriaceus have allopatric distributions: P. coriaceus coriaceus unit \#1 is found from the Strait of Malacca to Lombok and southeastern China, unit \#2 is found in the Philippines and unit \#3 is found in eastern China and southern Japan. Platevindex coriaceus darwinensis sp. nov. is present in Halmahera, Queensland, and Northern Territory, and therefore is also allopatric with $P$. coriaceus coriaceus.

\section{Pairwise genetic divergences}

Pairwise p-distances were calculated between the 11 least-inclusive units identified through the barcode gap analysis (ABGD) of our COI data set (Fig. 8). Because P. luteus and P. applanatus are regarded as one single unit by ABGD based on COI sequences, distances were also calculated for those two species separately. As a result, pairwise distances and barcode gaps between intra-unit and inter-unit distances

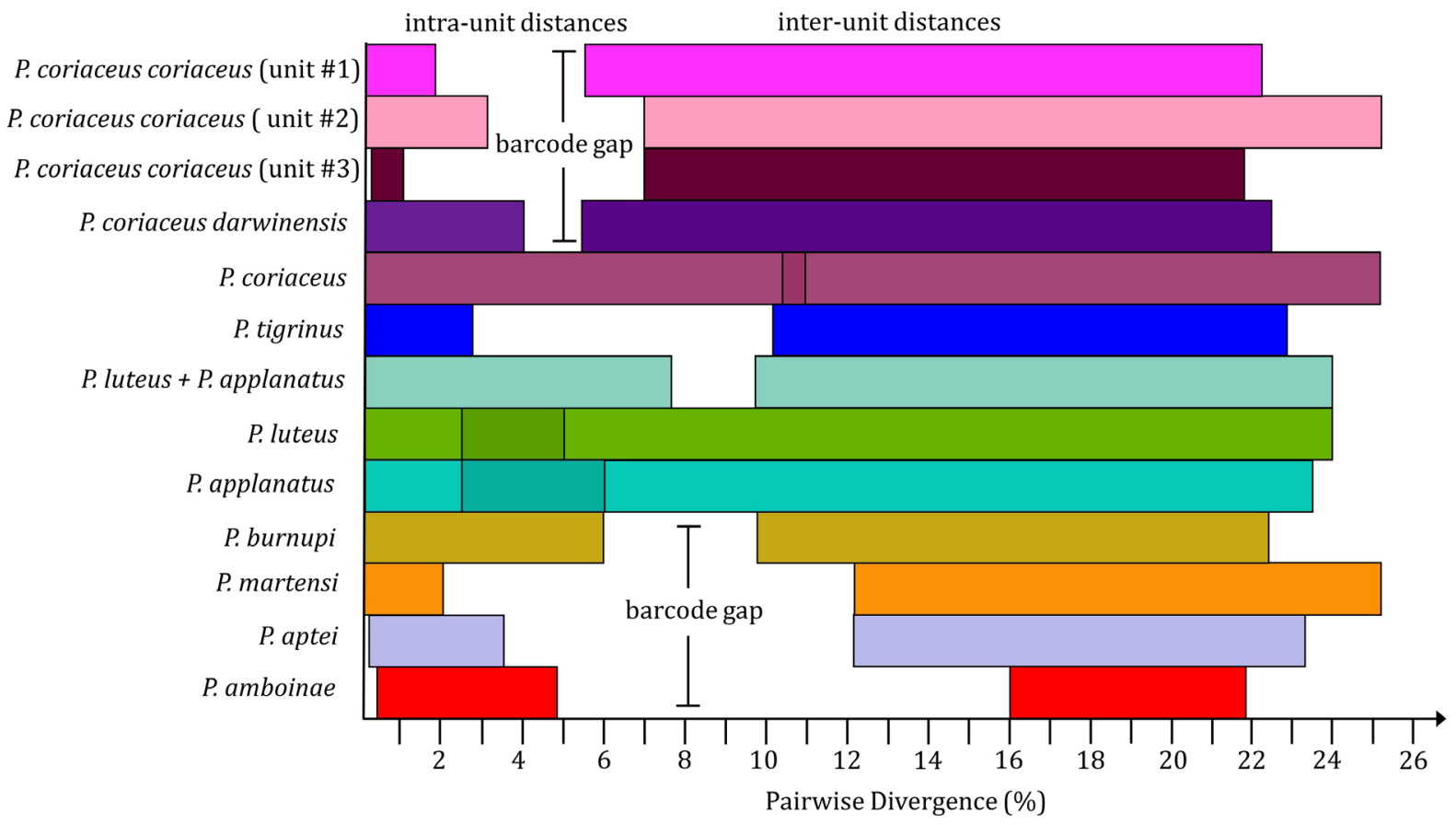

Fig. 9. Diagram illustrating pairwise genetic p-distances between COI sequences within and between mitochondrial molecular units in Platevindex delineated by Automatic Barcode Gap Discovery. Colored bars show intraspecific and interspecific genetic distances (in percent) and the "barcode gap" between these. 
are presented for a total of 13 units, including $P$. luteus and $P$. applanatus taken together as a single unit and considered separately (Fig. 9, Table 3).

As might be expected, barcode gaps are not strictly identical across the genus. Large barcode gaps between intra-unit and inter-unit distances are found for species that are strongly supported in all three (morphological, mitochondrial and nuclear) data sets: P. amboinae (barcode gap from 4.8 to 16.0\%), P. aptei sp. nov. (gap from 3.5 to $12.2 \%$ ), P. martensi (gap from 2.1 to $12.2 \%$ ) and P. tigrinus (gap from 2.7 to $10.1 \%$ ). There also is a large barcode gap between the three units of $P$. coriaceus coriaceus (e.g., from 3.1 to $7.0 \%$ for $P$. coriaceus coriaceus unit \#2) as well as for the southern clade of P. burnupi (gap from 0.2 to $5.4 \%$ ) and the northern clade (gap from 0.9 to $5.4 \%$ ). However, no barcode gap applies to $P$. luteus or P. applanatus, even though they are regarded as species based on further evidence from anatomy and nuclear data (see below). When P. luteus and P. applanatus are considered separately, genetic distances within $P$. luteus ( 0.0 to $5.0 \%$ ) overlap with the interspecific distances between $P$. luteus and P. applanatus (2.5 to 7.7\%). In fact, based on COI sequences, a few individuals of $P$. applanatus are within the $P$. luteus clade (Fig. 7). As a result, these two species are not reciprocally monophyletic and are regarded as a single unit by ABGD. When they are taken together as a single unit, intraspecific genetic distance is between 0.0 and $7.7 \%$, and thus the barcode gap for the two species grouped together is between 7.7 and $9.7 \%$ (Fig. 9, Table 3).

\section{Comparative anatomy}

All Platevindex slugs share some traits that are not found in any other onchidiids. In particular, they are characterized by a dorso-ventrally flattened body and a very narrow foot which make them relatively easy to identify to the genus level in the field. In addition, species of Platevindex differ both internally and externally (Table 4) and their differences can be combined for species identification (see the identification key provided after the Discussion).

The dorsal color of most species of Platevindex is similar (generally shades of brown and black), with the notable exception of bright yellow longitudinal markings often observed in P. applanatus. The ventral color (foot and hyponotum) is similar in most species except in P. martensi, the only species with an orange foot, and $P$. aptei sp. nov., the only one with a black foot. Other external traits differ between species (Table 4). Prominent dorsal papillae (with or without dorsal eyes) and a nearly hemispherical body when the animal is contracted are only found in $P$. luteus and $P$. applanatus. The very large papillae found in $P$. latus are also different from those found in $P$. luteus and $P$. applanatus. Longitudinal ridges are only found on the dorsal notum of $P$. martensi and $P$. aptei sp. nov. And, finally, dorsal eyes can be absent (P. amboinae and P. latus) or present (all other species) and, when present, they are very close $(<2 \mathrm{~mm})$ to the notum edge (P. martensi and $P$. aptei sp. nov.) or not (all other species with dorsal eyes).

Species also differ with respect to several internal traits (Table 4). Some of those traits are fairly easy to observe, such as the type of intestinal loops (types I, II and III) and the insertion of the retractor muscle of the penis (e.g., near the heart in the middle of the visceral cavity or at the posterior end of the visceral cavity), as these structures are within the body cavity of the slug and can be checked after cutting open the notum. However, some expertise is required to observe some other traits, such as the length of the flexible portion of the penis (with or without hooks) and the penial hooks (present or absent), which cannot be examined without the dissection of the reproductive parts.

\section{Species delineation}

Species are delineated based on three lines of evidence: morphological differences, analyses of mitochondrial DNA sequences and analyses of nuclear DNA sequences. There is complete congruence between morphological and nuclear data. The 9 least-inclusive units obtained in trees based on nuclear 
data are exactly those that are distinct morphologically, possibly with the exception of $P$. coriaceus coriaceus and $P$. coriaceus darwinensis subsp. nov., which are hard to distinguish morphologically (Figs 5-6). Mitochondrial COI sequences yield 11 least-inclusive units, most of which are the same as those supported by morphology and nuclear data. In all those cases where all three lines of evidence are in agreement, it is easy to decide what least-inclusive units should be recognized as taxa and properly named. For instance, $P$. martensi and $P$. aptei sp. nov. are recovered as two closely-related, reciprocallymonophyletic, least-inclusive units in all nuclear and mitochondrial analyses, they are separated by a large gap between intra- and interspecific genetic (COI) distances, they differ anatomically, they can be distinguished externally, and they are even sympatric in Peninsular Malaysia, indicating that they must be reproductively isolated (otherwise nuclear haplotypes would be similar between both species). Two least-inclusive units within P. burnupi are considered a single species, based on similar anatomy; the high intraspecific genetic distance is likely influenced by the geographic distance between sampling localities $(5.4-6.0 \%)$.

Incongruence between mitochondrial data, on one side, and nuclear and anatomical data, on the other side, is exclusively limited to two cases: the distinction between P. luteus and P. applanatus, and to the distinction between $P$. coriaceus coriaceus units \#1 and \#2. In those cases, it is considered that two congruent lines of evidence (anatomical and nuclear data) should have priority over a single line of evidence (mitochondrial data). Mitochondrial DNA is still used in the delineation of species of Platevindex but is interpreted in conjunction with other data, as introgression in mitochondrial DNA has been shown to be common across diverse taxa (Funk \& Omland 2003). In onchidiids, nuclear loci have been critically important in delineating species, as high intraspecific mitochondrial divergence occurs in many species, including Paromoionchis tumidus (up to 7.2\%; Dayrat et al. 2019a), Laspionchis bourkei Dayrat \& Goulding, 2019 (up to 7.8\%; Dayrat et al. 2019b) and Peronina zulfigari (up to 9.9\%; Goulding et al. 2018c), but is not accompanied by any morphological differences or genetic divergence in nuclear sequences. According to mitochondrial trees (Figs 7-8), P. applanatus is paraphyletic at the base of $P$. luteus, while nuclear DNA sequences recover $P$. applanatus and $P$. luteus as monophyletic, although the relationship between the two species is unclear due to an unresolved polytomy (Figs 5-6). Because P. applanatus is anatomically distinct and a highly-supported clade with ITS2 and 28S sequences (Fig. 6), it is regarded as a distinct species (see the Discussion). Units $\# 1$ and $\# 2$ of $P$. coriaceus coriaceus are reciprocally-monophyletic in mitochondrial analyses (Figs 5-6), while individuals of those two units (which are anatomically indistinguishable) are mixed with each other in nuclear analyses (Figs 7-8), suggesting that there is still gene flow between populations of those two mitochondrial units (because the mitochondrial genome is maternally-inherited while the nuclear genome is inherited from both parents). As a result, the mitochondrial units $\# 1$ and \#2 of $P$. coriaceus coriaceus are not named and recognized as distinct taxa. Note that we did not have access to fresh material and nuclear sequences for mitochondrial unit $\# 3$ of $P$. coriaceus coriaceus, from eastern China and southern Japan. It may or may not be a distinct subspecies of $P$. coriaceus.

Two subspecies are recognized in P. coriaceus: P. coriaceus darwinensis subsp. nov. and P. coriaceus coriaceus (units \#1, \#2 and \#3), which are recovered as distinct in all analyses. They differ by seven consecutive base pairs in the ITS2 sequence, a low level of divergence compared to the other species recognized here. Also, they only differ anatomically in minute details of the reproductive system. Thus, $P$. coriaceus coriaceus and P. coriaceus darwinensis subsp. nov. are ranked as subspecies (see the Discussion). Two least-inclusive, reciprocally-monophyletic clades are also consistently recovered within Platevindex burnupi, and there is greater genetic divergence between these two units of $P$. burnupi than between the units of $P$. coriaceus. However, due to the limited geographic sampling for $P$. burnupi, these two clades may not represent two distinct molecular groups. Platevindex burnupi is considered a single species, but further study is needed to understand dispersal and population connectivity. 


\title{
Systematics and anatomical descriptions
}

\author{
Class Gastropoda Cuvier, 1795 \\ Subclass Heterobranchia Burmeister, 1837 \\ Order Systellomatophora Pilsbry, 1948 \\ Superfamily Onchidioidea Rafinesque, 1815 \\ Family Onchidiidae Rafinesque, 1815
}

Genus Platevindex Baker, 1938

\section{Type species}

Onchidium coriaceum Semper, 1880, by original designation (Baker 1938: 88).

\section{Diagnosis}

Body dorso-ventrally flattened. Notum hard. No dorsal gills. Dorsal eyes present (in most species) or absent (only in two species). Dorsal eyes occur individually, never in groups. Eyes at the tip of short ocular tentacles. Foot narrow, approximately $1 / 4$ to $1 / 3$ of total width. Pneumostome median, on ventral hyponotum. Intestinal loops of types I, II or III. Accessory penial gland absent. Male opening below two ocular tentacles, almost centered, but slightly to right side (in dorsal view). Rectal gland present. Penis composed of two regions: rigid proximal region and flexible distal region. Penial hooks in distal region present (in most species) or absent.

\section{Gender}

The gender is masculine (ICZN Article 30.1.1). The generic name Platevindex was formed from the family name of the German zoologist Dr. Ludwig H. Plate (1862-1937), professor at Jena, who described several onchidiid species. No gender was specified in Baker's (1938) original publication of the generic name Platevindex. However, Baker (1938: 88) changed the ending of the specific name coriacea (combined with the generic name Oncis Plate, 1893) to coriaceus, indicating that he considered Platevindex to be of masculine gender. Also, the Latin word 'vindex', meaning 'protector' or 'champion', is masculine. As a result, the ending of all specific names transferred to Platevindex must become masculine (e.g., Onchidium luteum becomes Platevindex luteus).

\section{Distinctive diagnostic features}

Platevindex slugs can easily be identified in the field by their dorso-ventrally flattened body, firm notum and very narrow foot (one third of the total width or less when the animal is not active). However, no combination of internal characters is unique to Platevindex. Slugs with a rectal gland and no accessory penial glands are also found in Melayonchis and Onchidina. Also, among Platevindex, Melayonchis and Onchidina slugs, intestinal loops of type I are found only in Platevindex, but intestinal loops of type II are found in all three genera and intestinal loops of type III are found in both Platevindex and Melayonchis. The lateral radular teeth of Platevindex are characterized by a slight protuberance on their inner lateral margin (e.g., see arrows on Figs 18B, 34C, 48C, 57C, 66C). This kind of radular protuberance is unusual among onchidiids. Apart from in Platevindex, it has been observed only in Marmaronchis, in which the protuberance is also slight (Dayrat et al. 2018), and in Melayonchis, where it is much more conspicuous and sharp (Dayrat et al. 2019c).

\section{Remarks}

Several of the species that belong to Platevindex were classified in Plate's genus Oncis. Baker (1938) established the generic name Platevindex as a replacement name for Oncis Plate, 1893, which he treated as a junior homonym of Oncis Herrmannsen, 1847. However, Oncis Herrmannsen, 1847 was a mere 
nomenclator entry ("Oncis - vid. Onchis") which referred to Onchis Férussac, 1822, an available generic name, and which Herrmannsen treated as a full entry. Because Oncis was not treated as the valid name of a taxon by Herrmannsen (1847), it is not an available name under ICZN Article 11.5.

Regardless of the nomenclatural status of Oncis Herrmannsen, 1847, the generic name Oncis Plate, 1893 is not available because it is a junior objective synonym of Onchis Férussac, 1822. Indeed, under ICZN Article 33.2.1, one reason for a change in the original spelling of a name to be interpreted as "demonstrably intentional" is "when two or more names in the same work are treated in a similar way." In his revision of the onchidiids, Plate (1893) changed the original spelling of Onchidium to Oncidium, that of Onchidina to Oncidina, and that of Onchidella Gray, 1850 to Oncidiella. It is thus obvious that Plate (1893) considered that Oncis was a "demonstrably intentional" spelling change from Onchis. The generic name Oncis Plate, 1893 is thus an emendation of Onchis Férussac, 1822, but it is an unjustified emendation because Plate's (1893) correction was not made in accordance with Article 32.5. As an unjustified emendation, Oncis Plate, 1893 is a junior objective synonym of Onchis Férussac, 1822 and it enters in homonymy (Article 33.2.3). The fact that Plate (1893: 164) claimed that Oncis was a new generic name does not change the fact that, according to the Code, it is treated as an unjustified emendation of Onchis Férussac, 1822. Interestingly, several authors already treated Oncis Plate, 1893 as a junior objective synonym of Onchis Férussac, 1822. For instance, according to Woodward (1894: 57), Oncis Plate, 1893 is a "nom. preocc. Onchis (i.e ., Oncis), Fér., = Peronia, Blainv.". Also, Woodward (1894: 57) designated Oncis coriacea as the type species of Oncis. Regardless, being a junior objective synonym of Onchis Férussac, 1822, Oncis Plate, 1893 is objectively invalid. Oncis Plate, 1893 actually refers to the taxon of which the type species is Onchidium peronii Cuvier, 1804 (i.e., the type species of Onchis Férussac, 1822), and thus refers to the genus Peronia Fleming, 1822, not Platevindex (Dayrat et al. 2020). As a result, the valid generic name for the genus revised here is Platevindex, which Baker (1938) rightly established as a new generic name to refer to the taxon erroneously named Oncis by Plate (1893), even though the justification provided by Baker was not completely appropriate. Finally, Baker (1938: 87) correctly pointed out that the generic name Semperella Labbé, 1934 was a junior homonym of Semperella Gray, 1868 (Porifera). Baker (1938: 87) considered Semperella Labbé as a subjective synonym of Platevindex but provided no explanation; Semperella Labbé was later replaced by Semperoncis Starobogatov, 1976, which refers to a genus of terrestrial onchidiids (Dayrat 2009, 2010).

\section{Distribution}

Platevindex is broadly distributed in the Indo-West Pacific from the eastern coast of South Africa ( $\sim 32^{\circ}$ South) to New Ireland, Papua New Guinea and eastern Australia in the Pacific ( $21^{\circ}$ South). It has been documented up to $33^{\circ}$ North in southern Japan (Takagi et al. 2019). The known geographic range of each species is illustrated in Fig. 10.

\section{Platevindex coriaceus coriaceus (Semper, 1880)}

Figs 11-21

Onchidium coriaceum Semper, 1880: pl. 19, figs 1, 16, pl. 23, fig. 12.

Onchidella condoriana Rochebrune, 1882: 67. Syn. nov.

Oncis semperi Plate, 1893: 192-193. Syn. nov.

Onchidium coriaceum - Semper 1882: 271-273, pl. 21, fig. 7.

Oncis coriacea - Plate 1893: 190-191. — Stantschinsky 1907: 395.

Oncis semperi - Stantschinsky 1907: 395.

Platevindex coriaceus - Baker 1938: 88.

Platevindex mortoni - Sun et al. 2014: 63 [non Platevindex mortoni Britton, 1984]. 


\section{Material examined}

\section{Lectotype of Onchidium coriaceum}

PHILIPPINES • lectotype (here designated; 20/16 mm); ZMB/Moll 39028a.

\section{Paralectotypes of Onchidium coriaceum}

MALAYSIA • 1 paralectotype; Penang; ZMB/Moll 39029.

PHILIPPINES • 6 paralectotypes; ZMB/Moll 39028b.

SINGAPORE • 2 paralectotypes; Semper leg.; ZMB/Moll 39030.

\section{Holotype of Onchidella condoriana}

VIETNAM • holotype (23/16 mm), by monotypy; Poulo-Condor [Côn Son, the largest island of the Côn Đảo archipelago, off the coast of southern Vietnam]; 1876; Dr Harmand leg.; MNHN-IM-2000-22952.

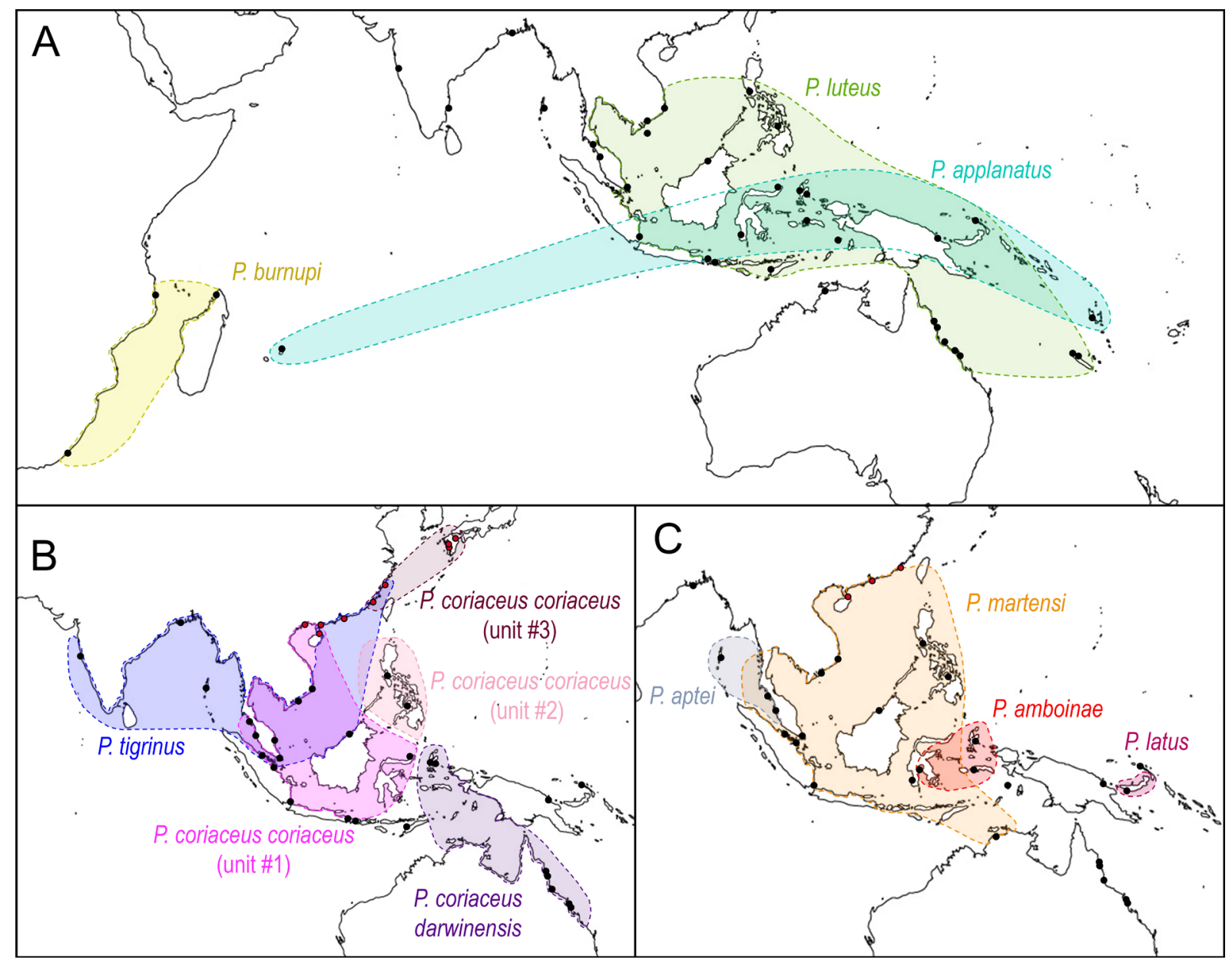

Fig. 10. Geographic distributions of species of Platevindex. Colored areas correspond to hypothetical ranges proposed based on all known records, and the colors are the same as those used for each species in the phylogenetic trees (Figs 1-5). Distinct colors are used for each subspecies and mitochondrial unit in P. coriaceus (Semper, 1880) as well as for each subspecies of P. burnupi (Collinge, 1902). Black dots show sites sampled for this study and red dots (China and Japan) show localities of previously published genetic sequences included in the phylogenetic analyses. A. Platevindex luteus (Semper, 1880), P. applanatus (Simroth, 1920), P. burnupi. B. Platevindex tigrinus (Stoliczka, 1869), P. coriaceus coriaceus (units \#1, \#2, and \#3) and P. coriaceus darwinensis subsp. nov. C. Platevindex martensi (Plate, 1893), P. aptei Goulding \& Dayrat sp. nov., P. amboinae (Plate, 1893) and P. latus (Plate, 1893). 
Syntypes of Oncis semperi

PHILIPPINES • 2 syntypes (25/20 and 21/20 mm); Mindanao; ZMB/Moll 45661.

\section{Notes on type material}

Onchidium coriaceum. According to the original description, the lectotype and paralectotypes from the Philippines were collected from Bohol, Manila (Luzon) and Zamboanga (Mindanao). However, they are all mixed together in the same jar and nothing allows us to assign them to Bohol, Manila or Zamboanga. Thus, the type locality is simply "Philippines". The lectotype is selected because it is well preserved and was dissected for the present study (all internal organs remain in the specimen); the anatomy of the lectotype matches perfectly the characters observed in our recently-collected material (retractor muscle inserting at the posterior end of the visceral cavity, penis almost as long as the visceral cavity, intestinal loops of type II, deferent duct attached to the surface of the oviduct and tightly coiled with many U-turns). All other syntypes become paralectotypes. All six paralectotypes (30/22 to 23/16 mm) from the Philippines (ZMB/Moll 39028b) were dissected previously, likely by Semper himself or Plate (1893). Three of these paralectotypes (30/22, 28/28 and 23/16 mm) are missing most of the reproductive and digestive systems, but parts of the oviduct, intestine and rectal gland remain; one paralectotype (23/16 mm) corresponds to only the left half of a slug with some organs remaining; two paralectotypes $(27 / 26$ and $20 / 16 \mathrm{~mm})$ were previously dissected but all organs remain. The large $(22 / 10 \mathrm{~mm})$ paralectotype from Singapore (ZMB/Moll 39030) was previously dissected and its penial apparatus is missing; the notum of a small $(20 / 17 \mathrm{~mm}$ ) paralectotype from Singapore (ZMB/Moll 39030) was cut open for the present study to check several characters. The paralectotype $(27 / 25 \mathrm{~mm})$ from Penang (ZMB/Moll 39029) was previously dissected and the penial complex is missing; the deferent duct in its posterior reproductive system is not attached to the oviduct, indicating that this paralectotype is not part of the species described here but, instead, is a misidentification of P. martensi. Semper (1882: 272) also mentioned some material (likely only one specimen) collected in Brisbane (Queensland, Australia) which could not be located. While Queensland is part of the geographic distribution of the species described here, that material from Brisbane could belong to P. luteus. Finally, Semper (1882: 272) mentioned two specimens from "des Wiener Museums" (the Vienna Museum) but from an unknown locality. Due to the presence of at least two species of Platevindex in the type material (certainly $P$. coriaceus and P. martensi, and possibly P. luteus; see Remarks for more details), it is necessary to designate a lectotype to clarify the application of the name $P$. coriaceus.

Onchidella condoriana. The radula, the penial complex and most of the posterior (female) reproductive parts were all previously removed and are missing from the holotype. Some parts remain though (digestive gland, intestine, oviduct of the posterior reproductive parts). It is unclear how many specimens were used by Rochebrune (1882) for the original description, but only one specimen is present at the MNHN and it is regarded as the holotype (there is no evidence suggesting that Rochebrune examined more than one specimen).

Oncis semperi. Both syntypes were previously emptied of all their internal organs, likely by Plate himself. Two stomachs and some pieces of digestive glands remain in the jar but the type of intestinal loops could not be checked. Plate's description of intestinal loops of type I (Plate 1893) is inconsistent with P. coriaceus but it was most likely a mistake (see our remarks below). The designation of a lectotype would be pointless because the two syntypes are externally similar and it is unclear whether Plate's description was mostly based on the largest specimen or both specimens.

\section{Other material}

BRUNEI • 1 spec. (30/27 [1031] mm); Pulau Kaingara; 0457.020’ N, 11501.785' E; 28 Jul. 2011; station 33; open mangrove with Rhizophora trees and logs, by the river; BDMNH 1 spec. $(25 / 20$

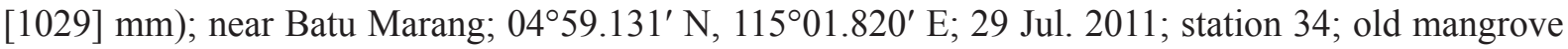
with tall Rhizophora trees with high roots and Thalassina mounds; BDMNH. 
INDONESIA - Sumatra • 1 spec. (38/29 [1772] mm); Pulau Sinaboi; 02¹8.145’ N, 10059.309' E; 8 Oct. 2012; station 73; some small Avicennia and Rhizophora near shore; UMIZ 00075 2 specs (30/19 [1735] and 24/20 [1731] mm); Kualapenet; $05^{\circ} 16.275^{\prime} \mathrm{S}, 1^{\circ} 5^{\circ} 51.287^{\prime} \mathrm{E}$; 17 Oct. 2012; station 77; narrow band of mangrove between ocean and fish ponds; UMIZ 00076. - Sulawesi - 1 spec. (49/34 [2190] mm); Wawontulap; $01^{\circ} 19.275^{\prime} \mathrm{N}, 1^{2} 4^{\circ} 31.053^{\prime} \mathrm{E}$; 11 Mar. 2013; station 86; Rhizophora mangrove with some Avicennia and dead logs; UMIZ 00078. - Lombok • 2 specs (35/23 [3000] and 29/18 [3001] mm); Kayangan Bay, Bajo Village; 08²9.491' S, 116³9.719’ E; 28 Mar. 2014; station 151; mangrove of small, sparse Avicennia trees, and a few older trees; UMIZ 00079.

MALAYSIA - Peninsular Malaysia - 1 spec. (30/26 [941] mm); Sungai Ular; 0356.512' N, $103^{\circ} 22.320^{\prime} \mathrm{E}$; $14 \mathrm{Jul}$. 2011; station 20; dense forest of mostly Rhizophora, higher intertidal; USMMC $00025 \cdot 3 \operatorname{specs}\left(35 / 21\right.$ [937], 28/21 [940] and 25/29 [918] mm); Merbok; 05 $39.035^{\prime} \mathrm{N}, 100^{\circ} 25.782^{\prime} \mathrm{E}$; 18 Jul. 2011; station 21; deep Rhizophora forest with old, tall trees, hard mud, many small creeks and dead logs; USMMC 00026 • 1 spec. (24/18 [935] mm); Matang, close to Crocodile River; 04²49.097' N, $100^{\circ} 37.37^{\prime} \mathrm{E}$; $19 \mathrm{Jul}$. 2011; station 28; old and open Rhizophora forest with tall trees, hard mud, creeks, and many dead logs; USMMC 00027.

PHILIPPINES - Luzon • 3 specs (44/26 [3193],31/17 [3170] and 21/14 [3194] mm); Nasugbu, Batangas; $14^{\circ} 10.714^{\prime} \mathrm{N}, 120^{\circ} 36.817^{\prime} \mathrm{E}$; 6 Jul. 2014; station 182; dense forest of Avicennia and Rhizophora; PNM 041236. - Bohol • 3 specs (30/29 [3247], 28/18 [3245] and 26/15 [3248] mm); Inabanga; $10^{\circ} 00.389^{\prime} \mathrm{N}$, $124^{\circ} 03.522^{\prime}$ E; 12 Jul. 2014; station 186; rehabilitated fish ponds with mostly young Rhizophora; PNM $041237 \cdot 2$ specs (33/17 [3256] and 27/19 [3257] mm); Inabanga; $10^{\circ} 04.432^{\prime} \mathrm{N}, 124^{\circ} 04.691^{\prime} \mathrm{E} ; 13 \mathrm{Jul}$. 2014; station 188; old forest of mostly Avicennia with many dead logs; PNM $041238 \cdot 2$ specs (37/25 [3293] and 34/24 [3290] mm); Mabini; 09 51.532' N, 124³1.685' E; 17 Jul. 2014; station 194; narrow mangrove on the edge of fish ponds, tall Rhizophora and Avicennia, many dead logs; PNM 041239 • 1 spec. (34/22 [3356] mm); Mabini; 0951.402' N, 124³0.982' E; 18 Jul. 2014; station 195; narrow Rhizophora and Avicennia mangrove by the sea with fish ponds built on landward side, cement ditches between the mangrove patches and the ponds; PNM 041240.

SINGAPORE • 1 spec. (28/20 [998] mm); Lim Chu Kang; 01²6.785’ N, 103²42.531' E; 2 Apr. 2010; station 7; mud outside mangrove on sun-exposed mudflat; ZRC.MOL.10475.

VIETNAM - 1 spec. (32/15 [5625] mm); Can Gio mangrove forest; $10^{\circ} 24.430^{\prime} \mathrm{N}, 106^{\circ} 53.878^{\prime} \mathrm{E}$; 11 Jul. 2015; station 222; Avicennia and Rhizophora mangrove patch by road; ITBZC IM 00012 • 2 specs (38/16 [5629] and 27/23 [5657] mm); Can Gio mangrove forest; $10^{\circ} 27.804^{\prime} \mathrm{N}, 106^{\circ} 53.289^{\prime} \mathrm{E}$; 16 Jul. 2015; station 228; open forest of tall Rhizophora, hard mud; ITBZC IM 00014.

\section{Description}

Color and morphology of live animals (Fig. 11)

Live animals are not usually covered with mud, and their natural color can be observed without washing. The dorsal notum is typically dark brown, dark grey or black and often has some lighter brown longitudinal bands or mottling. The dorsal surface is typically bumpy, granular and not smooth. The color of the hyponotum in unit \#1 (from Peninsular Malaysia to China and Sulawesi) is grey or blue-grey, or occasionally light grey (Fig. 11J-K), while in unit \#2 (Philippines) it is generally dark grey or dark blue (Fig. 11D-E). The margin of the hyponotum may be bright white, which is especially common in unit \#2. No specimens or pictures of the hyponotum were available for unit \#3 from China or Japan (only a photo of the dorsal notum was published by Takagi et al. 2019). The foot is light yellow in units $\# 1$ and $\# 2$. The ocular tentacles are frequently retracted when animals are observed in the field, but extended ocular tentacles are brown and short (up to $4 \mathrm{~mm}$ long). Inferior to the ocular tentacles, superior to the mouth, the head bears a pair of oral lobes. On each oral lobe, there is an elongated bump or protuberance, likely with sensitive receptors. 

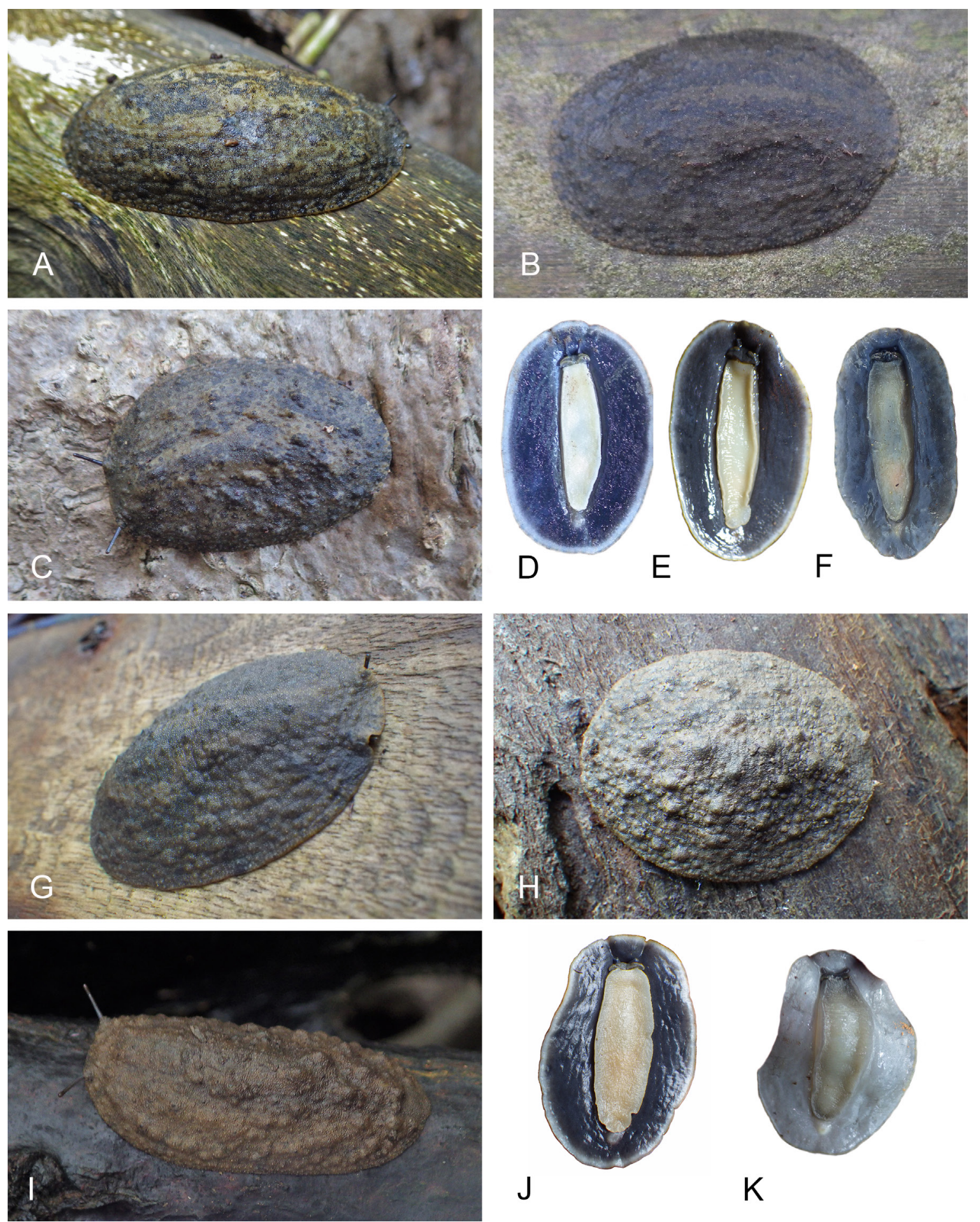

Fig. 11. Platevindex coriaceus coriaceus (Semper, 1880), live animals. A-F. Mitochondrial unit \#2. A. Dorsal view, $44 \mathrm{~mm}$ long [3193], Philippines, Luzon (PNM 041236). B. Dorsal view, $34 \mathrm{~mm}$ long [3356], Philippines, Bohol (PNM 041240). C. Dorsal view, $37 \mathrm{~mm}$ long [3293], Philippines, Bohol (PNM 041239). D. Ventral view, same as B. E. Ventral view, same as A. F. Ventral view, $33 \mathrm{~mm}$ long [3256], Bohol (PNM 041238). G-K. Mitochondrial unit \#1. G. Dorsal view, 49 mm long [2190], Indonesia, Sulawesi (UMIZ 00078). H. Dorsal view, $38 \mathrm{~mm}$ long [1772], Indonesia, Sumatra (UMIZ 00075). I. Dorsal view, $38 \mathrm{~mm}$ long [5629], Vietnam, Can Gio (ITBZC IM 00014). J. Ventral view, same as G. K. Ventral view, $27 \mathrm{~mm}$ long [5657], Vietnam, Can Gio (ITBZC IM 00014). 
Dorsal gills are absent. Papillae with dorsal eyes are present. The exact number of papillae bearing dorsal eyes is variable (between 20 and 68 in unit \#1 and between 17 and 45 in unit \#2), with the largest animals bearing the largest numbers of eyes. The number of eyes on each papilla is one. The dorsal eyes are distributed across the notum but are absent on the margin (are never $<2 \mathrm{~mm}$ from the notum edge).

External morphology (Fig. 12A-C)

The notum is oval and the body is dorso-ventrally flattened (Fig. 12A). The foot is narrow in proportion to the hyponotum and is approximately $1 / 4$ to $1 / 3$ of the total width. The anus is posterior, median, close to the edge of the pedal sole. The pneumostome is median and is near the anus (closer to the anus than to the posterior margin of the hyponotum) (Fig. 12C). On the right side (to the left in ventral view), a peripodial groove is present at the junction between the pedal sole and the hyponotum, running longitudinally from the buccal area to the posterior end and ending with the female opening. The female opening is approximately 1 to $3 \mathrm{~mm}$ from the anus in most individuals but may be up to $6 \mathrm{~mm}$ away in large specimens (observed in unit \#1). The male aperture is below the ocular tentacles, almost centered between them, but slightly to the right side (Fig. 12B).

\section{Visceral cavity and pallial complex}

The heart is enclosed in the pericardium, on the right side of the visceral cavity, slightly posterior to the middle. The large, anterior ventricle becomes a large aorta that branches into smaller vessels delivering blood to the visceral organs. The auricle, significantly smaller than the ventricle, is posterior. The pericardium communicates through a small hole with the right portion of the renal-pulmonary complex. The kidney is intricately attached to the pulmonary cavity, which is slightly asymmetrical, the right part being slightly larger than the left part.

Digestive system (Figs 2B, H, 13-17A)

There is no jaw. The left and right salivary glands have numerous branches and join the buccal mass dorsally on either side of the esophagus. The radula is located between two large posterolateral muscular masses. Radulae measure up to $6.1 \mathrm{~mm}$ in length (unit \#1) and $4.7 \mathrm{~mm}$ (unit \#2). Each radular row contains a central rachidian tooth and two, left and right, half rows of lateral teeth. Examples of radular formulae are presented in Table 5. The half rows of lateral teeth form an angle of $45^{\circ}$ with the rachidian axis. The rachidian teeth are unicuspid: a median cusp is always present; there are no distinct lateral cusps (Figs 13A, 14A). The lateral aspect of the base of the rachidian teeth is straight (neither concave nor convex). The length of the cusp of each rachidian tooth is approximately 15-35 $\mu \mathrm{m}$, significantly smaller than that of the lateral teeth. The hook of the lateral teeth is extended posteriorly by a tail-like structure attaching to the radular membrane and making the hook look longer. The tail-like structure (posterior hook extension, Fig. 13D) is most noticeable in the outermost lateral teeth. The lateral teeth are unicuspid with a flattened hook. The tip of the hook may be rounded or pointed, which varies between individuals and even within a particular radula. Lateral teeth are approximately 35 to $75 \mu \mathrm{m}$ long, and their length gradually increases along the half row, excluding the few innermost lateral teeth and outermost lateral teeth which are significantly smaller (Fig. 13B, D). The lateral teeth bear an outer pointed spine on the lateral expansion of the base. In most cases, the basal lateral spine cannot be observed because it is hidden below the hook of the adjacent lateral tooth. It can only be observed when the teeth are not too close together or when the teeth are turned in an unusual position (Fig. 13E-F). The inner lateral aspect of the hook of the lateral teeth is not straight. It is marked by a moderate protuberance placed over the inner adjacent tooth. That protuberance is slight and rounded (not pointed) and makes the inner aspect of the hook look wavy. The protuberance diminishes in the outermost teeth, and, as a result, their lateral aspect is almost straight.

The esophagus, narrow and straight, enters the stomach anteriorly. The stomach is located on the left, dorsal side of the visceral mass. In dorsal view, only a portion of the stomach can be seen because it is partly covered by the lobes of the digestive gland. The dorsal lobe is mainly on the right. The left, lateral 
lobe is mainly ventral. The posterior lobe covers the posterior aspect of the stomach. The stomach is a U-shaped sac divided into four chambers (Fig. 15C-D). The first chamber, just distal to the esophagus, is delimited by a thin layer of tissue, and receives the ducts of the dorsal and left lateral lobes of the digestive gland. The second chamber is delimited by a thick, muscular layer of tissue and receives the duct of the posterior lobe of the digestive gland. In the third chamber of the stomach, thick ridges extend towards the middle of the chamber. The fourth chamber is externally similar to the third chamber but is characterized by much lower and thinner internal ridges. The intestine is long and narrow, with intestinal loops of type II. The transitional loop is oriented between 7 and 9 o'clock in unit \#1 (Fig. 16), and between 6 and 9 o'clock in unit \#2 (Figs 2B, H, 16-17). A rectal gland is present.

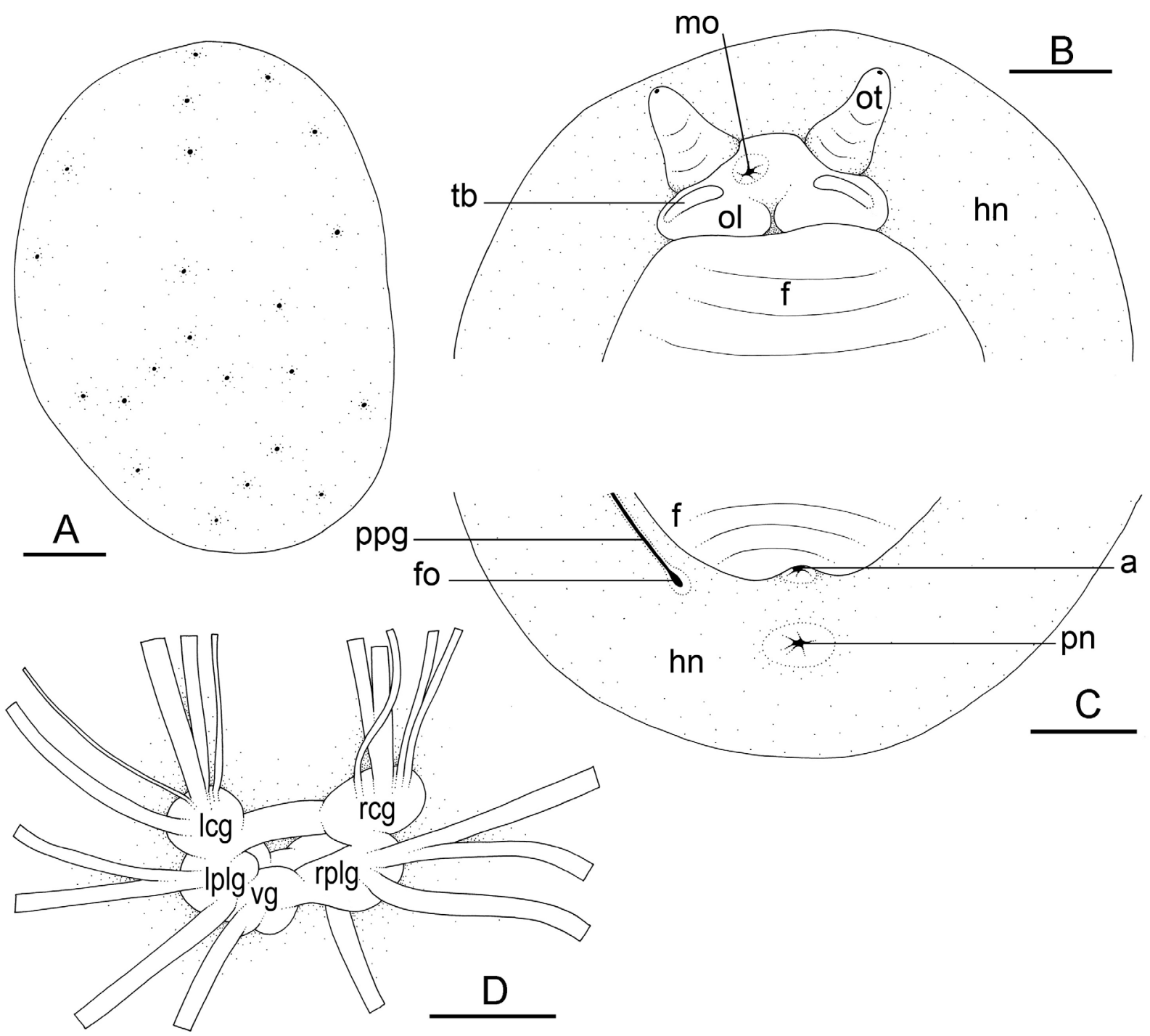

Fig. 12. Platevindex coriaceus coriaceus (Semper, 1880) unit \#2, external morphology and nervous system, Bohol, Philippines. A. Dorsal view [3290] (PNM 041239). B. Anterior, ventral view [3256] (PNM 041238). C. Posterior, ventral view, same as B. D. Nervous system, dorsal view [3257] (PNM 041238). Abbreviations: $\mathrm{a}=$ anus; $\mathrm{f}=\mathrm{foot}$; $\mathrm{fo}=$ female opening; $\mathrm{hn}=$ hyponotum; $\mathrm{lcg}=$ left cerebral ganglion; $1 \mathrm{plg}=$ left pleural ganglion; $\mathrm{mo}=$ male opening; ol = oral lobe; ot $=$ ocular tentacle; $\mathrm{pn}=$ pneumostome; $\mathrm{ppg}=$ peripodial groove; $\mathrm{rcg}=$ right cerebral ganglion; $\mathrm{rplg}=$ right pleural ganglion; $\mathrm{tb}=$ transverse protuberance; $\mathrm{vg}=$ visceral ganglion. Scale bars: $\mathrm{A}=5 \mathrm{~mm} ; \mathrm{B}-\mathrm{C}=2 \mathrm{~mm} ; \mathrm{D}=1 \mathrm{~mm}$. 
GOULDING T.C. et al., Systematic revision of Platevindex

Table 5. Radular formulae in species of Platevindex Baker, 1938.

\begin{tabular}{|c|c|c|c|c|}
\hline Species & Radular formula & $\begin{array}{l}\text { Specimen } \\
\text { length }(\mathrm{mm})\end{array}$ & Catalog Number & DNA extraction number \\
\hline \multirow[t]{3}{*}{ P. coriaceus coriaceus (unit \#1) } & $82 \times(120-1-120)$ & 49 & UMIZ 00078 & 2190 \\
\hline & $70 \times(90-1-90)$ & 28 & ZRC.MOL.10475 & 998 \\
\hline & $70 \times(100-1-100)$ & 38 & ITBZC IM 00014 & 5629 \\
\hline \multirow[t]{3}{*}{ P. coriaceus coriaceus (unit \#2) } & $58 \times(70-1-70)$ & 21 & PNM 041236 & 3194 \\
\hline & $65 \times(80-1-80)$ & 33 & PNM 041238 & 3256 \\
\hline & $63 \times(85-1-85)$ & 34 & PNM 041240 & 3356 \\
\hline \multirow[t]{3}{*}{ P. coriaceus darwinensis subsp. nov. } & $90 \times(115-1-115)$ & 23 & MTQ stn 123 & $\# 1$ \\
\hline & $62 \times(80-1-80)$ & 28 & UMIZ 00080 & 5021 \\
\hline & $59 \times(70-1-70)$ & 22 & UMIZ 00081 & 5111 \\
\hline \multirow[t]{3}{*}{ P. tigrinus } & $68 \times(75-1-75)$ & 19 & USMMC 00022 & 955 \\
\hline & $67 \times(85-1-85)$ & 26 & USMMC 00023 & 5522 \\
\hline & $62 \times(70-1-70)$ & 23 & BDMNH & 1030 \\
\hline \multirow[t]{3}{*}{ P. luteus } & $47 \times(50-1-50)$ & 22 & MTQ stn 108 & 2597 \\
\hline & $41 \times(35-1-35)$ & 28 & UMIZ 00089 & 2837 \\
\hline & $43 \times(40-1-40)$ & 22 & PNM 041246 & 3367 \\
\hline \multirow[t]{9}{*}{ P. applanatus } & $35 \times(35-1-35)$ & 9 & MNHN-IM-2019-1393 & 3152 \\
\hline & $30 \times(23-1-23)$ & 7 & MNHN-IM-2019-1394 & 3442 \\
\hline & $30 \times(26-1-26)$ & 6.5 & MNHN-IM-2019-1392 & 3604 \\
\hline & $40 \times(35-1-35)$ & 22 & UMIZ 00101 & 2754 \\
\hline & $46 \times(55-1-55)$ & 18 & UMIZ 00101 & 2755 \\
\hline & $54 \times(65-1-65)$ & 16 & UMIZ 00102 & 2893 \\
\hline & $52 \times(60-1-60)$ & 16 & MNHN-IM-2013-14043 & 5424 \\
\hline & $49 \times(60-1-60)$ & 13 & MNHN-IM-2013-14051 & 5450 \\
\hline & $36 \times(35-1-35)$ & 12 & MNHN-IM-2013-62402 & 5491 \\
\hline \multirow[t]{6}{*}{ P. burnupi } & $56 \times(70-1-70)$ & 32 & ELM W04105 & 6146 \\
\hline & $50 \times(60-1-60)$ & 19 & ELM W04109 & 6148 \\
\hline & $50 \times(60-1-60)$ & 20 & ELM W04107 & 6149 \\
\hline & $55 \times(65-1-65)$ & 22 & ELM W04108 & 6153 \\
\hline & $41 \times(50-1-50)$ & 12 & MNHN-IM-2019-1397 & 3602 \\
\hline & $47 \times(60-1-60)$ & 16 & MNHN-IM-2019-1395 & 3603 \\
\hline \multirow[t]{3}{*}{ P. martensi } & $75 \times(95-1-95)$ & 30 & USMMC 00029 & 964 \\
\hline & $75 \times(100-1-100)$ & 39 & NTM P.57611 & 1711 \\
\hline & $48 \times(65-1-65)$ & 14 & PNM 041250 & 3336 \\
\hline \multirow[t]{3}{*}{ P. aptei sp. nov. } & $81 \times(95-1-95)$ & 35 & USMMC 00078 & 5955 \\
\hline & $76 \times(115-1-115)$ & 42 & USMMC 00078 & 5967 \\
\hline & $77 \times(105-1-105)$ & 37 & USMMC 00078 & 5968 \\
\hline \multirow[t]{3}{*}{ P. amboinae } & $80 \times(120-1-120)$ & 38 & UMIZ 00105 & 2883 \\
\hline & $85 \times(120-1-120)$ & 32 & UMIZ 00106 & 5043 \\
\hline & $87 \times(110-1-110)$ & 32 & UMIZ 00106 & 5843 \\
\hline \multirow[t]{2}{*}{ P. latus } & $98 \times(145-1-145)$ & 32 & ZMB/Moll 45656 & N/A (spm \#1) \\
\hline & $93 \times(145-1-145)$ & 30 & ZMB/Moll 45656 & N/A (spm \#2) \\
\hline
\end{tabular}


Nervous system (Fig. 12D)

The circum-esophageal nerve ring is post-pharyngeal and pre-esophageal. The cerebral commissure between the paired cerebral ganglia is short but its length varies among individuals. The paired pleural and pedal ganglia are also all distinct. The visceral commissure is short but distinctly present and the visceral ganglion is approximately median. Cerebro-pleural and pleuro-pedal connectives are very short,
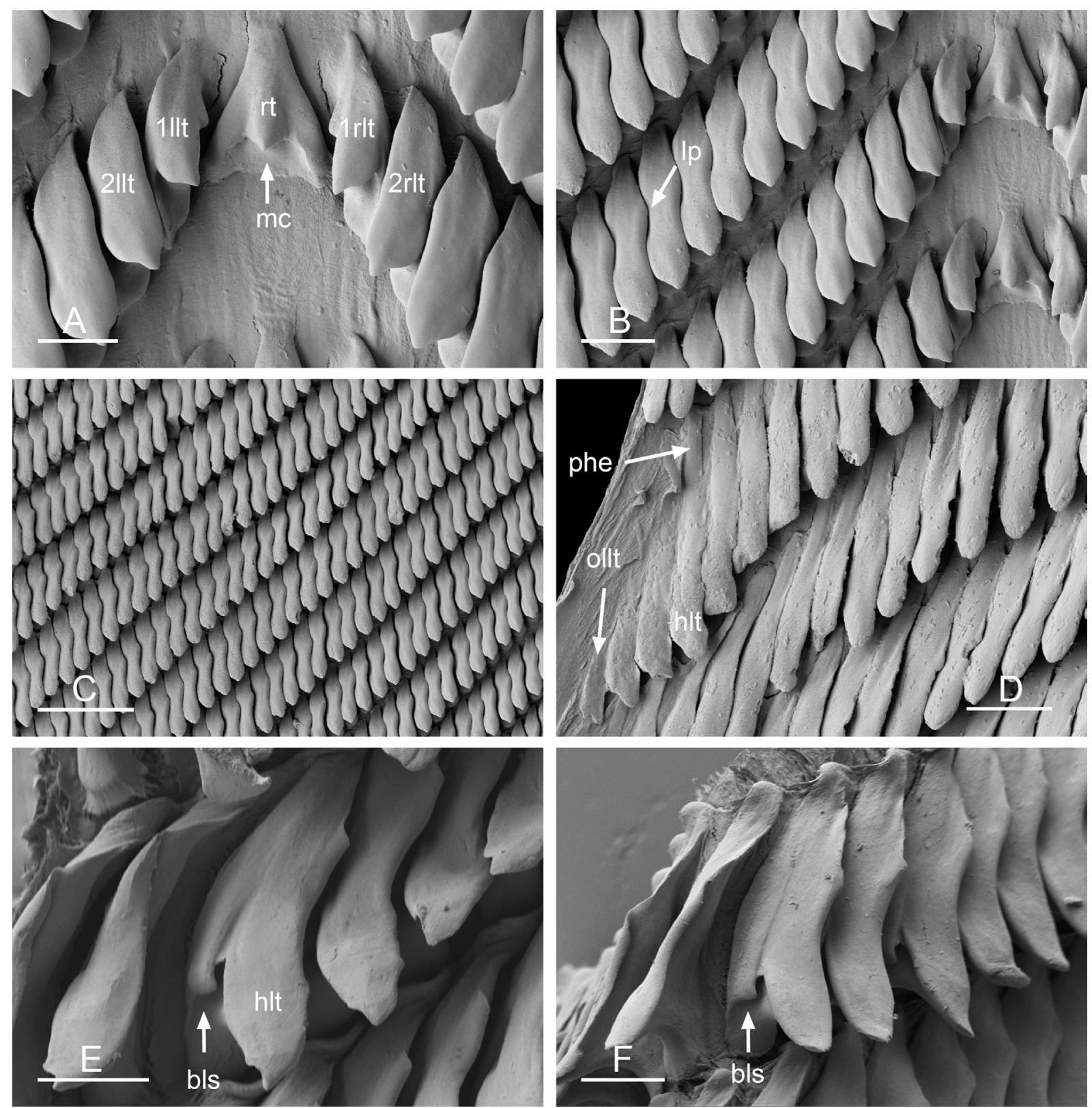

Fig. 13. Platevindex coriaceus coriaceus (Semper, 1880) unit \#2, radula, Philippines. A-D. Bohol [3356] (PNM 041240). A. Rachidian and innermost lateral teeth. B. Lateral teeth with rachidian teeth. C. Lateral teeth. D. Outermost lateral teeth. E-F. Luzon [3170] (PNM 041236). E. Close up of separated lateral teeth and basal lateral spine. F. Lateral teeth separated to reveal basal lateral spine. Abbreviations: $111 \mathrm{t}=$ first, left, lateral tooth; $1 \mathrm{rlt}=$ first, right, lateral tooth; $21 \mathrm{lt}=$ second, left, lateral tooth; $2 \mathrm{rlt}=$ second, right, lateral tooth; bls = basal lateral spine (of lateral tooth); hlt = hook of lateral tooth; $1 \mathrm{p}=$ lateral protuberance; $\mathrm{mc}=$ median cusp of rachidian tooth; ollt $=$ outermost, left, lateral tooth; $\mathrm{phe}=$ posterior hook extension; $\mathrm{rt}=$ rachidian tooth. Scale bars: $\mathrm{A}=20 \mu \mathrm{m} ; \mathrm{B}, \mathrm{D}=30 \mu \mathrm{m} ; \mathrm{C}=100 \mu \mathrm{m} ; \mathrm{E}-\mathrm{F}=20 \mu \mathrm{m}$. 
and pleural and cerebral ganglia touch each other. Nerves from the cerebral ganglia innervate the buccal area and the ocular tentacles, and, on the right side, the penial complex. Nerves from the pedal ganglia innervate the foot. Nerves from the pleural ganglia innervate the lateral and dorsal regions of the mantle. Nerves from the visceral ganglion innervate the visceral organs.

\section{Reproductive system (Figs 18-19)}

Sexual maturity is correlated with animal length. Mature individuals have large, posterior, female (hermaphroditic) organs and fully-developed, anterior, male copulatory parts. Immature individuals $(<22 \mathrm{~mm}$ long) may have small or simply no posterior female organs, and rudimentary male parts. Hermaphroditic organs are located at the posterior end of the visceral cavity and consist of the female parts mixed with some male parts (Fig. 18). The hermaphroditic gland is a single mass. A hermaphroditic duct conveys the eggs and the autosperm from the hermaphroditic gland to the fertilization chamber, which connects to a large receptaculum seminis (caecum). The receptaculum seminis is generally elongated but its shape varies and it may be oval-shaped or almost spherical. The female gland mass contains various glands (mucus and albumen) of which the exact connections remain uncertain. The spermoviduct (for autosperm, exosperm and eggs) is embedded within the female gland mass, at least proximally. Distally, the spermoviduct branches into the deferent duct (which conveys the autosperm to the anterior region, running through the body wall) and the oviduct. The latter conveys the eggs up to the female opening and the exosperm from the female opening to the fertilization chamber. The section of the oviduct distal to the spermatheca is long, up to three or four times the length of the proximal section
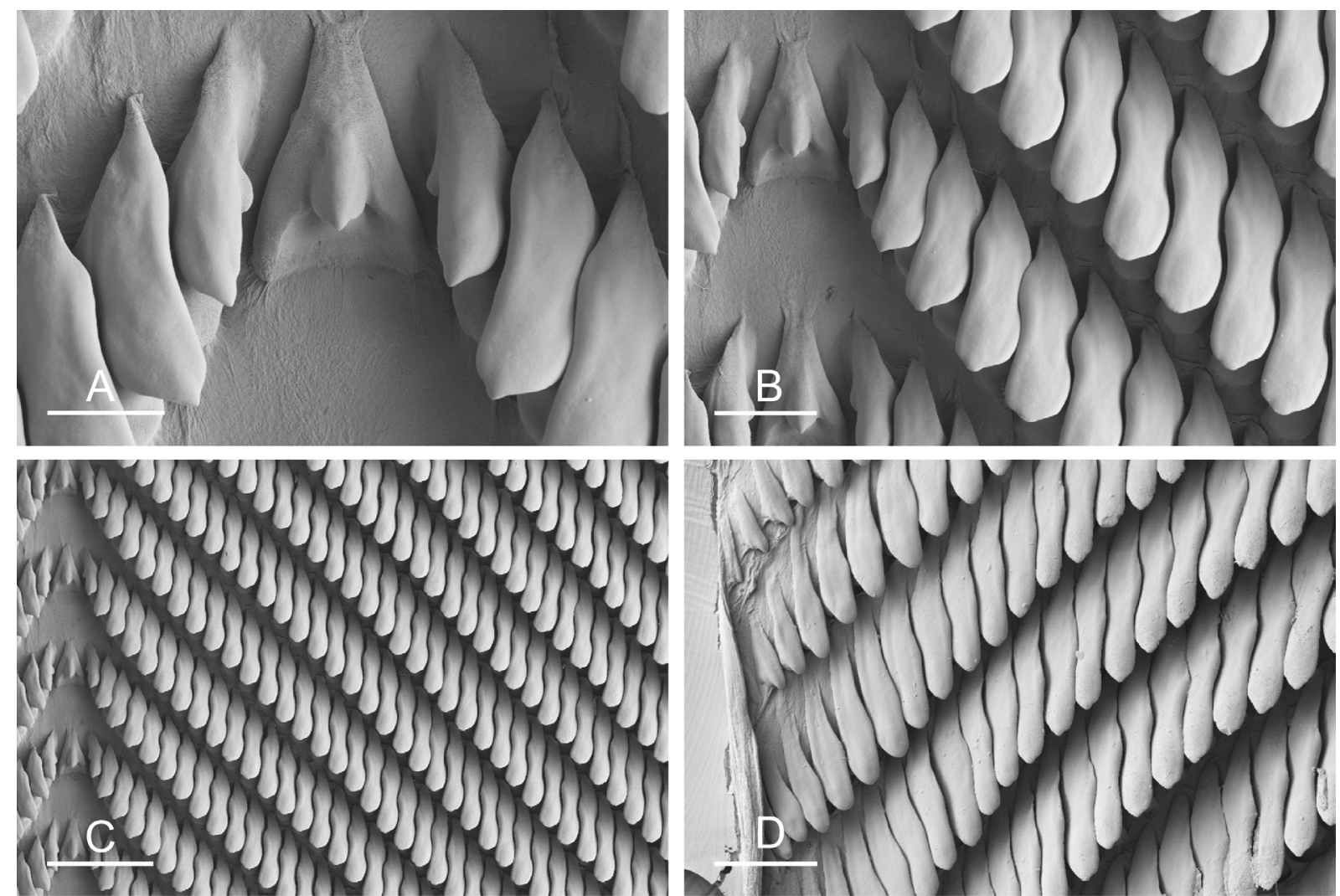

Fig. 14. Platevindex coriaceus coriaceus (Semper, 1880) unit \#1, radula. A. Rachidian and innermost lateral teeth, Vietnam, Can Gio [5629] (ITBZC IM 00014). B. Lateral teeth with rachidian teeth, same as A. C. Lateral teeth, same as A. D. Outermost lateral teeth, Singapore, Lim Chu Kang [998] (ZRC MOL.10475). Scale bars: $A=20 \mu \mathrm{m} ; \mathrm{B}=30 \mu \mathrm{m} ; \mathrm{C}=100 \mu \mathrm{m} ; \mathrm{D}=50 \mu \mathrm{m}$. 
(from the female gland mass to the spermatheca). The oviduct is much wider (at least two or three times wider) than the deferent duct. The latter is closely attached to the surface of the oviduct, and is highly coiled, with U-shaped turns back and forth. The spherical spermatheca connects to the distal portion of the oviduct through a short duct.

The male anterior organs include the penial complex (penis, vestibule, deferent duct, retractor muscle) (Fig. 19). There is no accessory penial gland. The penial sheath protects the penis for its entire length. The vestibule is continuous with the distal part of the penial sheath. The vestibule is cylindrical. Short muscle fibers connect the distal part of the penial sheath, near the vestibule, to the anterior wall of the visceral cavity. Inside the penial sheath, the penis is a narrow, thin, elongated, hollow tube. Its proximal region is rigid. Its distal region is flexible and bears hooks measuring from 80 to $130 \mu \mathrm{m}$ (Fig. 20). The flexible region of the penis with hooks is generally between 4 and $8 \mathrm{~mm}$ long and approximately 160 to $190 \mu \mathrm{m}$ wide. The hooks are inside the tube-like penis when it is inside the penial sheath (but can be

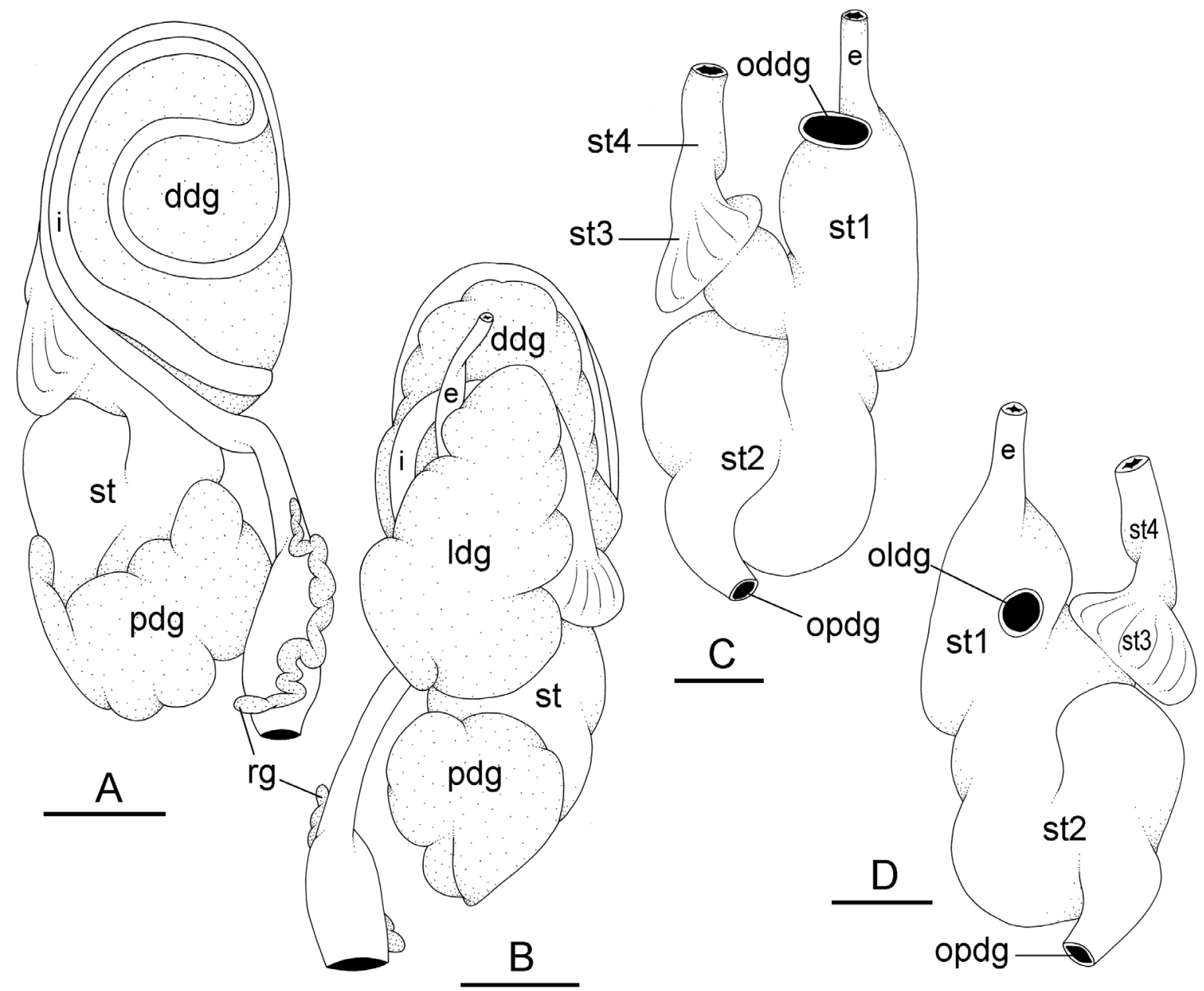

Fig. 15. Platevindex coriaceus coriaceus (Semper, 1880) unit \#2, digestive system, [3356] (PNM 041240), Bohol, Philippines. A. Dorsal view. B. Ventral view. C. Stomach, dorsal view. D. Stomach, ventral view. Abbreviations: $\mathrm{ddg}=$ dorsal digestive gland; $\mathrm{e}=$ esophagus; $\mathrm{i}=$ intestine; $1 \mathrm{dg}=$ lateral digestive gland; oddg = opening of the dorsal lobe of the digestive gland; oldg = opening of the lateral lobe of the digestive gland; opdg = opening of the posterior lobe of the digestive gland; $\mathrm{pdg}=$ posterior digestive gland; $\mathrm{rg}=$ rectal gland; $\mathrm{st}=$ stomach; $\mathrm{st} 1=$ stomach chamber 1 ; st2 = stomach chamber 2 ; st $3=$ stomach chamber 3 ; st $4=$ stomach chamber 4 . Scale bars: $A-B=3 \mathrm{~mm} ; \mathrm{C}-\mathrm{D}=2 \mathrm{~mm}$. 
seen by transparency) and are outside when the penis is evaginated like the finger of a glove. The penial sheath measures from approximately $2 / 3$ the length of the visceral cavity to nearly the entire length of the visceral cavity. The beginning of the retractor muscle marks the separation between the penial sheath and the deferent duct. The retractor muscle inserts at the posterior end of the body cavity near the rectum (in mature specimens). The length of the retractor muscle is variable. In unit \#1, the retractor muscle is either shorter than the penial sheath (as short as $1 / 8$ of its length) to almost equal to it. In unit $\# 2$, the retractor muscle is shorter than the penial sheath (between $1 / 3$ and $1 / 8$ of its length). The deferent duct is highly convoluted, with many loops, though it is less convoluted in immature specimens.
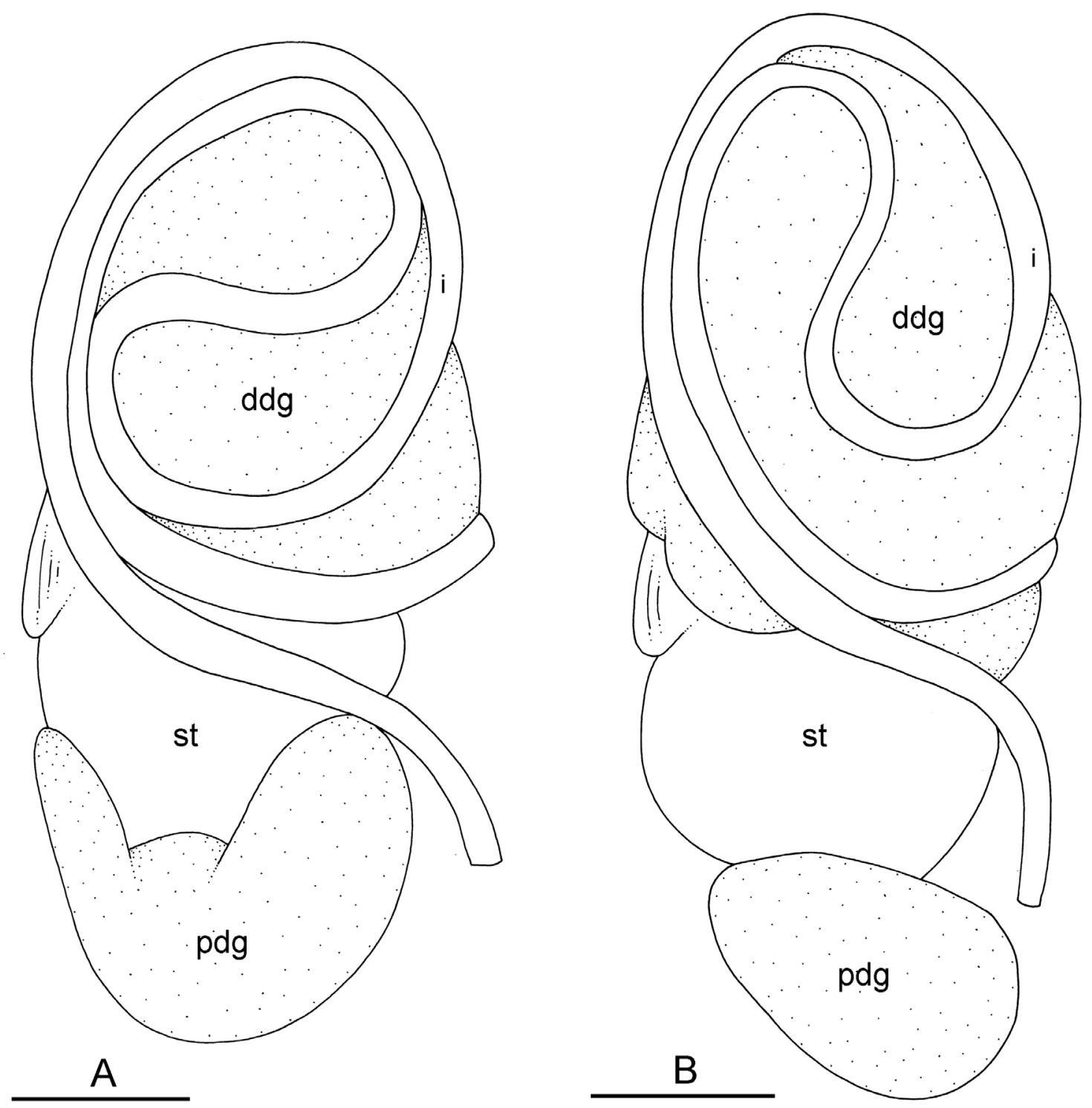

Fig. 16. Platevindex coriaceus (Semper, 1880), digestive system. A. Dorsal view of intestinal loops of type II, with a transitional loop oriented at 9 o'clock, Platevindex coriaceus coriaceus unit \#1, Vietnam [5629] (ITBZC IM 00014). B. Dorsal view with no digestive glands, type II, with a transitional loop oriented at 7 o'clock, Platevindex coriaceus darwinensis Goulding \& Dayrat subsp. nov., Northern Territory, Australia [1663] (NTM P.57602). Abbreviations: ddg = dorsal digestive gland; $\mathrm{i}=$ intestine; oddg = opening of the dorsal lobe of the digestive gland; opdg = opening of the posterior lobe of the digestive gland; $\mathrm{pdg}=$ posterior digestive gland; $\mathrm{rg}=$ rectal gland; $\mathrm{st}=$ stomach. Scale bars $=3 \mathrm{~mm}$. 


\section{Distinctive diagnostic features (Table 4)}

Externally, P. coriaceus coriaceus cannot be confused with the only two species of Platevindex which lack dorsal eyes (P. amboinae and P. latus). Externally, the blue-grey hyponotum and light yellow foot differentiate $P$. coriaceus coriaceus from $P$. martensi (orange foot) and P. aptei sp. nov. (black foot). Platevindex coriaceus coriaceus can generally be distinguished from $P$. luteus and $P$. applanatus by the presence of distinctly-raised dorsal papillae in the two latter species (which are absent in P. coriaceus).
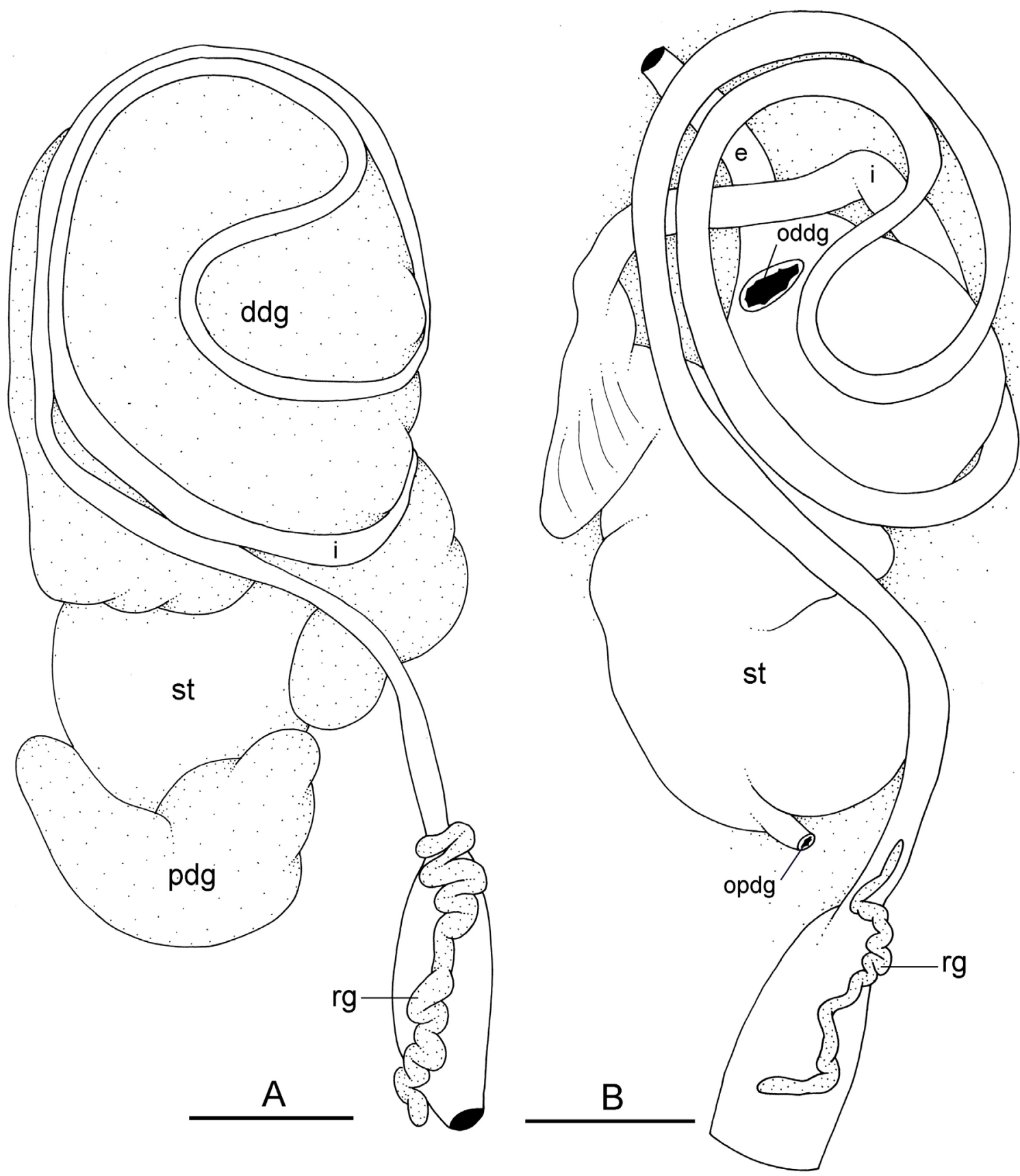

Fig. 17. Platevindex coriaceus coriaceus (Semper, 1880) unit \#2, digestive system, dorsal view, intestinal loops of type II. A. Transitional loop oriented at 9 o'clock, Luzon, Philippines [3170] (PNM 041236). B. Transitional loop oriented at 7 o'clock, Bohol, Philippines [3256] (PNM 041238). Abbreviations: $\mathrm{ddg}=$ dorsal digestive gland; $\mathrm{i}=$ intestine; $\mathrm{pdg}=$ posterior digestive gland; $\mathrm{rg}=$ rectal gland; $\mathrm{st}=$ stomach. Scale bars $=2 \mathrm{~mm}$. 


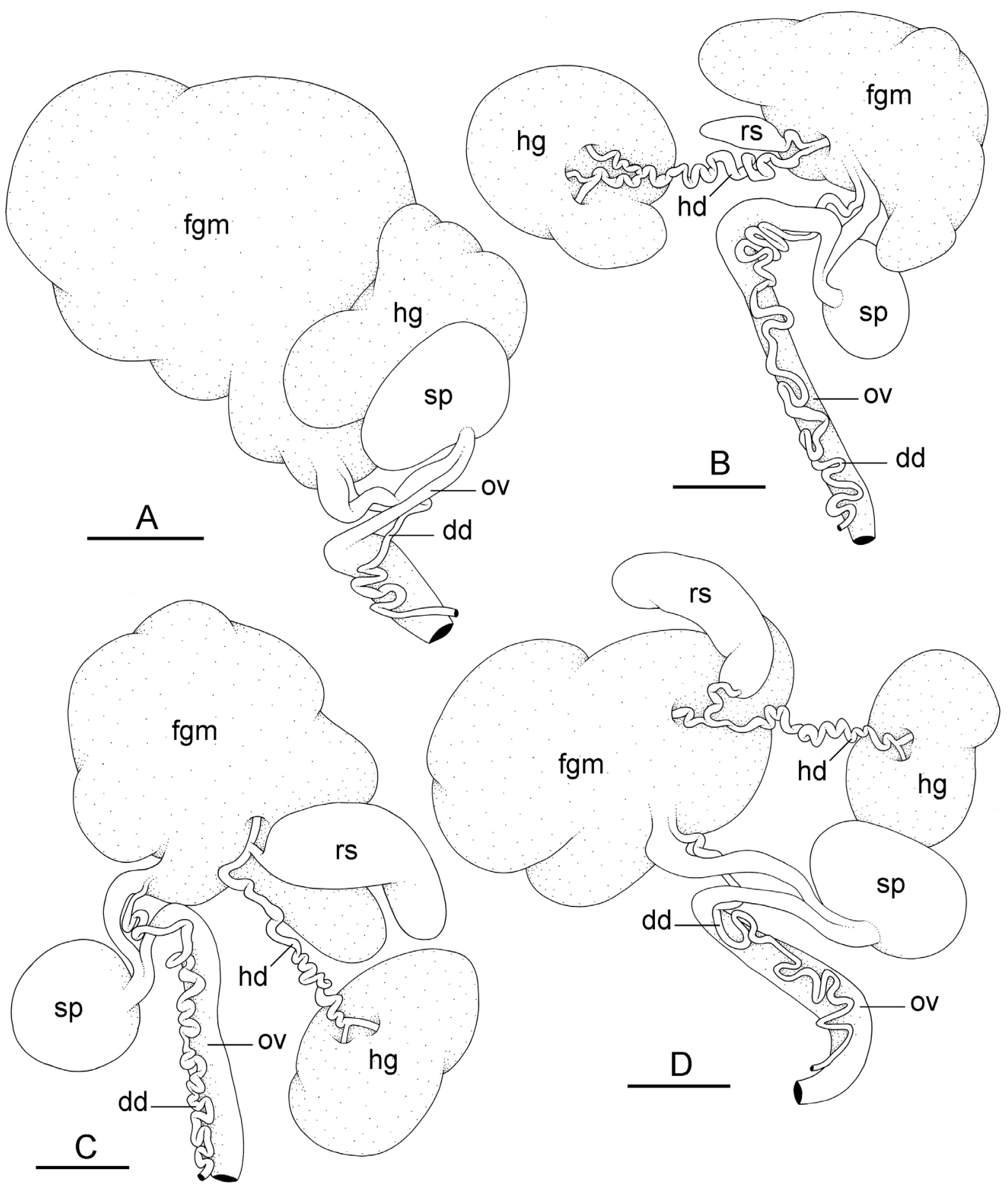

Fig. 18. Platevindex coriaceus (Semper, 1880), posterior reproductive system. A. Platevindex coriaceus coriaceus unit \#2, Philippines, lectotype (ZMB/Moll 39028a). B. Platevindex coriaceus coriaceus unit \#2, Bohol, Philippines [3356] (PNM 041240). C. Platevindex coriaceus coriaceus unit \#1, Vietnam [5629] (ITBZC IM 00014). D. Platevindex coriaceus darwinensis Goulding \& Dayrat subsp. nov., Northern Territory, Australia [1690] (NTM P.57606). Abbreviations: $d d=$ deferent duct; fgm $=$ female gland mass; hd = hermaphroditic duct; $h g=$ hermaphroditic gland; ov = oviduct; rs $=$ receptaculum seminis; $\mathrm{sp}=$ spermatheca. Scale bars $=2 \mathrm{~mm}$. 
Large individuals of $P$. coriaceus coriaceus ( $>40 \mathrm{~mm}$ long) can be distinguished from $P$. luteus, $P$. applanatus and $P$. burnupi $(<30 \mathrm{~mm})$ by their size. Small individuals of $P$. coriaceus coriaceus could potentially be confused with individuals of $P$. burnupi (which, unlike $P$. luteus and $P$. applanatus, lack distinctly-raised dorsal papillae). However, note that based on current data, $P$. burnupi is only found in the western Indian Ocean and does not overlap geographically with $P$. coriaceus coriaceus. In addition, $P$. coriaceus coriaceus is distinct from $P$. luteus, $P$. applanatus and $P$. burnupi based on several details of the reproductive and digestive systems (Table 4). For instance, the deferent duct is closely attached to the oviduct in P. coriaceus coriaceus while it is not (or only loosely) attached to it in P. luteus and $P$. burnupi. Internally, also, the intestinal loops are of type II in $P$. coriaceus coriaceus and of type I in P. applanatus.

The only species with which Platevindex coriaceus coriaceus overlaps geographically and cannot be distinguished externally is P. tigrinus, due to a similar foot color (variants of grey and yellow) and hyponotum color (variants of blue and grey). Internally, however, $P$. coriaceus coriaceus can easily be distinguished from P. tigrinus: the retractor muscle of the penis inserts at the posterior end of the visceral
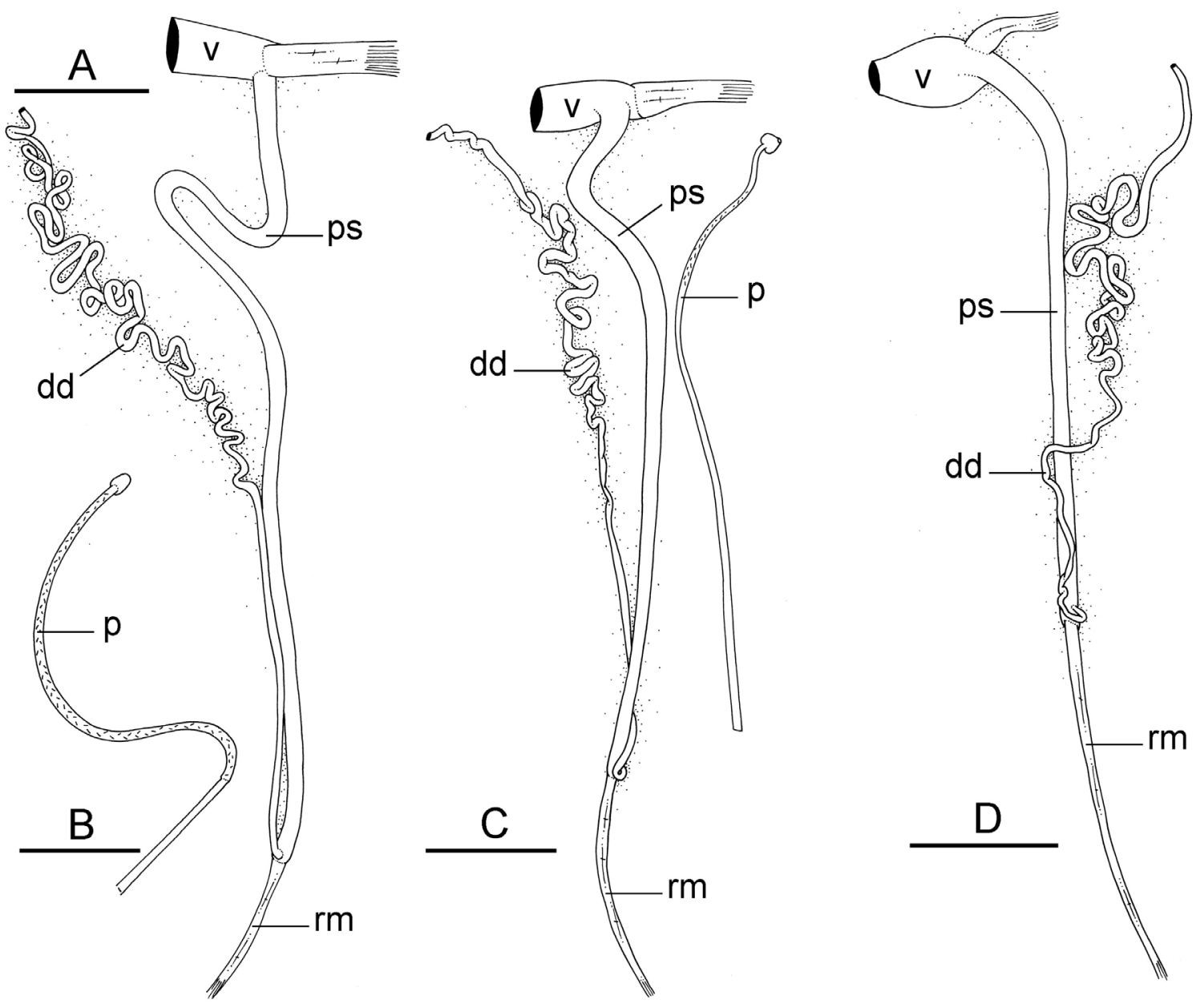

Fig. 19. Platevindex coriaceus (Semper, 1880), anterior, male copulatory apparatus. A. Platevindex coriaceus coriaceus unit \#2, Bohol, Philippines [3356] (PNM 041240). B. Penis (extracted from the penial sheath), same as A. C. Platevindex coriaceus coriaceus unit \#1, Vietnam [5629] (ITBZC IM 00014). D. Platevindex coriaceus darwinensis Goulding \& Dayrat subsp. nov., Northern Territory, Australia [1663] (NTM P.57602). Abbreviations: $d d=$ deferent duct; $p=$ penis; $p s=$ penial sheath; $\mathrm{rm}=$ retractor muscle; $\mathrm{v}=$ vestibule. Scale bars: $\mathrm{A}, \mathrm{C}-\mathrm{D}=3 \mathrm{~mm} ; \mathrm{B}=2 \mathrm{~mm}$. 
cavity in P. coriaceus coriaceus and near the heart in P. tigrinus; the distal, flexible region of the penis with hooks is $>4 \mathrm{~mm}$ long in $P$. coriaceus coriaceus and $<1.5 \mathrm{~mm}$ long in P. tigrinus; in the posterior part of the reproductive system, the deferent duct (closely attached to the oviduct) is tightly convoluted in $P$. coriaceus coriaceus while it is almost straight in P. tigrinus.

\section{Distribution (Fig. 10B)}

Mitochondrial unit \#1. Brunei. China: Qinzhou and Guangxi (Sun et al. 2014, misidentified as P. mortoni). Indonesia: Lombok, Sumatra and Sulawesi. Peninsular Malaysia. Singapore (paralectotypes of $P$. coriaceus and newly collected specimens). Vietnam (type locality of $O$. condoriana and newly collected specimens).

Mitochondrial unit \#2. Philippines (type locality of O. coriaceum): Luzon, Bohol, and Mindanao. Fresh specimens were collected from Luzon and Bohol, but not from Mindanao. It could not be determined whether the lectotype selected here was from Manila (Luzon), Bohol, or Zamboanga (Mindanao).

Mitochondrial unit \#3. China: Fujian Province (Sun et al. 2014, misidentified as P. mortoni). Japan (Takagi et al. 2019, identified as Platevindex sp. A).

All records are new, except for the localities of some of the type material. Note that the paralectotype(s) of $O$. coriaceum from Brisbane are not included in the distribution of $P$. coriaceus coriaceus.

\section{Habitat (Fig. 21)}

Platevindex coriaceus coriaceus is found in mangrove forests, on tree roots and trunks, and on dead logs, but not directly on mud. The logs and trees may be in silty mud saturated with water or on harder mud. It does not live on rocky shores. Platevindex coriaceus coriaceus is very common across its range, except in central Indonesia where it seems less common. Few specimens were found in Lombok and Sulawesi and it was not found in Maluku (Ambon, Seram and Kei Islands).

\section{Remarks}

The publication dates of the various sections of the volume on Landmollusken by Carl Semper in the Reisen im Archipel der Philippinen series were clarified by Johnson (1969). The species name Onchidium coriaceum was first published with three figures illustrating the external morphology, dorsal eyes and penial hooks (Semper 1880: pl. 19, figs 1, 16, pl. 23, fig. 12) and no written description. Because Onchidium coriaceum was published before 1931, ICZN Article 12.2.7 applies and Semper's figures are regarded as an indication accompanying the new name Onchidium coriaceum. The text of the description and the illustration of the radula (pl. 21, fig. 7) were published in 1882. However, not everything in the written description refers to the subspecies described here (see below for more details). The illustrations of the dorsal surface (pl. 19, fig. 1), the dorsal eyes (pl. 19, fig. 16) and the radular teeth (pl. 21, fig. 7) could apply to any almost any species of Platevindex, so there is no reason to consider
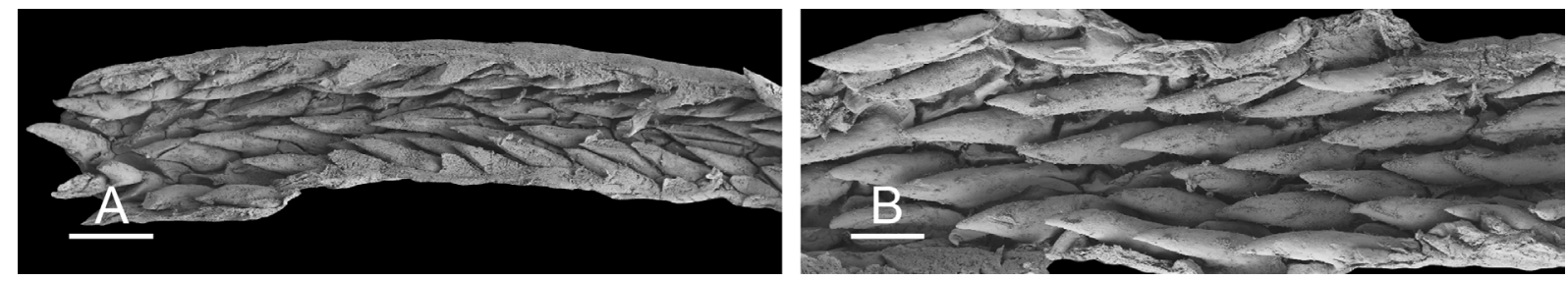

Fig. 20. Platevindex coriaceus coriaceus (Semper, 1880), penial hooks. A. Unit \#1, Vietnam, Can Gio [5629] (ITBZC IM 00014). B. Unit \#2, Philippines, Bohol [3248] (PNM 041237). Scale bars: $\mathrm{A}=100 \mu \mathrm{m} ; \mathrm{B}=50 \mu \mathrm{m}$. 
that they do not refer to the subspecies described here. The illustration of the male apparatus (pl. 23, fig. 12) could refer to the subspecies described here (if Semper illustrated one of the paralectotypes from Singapore or the Philippines) or P. coriaceus darwinensis subsp. nov. (if Semper illustrated the paralectotype from Brisbane, both subspecies being anatomically cryptic), even though his written description of the insertion of the retractor muscle (near the heart) matches that of $P$. tigrinus instead of the subspecies described here (insertion near the posterior end of the visceral cavity).

Semper (1880) originally described Onchidium coriaceum based on syntypes from Brisbane (Australia), Penang (Malaysia), Singapore, and Manila (Luzon), Bohol and Zamboanga (Mindanao) in the Philippines. Our sampling across the Indo-West Pacific shows that multiple species of Platevindex are present across the region encompassing these countries. A re-examination of the type material and a critical analysis of the original description reveal that, when describing $O$. coriaceum, Semper used specimens that were part of at least two distinct species.

The lectotype from the Philippines (ZMB/Moll 39028a) designated here clarifies the application of the name Platevindex coriaceus because it was dissected for the present study and it displays all the diagnostic features of the nominotypical subspecies described here. Two paralectotypes (27/26 and 20/16 mm) from the Philippines (ZMB/Moll 39028b) are also part of $P$. coriaceus coriaceus. The other paralectotypes from the Philippines, however, cannot be identified to the species level because the male reproductive parts were previously removed by Semper. Even though they seem to be part of $P$. coriaceus coriaceus, they potentially could belong to $P$. luteus or $P$. martensi, both of which are found in the Philippines.

Semper mentioned that the paralectotype (27/25 mm) from Penang (ZMB/Moll 39029) had previously been misidentified as Onchidium typhae (there is only one dorsal eye on each of its papillae while there are 3 or 4 eyes per papilla in $O$. typhae). This paralectotype from Penang was dissected (likely by Semper) and its penial complex is missing; however, the deferent duct in its posterior reproductive system is not attached to the oviduct, indicating that this paralectotype is not part of the subspecies described here but is, instead, a misidentification of $P$. martensi (an undescribed species at that time). Platevindex martensi also differs from $P$. coriaceus coriaceus with respect to the insertion of the retractor muscle: in the posterior half of the visceral cavity (from $1 / 2$ to $3 / 4$ its length) in $P$. martensi and near the end of the visceral cavity in $P$. coriaceus coriaceus. Also, in P. martensi, the length of the flexible portion of the penis with hooks does not exceed $2.5 \mathrm{~mm}$, while it measures from 4 to $8 \mathrm{~mm}$ in P. coriaceus coriaceus. Finally, the position of 20 dorsal eyes on the edge of the mantle described by Semper is a character compatible with $P$. martensi, but not with P. coriaceus coriaceus or any related species within clade A (Figs 1, 5). Labbé (1934) considered that the paralectotype from Penang was part of Onchidium tigrinum rather than $O$. coriaceum (likely based on Semper's description because Labbé, who did not comment on the anatomy of that specimen, does not seem to have examined it).

The large (22/10 mm) paralectotype from Singapore (ZMB/Moll 39030) was previously dissected and its copulatory apparatus is missing. However, it seems to be part of the subspecies described here because even though its posterior reproductive system is largely destroyed, the highly-coiled deferent duct is attached to the distal part of the oviduct, which is characteristic of P. coriaceus coriaceus. The notum of the small $(20 / 17 \mathrm{~mm}$ ) paralectotype from Singapore (ZMB/Moll 39030) was cut open for the present study. It is partly immature (its posterior reproductive system is not developed) but is definitely part of the subspecies described here because its penis is almost as long as the visceral cavity.

Semper (1882: 272) also mentioned some material (likely only one specimen) collected in Brisbane (Queensland, Australia) which could not be located by us. Queensland is not part of the geographic distribution of $P$. coriaceus coriaceus, so Semper's material from Brisbane most likely did not belong 

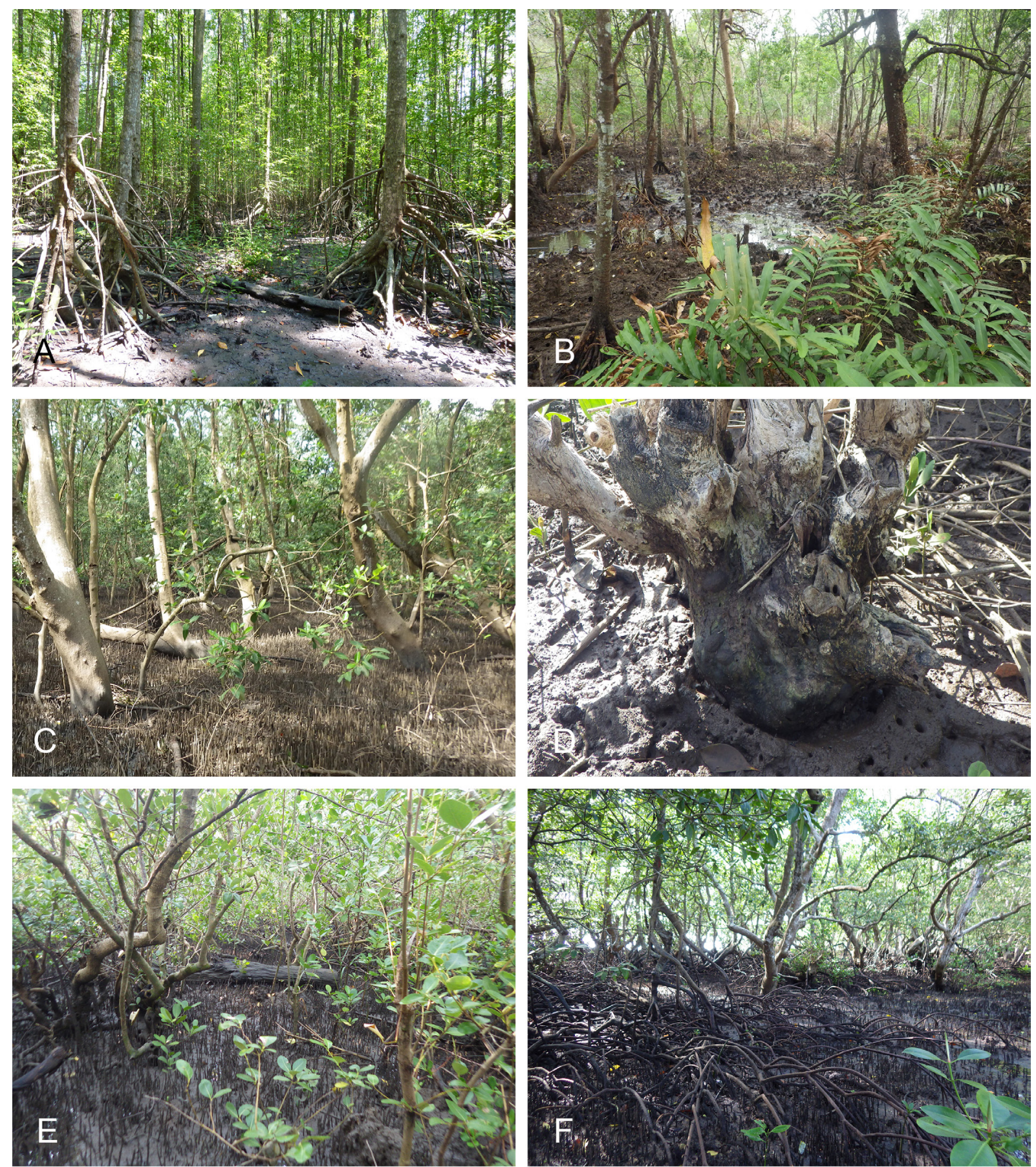

Fig. 21. Habitats of Platevindex coriaceus coriaceus (Semper, 1880). A. Peninsular Malaysia, Matang, old and open Rhizophora forest with tall trees, creeks, hard mud and many dead logs (station 28). B. Indonesia, Sumatra, high intertidal open mangrove with Rhizophora trees, mounds of Thalassina and dead logs (station 80). C. Vietnam, Can Gio, open mangrove with big Avicennia trees, soft mud and some dead logs (station 231). D. Indonesia, Lombok, mangrove next to village with small, sparse Avicennia in open mangrove with a few older trees (station 151). E. Philippines, Bohol, Inabanga, old forest of mostly Avicennia with many dead logs (station 188). F. Philippines, Bohol, Mabini, narrow mangrove on the edge of fish ponds, tall Rhizophora and Avicennia, many dead logs (station 194). 
to $P$. coriaceus coriaceus. Instead, it could belong to $P$. coriaceus darwinensis subsp. nov. or $P$. luteus. Finally, Semper (1882: 272) mentioned two specimens at the Vienna Museum but from an unknown locality. It is not possible to determine which species of Platevindex Semper observed, which, thanks to the designation of the lectotype from the Philippines, is not an issue.

Semper (1882: 273) noted that the only character which differed between the descriptions of O. coriaceum and $O$. tigrinum was Stoliczka's description of a "supplementary albuminous gland" (i.e., accessory penial gland) (Stoliczka 1869: 107), and indicated that $O$. coriaceum could be a synonym of Stoliczka's O. tigrinum. Semper was not able to properly compare the anatomy of the two species without examining Stoliczka's specimens and stated and that he could not be sure about the synonymy. An accessory penial gland is actually absent in Platevindex tigrinus, which is anatomically and genetically distinct from $P$. coriaceus coriaceus.

Finally, Semper's description of the penial morphology in the original description of $O$. coriaceum needs to be commented on. The length of the flexible distal region of the penis with hooks was described by Semper as being $6 \mathrm{~mm}$ long, which is within the range observed here in $P$. coriaceus coriaceus (4 to $8 \mathrm{~mm}$ ) but is incompatible with those of P. tigrinus (1 to $1.5 \mathrm{~mm}$ ) or P. martensi (2 to $2.5 \mathrm{~mm}$ ). However, Semper also described a retractor muscle inserting "at the height of the heart" (1882: 272, translated from German), which is compatible with $P$. tigrinus (the retractor muscle inserts near the heart), somewhat compatible with P. martensi (insertion in the posterior half of the visceral cavity), but not with $P$. coriaceus coriaceus (insertion at the posterior end of the visceral cavity). There are only two possible explanations. First, Semper's written description of the insertion of the retractor muscle is based on the paralectotype from Penang (which belongs to P. martensi), or, second, Semper made a mistake.

The description of Onchidella condoriana by Rochebrune did not include any information about the internal anatomy. Externally, O. condoriana was described as "granulous and sprinkled with whitish tubercles and grey underneath" (Rochebrune 1882: 67, translated from Latin). The holotype (23/16 mm) can readily be identified as a Platevindex by the hard, flattened notum, but it was previously dissected by someone who removed the penial complex (it is unclear who dissected it because the species was not mentioned by Plate and neither Hoffmann nor Labbé commented on the internal anatomy). Most of the posterior (female) reproductive system is missing but the oviduct, which remains, is similar to that of the subspecies described here (with the highly-coiled deferent duct attached to it). Thus, the holotype of $O$. condoriana belongs to $P$. coriaceus coriaceus and not $P$. tigrinus (in which the deferent duct is almost straight). Note that $P$. tigrinus is likely also present in Vietnam because it is known from western India all the way to China, even though we did not find it there. Because the type locality of $O$. condoriana (Côn Son Island, Côn Đảo Archipelago, Vietnam) is within the range of mitochondrial unit \#1 (from Peninsular Malaysia to China and Sulawesi), the name Platevindex condorianus could potentially apply to it, if it would ever need to be formally named. Platevindex slugs were not found at the type locality of O. condoriana (we explored the Côn Đảo Archipelago in 2015), but were found in mainland Vietnam, in the Can Gio mangrove forest protected area. All those Platevindex slugs from the Can Gio mangrove forest belonged to P. coriaceus coriaceus. Finally, P. martensi is likely also present in Vietnam (Fig. 10), but the lack of dorsal eyes at the margin of the notum and the deferent duct being attached to the oviduct indicate that Rochebrune's type of $O$. condoriana is not part of $P$. martensi.

Plate (1893: 190-191) re-described P. coriaceus based on Semper's original specimens from the Philippines. Semper did not indicate how many individuals he examined from the Philippines, but Plate listed ten specimens. Only seven of Semper's type specimens were located from the Philippines (ZMB/Moll 39028), suggesting that some specimens may have been previously destroyed. Plate's description of one single dorsal eye per papilla with papillae irregularly distributed is consistent with 
a species of Platevindex. He also mentioned new details that were not included in Semper's original description, such as the granular notum, the male pore being above and to the left of the right oral lobe (i.e., below and to the left of the right oral tentacle) and intestinal loops of type II. The number of radular teeth per half row (120) described by Plate is within the range reported here (from 70 to 120), and it is expected that the number he observed would be at the high end of the range due to the large size of the specimens that he examined (up to $47 \mathrm{~mm}$ long).

Plate described Oncis semperi based on two syntypes (22/18 and 22/18 mm) from Mindanao (ZMB/Moll 45661). The width of the foot and the position of the male opening confirm that they belong to a species of Platevindex. According to Plate (1893: 193), the penis of Oncis semperi is extremely long ( $26 \mathrm{~mm}$ in a slug that was only $24.5 \mathrm{~mm}$ long), inserts at the posterior end of the body cavity, and its distal, flexible region with hooks is $8 \mathrm{~mm}$ long. This description is only consistent with P. coriaceus (Table 4). However, Plate's description of intestinal loops of type I is problematic because it is inconsistent with P. coriaceus. Two explanations are possible. Most likely, Plate's description of a type I was a mistake (his description of the intestinal loops in $P$. amboinae was a mistake). Alternatively, one of the syntypes could belong to P. luteus (in which the intestine can be of type I). Because Plate's description of the copulatory apparatus matches perfectly that of $P$. coriaceus, $P$. semperi is regarded as a synonym of $P$. coriaceus and it is assumed that Plate confused the types of intestinal loops.

Semper (1882: 272) questioned whether Platevindex coriaceus could be a synonym of Onchidium marmoratum Lesson, 1831, and noted that the original description was insufficient to separate it from O. coriaceum. Bretnall (1919: 323) also listed this potential synonymy with a question mark. The original description of $O$. marmoratum did not indicate any characters which would distinguish it from $P$. coriaceus, but the type specimens of $O$. marmoratum do not share the flattened shape of Platevindex slugs and clearly do not belong to this genus. Onchidium marmoratum was recently transferred to the genus Marmaronchis Dayrat \& Goulding, 2018 (Dayrat et al. 2018). Hoffmann (1928: 88) suggested that $O$. coriaceum, O. martensi and O. condoriana were all synonyms of Oncis stuxbergi (Westerlund, 1883) but he did not describe the anatomy of Oncis stuxbergi. Westerlund (1883: 165) also did not describe the internal anatomy of this species (described as Vaginulus stuxbergi). Thus, neither Westerlund's description nor Hoffmann's remarks can be attributed to Platevindex coriaceus. The specific name stuxbergi applies to a species in the genus Onchidium as a result of the designation of a lectotype (Dayrat et al. 2016: 22). Note that Hoffmann (1928) thought that Onchidium coriaceum was a junior synonym of Oncis stuxbergi because he adopted 1885 as the date of publication for Semper's monograph in the Reisen im Archipel der Philippinen series (for a collation of Semper's monograph, see Johnson 1969). Labbé (1934: 235-236), who does not seem to have examined any specimens, followed Hoffmann in considering Oncis coriacea a synonym of Oncis stuxbergi. For unclear reasons, he indicated an insertion of the penial retractor near the heart, which is not consistent with Platevindex coriaceus.

DNA sequences of $P$. coriaceus from southern China were misidentified as $P$. mortoni by Sun et al. (2014). Recent COI DNA sequences by Wang et al. (unpublished, GenBank Accession GU166575 and GU166577) were also identified as P. mortoni, and are shown here to belong to P. coriaceus. Therefore, P. coriaceus is not restricted to southernmost China but is also present in the Fujian Province of China (the province facing Taiwan). Platevindex coriaceus should also be present around Hong Kong, which is south of Fujian province. Hong Kong is the type locality for Platevindex mortoni, a name which is regarded here as a nomen dubium (see our remarks on P. tigrinus and P. luteus). Additionally, DNA sequences published by Takagi et al. (2019) show that $P$. coriaceus is present in southern Japan, and is closely related to individuals from northern China, i.e., north of Taiwan (P. coriaceus coriaceus unit \#3). Finally, a voucher specimen identified as Platevindex cf. coriaceus (Dayrat et al. 2011) in the collection of the Natural History Museum in London (NHMUK 20060274) actually belongs to Platevindex burnupi. 
Von Martens (1897: 127) indicated that Oncis coriacea was identified from "Celebes: bei Luwu" [Luwu, Sulawesi, Indonesia] by M. Weber, from "Halmaheira: Dodinga" by himself, as well as from Java and "Nikobaren, Pulo Pinang und Philippinen" [Nicobar Islands; Penang, Malaysia; the Philippines] based on specimens in the Berlin Museum. Von Martens did not provide any details about how the specimens were identified. The specimens from Halmahera, Java, Malaysia, the Philippines and Sulawesi, Indonesia could be either P. coriaceus or P. tigrinus. Platevindex coriaceus was not found in the Andaman Islands, but could be present in the Nicobar Islands.

Platevindex coriaceus darwinensis Goulding \& Dayrat subsp. nov. urn:Isid:zoobank.org:act:A609EB85-101E-467E-AFD5-812043EDAFFE

Figs $16 \mathrm{~B}, 18 \mathrm{D}, 19 \mathrm{D}, 22-25$

\section{Etymology}

Platevindex coriaceus darwinensis subsp. nov. is named after Darwin, Northern Territory, Australia, which is the type locality.

\section{Material examined}

Type material

AUSTRALIA - holotype (28/26 [1700] mm); Northern Territory, Darwin, close to Tiger Brenan Rd; $12^{\circ} 28.782^{\prime} \mathrm{S}, 130^{\circ} 54.750^{\prime} \mathrm{E}$; 19 Aug. 2012; station 69; high tidal Ceriops mangrove by small service road; NTM P.57601.

\section{Other material}

AUSTRALIA - Northern Territory -3 specs (40/25 [1674], 29/21 [1663] and 20/14 [1672] mm); Darwin, Talc Head; $12^{\circ} 28.765^{\prime}$ S, $130^{\circ} 46.297^{\prime}$ E; 15 Aug. 2012; station 62; open forest of large Sonneratia alba with mud saturated with water; NTM P.57602 • 1 spec. (29/16 [1677] mm); Darwin, Near Berrimah; $12^{\circ} 28.786^{\prime}$ S, $130^{\circ} 54.750^{\prime}$ E; 16 Aug. 2012; station 63; Sonneratia, Rhizophora and Ceriops mangrove forest; NTM P.57603 • 1 spec. (32/17 [1633] mm); Darwin, near Channel Island Rd; $12^{\circ} 33.557^{\prime} \mathrm{S}, 130^{\circ} 52.889^{\prime}$ E; 16 Aug. 2012; station 64; Sonneratia, Rhizophora and Ceriops mangrove forest; NTM P.57604 • 1 spec. (27/19 [1690] mm); Darwin, end of Channel Island Rd; $12^{\circ} 33.557^{\prime}$ S, $130^{\circ} 52.894^{\prime}$ E; 17 Aug. 2012; station 66; Sonneratia, Rhizophora and Ceriops mangrove forest; NTM P.57606 • 1 spec. (33/25 [1701] mm); Darwin, close to Tiger Brenan Rd; $12^{\circ} 28.782^{\prime} \mathrm{S}, 130^{\circ} 54.750^{\prime} \mathrm{E}$; 19 Aug. 2012; station 69; high tidal Ceriops mangrove by small service road; NTM P.57608. Queensland • 1 spec. (31/26 [2549] mm); Cairns; 16 $6^{\circ} 52.972^{\prime}$ S, $145^{\circ} 45.665^{\prime}$ E; 15 Jun. 2013; station 98; Rhizophora, Bruguiera and Ceriops, not many dead logs; MTQ • 1 spec. (50/27 [no DNA] mm); Flying Fish Point; $17^{\circ} 30.001^{\prime} \mathrm{S}, 146^{\circ} 04.295^{\prime}$ E; 20 Jun. 2013; station 104; mangrove by creek with sandy mud; MTQ • 1 spec. (24/18 [2590] mm); Magnetic Island; 19¹0.096' S, 146²49.366' E; 23 Jun. 2013; station 106; mostly Avicennia mangrove with mounds of mud; MTQ 1 spec. (34/25 [2679] mm); Campwin Beach; $2^{\circ} 22.455^{\prime} \mathrm{S}, 1^{\circ} 9^{\circ} 18.753^{\prime} \mathrm{E}$; 5 Jul. 2013; station 121; narrow Rhizophora mangrove with watery mud and large rocks by creek; MTQ 22 specs (48/34 [no DNA] and 23/17 [2689] mm); Armstrong Beach; 21 ${ }^{\circ} 27.129^{\prime} \mathrm{S}, 1^{\circ} 9^{\circ} 17.084^{\prime} \mathrm{E}$; 6 Jul. 2013; station 123; margin of Rhizophora and Avicennia mangrove with open mudflat; MTQ $11 \mathrm{spec}$. (48/29 [no DNA] mm); Queensland, Pioneer River; $21^{\circ} 08.511^{\prime} \mathrm{S}, 149^{\circ} 12.076^{\prime} \mathrm{E}$; 8 Jul. 2013; station 125; Avicennia \& Rhizophora mangrove; MTQ.

INDONESIA - Halmahera 2 specs (36/24 [5071] and 28/18 [5021] mm); Dodinga; 00 $51.348^{\prime} \mathrm{N}$, $127^{\circ} 38.504^{\prime}$ E; 9 Mar. 2015; station 206; high intertidal back of mangrove with Acrostichum sp. and mounds of mud; UMIZ 00080 • 4 specs (34/19 [5112], 34/18 [5109], 22/17 [5111] and 19/13 [5110] mm); Buli; $00^{\circ} 55.446^{\prime} \mathrm{N}, 128^{\circ} 20.612^{\prime} \mathrm{E}$; 16 Mar. 2015; station 212; logged area in front of old Rhizophora forest; UMIZ 00081. 

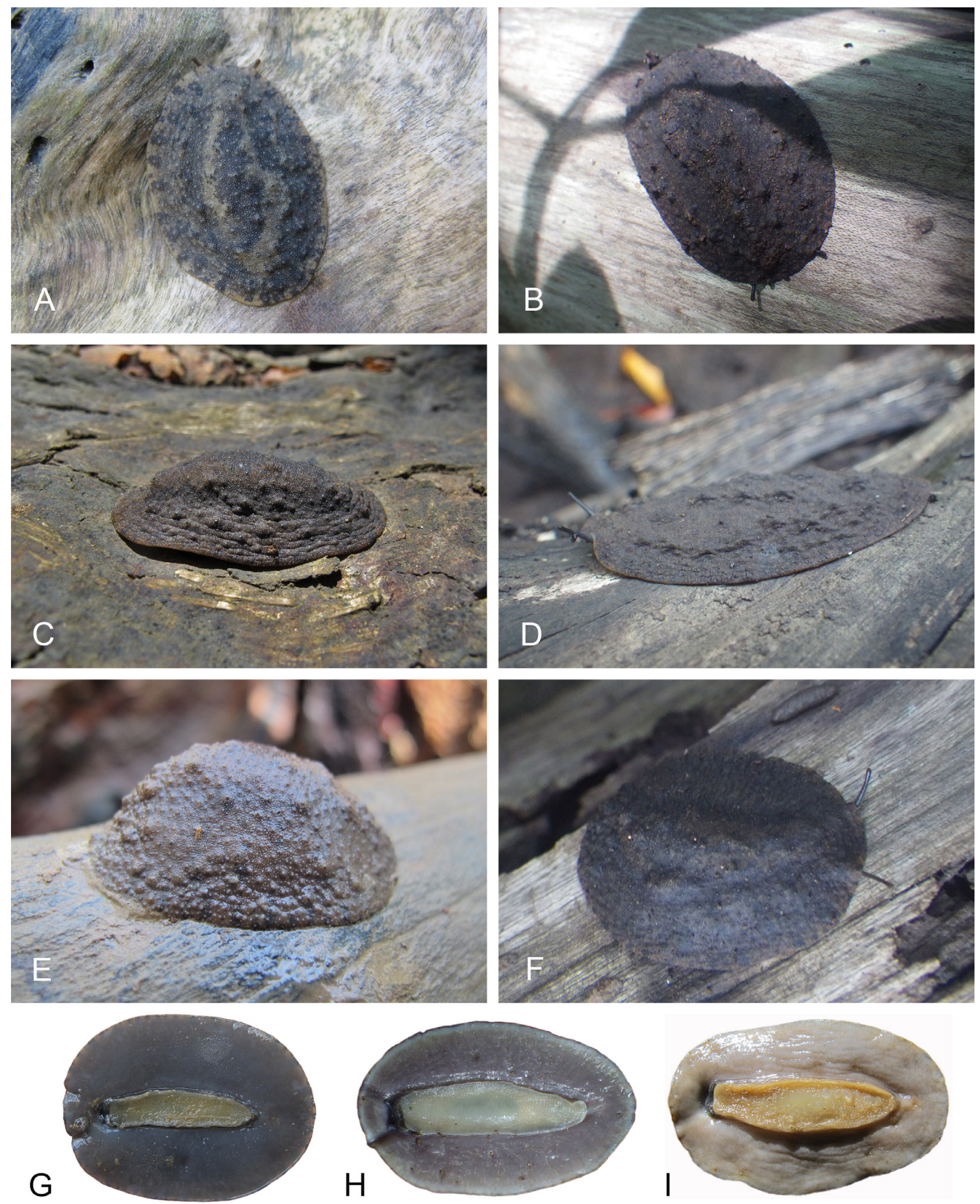

Fig. 22. Platevindex coriaceus darwinensis Goulding \& Dayrat subsp. nov., live animals. A. Dorsal view, $20 \mathrm{~mm}$ long [1672], Australia, Darwin (NTM P.57602). B. Dorsal view, $36 \mathrm{~mm}$ long [5071], Indonesia, Halmahera (UMIZ 00080). C. Dorsal view, 36 mm long [1674], Australia, Darwin (NTM P.57602). D. Dorsal view, $34 \mathrm{~mm}$ long [5109], Indonesia, Halmahera (UMIZ 00081). E. Dorsal view, holotype, $28 \mathrm{~mm}$ long [1700], Australia, Darwin (NTM P.57601). F. Dorsal view, $22 \mathrm{~mm}$ long [5111], Indonesia, Halmahera (UMIZ 00081). G. Ventral view, 33 mm long [1701], Australia, Darwin. H. Ventral view, same as B. I. Ventral view, same as C. 
Other museum material without DNA sequences

AUSTRALIA - Western Australia - 13 specs (from 35/30 to 20/20 mm); Kimberley, Whirlpool Pass; $16^{\circ} 15.81^{\prime} \mathrm{S}, 123^{\circ} 29.88^{\prime} \mathrm{E}$; on mangroves; WAM S42812 6 specs (from $25 / 25$ to $17 / 15 \mathrm{~mm}$ ); Kimberley, Cambridge Gulf, Cape Domett; $14^{\circ} 49.78^{\prime}$ S, $128^{\circ} 23.20^{\prime}$ E; WAM S26581 • 4 specs (from $35 / 30$ to $15 / 15 \mathrm{~mm}$ ); Exmouth Gulf, Tubridgi Point Boat Channel; $21^{\circ} 50.0^{\prime} \mathrm{S}, 114^{\circ} 39.90^{\prime} \mathrm{E}$; WAM S26772 • 5 specs (from 30/30 to 8/8 mm); Exmouth Gulf, NE of Tent Point; $22^{\circ} 00.0^{\prime} \mathrm{S}, 114^{\circ} 30.5^{\prime} \mathrm{E}$ to $22^{\circ} 00.4^{\prime} \mathrm{S}, 114^{\circ} 32.1^{\prime} \mathrm{E}$; WAM S26777.

\section{Description}

Color and morphology of live animals (Fig. 22)

Identical to $P$. coriaceus coriaceus (see above), acknowledging some minor variations: the hyponotum is grey or light grey; the foot is light yellow; there are between 20 and 36 papillae with dorsal eyes, the largest animals bearing the largest numbers of eyes.

\section{Digestive system (Figs 17B, 23)}

Identical to that of $P$. coriaceus coriaceus (see above), acknowledging some minor variations: radulae measure up to $7.4 \mathrm{~mm}$; examples of radular formulae are presented in Table 5; intestinal loops are of type II, with a transitional loop oriented between 6 and 8 o'clock (Fig. 17B).

Reproductive system (Figs 18-19, 24)

Identical to that of $P$. coriaceus coriaceus (see above), acknowledging some minor variations: the distal section of the oviduct (i.e., distal to the spermatheca) is long, up to two times the length of the proximal
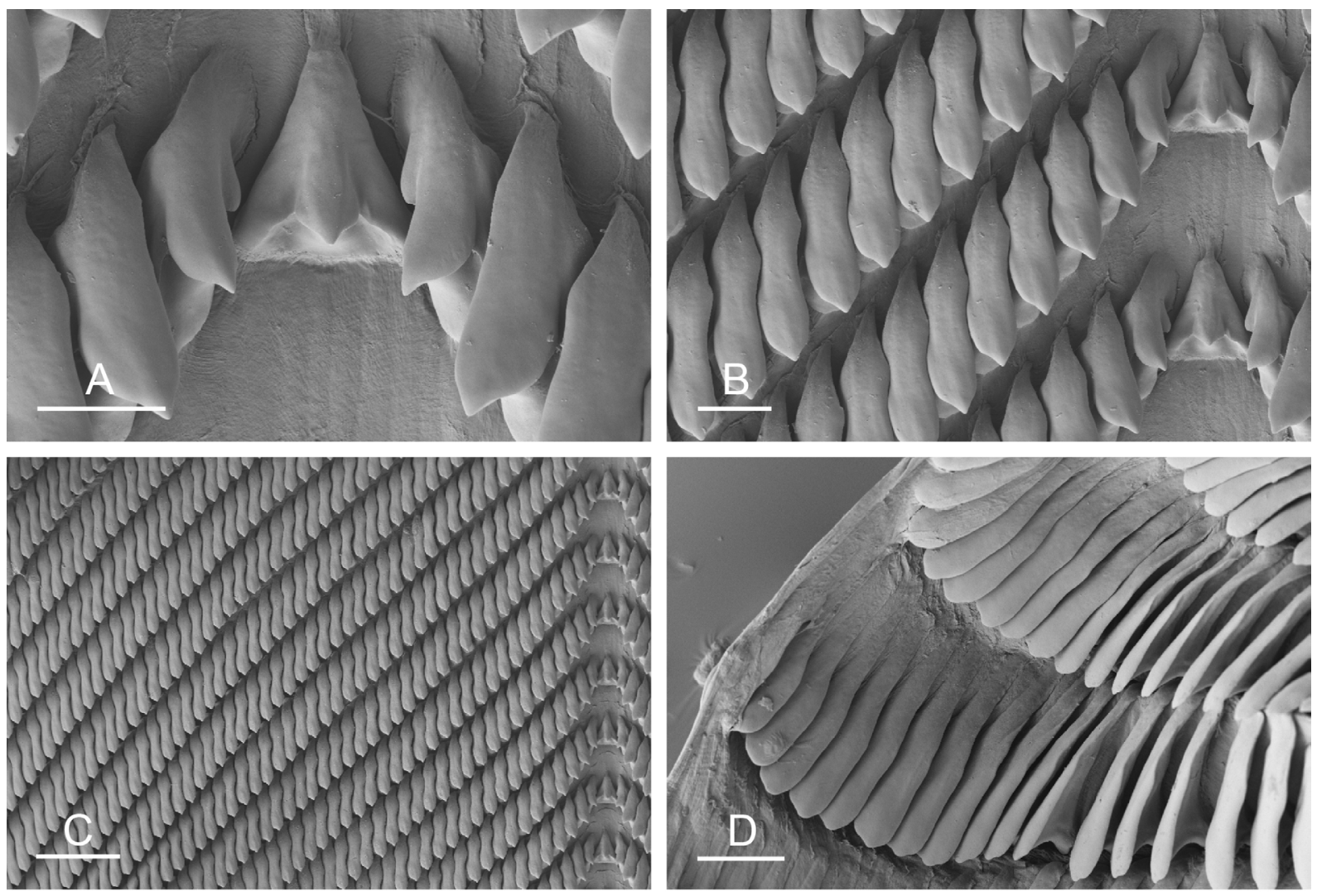

Fig. 23. Platevindex coriaceus darwinensis Goulding \& Dayrat subsp. nov., radula, Indonesia, Halmahera [5021] (UMIZ 00080). A. Rachidian and innermost lateral teeth. B. Lateral teeth with rachidian teeth. C. Lateral teeth. D. Outermost lateral teeth. Scale bars: A $=50 \mu \mathrm{m} ; \mathrm{B}=10 \mu \mathrm{m} ; \mathrm{C}=100 \mu \mathrm{m} ; \mathrm{D}=30 \mu \mathrm{m}$. 
section (from the female gland mass to the spermatheca); the oviduct is much wider (up to five times) than the deferent duct; penial hooks measure from 60 to $110 \mu \mathrm{m}$; the flexible region of the penis with hooks is between 2 and $8 \mathrm{~mm}$ long (Fig. 24); the retractor muscle varies from the length of the sheath to $1 / 4$ of its length.

\section{Distinctive diagnostic features (Table 4)}

Platevindex coriaceus coriaceus and P. coriaceus darwinensis subsp. nov. are indistinguishable externally. The only minor difference in color variation is that a dark blue-grey hyponotum was observed in $P$. coriaceus coriaceus (most commonly in the Philippines) but never in P. coriaceus darwinensis subsp. nov. Internally, both subspecies can hardly be distinguished either. The ratio between the oviduct width and the deferent duct width tends to be much higher in P. coriaceus darwinensis subsp. nov. than in $P$. coriaceus coriaceus, but a higher variation may be discovered in the future. However, based on current data, P. coriaceus coriaceus and P. coriaceus darwinensis subsp. nov. do not overlap geographically.

\section{Distribution (Fig. 10B)}

Australia: Northern Territory and Queensland. Indonesia: Halmahera.

\section{Habitat (Fig. 25)}

Platevindex coriaceus darwinensis subsp. nov. is found in the same habitat as the nominotypical subspecies, i.e., mangrove forests, on tree roots, tree trunks and logs. It is very common in the Northern Territory (Australia) and Halmahera (Indonesia). It seems to be less common in Queensland (Australia), with Platevindex luteus found in higher abundance.

\section{Remarks}

A new subspecific name is needed because no existing species-group name could apply with confidence to the taxon recognized here. Platevindex cinereus was described from Broome, Western Australia, by Odhner (1917) as Oncis cinerea, exclusively known from the holotype, by monotypy, which is a small $(9 / 9 \mathrm{~mm})$ and immature specimen (SMNH 945). There is no doubt that the holotype of Oncis cinerea belongs to a species of Platevindex, but, because it is immature, it is not possible to determine which one. Platevindex cinereus could apply to either of the two species sampled in the Northern Territory, Australia, P. coriaceus darwinensis subsp. nov. or P. martensi, and even to the widespread species $P$. luteus, although the latter has not been recorded from Northern Territory or Western Australia. Because it will remain impossible to confidently apply $P$. cinereus to any particular species of Platevindex, it is regarded here as a nomen dubium. Some onchidiid slugs from the collections of the Western Australia

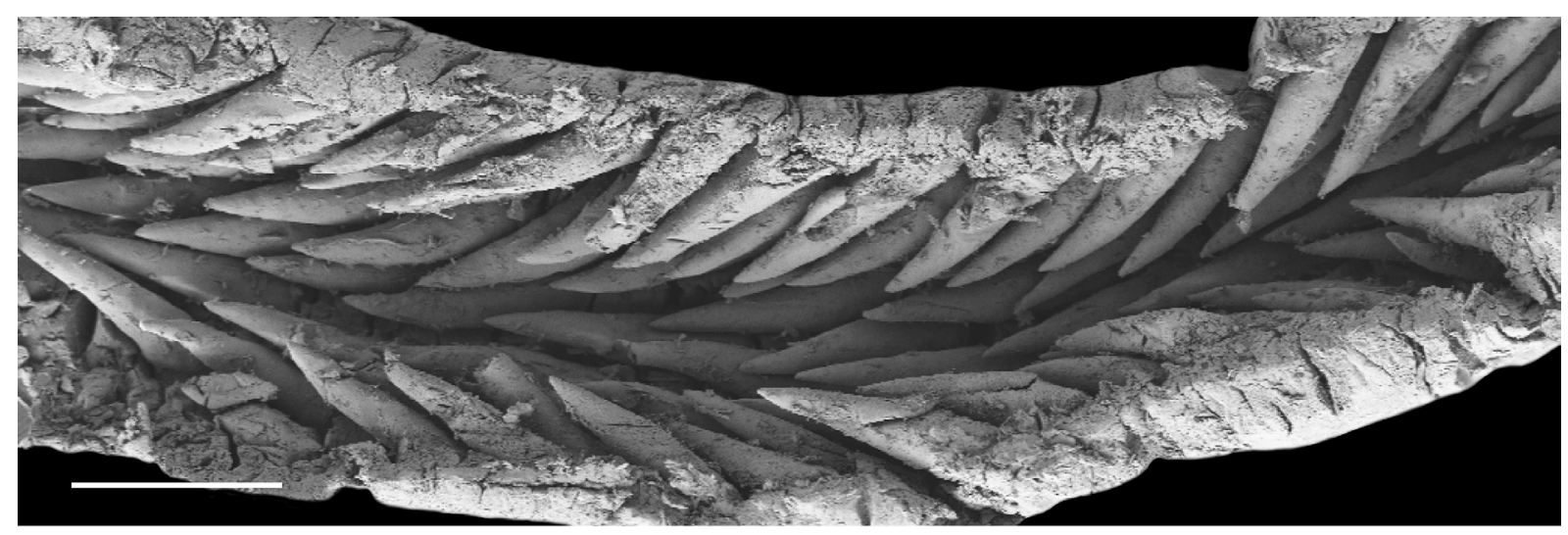

Fig. 24. Platevindex coriaceus darwinensis Goulding \& Dayrat subsp. nov., penial hooks, Australia, Queensland, [no DNA] (MTQ). Scale bar $=100 \mu \mathrm{m}$. 
Museum are identified here as $P$. coriaceus based on the position of their dorsal eyes and their reproductive anatomy. Whether populations of P. coriaceus from Western Australia belong to P. coriaceus coriaceus, P. coriaceus darwinensis subsp. nov., or even a distinct subspecies would have to be checked with fresh material from Western Australia.

Bretnall's (1919: 323) description of Onchidium coriaceum from Queensland does not appear to be based on Platevindex slugs: "short conical papillae" and a hyponotum "regularly yellowish" are not compatible with $P$. coriaceus darwinensis subsp. nov.

Platevindex tigrinus (Stoliczka, 1869) comb. nov.

Figs 26-30

Onchidium tigrinum Stoliczka, 1869: 105-107, pl. 15, fig. 2.

Platevindex mortoni - Sun et al. 2014: 63. —Zhang et al. 2017: fig. 1 [non Platevindex mortoni Britton, 1984].
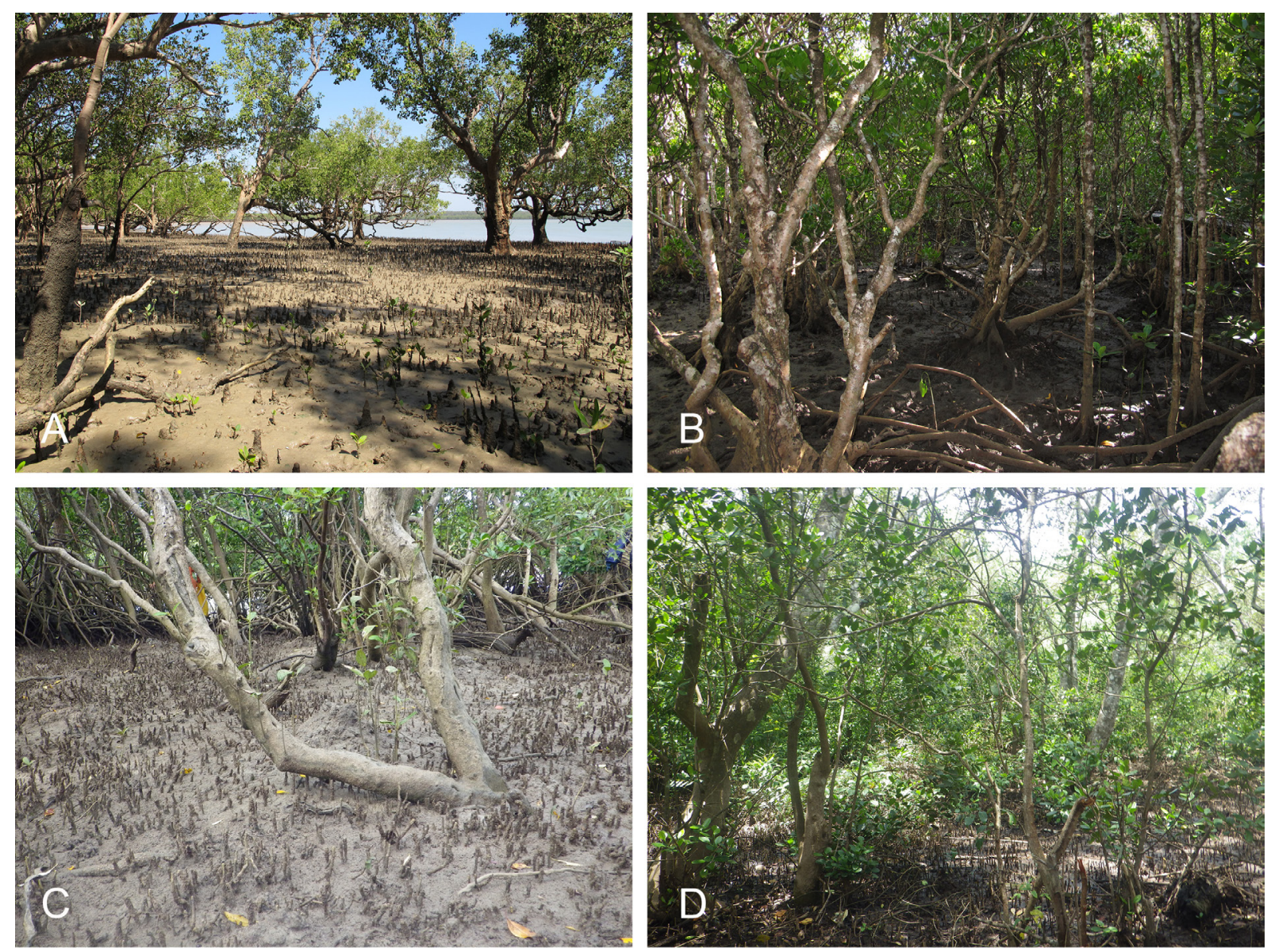

Fig. 25. Habitats of Platevindex coriaceus darwinensis Goulding \& Dayrat subsp. nov. A. Australia, Darwin, large Sonneratia alba, open forest, soft mud by shore (station 62). B. Australia, Queensland, Rhizophora, Bruguiera and Ceriops by boardwalk, not many dead logs (station 98). C. Australia, Queensland, open forest with Avicennia, some Rhizophora and soft mud (station 124). D. Indonesia, Halmahera, high intertidal back of a mangrove, with Acrostichum ferns and mounds of mud (station 206). 


\section{Material examined}

Neotype (here designated)

INDIA • neotype (28/18 [1066] mm); Sundarbans, Bali Island; $22^{\circ} 04.387^{\prime} \mathrm{N}, 88^{\circ} 41.828^{\prime}$ E; 6 Jan. 2011; station 50; soft mud by the sea with a few mangrove trees and dead logs; BNHS 18-1066.

\section{Notes on type material}

The designation of a neotype is needed in order to clarify the application of the name Onchidium tigrinum (ICZN Article 75.3.1). The characters that differentiate P. tigrinus from other species of Platevindex are mentioned below in a section on 'Distinctive diagnostic features' (ICZN Article 75.3.2). The neotype is preserved separately and will be easily recognized (ICZN Article 75.3.3). The syntypes could not be located after an exhaustive search of museum collections (Dayrat 2009) (ICZN Article 75.3.4). What is known of the former syntypes, from the original description and illustrations, is consistent with the neotype (ICZN Article 75.3.5). The type locality is the banks of the Mutlah River at Port Canning [Matla River, Ganges Delta, India] and the neotype was collected as nearly as practicable from the original type locality in West Bengal (ICZN Article 75.3.6), and it is already the property of a scientific institution, the Bombay Natural History Society, in Mumbai, India (ICZN Article 75.3.7). The neotype was collected on soft mud by the sea with a few mangrove trees and dead logs. The designation of a neotype is exceptionally needed in order to make sure that the application of the name Onchidium tigrinum remains unambiguous (see Remarks below).

\section{Other material}

BRUNEI - 2 specs (29/18 [1033] and 15/14 [1032] mm); Sungai; 04 $53.756^{\prime} \mathrm{N}, 114^{\circ} 59.496^{\prime} \mathrm{E}$; 26 Jul. 2011; station 31; very large, tall Rhizophora mangrove with soft mud; BDMNH 1 spec. (23/16 [1030] mm); Pulau Pyatan, Teluk Brunei; 0455.246' N, 11502.764' E; 27 Jul. 2011; station 32; open mangrove with a few sparse old trees and large old logs, by the river; BDMNH.

INDIA - West Bengal 1 spec. (13/10 [1065] mm); same collection data as for neotype; BNHS 18-1065 1 spec. $(22 / 15$ [\#1] mm); same collection data as for neotype; BNHS 18. - Andaman Islands • 1 spec. (40/30 [1094] mm); Shamkund, near Rangat; $12^{\circ} 29.448^{\prime}$ N, $92^{\circ} 50.620^{\prime}$ E; 11 Jan. 2011; station 57; by a large river, deep mangrove with tall trees, small creeks and old muddy logs, next to a road and a small cemented bridge across creek; BNHS 2-1094 - 2 specs (35/22 [\#1] and 24/15 [1114] mm); Shantipur, Kadamtala; $02^{\circ} 19.844^{\prime}$ N, $92^{\circ} 46.377^{\prime}$ E; 12 Jan. 2011; station 58; open area with hard mud and many old logs, next to a mangrove; BNHS 12-1114 1 spec. $(25 / 22$ [1123] mm); Shoal Bay, by Bamboo Flat; $11^{\circ} 47.531^{\prime} \mathrm{N}, 92^{\circ} 42.576^{\prime} \mathrm{E}$; 13 Jan. 2011; station 59; open mangrove with hard mud, old logs, next to a road and a small cemented bridge across creek; BNHS 1-1123. - Maharashtra 1 spec. (25/16 [1140] mm); Khandra mangrove; $1^{\circ} 03.876^{\prime} \mathrm{N}, 7^{\circ} 49.296^{\prime} \mathrm{E}$; 18 Dec. 2011; station 43; very small Avicennia trees in mud; BNHS 35-1140 1 spec. (36/26 [1160] mm); Vatad; $17^{\circ} 15.791^{\prime} \mathrm{N}$, $73^{\circ} 17.623^{\prime}$ E; 23 Dec. 2011; station 46; Avicennia mangroves by field with deep and very watery mud; BNHS 104-1160 1 spec. (29/16 [1178] mm); Areware mangrove; 1704.404' N, 73⒘747' E; 24 Dec. 2011; station 47; mangrove of Avicennia and a few small Rhizophora with soft mud and areas with pooled water; BNHS 33-1178.

MALAYSIA - Peninsular Malaysia - $3 \operatorname{specs}(23 / 17$ [953], 21/18 [955] and 14/12 [956] mm); Matang, Crocodile River off Kuala Septang; 04²4.521' N, 100 37.630' E; 10 Jul. 2011; station 16; mangrove with tall Rhizophora; USMMC $00022 \bullet 2$ specs (27/18 [939] and 26/14 [5522] mm); Merbok; $05^{\circ} 39.035^{\prime} \mathrm{N}, 100^{\circ} 25.782^{\prime} \mathrm{E}$; 18 Jul. 2011; station 21; deep Rhizophora forest with old, tall trees, hard mud, many small creeks and dead logs; USMMC $00023 \bullet 1$ spec. (14/13 [936] mm); Langkawi Island, Tanjung Rhu; 06 $25.771^{\prime}$ N, 99 $49.436^{\prime}$ E; 13 Jul. 2011; station 23; young Rhizophora, Sonneratia and Avicennia in a dense forest with small creeks; USMMC 00024. 
SINGAPORE • 1 spec. (21/17 [992] mm); Lim Chu Kang; 01²6.785’ N, 10342.531' E; 2 Apr. 2010; station 7; open mangrove forest with tall trees and soft mud by river, ending on sun-exposed mudflat; ZRC.MOL.10472 • 1 spec. (18/17 [993] mm); Semakao Island; 01²12.083' N, 103²45.585' E; 3 Apr. 2010; station 8; landfill island with newly planted mangrove, very dense; ZRC.MOL.10473 1 spec. (19/13 [994] mm); Lim Chu Kang; 01²6.785’ N, 103²42.531' E; 5 Apr. 2010; station 9; open mangrove forest with tall trees and soft mud by river, ending on sun-exposed mudflat; ZRC.MOL.10474.

\section{Description}

Color and morphology of live animals (Fig. 26)

The dorsal surface is bumpy, not smooth, and typically brown with dark brown or yellow-brown markings. The hyponotum color varies from bluish grey to light grey. The edge of the hyponotum may be slightly lighter, but there is no prominent light-colored line around the entire edge. The foot color varies from dark blue-grey to light yellow. The number of papillae with dorsal eyes is variable (generally between 25 and 50). Dorsal eyes are distributed across the notum but are absent from its margin (i.e., eyes are never $<2 \mathrm{~mm}$ from the notum edge).

Digestive system (Figs 27A, 28)

Radulae measure up to $5 \mathrm{~mm}$ in length. Examples of radular formulae are presented in Table 5. The intestinal loops are of type II, with transitional loops oriented between 6 and 9 o'clock (Fig. 27A).

Reproductive system (Figs 27B-C, 29)

The oviduct is much wider than the deferent duct (approximately up to three times). Its distal section (distal to the spermatheca) is up to three times as long as its proximal section (Fig. 27B). The deferent duct is closely attached to the oviduct and almost straight (with only loose turns). The distal, flexible, hook-bearing section of the penis is 1 to $1.5 \mathrm{~mm}$ long. The penial hooks are approximately 60 to $100 \mu \mathrm{m}$ long, and can be seen inside the semi-transparent penis. In mature specimens, the retractor muscle inserts on the right side of the visceral cavity near the heart. The retractor muscle is from one quarter as long as the penial sheath to equal to it in length (Fig 27C). The deferent duct is not highly convoluted, with only a few loops (and is even less convoluted in immature specimens).

\section{Distinctive diagnostic features (Table 4)}

Externally, the yellow foot of Platevindex tigrinus clearly distinguishes it from P. martensi (orange foot) and P. aptei sp. nov. (black foot). Platevindex tigrinus is very similar externally to P. amboinae, except that the notum of $P$. tigrinus bears many dorsal eyes which are absent in P. amboinae. Platevindex tigrinus can be distinguished from $P$. latus by its granular dorsal surface and the lack of large, thorny dorsal papillae. Its granular dorsal surface also helps to distinguish it from P. luteus and P. applanatus, which bear prominent dorsal papillae when disturbed, although it is still possible to confuse these three species. Platevindex tigrinus cannot be distinguished externally from $P$. coriaceus, which has been found in many of the same sites, except in India (where P. coriaceus has not been found so far).

Internally, the intestinal loops clearly distinguish $P$. tigrinus (type II) from P. applanatus (type I). Some individuals of $P$. luteus are characterized by intestinal loops of type II and cannot be distinguished from $P$. tigrinus based only on the digestive system. The reproductive system can also be used to differentiate $P$. tigrinus from $P$. coriaceus, $P$. luteus and $P$. burnupi. In P. tigrinus, the retractor muscle for the penis inserts near the heart on the right side of the visceral cavity (i.e., in the posterior half or third of the cavity) while it inserts at the posterior end of the cavity in P. coriaceus. In P. tigrinus the deferent duct is closely attached to the oviduct (in the posterior reproductive system), while it is only loosely attached to it in P. luteus and P. burnupi. This trait also differs slightly between P. tigrinus and P. coriaceus: the deferent duct, which is closely attached to the oviduct in both species, is almost straight in $P$. tigrinus and highly-convoluted, with tight, $\mathrm{U}$-shaped turns in P. coriaceus. 

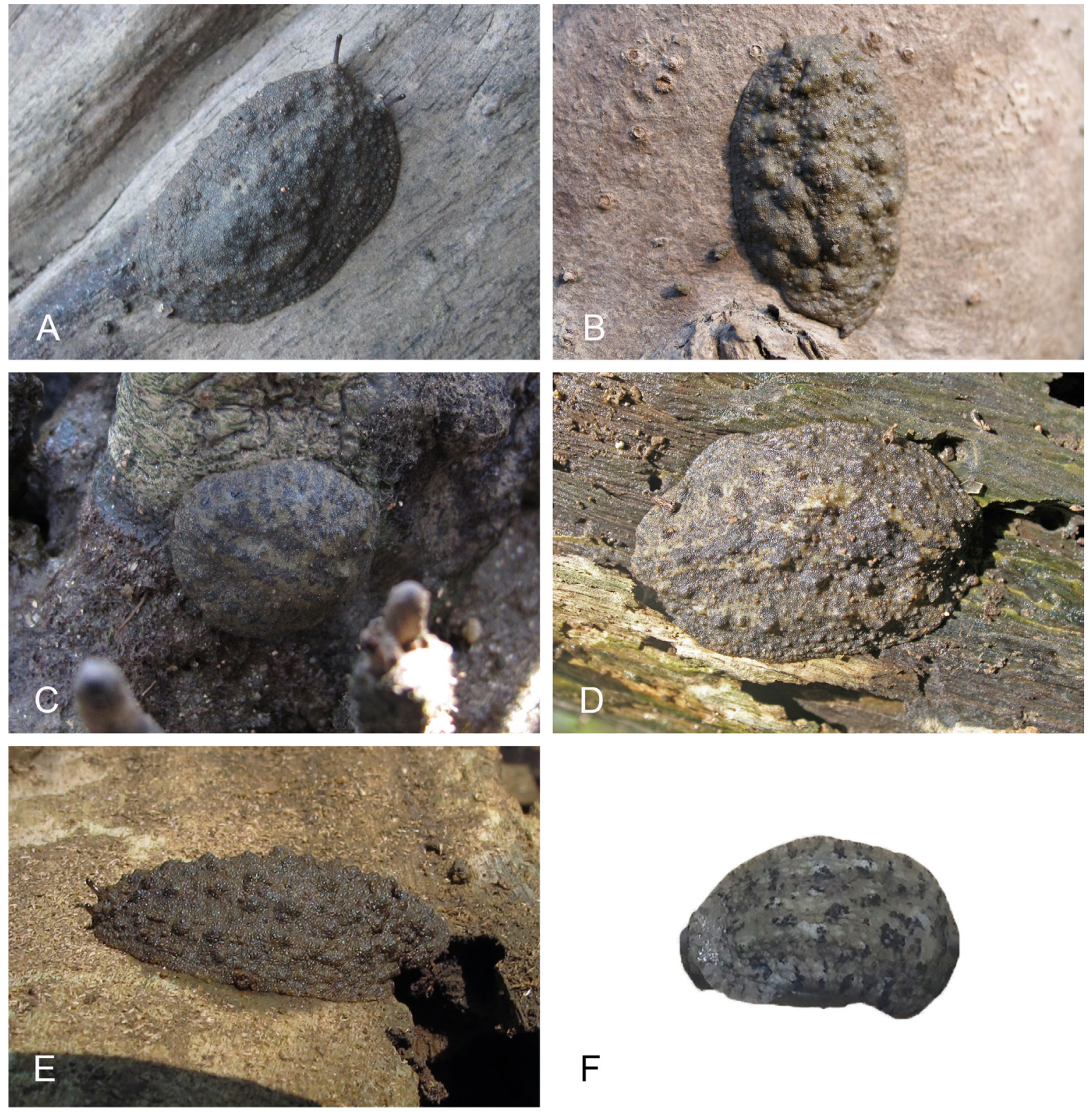

$\mathrm{F}$
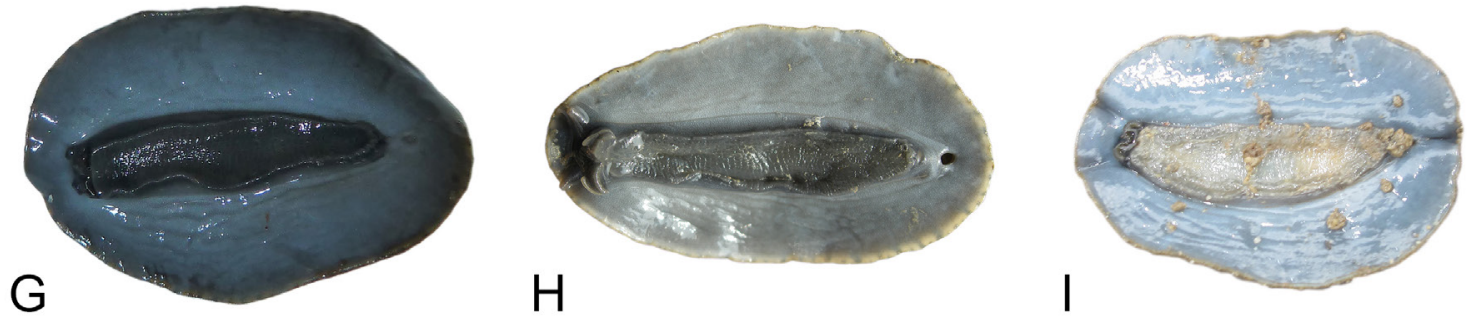

Fig. 26. Platevindex tigrinus (Stoliczka, 1869), live animals. A. Dorsal view, $35 \mathrm{~mm}$ long [\#1], India, Andaman Islands, Shantipur, Kadamtala (BNHS 12). B. Dorsal view, $22 \mathrm{~mm}$ long [\#1], India, Sundarbans, Bali Island (BNHS 18). C. Dorsal view, $25 \mathrm{~mm}$ long [1140], India, Maharashtra, Khandra mangrove (BNHS 35-1140). D. Dorsal view, 19 mm long [994], Singapore, Lim Chu Kang (ZRC.MOL.10474). E. Dorsal view, $29 \mathrm{~mm}$ long [1178], India, Maharashtra (BNHS 33-1178). F. Dorsal view, neotype, $28 \mathrm{~mm}$ long [1066], India, West Bengal, Sundarbans, Bali Island (BNHS 18-1066). G. Ventral view, $27 \mathrm{~mm}$ long [939], Malaysia, Merbok (USMMC 00023). H. Ventral view, same as B. I. Ventral view, same as A. 
Distribution (Fig. 10B)

Brunei. India: Andaman Islands, Maharashtra and West Bengal (type locality and fresh specimens newly collected). Peninsular Malaysia. Singapore. Southern China (specimens misidentified as Platevindex mortoni in Sun et al. 2014 and Zhang et al. 2017). All records are new, except for the type locality.

\section{Habitat (Fig. 30)}

Platevindex tigrinus is found in mangroves, on tree trunks and roots and dead logs, but is not found directly on mud. Those logs and trees may be in silty mud saturated with water or in the mid-intertidal. It does not live on rocky shores. Platevindex tigrinus is common across most of its geographic range. It is one of the most abundant onchidiid species in the mangroves of India.

\section{Remarks}

Stoliczka's illustration of the external appearance of $O$. tigrinum clearly shows a Platevindex slug (Stoliczka 1869: fig. 2). In his description of O. tigrinum, Stoliczka emphasized the flattened shape of the slug, the narrow foot and the hardened notum, which are all diagnostic of Platevindex. Other aspects of the original description are also in agreement with Platevindex: a granular dorsal surface, a foot from one third to one fourth the total width of the body, dorsal eyes on papillae of the notum and a male opening above the right oral lobe. Therefore, O. tigrinum is transferred to Platevindex.

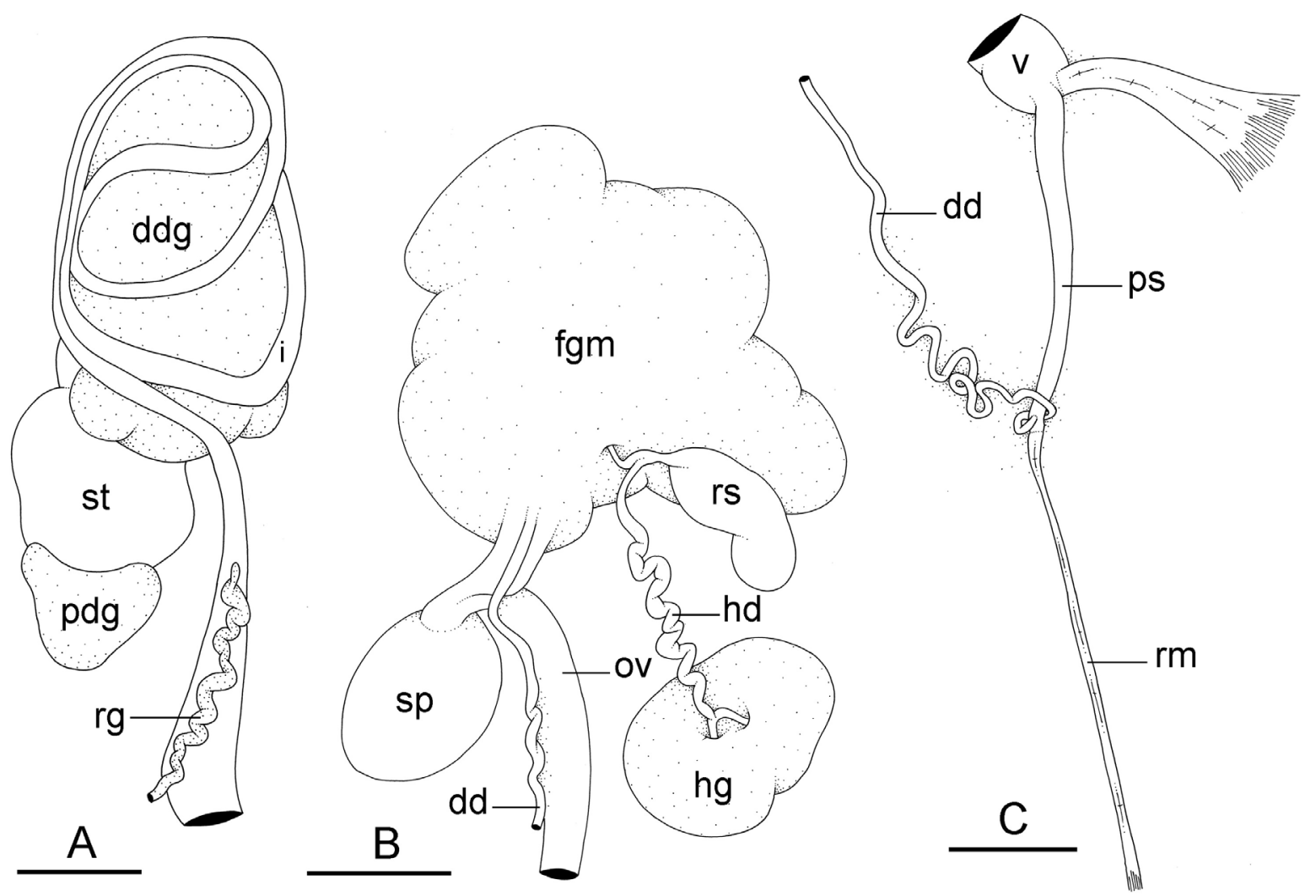

Fig. 27. Platevindex tigrinus (Stoliczka, 1869), digestive and reproductive systems, Peninsular Malaysia [5522] (USMMC 00023). A. Digestive system, dorsal view, type II with a transitional loop oriented at 9 o'clock. B. Posterior reproductive system. C. Anterior, male copulatory apparatus. Abbreviations: $\mathrm{dd}=$ deferent duct; $\mathrm{ddg}=$ dorsal digestive gland; fgm = female gland mass; hd = hermaphroditic duct; hg = hermaphroditic gland; $\mathrm{i}=$ intestine; $\mathrm{ov}=$ oviduct; $\mathrm{pdg}=$ posterior digestive gland; $\mathrm{ps}=$ penial sheath; $\mathrm{rg}=$ rectal gland; $\mathrm{rm}=$ retractor muscle; $\mathrm{rs}=$ receptaculum seminis; $\mathrm{sp}=$ spermatheca; $\mathrm{st}=$ stomach; $\mathrm{v}=$ vestibule. Scale bars: $\mathrm{A}=3 \mathrm{~mm} ; \mathrm{B}-\mathrm{C}=2 \mathrm{~mm}$. 
Stoliczka's description of the color of the ventral surface is as follows: "Young specimens have the mantle below uniform light bluish with very numerous and white dots; large ones have occasionally a number of dark green or rusty, more or less confluent spots along the lateral margins, and the general colour is pale. The foot (...) is of a uniform dark bluish grey colour." (Stoliczka 1869: 106). The color of Stoliczka's young specimens perfectly matches the species described here and the color of the large ones is also within the observed color variation. The species treated here is the only one that we found at the type locality of $O$. tigrinum with a blue-grey ventral surface, strongly suggesting that the name $O$. tigrinum applies to the species described here. Also, Stoliczka mentioned that, at the type locality, O. tigrinum was common and found crawling on old wood, which is in complete agreement with our observations in the field, including at the type locality.

There is, however, a problem with Stoliczka's original description of O. tigrinum. Indeed, Stoliczka (1869: 107) stated that the "internal vas deferens is about 5 inches, and its supplementary albuminous string [Stoliczka's term for the accessory penial gland] about 8 inches long." An accessory penial gland is not present in any species of Platevindex and this strongly suggests that a species from another genus was part of the type material, although it cannot be excluded that he made a mistake. Thus, the designation of a neotype is needed because it allows us to ensure that, in the future, O. tigrinum will always apply to the species described here. The designation of a neotype is far more preferable to a lectotype designation based on an illustration or description. Indeed, even though the species described here is the only Platevindex we found at the type locality of $O$. tigrinum, it cannot be excluded that other species, especially P. luteus, will be found there in the future. Because P. luteus and P. tigrinus are hardly distinguishable externally, it is possible that Stoliczka also examined some specimens of $P$. luteus. For all the reasons above, the neotype designated here efficiently clarifies the application of $O$. tigrinum.
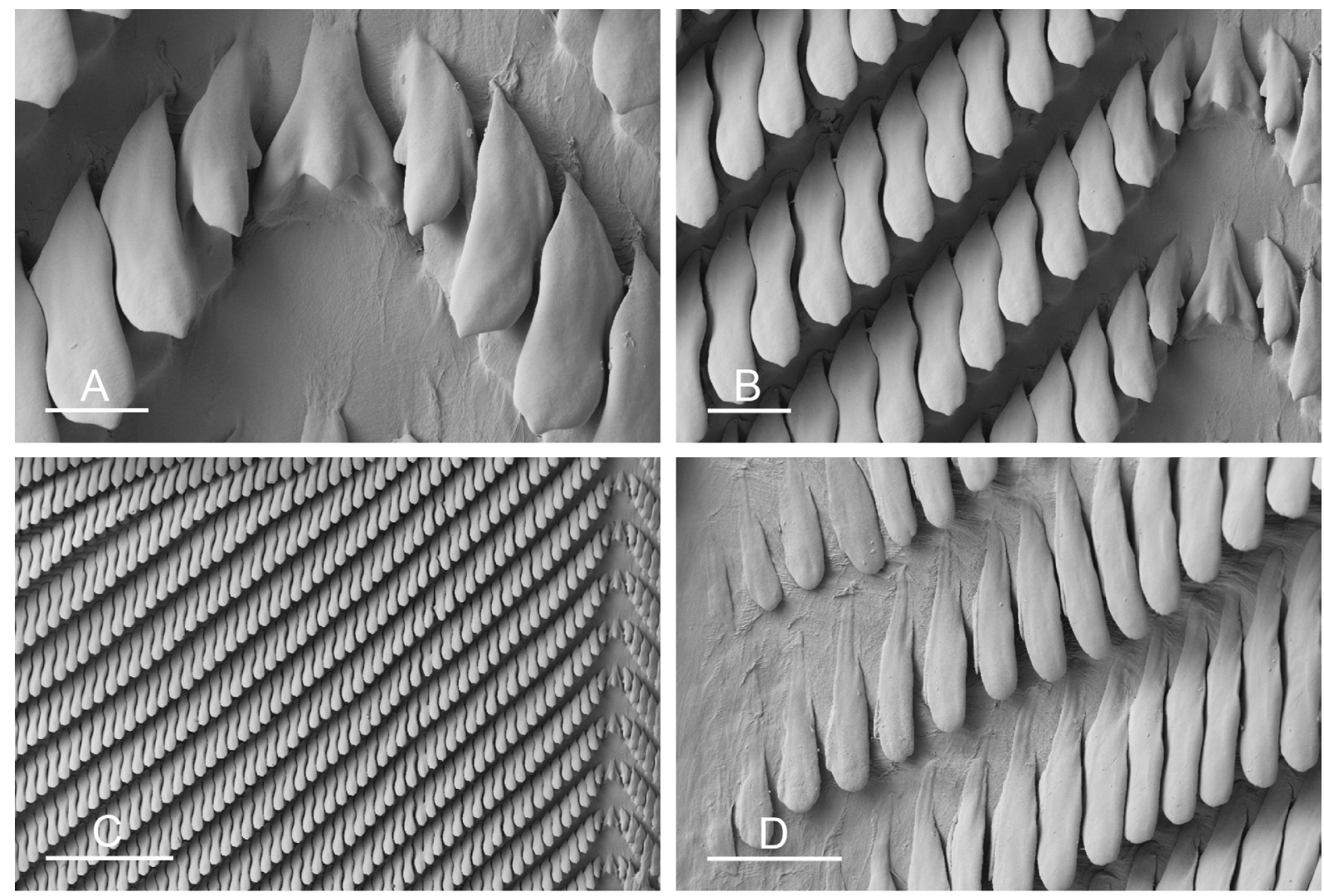

Fig. 28. Platevindex tigrinus (Stoliczka, 1869), radula, Peninsular Malaysia, Merbok [5522] (USMMC 00023). A. Rachidian and innermost lateral teeth. B. Lateral teeth with rachidian teeth. C. Lateral teeth. D. Outermost lateral teeth. Scale bars: $A=20 \mu \mathrm{m} ; \mathrm{B}=30 \mu \mathrm{m} ; \mathrm{C}=200 \mu \mathrm{m} ; \mathrm{D}=50 \mu \mathrm{m}$. 
In his remarks on Onchidium coriaceum, Semper (1882: 273) addressed the similarity between the species he described and Stoliczka's description of Onchidium tigrinum. Semper pointed out that the only difference between the two descriptions is the presence of an accessory penial gland in O. tigrinum, but doubted that one was actually present in Stoliczka's specimens of O. tigrinum. Semper considered $O$. tigrinum to be a synonym of $O$. coriaceum (although with a question mark), even though he was not able to properly compare the anatomy of the two species, and even though, strictly speaking, $O$. tigrinum had priority over $O$. coriaceum. Platevindex tigrinus is shown here to be genetically and anatomically distinct from $P$. coriaceus.

Hoffmann (1928: 77) noted Semper's comments on the similarity between Onchidium tigrinum and Oncis stuxbergi, but did not provide additional comments on the species or add new localities. Hoffmann's indication that the species was from "Port Canning (Penang, Malayische Halbinsel)" [Penang, Peninsular Malaysia] appears to be a mistake for Stoliczka's locality of Port Canning in West Bengal, India. Labbé (1934: 223) repeated Hoffmann's erroneous record but did not provide new information about the species.

The type material of Platevindex mortoni, a species originally described by Britton (1984) from Hong Kong, includes a holotype by original designation (NHMUK 1982288) and three paratypes (NHMUK 1982289/1,2 and NHMUK 1982289/3). The holotype (18/16 mm) is missing both the male and female reproductive parts, which were not described in detail by Britton. Also, its digestive system is largely destroyed (the intestinal loops cannot be observed) even though the radula remains. The two largest paratypes (22/18 and $15 / 15 \mathrm{~mm})$ are empty of all internal organs. All organs remain in the smallest $(9 / 9 \mathrm{~mm})$ paratype but it is not fully mature (the posterior, female reproductive parts are only partly developed). The intestinal loops of the smallest paratype are clearly of type II. Britton did not describe the color of the ventral surface (foot and hyponotum) of live animals. He only mentioned that the preserved holotype and two preserved paratypes (NHMUK 1982289/1,2) were brown with a darker mantle rim, while the third paratype (NHMUK 1982289/3) was grey with darker mottling. However, the dorsal color is useless for identifying species of Platevindex and a brown dorsal surface with a darker mantle rim (color of the holotype) could apply to any species. Britton's description of the type of intestinal loops is also problematic. He described intestinal loops of type I in the holotype, of type II in what he called the "grey paratype" (NHMUK 1982289/3), which is the largest paratype, and intermediate between types I and II in the smallest paratype. Intestinal loops of type II are clearly present in the smallest paratype (the only type specimen with remaining intestinal loops) which Britton called the "smaller brown paratype." There are three possible explanations for that. First, Britton correctly described the intestinal loops of the holotype of $P$. mortoni (the only specimen with a name-bearing function) and the name $P$. mortoni
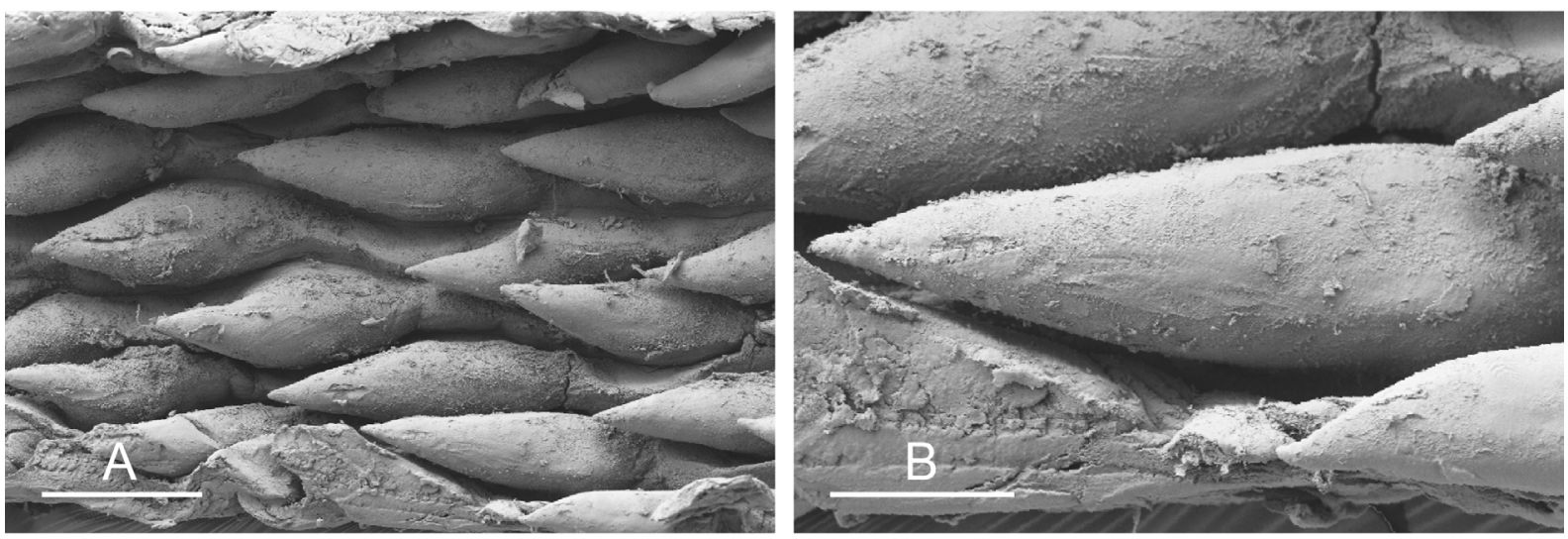

Fig. 29. Platevindex tigrinus (Stoliczka, 1869), penial hooks, Brunei [1030] (BDMNH). A. Penial hooks. B. Close up of penial hook. Scale bars: $A=50 \mu \mathrm{m} ; \mathrm{B}=20 \mu \mathrm{m}$. 
cannot apply to $P$. tigrinus or $P$. coriaceus, two species with intestinal loops of type II and which are known to be present in Hong Kong (see below). However, the name P. mortoni could apply to P. luteus, a species with intestinal loops of type I, but which is not known from Hong Kong (although it is known from the Philippines and Vietnam, among other places). Second, it is also possible (and quite likely) that Britton simply made a mistake in identifying the type of the intestinal loops in the holotype of P. mortoni because he also misidentified the intestinal type in another onchidiid that he called Paraoncidium reevesii (J.E. Gray, 1850) (see Goulding et al. 2018b). If Britton misidentified the intestinal loops in the holotype of $P$. mortoni, the description would be compatible with P. tigrinus. Third, it is also possible that the original description of $P$. mortoni was based on specimens from two different species (one with a type I and one with a type II), even though, strictly speaking, only the holotype is the name-bearer. Because Britton's description of $P$. mortoni is confusing and since critical characters cannot be checked in the type material, P. mortoni is regarded as a nomen dubium. It does apply to a species of Platevindex, but which one cannot be confidently determined.

DNA sequences of onchidiids from China published by Sun et al. (2014) show that there are several species of Platevindex in China and at least two in Hong Kong. For unclear reasons, Sun et al. applied the name P. mortoni to all Chinese onchidiids with a bluish-grey hyponotum and foot. By comparing
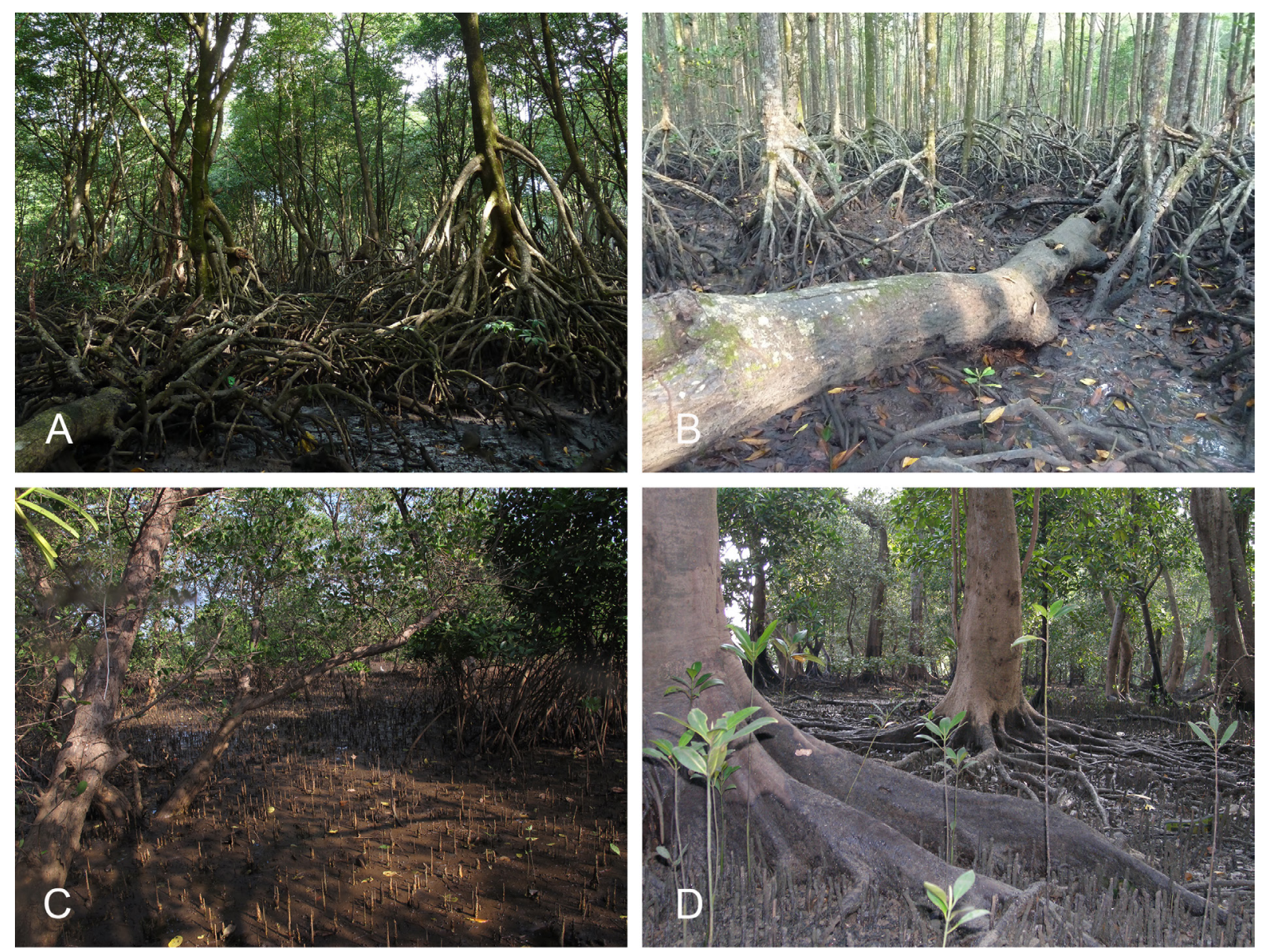

Fig. 30. Habitats of Platevindex tigrinus (Stoliczka, 1869). A. Brunei, Sungai, very large, tall Rhizophora with soft mud, access by boat from river (station 31). B. Peninsular Malaysia, Merbok, old, tall Rhizophora trees with hard mud (station 21). C. India, Maharashtra, small Avicennia trees and some Rhizophora with soft mud, trees in clumps with open area in between (station 47). D. Singapore, Lim Chu Kang, Avicennia mangrove (station 7). 
their DNA sequences with ours, we have determined that the sequenced specimens they called $P$. mortoni belong to $P$. tigrinus and $P$. coriaceus. The specimens called $P$. mortoni from southern China, east of Hainan (including Hong Kong), are here referred to P. tigrinus, while a specimen collected from southern China west of Hainan belongs to P. coriaceus.

Zhang et al. (2017) recently re-described a species they identified as Platevindex mortoni based on specimens from Hong Kong. This description did not address the inconsistency in the original description regarding the intestinal loops and appears to be based on multiple species of Platevindex. Despite the fact that COI sequences from Sun et al. (2014) showed that several species of this genus are present in China, including two in Hong Kong, Zhang et al. did not discuss how the species they re-described was different from other sympatric species of Platevindex. Photographs of live specimens by Zhang et al. clearly show that there are two different kinds of ventral coloration. The individual with a blue-grey foot and hyponotum (Zhang et al. 2017: fig. 1c) was either P. tigrinus or P. coriaceus (both could potentially be present in Hong Kong), and the individual with a bright orange foot (Zhang et al. 2017: fig. 1E) is identified here as $P$. martensi.

Platevindex tigrinus is distributed from western India to southern China (Hong Kong). It is one of few onchidiid species which is broadly distributed from the Indian Ocean to the South China Sea. It was not found in Tamil Nadu (southeastern India) during our recent (2016) survey in the mangroves of Pichavaram, but the diversity of mangrove molluscs was very low. Further exploration of southeastern India could reveal whether Platevindex tigrinus is present in low abundance, whether it varies in abundance seasonally, or is simply absent.

Platevindex luteus (Semper, 1880)

Figs 31-35

Onchidium luteum Semper, 1880: pl. 20, fig. 10, pl. 23, figs 2, 6.

Oncis schneideri Hoffmann, 1932: 135-137, fig. 1. Syn. nov.

Onchidium luteum - Semper 1882: 274-275, pl. 21, fig. 6. — Plate 1893: 181.

Oncis lutea - Stantschinsky 1907: 395. - Hoffmann 1928: 89-90.

Platevindex luteus - Dayrat 2009: 5. — Goulding et al. 2018a: 340; 2018b: 12; 2018c: 807. — Dayrat et al. 2019a: 6; 2019b: 38; 2019c: 560; 2019d: 30.

\section{Material examined}

Lectotype (here designated)

SINGAPORE • lectotype (14/11 mm); 1858; Semper leg.; ZMB/Moll 39031a.

Paralectotypes

SINGAPORE • 3 paralectotypes (15/11, 13/11 and 12/12 mm); 1858; Semper leg.; ZMB/Moll 39031b.

\section{Holotype of Oncis schneideri}

PAPUA NEW GUINEA • holotype $(7 / 5 \mathrm{~mm})$ by monotypy; Ostküste von Neu-Pommern [east coast of New Britain]; ZMB/Moll 114152.

\section{Notes on type material}

Onchidium luteum. The lectotype was selected because the male parts are present (although they were previously detached from the specimen). The posterior part of the lectotype is missing and the digestive system is not well preserved. The three paralectotypes were also previously dissected: the internal organs are missing in the two largest ones; the third and smallest paralectotype was cut longitudinally 
in two halves and is largely destroyed. Semper listed five syntypes, suggesting that one of the original syntypes is missing.

Oncis schneideri. The holotype was previously dissected. The penial complex was drawn by Hoffmann and likely destroyed by him (it is missing), and the insertion of the retractor muscle cannot be checked. Some parts of the female (posterior) reproductive system are inside the holotype, but are largely destroyed. The digestive system is largely destroyed; the radula is present but the intestine is missing and the intestinal type cannot be verified.

\section{Other material}

AUSTRALIA - Queensland • 1 spec. (17/14 mm [2551]); Cairns; $16^{\circ} 52.972^{\prime} \mathrm{S}, 145^{\circ} 45.665^{\prime}$ E; 15 Jun. 2013; station 98; Rhizophora, Bruguiera and Ceriops mangrove; MTQ • 1 spec. (22/16 mm [2597]); Magnetic Island; $19^{\circ} 09.733^{\prime} \mathrm{S}, 146^{\circ} 48.625^{\prime} \mathrm{E}$; 24 Jun. 2013; station 108; dead log over pool of water in mangrove; MTQ • 1 spec. (20/14 mm [2678]); Armstrong Beach; 21 2027.129' S, 149¹7.084' E; 5 Jul. 2013; station 120; margins of mangrove and mudflat with Rhizophora and Avicennia; MTQ.

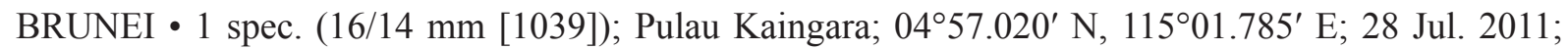
station 33; open mangrove with Rhizophora trees and logs, by the river; BDMNH.

INDONESIA - Sumatra $22 \operatorname{specs}\left(22 / 17 \mathrm{~mm}\right.$ [1792] and 15/7 mm [1789]); Sungai Lubuk; 05 $40.174^{\prime}$ S, $105^{\circ} 34.097^{\prime}$ E; 20 Oct. 2012; station 80; open mangrove with Rhizophora trees, Thalassina mounds and dead logs; UMIZ 00082. - Lombok • 1 spec. (11/9 mm [2958]); Seriwe Bay; 08 ${ }^{\circ} 51.960^{\prime}$ S, $116^{\circ} 32.838^{\prime}$ E; 25 Mar. 2014; station 146; Avicennia mangrove with hard mud and rocks; UMIZ 00094. - Bali • $3 \operatorname{specs}\left(19 / 16 \mathrm{~mm}\right.$ [3046], 18/13 mm [3040] and 14/12 mm [3044]); Denpasar; 08 47.435' S, $115^{\circ} 13.197^{\prime} \mathrm{E}$; 1 Apr. 2014; station 153; large mangrove by road, very soft mud; UMIZ 00095. - Sulawesi 1 spec. (17/14 mm [2335]); Makassar City, Tallo; 0506.117' S, 119²6.777' E; 21 Mar. 2013; station 92; small mangrove with outhouse in center; UMIZ 00191 • 1 spec. (23/16 mm [2364]); same locality as for preceding but 26 Mar. 2013; station 95; small mangrove with outhouse in center; UMIZ 00086. - Ambon - 1 spec. (28/18 mm [2837]); Lateri; 03³8.237' S, 128¹4.783' E; 14 Feb. 2014; station 131; muddy mangrove with Rhizophora; UMIZ 00089 • 1 spec. (17/10 mm [2858]); Lateri; 03³8.261' S, $128^{\circ} 14.716^{\prime} \mathrm{E}$; $16 \mathrm{Feb} .2014$; station 133; low intertidal mangrove, slugs on mangrove trees underneath bark; UMIZ 00188. - Seram - 1 spec. (23/20 mm [2886]); Piru; 0304.072' S, 128 11.362' E; 19 Feb. 2014; station 136; beach of palms and Acrostichum ferns behind Sonneratia mangrove; UMIZ 00189. - Kei Islands • 1 spec. (14/9 mm [2906]); Un; 05³8.273' S, 13245.738' E; 25 Feb. 2014; station 140; in back of mangrove on rocks, mud, inside logs and under leaf litter; UMIZ 00091 2 specs $(18 / 10 \mathrm{~mm}$ [2915] and 17/11 mm [2916]); Un; 05 38.282' S, 132 45.669' E; 26 Feb. 2014; station 141; Bruguiera and Rhizophora mangrove, slugs under the bark; UMIZ $00092 \cdot 1$ spec. (18/12 mm [2922]); Ohoi Ibra; $05^{\circ} 46.216^{\prime} \mathrm{S}, 132^{\circ} 46.116^{\prime} \mathrm{E}$; $27 \mathrm{Feb} .2014$; station 142; some old trees, others replanted, mud very soft; UMIZ 00093. - Ternate - 1 spec. (9/6 mm [5051]); Bastiong; 0046.407' N, 127²2.760' E; 7 Mar. 2015; station 203; small mangrove patch and some rocks nearby a harbor; UMIZ 00097. - Halmahera • 1 spec. (17/12 mm [5022]); Dodinga; 00 51.348' N, 127³8.504' E; 9 Mar. 2015; station 206; back of a mangrove, high intertidal with Acrostichum ferns and mounds of mud; UMIZ $00098 \cdot 1 \mathrm{spec}$. $(17 / 15 \mathrm{~mm}$ [5041]); Saolat; $00^{\circ} 53.435^{\prime}$ N, $127^{\circ} 56.475^{\prime}$ E; 12 Mar. 2015; station 209; open Rhizophora mangrove with soft dark mud, many dead logs; UMIZ 00099. - Timor • 1 spec. (17/12 mm [5939]); Tablolong; $10^{\circ} 18.895^{\prime} \mathrm{S}, 123^{\circ} 28.774^{\prime} \mathrm{E}$; $17 \mathrm{Jul} .2016$; station 255 ; mangrove patch with very dark mud by a village; UMIZ 00190.

NEW CALEDONIA • 1 spec. (9/8 mm [6344]); Upper Diahot River; $20^{\circ} 20.564^{\prime}$ S, $164^{\circ} 21.842^{\prime}$ E; 6 Sep. 2018; Our Planet Reviewed Koumac 2018 expedition leg.; station KM505; lower, wet (and dry) trunks and roots of trees in a forest of Rhizophora apiculata and Xylocarpus granatum with a patchy understory 
of Acrostium fern; MNHN-IM-2019-1474 • 1 spec. (12/8 mm [6361]); Diahot River; 20¹9.435' S, 164¹9.195' E; 8 Sep. 2018; Our Planet Reviewed Koumac 2018 expedition leg.; station KM510; firm sandy mud amongst prop roots in a Rhizophora stylosa forest fringing the river; MNHN-IM-2019-1475 - 1 spec. (15/11 mm [6367]); Hienghene, Hienghene River Bridge; 2041.756' S, $164^{\circ} 56.644^{\prime}$ E; 14 Sep. 2018; Our Planet Reviewed Koumac 2018 expedition leg.; station KM521; edge of Rhizophora apiculta mangrove forest near the high tide mark next to a bridge; MNHN-IM-2019-1476.

PAPUA NEW GUINEA - Madang • 1 spec. (9/8 mm [5429]); Meiro River, near airport; 05 $12.2^{\prime} \mathrm{S}$, 14547.4' E; 5 Nov. 2012; MNHN expedition Papua Niugini leg.; station PM01; Nypa palm swamp; MNHN-IM-2013-10407 • 1 spec. (9/7 mm [5431]); South Dumduman Island; 0500.2' S, $145^{\circ} 47.6^{\prime}$ E; 9 Nov. 2012; MNHN expedition Papua Niugini leg.; station PM12; limestone rocky intertidal; MNHNIM-2013-10409. - New Ireland • 1 spec. (8/5 mm [6101]); Kavieng, Lisinung Island; 02 ${ }^{\circ} 40.6^{\prime} \mathrm{S}$, $150^{\circ} 44.4^{\prime}$ E; 23 Jun. 2014; MNHN expedition Kavieng 2014 leg.; station KM60; platform with seagrass and mangrove; MNHN-IM-2013-55235 • 1 spec. ( $8 / 5 \mathrm{~mm}$ [6102]); same collection data as for preceding; MNHN-IM-2013-55239.

PHILIPPINES - Luzon • 1 spec. (10/9 mm [3198]); Batangas, Calantagan; 1355.319' N, 120³7.260' E; 7 Jul. 2014; station 183; open forest with mix of Avicennia and Rhizophora, sandy and muddy areas; PNM 041242 2 specs (13/10 mm [3224] and 11/7 mm [3225]); Batangas, Calantagan; 13⒌ $53.278^{\prime} \mathrm{N}$, $120^{\circ} 37.124^{\prime}$ E; 8 Jul. 2014; station 184; very narrow forest on the shore, mixed Avicennia and young Rhizophora; PNM 041243. - Bohol - 2 specs (19/14 mm [3281] and 15/8 mm [3280]); Maribojoc; $09^{\circ} 43.806^{\prime} \mathrm{N}, 123^{\circ} 51.234^{\prime} \mathrm{E}$; 15 Jul. 2014; station 192; pier at the beginning of Sabima boardwalk; PNM 041244 • 1 spec. (22/14 mm [3367]); Mabini; 0951.402' N, 124³0.982' E; 18 Jul. 2014; station 195; narrow Rhizophora and Avicennia mangrove by the sea with fish ponds built on landward side, cement ditches between the mangrove patches and the ponds; PNM 041246 • $1 \mathrm{spec}$. (22/12 $\mathrm{mm}$ [3428]); Maribojoc; $09^{\circ} 44.280^{\prime} \mathrm{N}, 123^{\circ} 49.389^{\prime} \mathrm{E}$; $20 \mathrm{Jul} .2014$; station 202; uplifted, dead coral flat covered with sand and algae, near Sonneratia trees; PNM 041248.

SINGAPORE • 1 spec. (14/11 mm [1000]); Mandai; 01²6.237' N, 103²5.730' E; 1 Apr. 2010; station 6; followed river in the mangrove from railroad towards sea; ZRC.MOL.10476 • $1 \mathrm{spec}$. mm (12/8 [997]); Semakao Island; $01^{\circ} 12.083^{\prime} \mathrm{N}, 103^{\circ} 45.585^{\prime} \mathrm{E}$; 3 Apr. 2010; station 8; artificial landfill island with low and very dense newly-planted Rhizophora trees, muddy areas in between Rhizophora patches and coral rubble close to the shore; ZRC.MOL.10477.

VIETNAM • $2 \operatorname{specs}\left(18 / 13 \mathrm{~mm}\right.$ [5668] and 14/11 mm [5613]); Can Gio mangrove forest; $10^{\circ} 24.157^{\prime} \mathrm{N}$, $106^{\circ} 53.950^{\prime}$ E; 19 Jul. 2015; station 233; rocks and gravel on side of Avicennia and Rhizophora mangrove; ITBZC IM 00016.

\section{Description}

Color and morphology of live animals (Fig. 31)

The dorsal notum of live animals may be covered by dry mud (especially when found underneath logs and rocks). The notum is bumpy with prominent, distinctly-raised papillae (with or without dorsal eyes). Individuals are flattened but often become almost hemispherical when disturbed. The dorsal color is typically brown, dark brown or nearly black, and occasionally yellowish-brown. The hyponotum color varies greatly: it may be dark blue, medium grey, white or variants in between. Papillae with dorsal eyes are present, many of which are distinctly raised. The exact number of papillae bearing dorsal eyes is difficult to determine as papillae may be retracted, but is usually between 10 and 22, although up to 35 dorsal eyes have been observed. Papillae bear only one dorsal eye. Dorsal eyes may be distributed across the entire notum or only in the middle but are absent from the margin (eyes are never $<2 \mathrm{~mm}$ from the notum edge). 

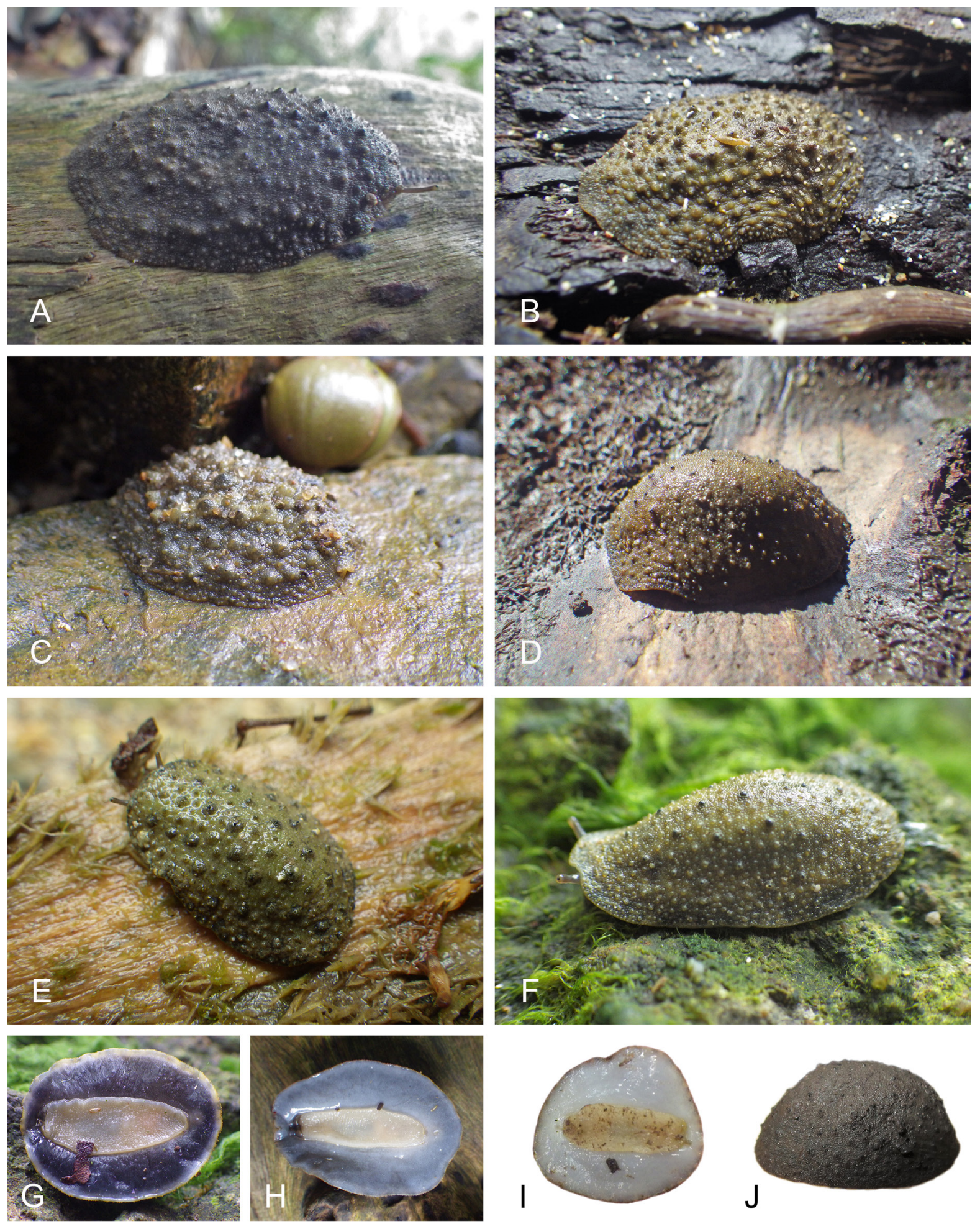

Fig. 31. Platevindex luteus (Semper, 1880), live animals. A. Dorsal view, $28 \mathrm{~mm}$ long [2837], Indonesia, Ambon (UMIZ 00089). B. Dorsal view, $17 \mathrm{~mm}$ long [2880], Indonesia, Seram (UMIZ 00090). C. Dorsal view, $14 \mathrm{~mm}$ long [5613], Vietnam, Can Gio (ITBZC IM 00016). D. Dorsal view, $18 \mathrm{~mm}$ long [3040], Indonesia, Bali (UMIZ 00095). E. Dorsal view, $22 \mathrm{~mm}$ long [3367], Philippines, Bohol (PNM 041246). F. Dorsal view, $15 \mathrm{~mm}$ long [3280], Philippines, Bohol (PNM 041244). G. Ventral view, $19 \mathrm{~mm}$ long [3281], Philippines, Bohol (PNM 041244). H. Ventral view, same as A. I. Ventral view, $17 \mathrm{~mm}$ long [5939], Indonesia, Timor. J. Ventral view, 17 mm long [5041], Indonesia, Halmahera (UMIZ 00099). 
Digestive system (Figs 1B, 1D, 2E, 32, 33A-E)

Radulae measure up to $3.7 \mathrm{~mm}$ in length. Examples of radular formulae are presented in Table 5. The intestinal loops are of type I, with a transitional loop oriented between 3 and 6 o'clock, and of type II, with a transitional loop oriented between 6 and 8 o'clock (Figs 1B, 1D, 2E, 32).

\section{Reproductive system (Figs 33F, 34)}

In the posterior part of the reproductive system, the oviduct is approximately twice as wide as the deferent duct. Its distal section (distal to the spermatheca) is shorter or equal to its proximal section. The deferent duct is not attached or only loosely attached to the oviduct, and generally loosely coiled (not with many tight, U-shaped loops), but individuals with a highly-coiled deferent duct exceptionally do exist. The position of the female pore varies from very close to the anus $(<1 \mathrm{~mm})$ up to $3 \mathrm{~mm}$ away from the anus. The flexible region of the penis with hooks is approximately 1 to $1.5 \mathrm{~mm}$ long. Penial hooks are large, approximately 45 to $90 \mu \mathrm{m}$ long, but between 20 to $60 \mu \mathrm{m}$ long in smaller individuals from Mauritius. The penial hooks can be seen inside the semi-transparent penis. The posterior retractor muscle inserts near the heart on the right side of the visceral cavity. Its length varies from being half the length of the penial sheath to three times as long. The deferent duct is not particularly long or convoluted, displaying only a few loose loops (it is even less convoluted in immature specimens).

\section{Distinctive diagnostic features (Table 4)}

The yellow foot of Platevindex luteus easily distinguishes it from P. martensi (black foot) and P. aptei sp. nov. (orange foot). However, its hyponotum color is highly variable and does not help distinguish it from other species of Platevindex with a blue or grey hyponotum (e.g., P. coriaceus, P. burnupi

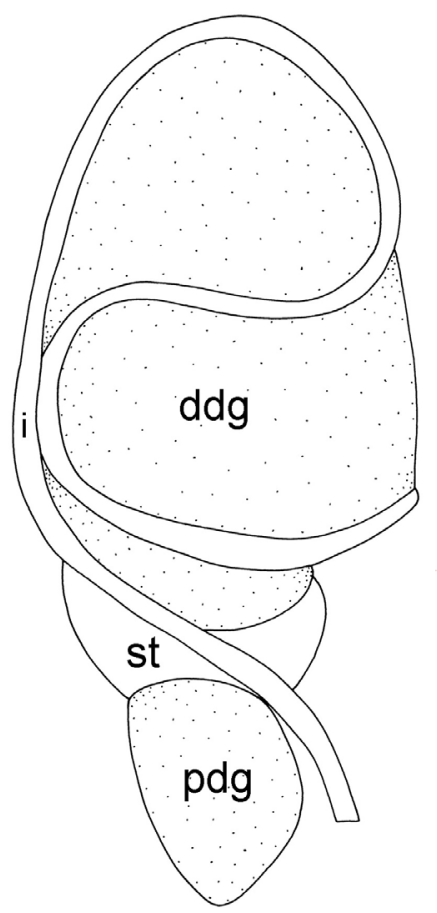

A

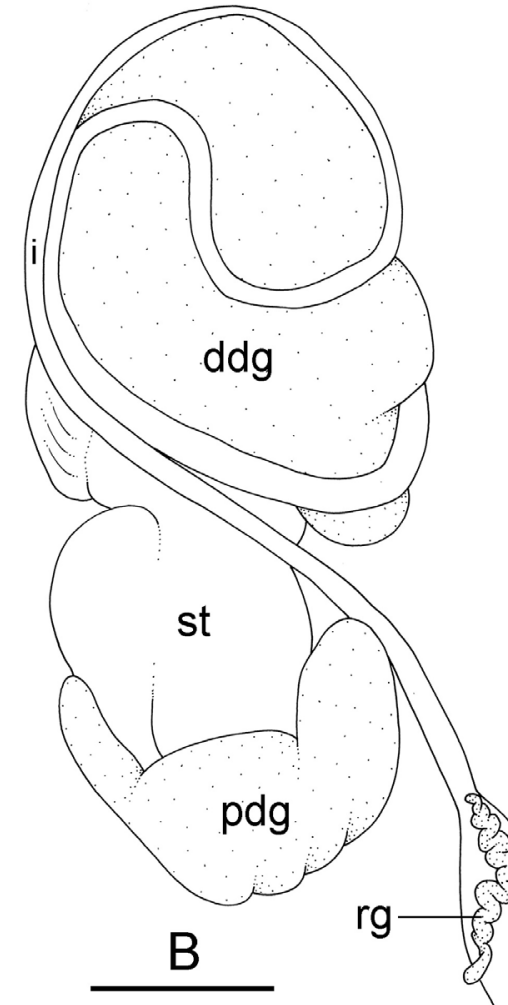

$\mathrm{B}$

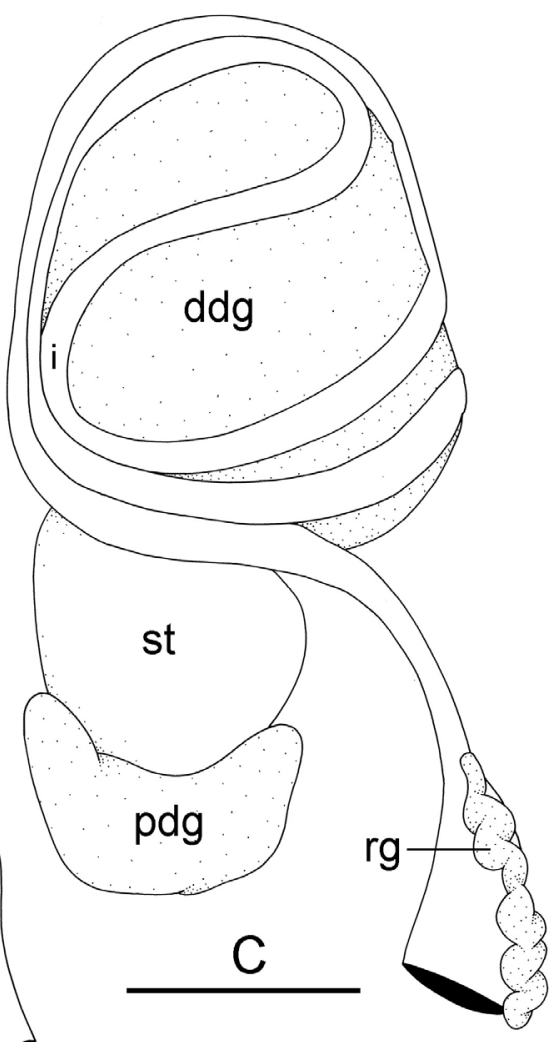

Fig. 32. Platevindex luteus (Semper, 1880), digestive system, dorsal view. A. Type I, with a transitional loop oriented at 3 o'clock, Vietnam [5613] (ITBZC IM 00016). B. Type I (or type II), with a transitional loop oriented at 6 o'clock, Ambon, Indonesia [2837] (UMIZ 00089). C. Type II, with a transitional loop oriented at 8 o'clock, Bohol, Philippines [3367] (PNM 041246). Scale bars $=3 \mathrm{~mm}$. 
and P. applanatus). Live individuals can be more hemispherical (especially when contracted) than in other species, but flattened individuals can easily be mistaken for small individuals of other species of Platevindex. Platevindex luteus reaches a smaller maximum size than other species with a similar ventral color, but the size range of all these species overlaps and cannot be used for identification. Finally, the notum of $P$. luteus bears prominent dorsal papillae, which are especially obvious when the animal is contracted, but these dorsal papillae are also present in P. applanatus and are thus not strictly diagnostic of $P$. luteus. The notum of $P$. burnupi is granular (i.e., not smooth), but does not bear prominent papillae, whether animals are disturbed or not.
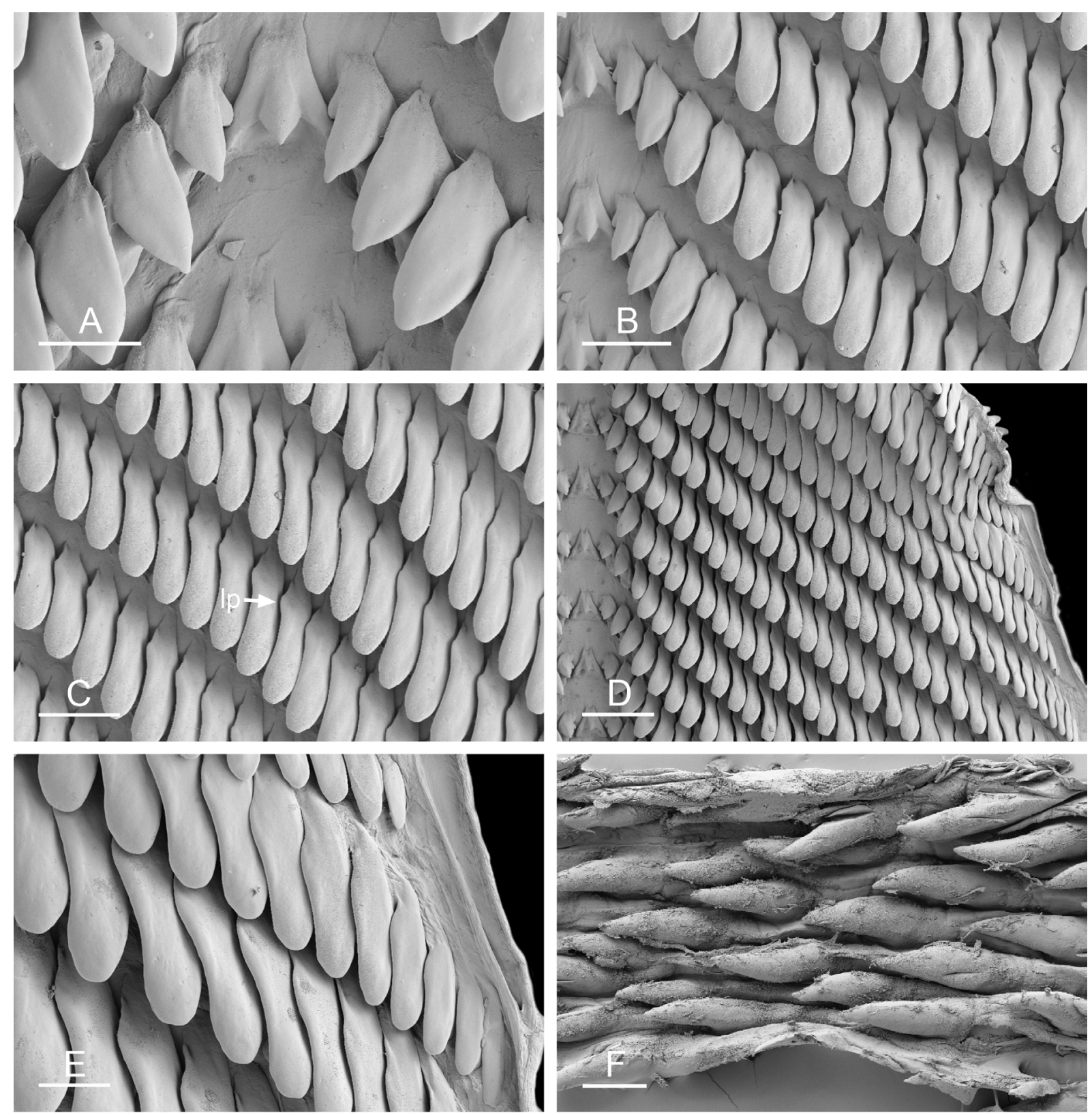

Fig. 33. Platevindex luteus (Semper, 1880). A-E. Radula. A. Rachidian and innermost lateral teeth, Philippines, Bohol [3367] (PNM 041246). B. Lateral teeth with rachidian teeth, same as A. C. Lateral teeth, same as A. D. Outermost lateral teeth, Indonesia, Ambon [2837] (UMIZ 00089). E. Outermost lateral teeth, same as D. F. Penial hooks, same specimen as D. Abbreviation: $1 \mathrm{p}=$ lateral protuberance. Scale bars: A, E-F=30 $\mu \mathrm{m} ; \mathrm{B}-\mathrm{C}=50 \mu \mathrm{m} ; \mathrm{D}=100 \mu \mathrm{m}$. 
Internally, intestinal loops help to distinguish $P$. luteus from $P$. applanatus, $P$. amboinae and $P$. latus (Table 4). The latter two species share intestinal loops of type III, while the intestine of $P$. luteus is of type I or II. Further, even though the intestinal loops of $P$. applanatus are also of type I, their transitional loop is oriented between 1 and 2 o'clock, while the transitional loop of individuals of $P$. luteus with a type I is oriented between 3 and 6 o'clock. Platevindex slugs with similar intestinal loops of type II can be distinguished by other means, especially the length of the region of the penis with penial hooks: P. luteus (approximately $1 \mathrm{~mm}), P$. coriaceus $(2-8 \mathrm{~mm}), P$. martensi $(2-2.5 \mathrm{~mm})$ and $P$. aptei $\mathrm{sp}$. nov. $(2.5-5 \mathrm{~mm})$. Note that $P$. amboinae and $P$. latus, which both completely lack penial hooks, also differ from $P$. luteus in that respect. In the posterior reproductive system, the deferent duct is short, usually loosely coiled and only loosely attached to the oviduct, which helps to differentiate $P$. luteus from $P$. coriaceus and $P$. tigrinus, in which the deferent duct is tightly coiled and attached to the oviduct. The insertion of the retractor muscle of the penis near the heart in $P$. luteus also clearly distinguishes it from $P$. coriaceus and $P$. aptei sp. nov., in which it inserts at the posterior end of the visceral cavity.

Finally, individuals of $P$. luteus with intestinal loops of type I can also be distinguished from P. burnupi (intestinal loops of type II) but individuals of $P$. luteus with intestinal loops of type II cannot. However, $P$. burnupi and $P$. luteus do not overlap geographically, and can be reliably distinguished using both mitochondrial and nuclear DNA sequences.

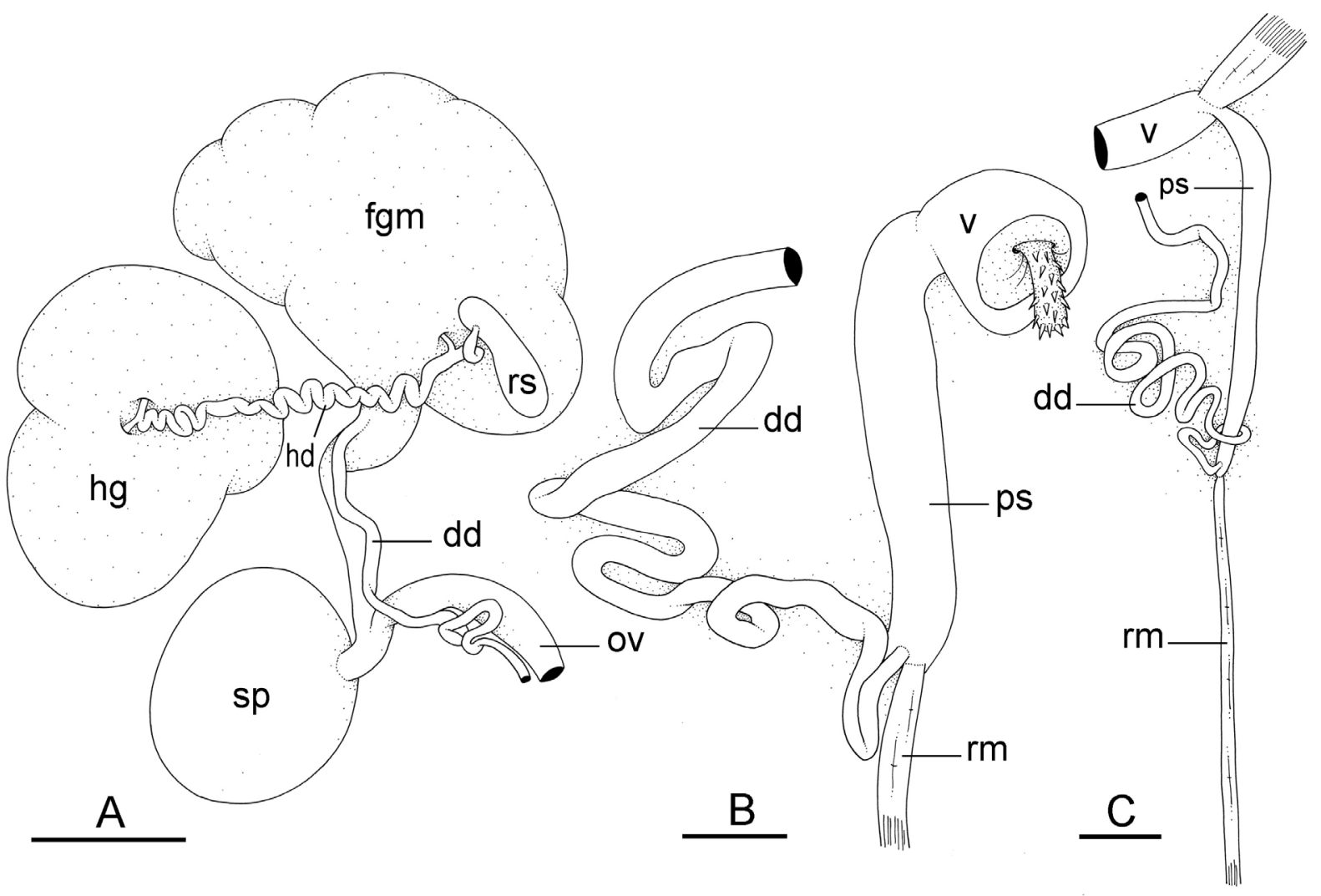

Fig. 34. Platevindex luteus (Semper, 1880), reproductive system. A. Posterior reproductive system, Ambon, Indonesia [2837] (UMIZ 00089). B. Anterior, male copulatory apparatus (ZMB/Moll 39031a). C. Anterior, male copulatory apparatus, same as A. Abbreviations: $\mathrm{dd}=$ deferent duct; fgm $=$ female gland mass; hd = hermaphroditic duct; hg = hermaphroditic gland; ov = oviduct; $\mathrm{ps}=$ penial sheath; $\mathrm{rm}=$ retractor muscle; $\mathrm{rs}=$ receptaculum seminis; $\mathrm{sp}=$ spermatheca; $\mathrm{v}=$ vestibule. Scale bars: $\mathrm{A}=2 \mathrm{~mm}$; $\mathrm{B}-\mathrm{C}=1 \mathrm{~mm}$. 


\section{Distribution (Fig. 10A)}

Australia: Queensland. Brunei. Indonesia: Ambon, Bali, Halmahera, Kei Islands, Lombok, Seram, Sulawesi, Sumatra, Ternate and Timor. Papua New Guinea: New Britain (type locality of $O$. schneideri), New Ireland and Madang. Philippines: Bohol and Luzon. Singapore (type locality of O. luteum and newly-collected material). Vietnam. All records are new, except for the type localities.

\section{Habitat (Fig. 31)}

Platevindex luteus is found both within mangroves and at mangrove margins. It is typically found on dead logs or tree trunks and, occasionally, on tree roots or under the loose bark of dead logs. In Timor, some individuals were found on pieces of wood and other plant material, but also on very dark mud (individuals were found directly on mud nowhere else).

\section{Remarks}

The publication dates of the different sections of Semper's Landmollusken in the Reisen im Archipel der Philippinen series were clarified by Johnson (1969). Because Onchidium luteum was published before 1931, ICZN Article 12.2.7 applies: Onchidium luteum was made available in 1880 because Semper's figures (pl. 20, fig. 10, pl. 23, figs 2,6) are regarded as an indication accompanying it, although the text of the description was not published until 1882.

The species treated here is common and broadly distributed in the Indo-West Pacific, and so many original descriptions had to be reviewed and many type specimens examined in order to determine which existing names apply to it. The lectotype of Onchidium luteum displays all the distinctive characteristics of a species of Platevindex: flattened shape, narrow foot and no accessory penial gland. Also, its male opening is slightly to the right of the midline between the oral tentacles, which agrees with Semper's (1882: 275) description and is perfectly compatible with Platevindex. Two main features indicate that the lectotype of $O$. luteum belongs to the species described here: the dorsal papillae on its notum as well as its penial anatomy, which is identical to what was observed in fresh material (Fig. 31C). Based on their dorsal notum (which also bears dorsal papillae) and Semper's description (1882: 275) of the internal anatomy, it is very likely that the paralectotypes also are part of the species described here. In particular, Semper described a short penis with a distal, flexible, hook-bearing region scarcely $1 \mathrm{~mm}$ long and a retractor muscle that inserts by the heart. Semper also described 16-25 dorsal eyes and noted that the dorsal eyes never reach the edge of the dorsal notum, which is in agreement with our observations and with all species of Platevindex in clade C (see Fig. 4).

Semper (1882) did not mention or illustrate the type of intestinal loops in the original description of Onchidium luteum, and it could not be checked for the present study because the intestine of the lectotype is not well preserved (and that of the paralectotypes could not be checked either). However, Plate (1893: 181) examined two of the former syntypes and indicated that intestinal loops are of type II, which is compatible with our observations on freshly-collected samples from Singapore.

The intraspecific variation in the type of intestinal loops observed in Platevindex luteus (type I, type II and intermediary between types I and II) is very unusual. Nearly all onchidiid species are characterized by only one type of intestinal loops. Another known exception is Alionchis jailoloensis characterized by intestinal loops of both types II and III (Goulding et al. 2018a; Dayrat et al. 2019c). The dissection of individuals for which the species identification was confirmed through DNA sequences allowed us to determine that intestinal types vary between individuals of $P$. luteus even at the exact same localities.

Platevindex schneideri was described by Hoffmann (1932: 135-137), as Oncis schneideri, from New Britain, Papua New Guinea, as a flat animal with a rectal gland, no accessory penial gland and a male pore to the left of the right eye tentacle. Combined, these features indicate that Hoffmann was correct in 

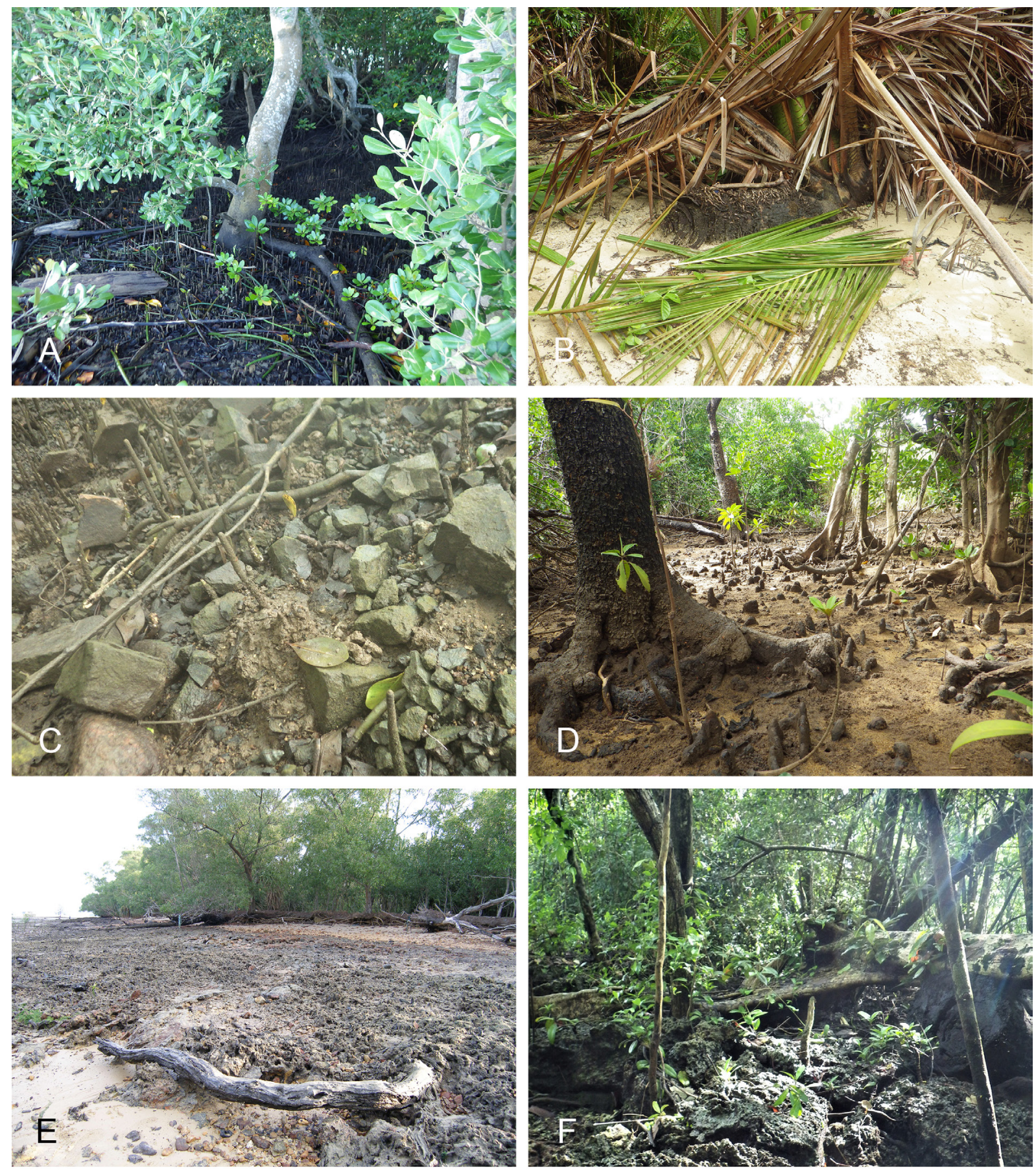

Fig. 35. Habitats of Platevindex luteus (Semper, 1880). A. Philippines, Bohol, narrow mangrove on the edge of fish ponds, tall Rhizophora and Avicennia, many dead logs (station 194). B. Indonesia, Seram, palms and Acrostichum ferns behind a Sonneratia mangrove (station 136). C. Vietnam, Can Gio mangrove forest, Avicennia and Rhizophora with rocks and gravel on side of mangrove (station 233). D. Australia, Queensland, mangrove by creek with sandy mud (station 104). E. Singapore, Semakao Island, landfill island with newly planted mangrove, very dense (station 8). F. Indonesia, Kei Islands, very soft mud with some older trees and some replanted (station 142). 
describing the species in Plate's genus Oncis (now Platevindex). Hoffmann (1932: 135) also described strong dorsal papillae (which he called 'Tuberkeln', or tubercles), a characteristic of P. luteus. The male parts of the holotype, now missing, were described and illustrated by Hoffmann (1932: 136), and the insertion of the retractor muscle at the level of the pericardium is compatible with $P$. luteus. The intestinal loops were described as of type II, which is compatible with the variation observed in $P$. luteus, but not with the sympatric species $P$. applanatus (in which intestinal loops are only of type I). For all the reasons above, Platevindex schneideri is regarded as a junior synonym of $P$. luteus.

Hoffmann (1932: 136) suggested that Platevindex schneideri might be a synonym of P. amboinae or $P$. granulosa (all as species of Oncis), but $P$. granulosa is a nomen dubium (see our species remarks on P. latus). However, since Hoffmann (1928: 36) considered Platevindex latus a synonym of P. granulosa, we can consider his comments on P. schneideri (Hoffmann 1932: 136) refer, in his mind, to P. amboinae and $P$. latus. Hoffmann's (1932: 136) description of $P$. schneideri includes penial hooks, which are not found in either P. amboinae or P. latus (Table 4). Hoffmann did not describe the dorsal eyes on the back of $O$. schneideri, but there are at least 18 eyes (one eye per papilla) on the dorsal notum of the holotype. The presence of dorsal eyes also precludes $P$. schneideri from being a synonym of $P$. amboinae or P. latus, which both lack dorsal eyes (Table 4).

Hoffmann (1932: 135) noted a similarity between Platevindex schneideri and P. semperi (Plate, 1893), but concluded that they could not refer to the same species because their intestinal loops differed (type II in the holotype of P. schneideri and type I in P. semperi according to Plate's original description). However, as mentioned above, $P$. luteus is an exception regarding intestinal loops, and both $P$. schneideri and $P$. semperi are compatible with the intraspecific variation in intestinal loops within $P$. luteus.

Plate's (1893) description of Oncis semperi, based on two syntypes (22/18 and 22/18 mm) from Mindanao (ZMB/Moll 45661), is only compatible with P. coriaceus, and Platevindex semperi is thus regarded as a junior synonym of $P$. coriaceus. The description of intestinal loops of type I suggests that one of the two syntypes could belong to $P$. luteus instead of $P$. coriaceus, but this is most likely simply a mistake (see our remarks on $P$. coriaceus).

Britton (1984) described Platevindex mortoni from Hong Kong based on four specimens with different intestinal types: two specimens (including the holotype) with intestinal loops of type I, one with intestinal loops of type II and one with intestinal loops of an intermediate type between types I and II. Only the latter could be checked here because the digestive system is missing in all other types (see our remarks on P. tigrinus for a detailed description of the type material of $P$. mortoni). If Britton was correct that the intestinal loops of the holotype of $P$. mortoni were of type I, then P. mortoni would be incompatible with $P$. tigrinus, $P$. coriaceus or $P$. martensi (which are all characterized by a digestive system of type II), and the holotype of $P$. mortoni could be part of $P$. luteus. However, it is unclear whether Britton's description of the intestinal loops of the holotype is correct (see our remarks on P. tigrinus for additional discussion of the status of $P$. mortoni). Also, P. luteus is not represented in the genetic sequences published by Sun et al. (2014) or other sequences available in GenBank from China. If $P$. luteus is later found in Hong Kong, then the name $P$. mortoni could be discussed as a possible synonym of $P$. luteus. For now, however, $P$. mortoni is regarded as a nomen dubium.

Von Martens (1897: 127) indicated that Onchidium luteum was found in "Celebes Djenemaedja bei Luwu" [Djenemaedja by Luwu, Sulawesi, Indonesia] by M. Weber, but did not provide any details with respect to identification. Hoffmann (1928: 89-90) noted that it was impossible to determine whether the specimens von Martens examined from Sulawesi were $O$. luteum, since only the external appearance was described. 
In a study focusing on the relative abundance of onchidiids across a Malaysian mangrove forest, Sabri \& Singh (2018) mentioned P. luteus from Selangor, western Peninsular Malaysia. Based on the small picture provided and the absence of any additional details regarding ventral coloration, anatomy or DNA sequences, it is unclear whether this identification is correct. We did not find $P$. luteus at any of the localities we visited in western Peninsular Malaysia. Thus, the presence of $P$. luteus in Selangor is regarded here as hypothetical.

Platevindex luteus is not a new combination because it was already used in our recent studies (Dayrat 2009: 5; Goulding et al. 2018a, 2018b, 2018c; Dayrat et al. 2019a, 2019b, 2019c, 2019d), even though the classification in Platevindex is demonstrated here for the first time. Note that Stantschinsky (1907: 395) and Hoffmann (1928: 89) had already moved Onchidium luteus to Plate's genus Oncis, based on information from the original description (Semper 1882).

Platevindex applanatus (Simroth, 1920) comb. nov.

Figs $36-45$

Onchidium applanatum Simroth, 1920: 294, pl. 20, figs 40-42.

\section{Material examined}

Holotype

INDONESIA - holotype (15/12 mm), by monotypy; Aru Inseln, Strand von Manumbai, Kobroor [Manumbai Beach, Kobroor Island, Aru Islands, Moluccas, Indonesia]; 13 Mar. 1908; H. Merton leg.; ZMB/Moll 104630.

\section{Notes on type material}

The notum of the holotype was cut open for the present study to check internal characters; all organs remain in the specimen.

\section{Other material}

INDONESIA - Ambon - 1 spec. (15/12 [2736] mm); Pulau Haruku; 0336.520' S, $128^{\circ} 25.068^{\prime}$ E; 11 Feb. 2014; station 127; dead log high on beach above rocky Sonneratia mangrove; UMIZ 00100 • 4 specs (22/15 [2754], 18/14 [2755], 18/14 [2757] and 15/12 [2750] mm); Passo; 03 ${ }^{\circ} 37.080^{\prime} \mathrm{S}$, $128^{\circ} 16.068^{\prime}$ E; 13 Feb. 2014; station 129; logs on rocky beach with coral rubble; UMIZ 00101. - Seram • 2 specs (24/20 [2877] and 17/11 [2880] mm); Piru; 0304.072' S, $128^{\circ} 11.362^{\prime}$ E; 19 Feb. 2014; station 136; beach of palms and Acrostichum ferns behind Sonneratia mangrove; UMIZ 00090. - Kei Islands • 6 specs (21/14 [2892], 17/11 [3563], 16/10 [2893], 16/10 [2895], 13/6 [2894] and 12/9 [2900] mm); Un; $05^{\circ} 38.273^{\prime}$ S, $132^{\circ} 45.738^{\prime}$ E; 23 Feb. 2014; station 137; Bruguiera and Rhizophora mangrove with coral rubble and thin layer of mud; UMIZ $00102 \cdot 1$ spec. (15/9 [2904] mm); Un; 05 $38.273^{\prime} \mathrm{S}, 132^{\circ} 45.738^{\prime} \mathrm{E}$; 25 Feb. 2015; station 140; back of mangrove with rocks, mud, dead logs, and leaf litter; UMIZ 00103 • 1 spec. (5/4 [2925] mm); Fiditan; 05 35 .957' S, 132 $45.112^{\prime}$ E; 28 Feb. 2014; station 144; rocks with mat of algae behind dense Rhizophora mangrove; UMIZ 00104. - Sulawesi - 1 spec. (17/11 [2160] $\mathrm{mm}$ ); Bahoi; $01^{\circ} 43.355^{\prime} \mathrm{N}, 125^{\circ} 01.232^{\prime} \mathrm{E}$; 10 Mar. 2013; station 85; sand, rocks and pieces of wood outside a mangrove; UMIZ 00083.

MAURITIUS • 1 spec. (7/4 [3604] mm); Pointe Maurice; 20¹5.447' S, 5747.670' E; 8 Jun. 2014; station 174; Rhizophora mangrove with very dark mud, slug under piece of wood; MNHN-IM-2019-1392 • 1 spec. (9/7 [3152] mm); Mahebourg; 20²5.059' S, 57²42.680' E; 10 Jun. 2014; station 176; mangrove with dark brown mud, slugs on rotting petiole of palm frond; MNHN-IM-2019-1393 • 1 spec. (7/5 [3442] mm); same collection data as for preceding; MNHN-IM-2019-1394. 

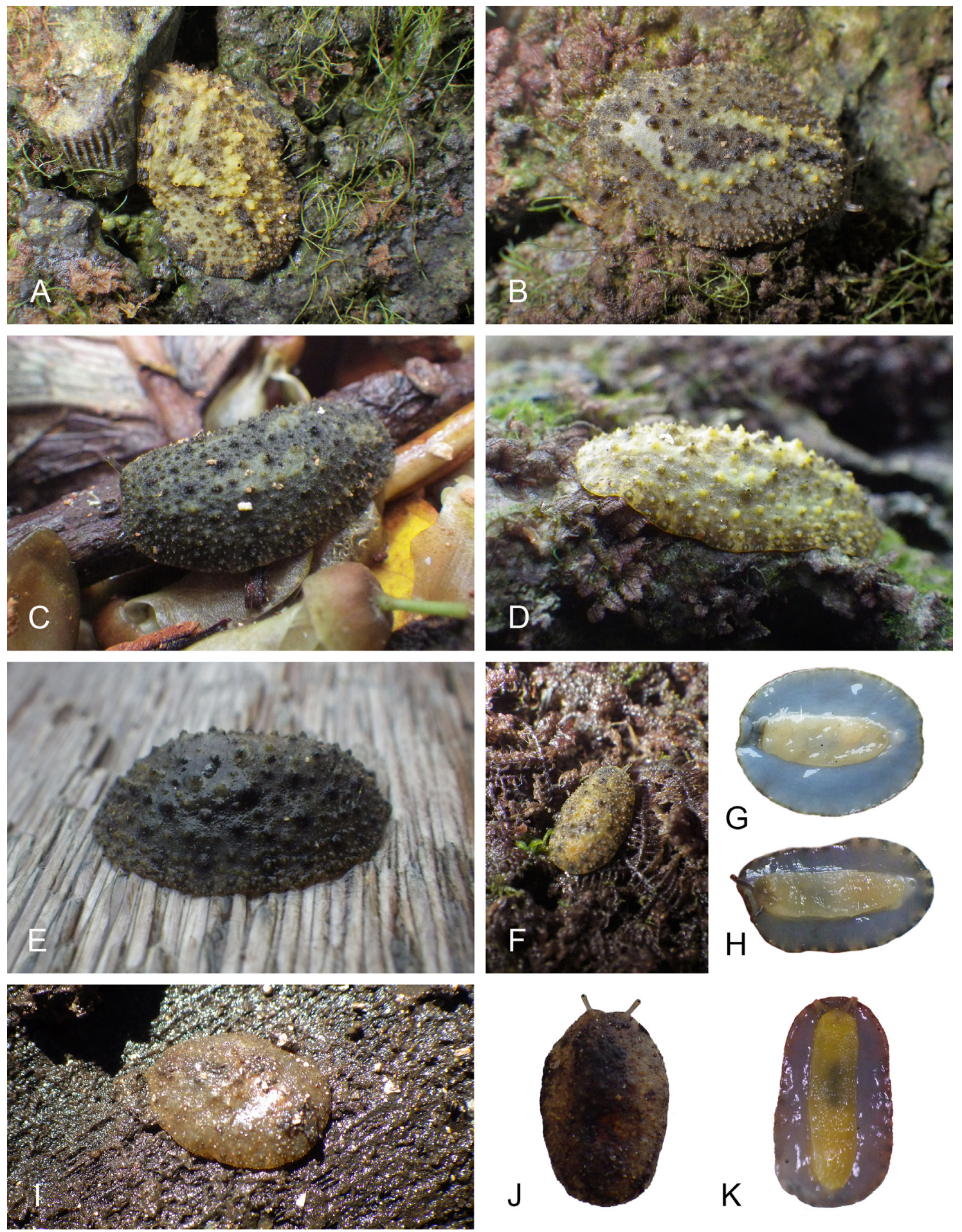

Fig. 36. Platevindex applanatus (Simroth, 1920) comb. nov., live animals. A. Dorsal view, $16 \mathrm{~mm}$ long [2893], Indonesia, Kei Islands (UMIZ 00102). B. Dorsal view, $16 \mathrm{~mm}$ long [2895], Indonesia, Kei Islands (UMIZ 00102). C. Dorsal view, 15 mm long [2904], Indonesia, Kei Islands (UMIZ 00103). D. Dorsal view, $16 \mathrm{~mm}$ long [3563], Indonesia, Kei Islands (UMIZ 00102). E. Dorsal view, $18 \mathrm{~mm}$ long [2757], Indonesia, Ambon (UMIZ 00101). F. Dorsal view, $5 \mathrm{~mm}$ long [2925], Indonesia, Kei Islands (UMIZ 00104). G. Ventral view, same as E. H. Ventral view, $12 \mathrm{~mm}$ long [2900], Indonesia, Kei Islands (UMIZ 00102). I. Dorsal view, 9 mm long [3152], Mauritius (MNHN-IM-2019-1393). J. Same as I. K. Ventral view, same as I. 
PAPUA NEW GUINEA - Madang • $1 \mathrm{spec} .(14 / 11$ [5437] mm); South Dumduman Island; 0500.2' S, 1454․ 6' E; 9 Nov. 2012; MNHN expedition Papua Niugini leg.; station PM12; limestone rocky intertidal; MNHN-IM-2013-12493 • 1 spec. (16/16 [5424] mm); Hargun Island; $05^{\circ} 01.6^{\prime} \mathrm{S}, 145^{\circ} 47.9^{\prime} \mathrm{E} ; 15,20$ Nov. 2012; MNHN expedition Papua Niugini leg.; station PM24; night tide; MNHN-IM-2013-14043 • 1 spec. (13/11 [5450] mm); same collection data as for preceding; MNHN-IM-2013-14051 - 1 spec. $(18 / 15$ [5420] mm); same collection data as for preceding; MNHN-IM-2013-13765 • 1 spec. (13/11 [5457] mm); Wonad Island; $05^{\circ} 08.1^{\prime} \mathrm{S}, 145^{\circ} 49.3^{\prime}$ E; 27 Nov. 2012, 9 Dec. 2012; MNHN expedition Papua Niugini leg.; station PM41; sandy beach and intertidal rocks; MNHN-IM-2013-15867 • 1 spec. (13/10 [5462] mm); Tab Island; $05^{\circ} 10.2^{\prime} \mathrm{S}, 145^{\circ} 50.4^{\prime} \mathrm{E}$; 28 Nov. 2012; MNHN expedition Papua Niugini leg.; station PM42; night tide, sandy beach and intertidal rocks; MNHN-IM-2013-15908. - New Ireland • 1 spec. (7/4 [6094] mm); Povalval, E coast of New Ireland; 02²4' S, 150 $57^{\circ}$ E; 11-13 Jun. 2014; MNHN expedition Kavieng 2014 leg.; station KM05; mixed hard platform and seagrass bed at outlet of rivulet; MNHN-IM-2013-53534 • 1 spec. (8/6 [6096] mm); Cape Jesehke, Manne Island; 02 $43.1^{\prime}$ S, $150^{\circ} 37.8^{\prime}$ E; 15, 26 Jun. 2014; MNHN expedition Kavieng 2014 leg.; station KM32; Rhizophora mangrove; MNHN-IM-2013-54161 1 spec. $(10 / 7$ [6097] mm); same collection data as for preceding; MNHN-IM-2013-54163 • 1 spec. (8/6 [6098] mm); same collection data as for preceding; MNHNIM-2013-54164.

VANUATU • 1 spec. (12/11 [5491] mm); Santo Rose Point; 15³4.9’ S, 16702.4' E; 10 Sep. 2006; MNHN expedition Santo 2006 leg.; station VM02; intertidal, coral sand; MNHN-IM-2013-62402 • 1 spec. (9/8 [5493] mm); same collection data as for preceding; MNHN-IM-2013-62404.
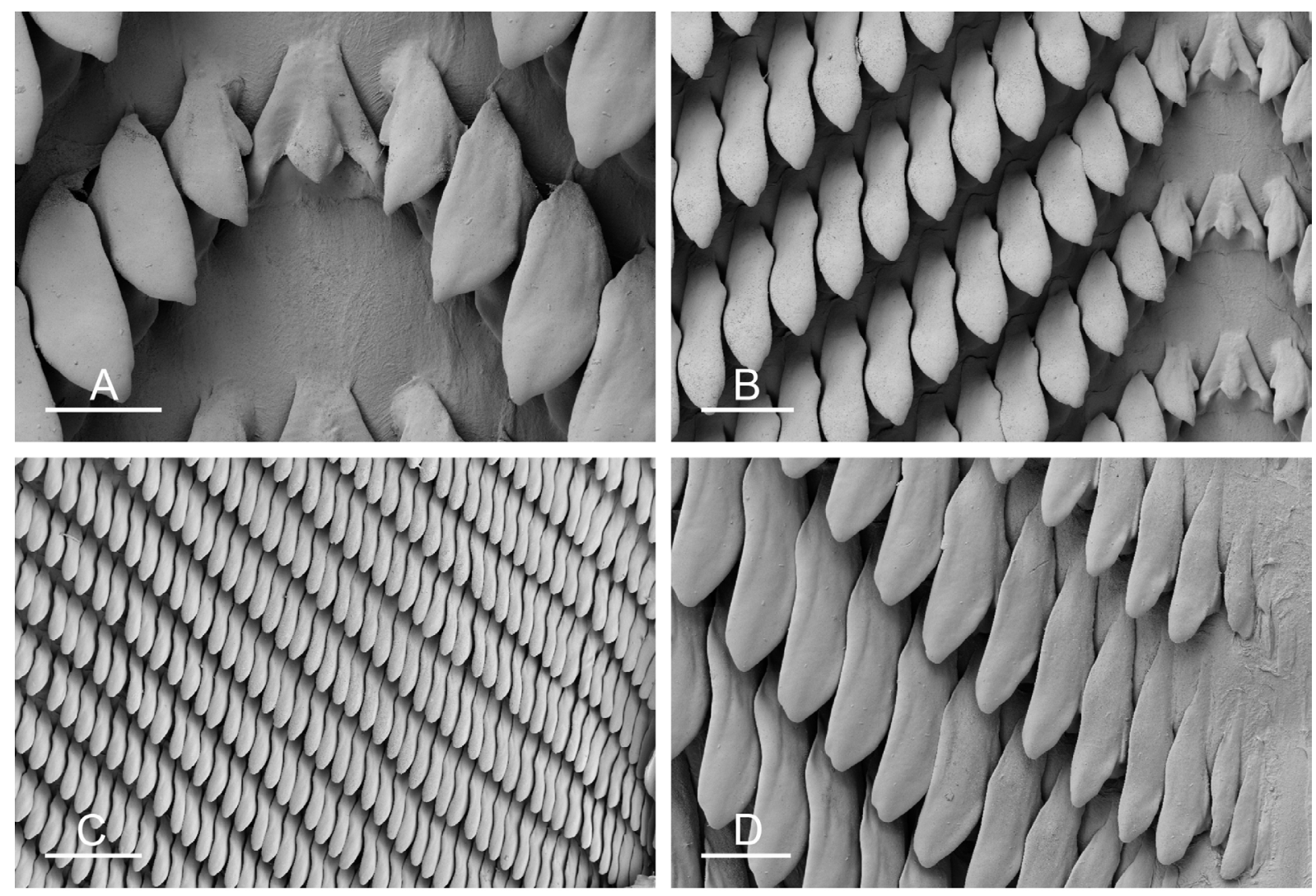

Fig. 37. Platevindex applanatus (Simroth, 1920) comb. nov., radula, Indonesia, Ambon. A. Rachidian and innermost lateral teeth [2754] (UMIZ 00101). B. lateral teeth with rachidian teeth, same as A. C. Lateral teeth [2755] (UMIZ 00101). D. Outermost lateral teeth, same as A. Scale bars: A, D = $30 \mu \mathrm{m}$; $\mathrm{B}=50 \mu \mathrm{m} ; \mathrm{C}=100 \mu \mathrm{m}$. 


\section{Description}

Color and morphology of live animals (Fig. 36)

Live animals are not covered with mud and their natural color can be seen without washing. The notum is bumpy with prominent, distinctly-raised papillae (with or without dorsal eyes). Live animals may become nearly hemispherical when disturbed. The dorsal color is variable although it is typically brown with yellow longitudinal (irregular) lines. Slugs with an entirely dark brown notum or a light beige notum also occur. The hyponotum is light grey and almost translucent in small specimens. The margin of the hyponotum is frequently translucent with the brown color of the notum showing through. The foot is light yellow.

Papillae with dorsal eyes are present. Their exact number is difficult to determine, as they are often retracted, but ranges approximately from 4 to 26, except in the case of very small specimens, in which as few as 2 dorsal eyes have been observed. Each papilla bears one dorsal eye. Dorsal eyes may be distributed across the notum or only present in the middle but are always absent on the margin (i.e., eyes are never $<2 \mathrm{~mm}$ from the notum edge).

Digestive system (Figs 1C, 37-40)

Radulae measure up to $4.3 \mathrm{~mm}$ in length. Examples of radular formulae are presented in Table 5. Due to the high genetic divergence (in COI sequences) between populations of $P$. applanatus, radulae are figured from Indonesia, Mauritius and Papua New Guinea (Figs 37-39). Intestinal loops are of type I, with a transitional loop oriented between 1 and 2 o'clock (Figs 1C, 40A-C).
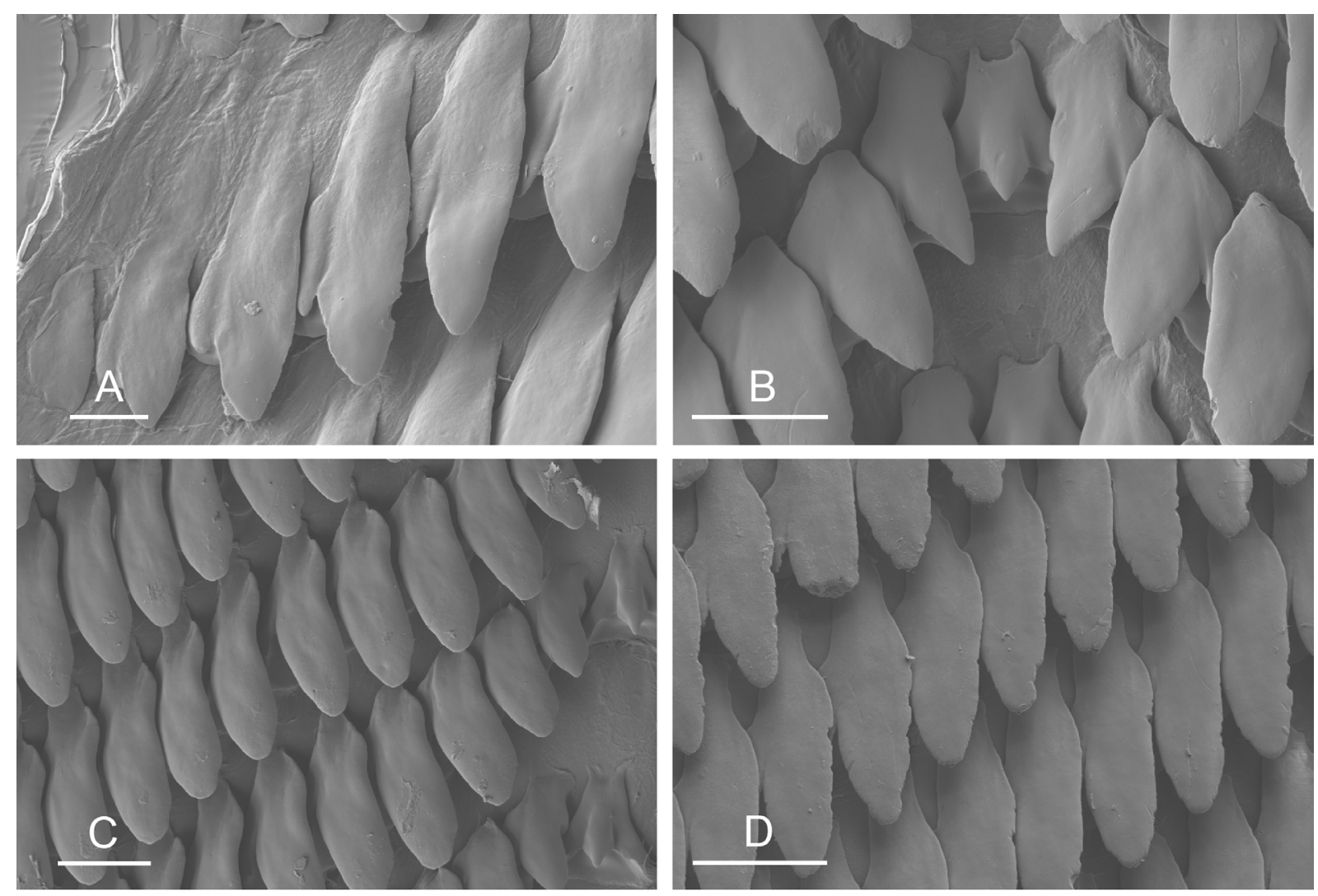

Fig. 38. Platevindex applanatus (Simroth, 1920) comb. nov., radula, Mauritius. A. Left, outermost, lateral teeth [3604] (MNHN-IM-2019-1392). B. Rachidian tooth and innermost lateral teeth, same as A. C. Rachidian tooth and left, innermost lateral teeth [3152] (MNHN-IM-2019-1393). D. Right, lateral teeth [3442] (MNHN-IM-2019-1394). Scale bars: A = $10 \mu \mathrm{m} ; \mathrm{B}-\mathrm{D}=20 \mu \mathrm{m}$. 


\section{Reproductive system (Figs 41-44)}

In the posterior part of the reproductive system, the oviduct is wider than the deferent duct (up to twice as wide). Its distal section (distal to the spermatheca) is slightly longer than its proximal section (up to two or three times as wide) or equal to it in length. The deferent duct is longer than the oviduct, loosely attached to it, and varies from slightly convoluted with a few loose loops to tightly coiled with U-shaped loops (Fig. 41). The position of the female pore varies from being adjacent to the anus to $4 \mathrm{~mm}$ away from it in large specimens. The flexible, distal region of the penis with hooks measures approximately 1.5 to $3 \mathrm{~mm}$ in length. In eastern Indonesia, the distal region is 2 to $3 \mathrm{~mm}$ long, while in Mauritius and Papua New Guinea it is approximately 1.5 to $2 \mathrm{~mm}$ long. The penial hooks are large and can be seen inside the semi-transparent penis. They are usually 45 to $90 \mu \mathrm{m}$ long (Figs 43, 44A), but between 20 to $60 \mu \mathrm{m}$ in smaller specimens from Mauritius (Fig. 44B-C). The insertion of the penial retractor muscle varies. It inserts at the posterior end of the visceral cavity in specimens from eastern Indonesia, except in a few specimens in which it inserts approximately $2 / 3$ down the length of the visceral cavity. It inserts approximately halfway to $2 / 3$ down the length of the visceral cavity in specimens from Papua New Guinea (and near the posterior end of the visceral cavity in one specimen). In Mauritius, it inserts at the posterior end of the visceral cavity in the largest specimen, and by the heart halfway down the visceral cavity in a smaller specimen. The length of the retractor muscle varies from much shorter than the penial sheath $(1 / 5$ to $1 / 3$ of its length) to as long as the penial sheath. The deferent duct is not particularly long and is only loosely convoluted (Fig. 42). It may even be nearly straight in immature specimens (Fig. 42C).
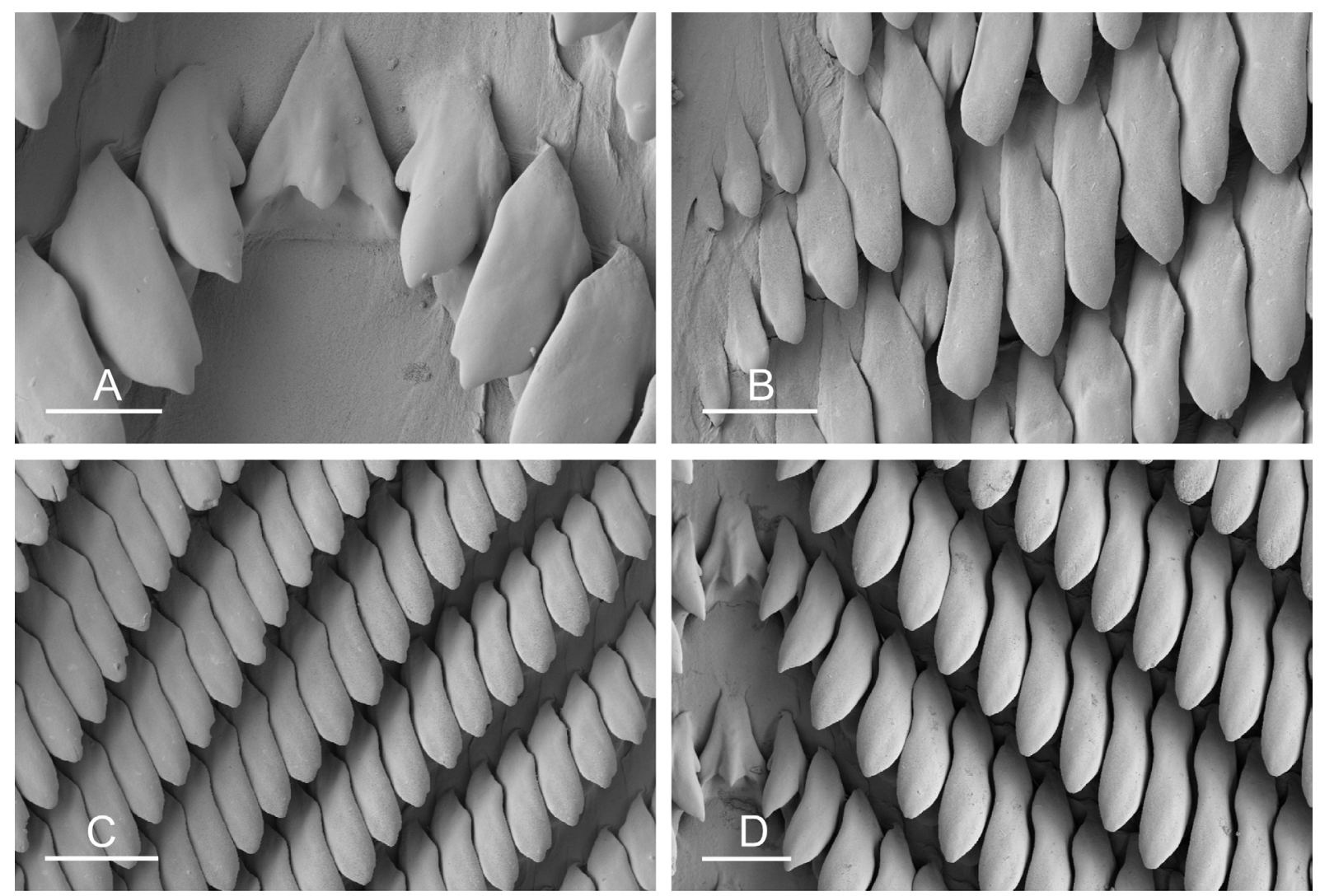

Fig. 39. Platevindex applanatus (Simroth, 1920) comb. nov., radula, Papua New Guinea. A. Rachidian and innermost lateral teeth [5450] (MNHN-IM-2013-14051). B. Outer lateral teeth, same as A. C. Inner lateral teeth, same as A. D. Rachidian and innermost lateral teeth [5424] (MNHN-IM-2013-14043). Scale bars: $\mathrm{A}=20 \mu \mathrm{m} ; \mathrm{B}, \mathrm{D}=30 \mu \mathrm{m} ; \mathrm{C}=50 \mu \mathrm{m}$. 


\section{Distinctive diagnostic features (Table 4)}

Externally, Platevindex applanatus can be easily distinguished from P. martensi and P. aptei sp. nov. by the light yellow color of its foot. The presence of prominent dorsal papillae helps to distinguish $P$. applanatus from other species of Platevindex, except $P$. luteus, which is characterized by similar prominent dorsal papillae. The dorsal coloration of Platevindex applanatus is much more variable than in other species of Platevindex, and this variation prevents reliable separation from P. luteus. However, the dorsal notum of $P$. applanatus is frequently marked by bright yellowish-green markings or bands, which were very rarely observed in $P$. luteus. Individuals of $P$. applanatus also reach a smaller maximum size than individuals of $P$. martensi and P. amboinae, two species that are sympatric in eastern Indonesia,
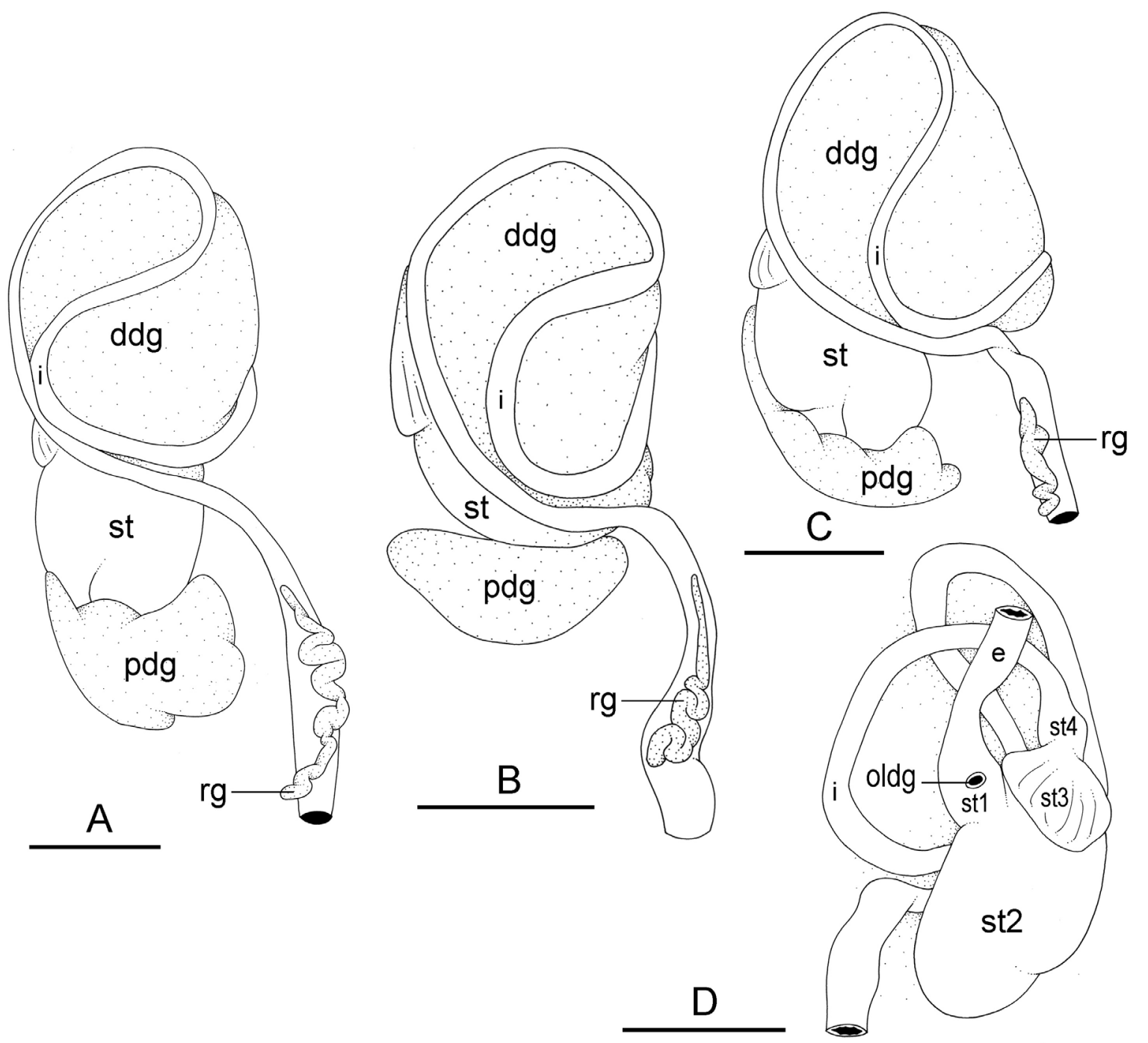

Fig. 40. Platevindex applanatus (Simroth, 1920) comb. nov., digestive system, intestinal loops of type I. A. Dorsal view, type I with a transitional loop oriented at 2 o'clock, Kei, Indonesia [2892] (UMIZ 00102). B. Dorsal view, type I with a transitional loop oriented at 2 o'clock, Mauritius [3152] (MNHNIM-2019-1393). C. Dorsal view, type I with a transitional loop oriented at 1 o'clock, Papua New Guinea [5420] (MNHN-IM-2013-13765). D. Stomach, ventral view, same as C. Abbreviations: ddg = dorsal digestive gland; $\mathrm{e}=$ esophagus; $\mathrm{i}=$ intestine; oldg = opening of the lateral lobe of the digestive gland; $\mathrm{pdg}=$ posterior digestive gland; $\mathrm{rg}=$ rectal gland; $\mathrm{st}=$ stomach; $\mathrm{st} 1=$ stomach chamber $1 ; \mathrm{st} 2=$ stomach chamber $2 ; \mathrm{st} 3=$ stomach chamber $3 ; \mathrm{st} 4=$ stomach chamber 4 . Scale bars: $\mathrm{A}, \mathrm{D}=3 \mathrm{~mm} ; \mathrm{B}=2 \mathrm{~mm}$; $\mathrm{C}=4 \mathrm{~mm}$. 
between the Halmahera Sea and the Banda Sea. However, animal sizes overlap between species and cannot be reliably used for identification.

Internally, the intestinal loops of $P$. applanatus (type I) distinguish it from all other species of Platevindex. The only other species with intestinal loops of type I is $P$. luteus. However, the orientation of the transitional loop can be used to reliably distinguish P. applanatus (between 1 and 2 o'clock) from P. luteus (between 3 and 8 o'clock). Platevindex applanatus can also be distinguished from $P$. luteus based on reproductive anatomy. The deferent duct in the posterior reproductive system is more closely attached to the oviduct, longer and more highly coiled in $P$. applanatus than in P. luteus. The

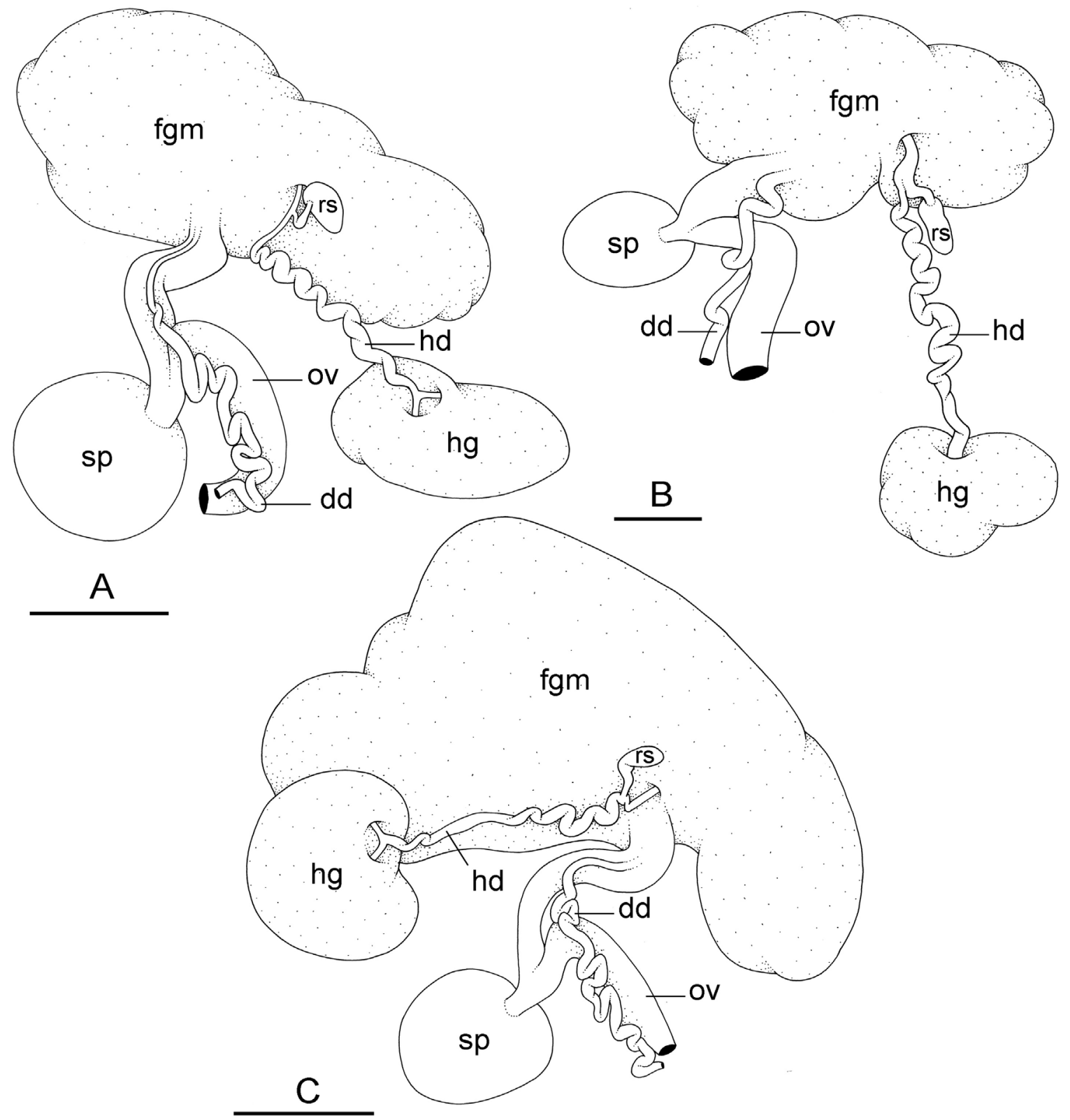

Fig. 41. Platevindex applanatus (Simroth, 1920) comb. nov., posterior reproductive system. A. Kei, Indonesia [2892] (UMIZ 00102). B. Mauritius [3152] (MNHN-IM-2019-1393). C. Papua New Guinea [5420] (MNHN-IM-2013-13765). Abbreviations: $d d=$ deferent duct; fgm = female gland mass; hd = hermaphroditic duct; $\mathrm{hg}=$ hermaphroditic gland; ov = oviduct; $\mathrm{rs}=$ receptaculum seminis; $\mathrm{sp}=$ spermatheca. Scale bars: $\mathrm{A}, \mathrm{C}=2 \mathrm{~mm} ; \mathrm{B}=1 \mathrm{~mm}$. 
distal region of the oviduct (distal to the spermatheca) is also longer in P. applanatus than in P. luteus. Finally, the distal region of the penis with hooks is longer in P. applanatus (up to $3 \mathrm{~mm}$ ) than in $P$. luteus (up to $1 \mathrm{~mm}$ ). The insertion of the retractor muscle varies greatly within $P$. applanatus (it may insert at the posterior end of the visceral cavity or near the heart), so this character does not help to reliably distinguish it from P. luteus.

Distribution (Fig. 10A)

Indonesia: Ambon, Aru Islands (type locality), Kei Islands. Mauritius. Papua New Guinea: Madang and New Ireland. Vanuatu. All records are new, except for the type locality.

\section{Habitat (Fig. 45)}

Platevindex applanatus is primarily found in the high intertidal, including on limestone, on rocks covered with a thin layer of algae. In the Kei Islands, individuals were found on rocks at the upper margin of the intertidal near a mangrove. In Ambon, individuals were found on logs very high in the intertidal, including at one locality that was not near any mangrove. In mangroves, individuals were typically
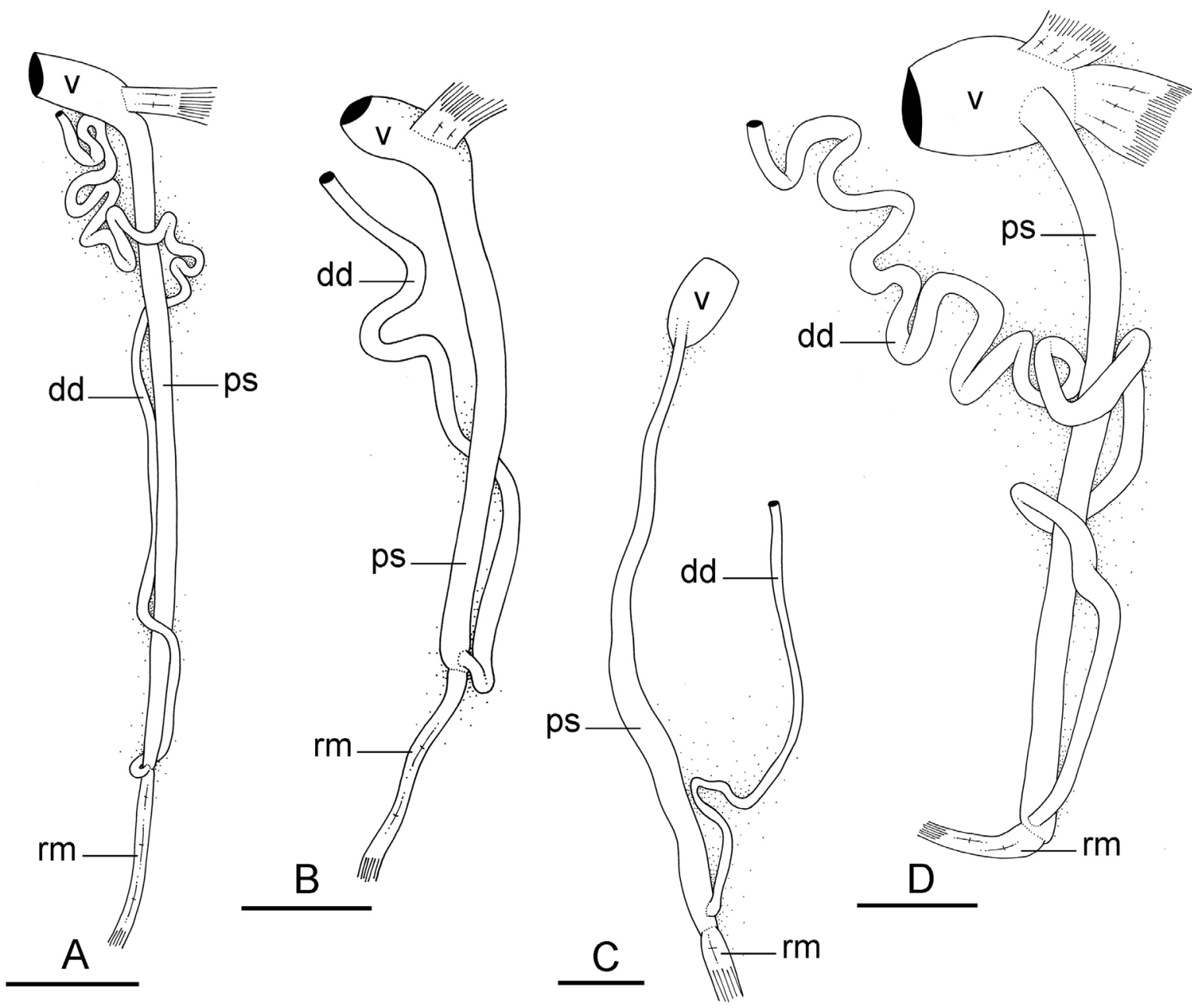

Fig.42. Platevindex applanatus (Simroth, 1920) comb.nov., anterior reproductive system, male copulatory apparatus. A. Kei, Indonesia [2892] (UMIZ 00102). B. Mauritius [3152] (MNHN-IM-2019-1393). C. Mauritius [3604] (MNHN-IM-2019-1392). D. Papua New Guinea [5420] (MNHN-IM-2013-13765). Abbreviations: $\mathrm{dd}=$ deferent duct; $\mathrm{ps}=$ penial sheath; $\mathrm{rm}=$ retractor muscle; $\mathrm{v}=$ vestibule. Scale bars: $\mathrm{A}=2 \mathrm{~mm} ; \mathrm{B}, \mathrm{D}=1 \mathrm{~mm} ; \mathrm{C}=0.5 \mathrm{~mm}$. 

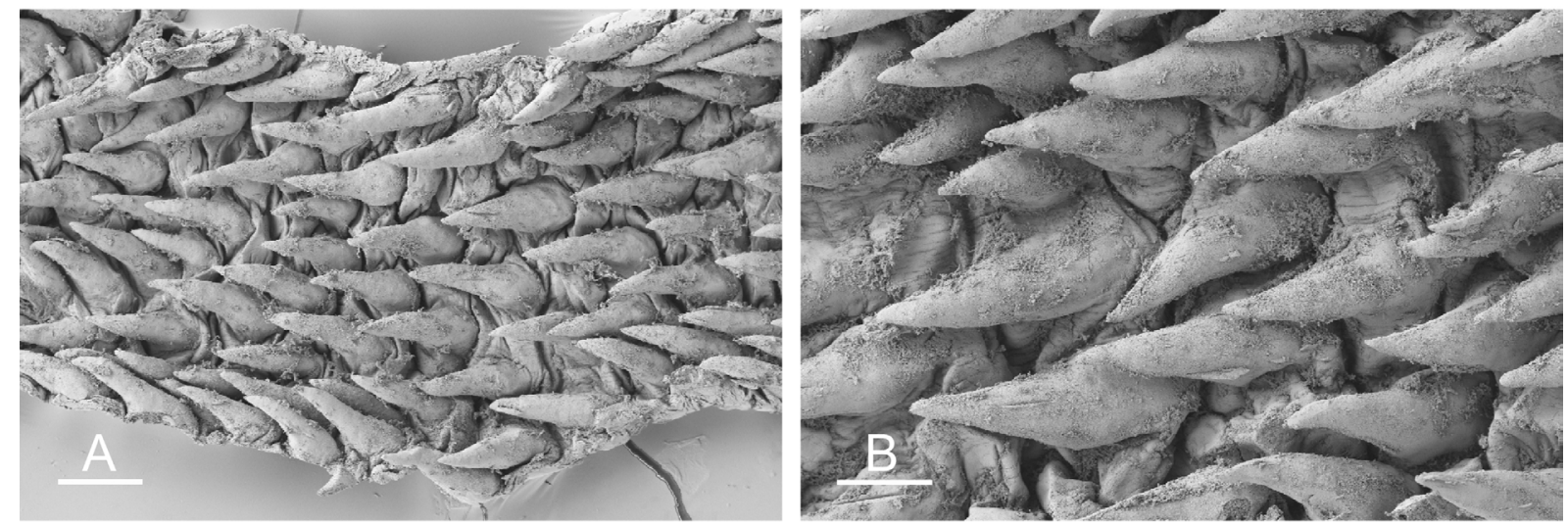

Fig. 43. Platevindex applanatus (Simroth, 1920) comb. nov., penial hooks. Indonesia, Ambon [2757] (UMIZ 00101). Scale bars: A $=50 \mu \mathrm{m} ; \mathrm{B}=60 \mu \mathrm{m}$.

collected on dead logs or tree trunks. In Mauritius, it was found in mangroves, on pieces of wood and wet petioles of palm leaves. Platevindex applanatus is not found directly on mud.

\section{Remarks}

Onchidium applanatum was originally described from the Aru Islands. Fresh material was collected from the Kei Islands, very close to Aru. The holotype of Onchidium applanatum is small (15/12 mm) but its flattened shape, the presence of a rectal gland and no accessory penial gland all indicate that it is a Platevindex slug. The prominent papillae on its dorsal notum and its digestive system of type I are compatible with the species described here as well as P. luteus. However, the retractor muscle of the
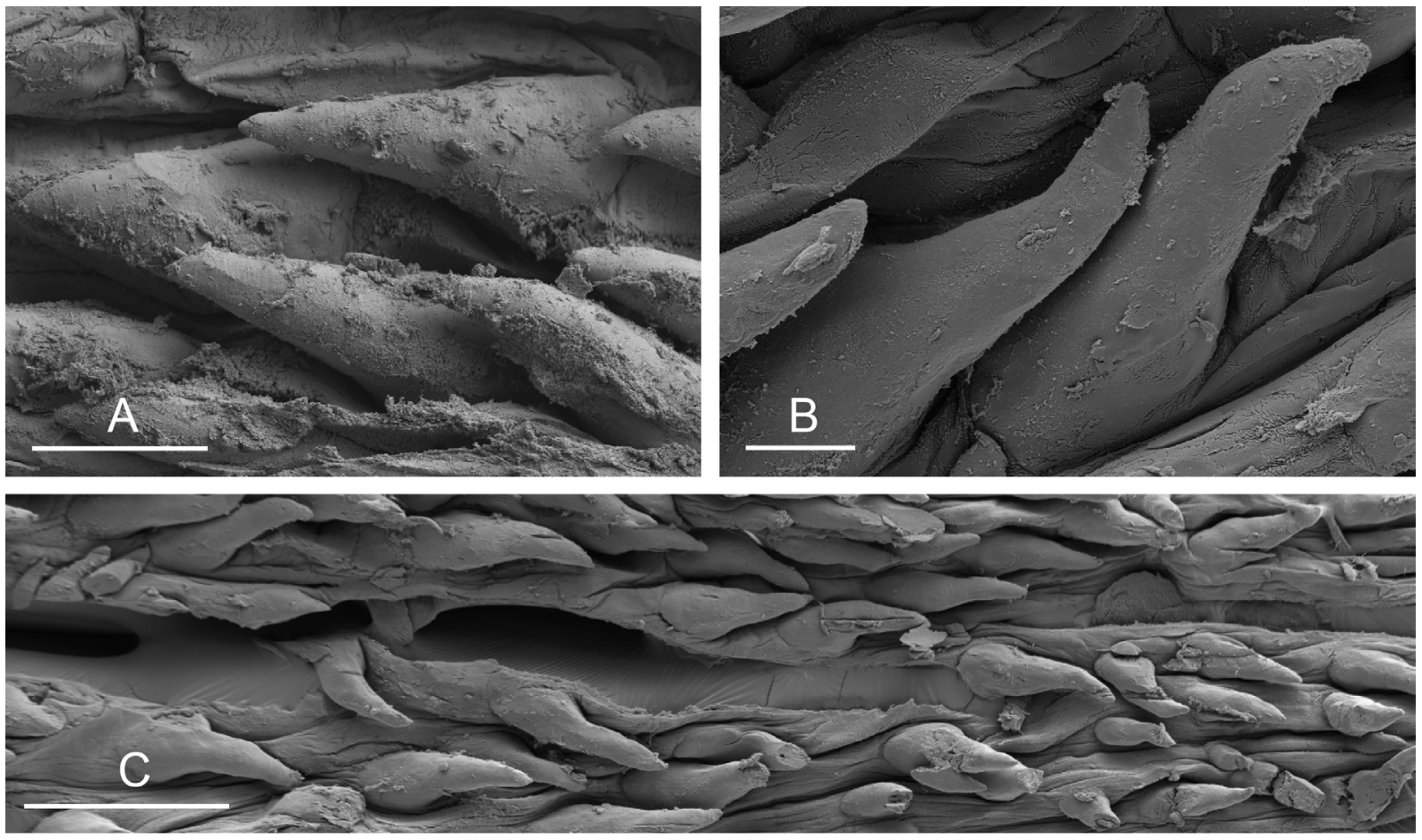

Fig. 44. Platevindex applanatus (Simroth, 1920) comb. nov., penial hooks. A. Papua New Guinea [5424] (MNHN-IM-2013-14043). B-C. Mauritius [3152] (MNHN-IM-2019-1393). Scale bars: A = $30 \mu \mathrm{m}$; $\mathrm{B}=10 \mu \mathrm{m} ; \mathrm{C}=60 \mu \mathrm{m}$. 

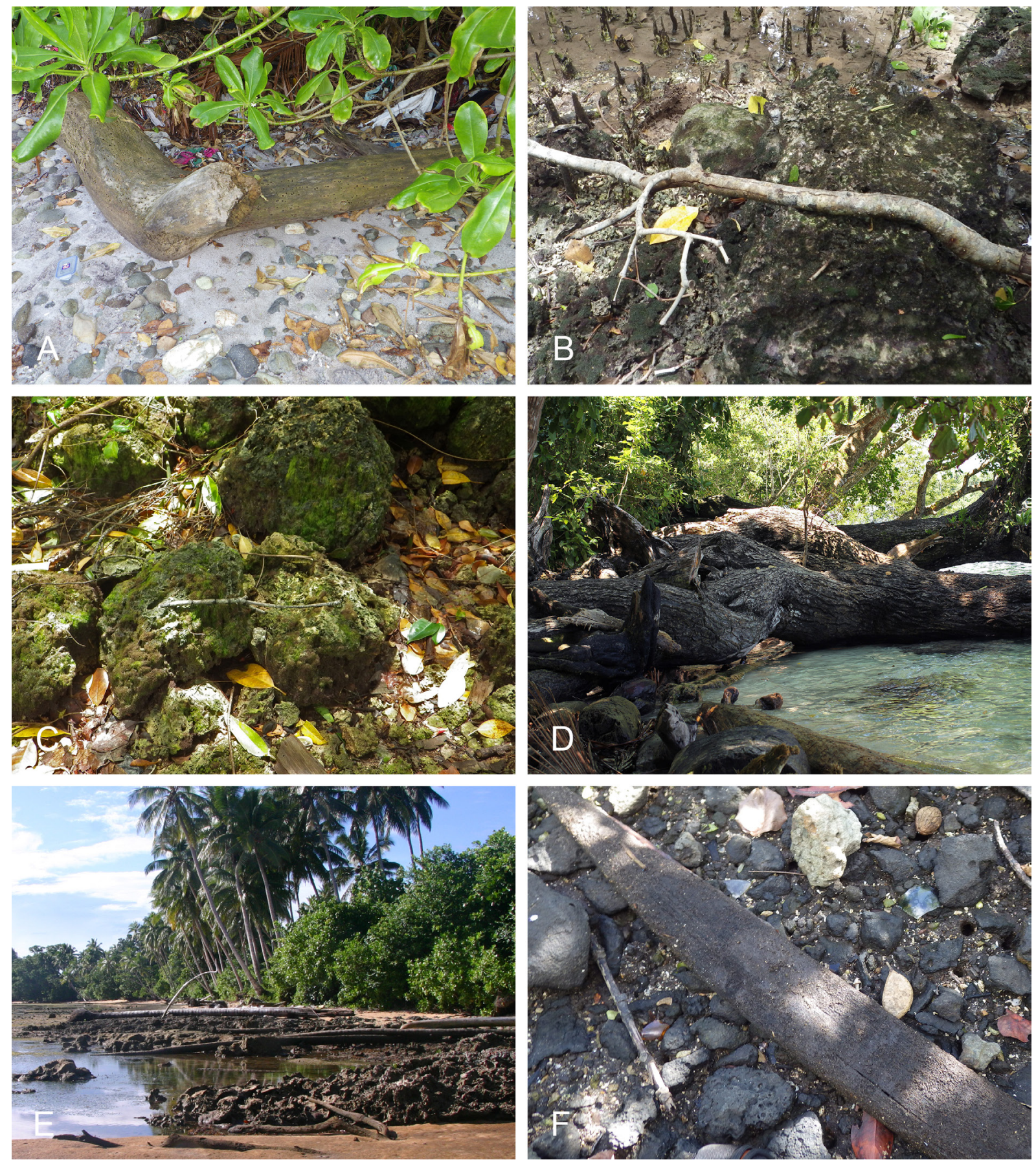

Fig. 45. Habitats of Platevindex applanatus (Simroth, 1920) comb. nov., Indonesia (A-C), Papua New Guinea (D-E) and Mauritius (F). A. Ambon, log behind a rocky mangrove in the very high intertidal, shaded by trees (station 127). B. Kei Islands, rocks with algae at the edge of the mangrove (station 137). C. Kei Islands, Un, rocks in the high intertidal behind a mangrove, surrounded by dry vegetation, algae growing on the rocks (station 137). D. Madang, Hargun Island, night tide (station PM24). E. New Ireland, Povalval, east coast of New Ireland, mixed hard platform and seagrass bed at outlet of rivulet (station KM05). F. Mahebourg, close up of rotting petiole of palm frond at margin of mangrove where juvenile onchidiids were found. 
holotype of $O$. applanatum is very long and inserts near the posterior end of the visceral cavity, which is only compatible with the species described here (in P. luteus, the retractor muscle inserts near the heart). Therefore, Platevindex applanatus is applied to the species described here from the Kei Islands and Ambon.

Hoffmann (1928: 84-85) and Labbé (1934: 225-226) considered that Onchidium applanatum and Onchidium tabularis Tapparone-Canefri, 1883 were both junior synonyms of Onchidium planatum Quoy \& Gaimard, 1825. Onchidium planatum, originally described from Guam, may not even refer to an onchidiid based on the brief written description. Two pieces of a notum were located recently at the MNHN which are part of the type series of O. planatum (MNHN-IM-2000-33706). However, these are so poorly preserved that it is not possible to determine whether they were part of an onchidiid slug. Tapparone-Canefri's (1883) description of $O$. tabularis from Wokam, Aru Islands, does not mention the internal anatomy, and the type specimens could not be located. As a result, both Onchidium planatum and Onchidium tabularis are considered here nomina dubia. Labbé's (1934: 225-226) specimens identified as $O$. planatum from Guam, New Caledonia and Mauritius (as île de France) cannot belong to P. applanatus or any other species of Platevindex due to the presence of a penial gland.

Platevindex burnupi (Collinge, 1902) comb. nov. Figs 46-53

Onchidium burnupi Collinge, 1902: 17, figs 1-2.

Onchidium burnupi - Collinge 1910: 171-172. — Connolly 1912: 224; 1939: 456. — Hoffmann 1928: 84.

\section{Material examined}

\section{Lectotype}

SOUTH AFRICA • lectotype (here designated; 21/16 mm); Natal, Umlaas Lagoon [now the Umlazi River]; NHMUK 1905.4.12.33.

Paralectotype

SOUTH AFRICA • 1 paralectotype (18/12 mm); NHMUK 1905.4.12.34.

\section{Notes on type material}

The notum of the lectotype was cut open for the present study, with all internal organs remaining. The paralectotype was not dissected.

\section{Other material}

MADAGASCAR • 1 spec. (10/6 [3599] mm); Mangaoka area; $12^{\circ} 15.984^{\prime} \mathrm{S}, 49^{\circ} 06.103^{\prime} \mathrm{E}$; 18 May 2014; station 160; mangrove of Avicennia and Rhizophora, many small trees in center of mangrove had been cut; MNHN-IM-2019-1396 • 1 spec. (16/9 [3150] mm); Madagascar, Ambaro Bay; 13²4.769' S, 48 47.341' E; 23 May 2014; Station 164; large, very dry mangrove of mostly Avicennia; MNHNIM-2019-1398 1 spec. (14/9 [3151] mm); same collection data as for preceding; MNHN-IM-2019-1399• 1 spec. (12/6 [3602] mm); same collection data as for preceding; MNHN-IM-2019-1397 • 1 spec. (16/10 [3603] mm); same collection data as for preceding; MNHN-IM-2019-1395.

MOZAMBIQUE • 1 spec. (13/10 [729] mm); Mecufi, $50 \mathrm{~km} \mathrm{~S}$ of Pemba, Cabo Delgado Province [about $13^{\circ} \mathrm{S}$; 13 Jul. 2006; D.G. Reid leg.; on base of Ceriops bush in landward zone of mangrove belt, $30 \mathrm{~cm}$ above firm mud; NHMUK 20060274. 

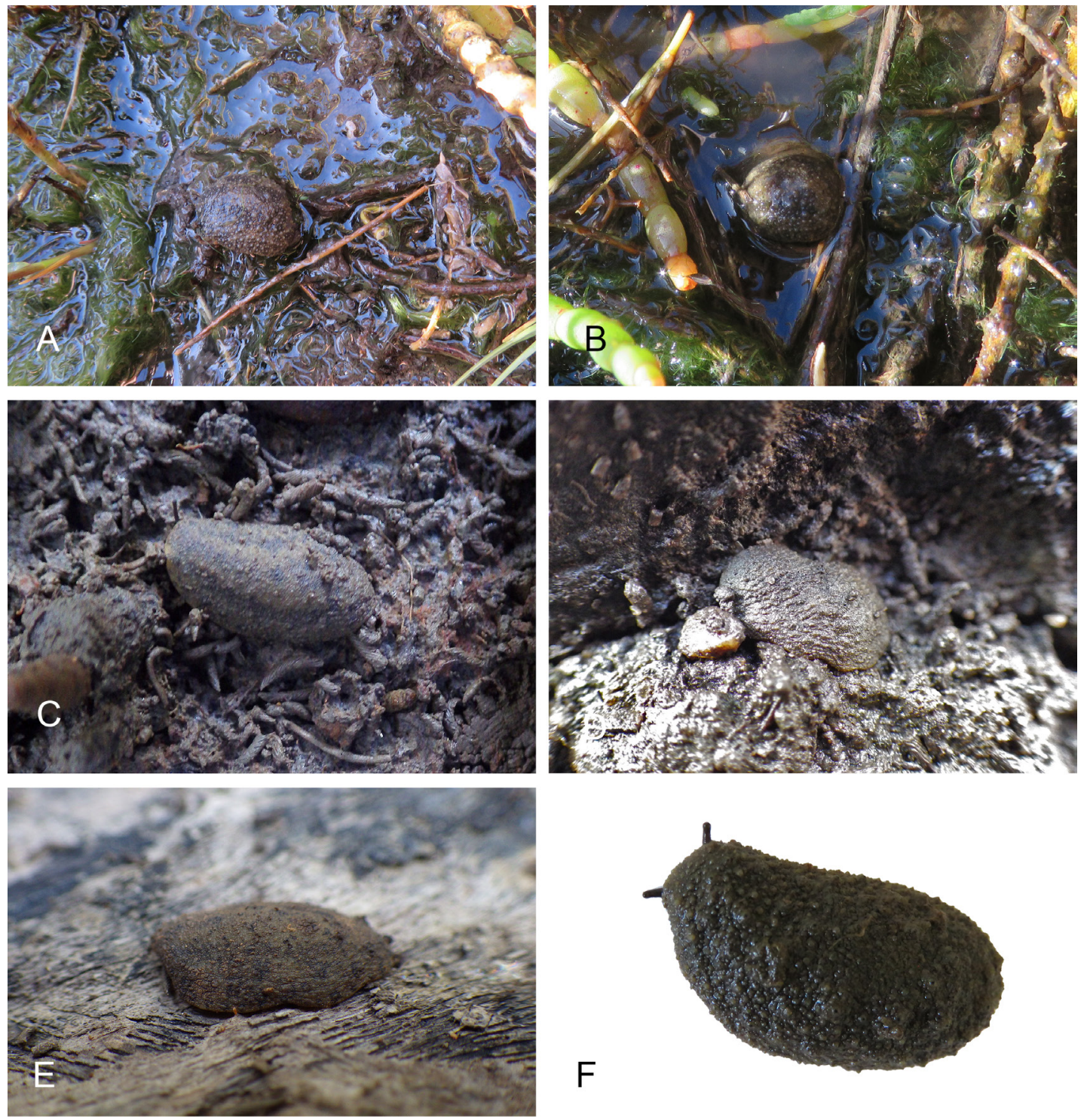

$\mathrm{F}$
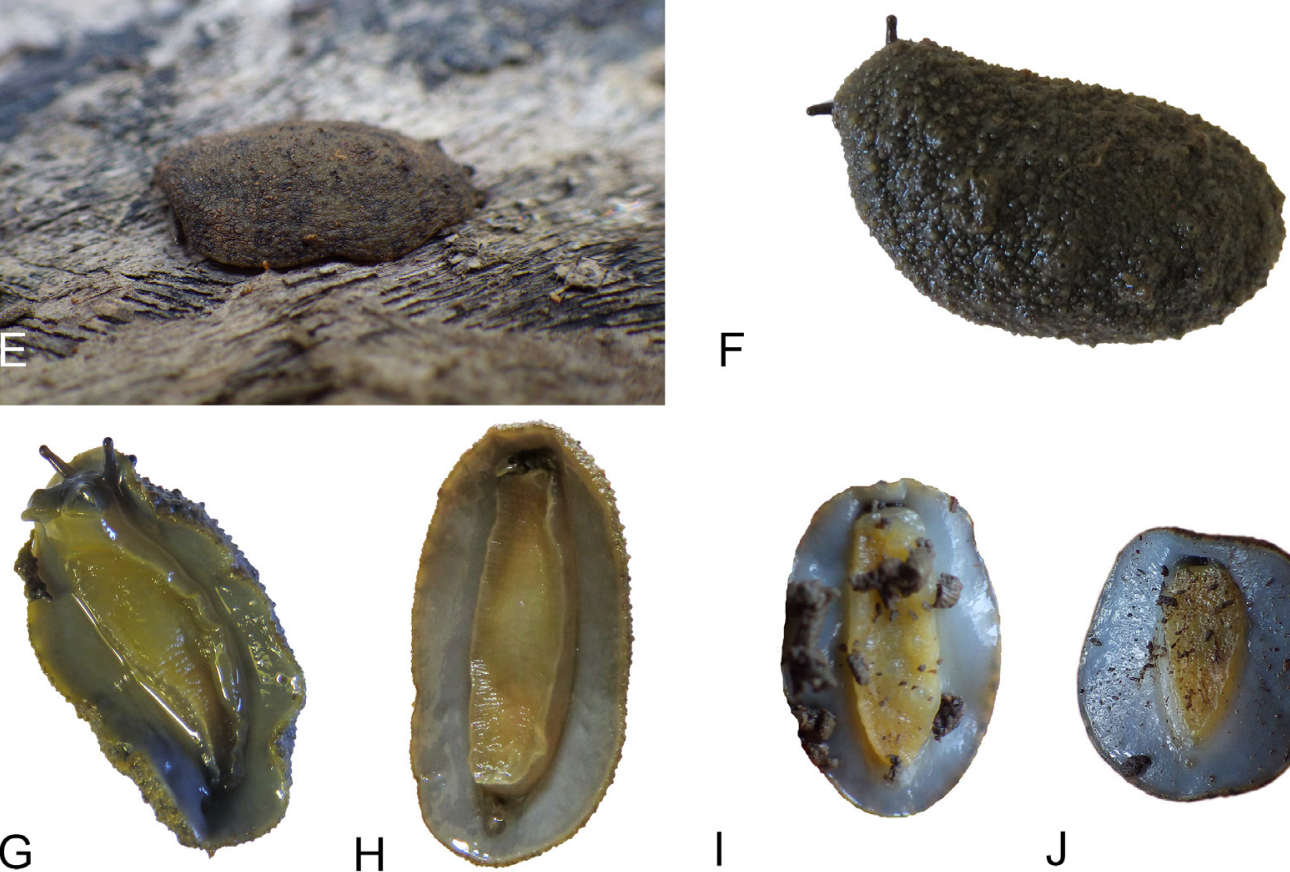

$\mathrm{H}$
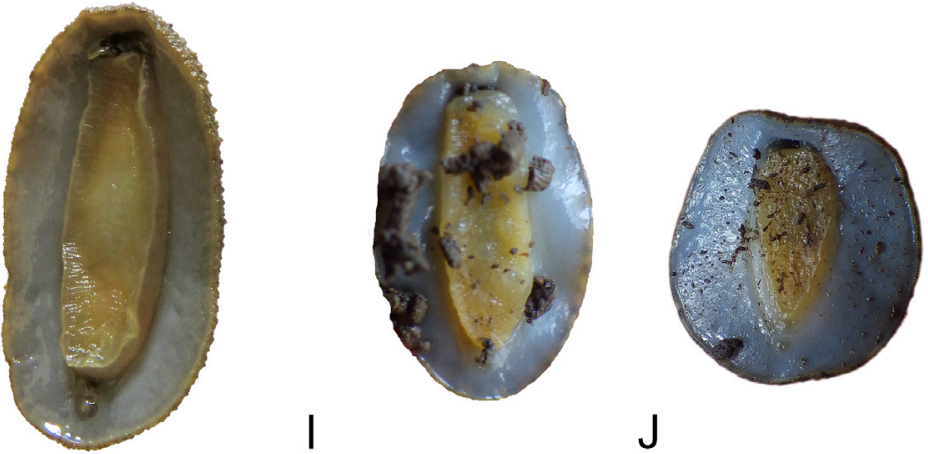

Fig. 46. Platevindex burnupi (Collinge, 1902) comb. nov., live animals. A-B. Dorsal view [unnumbered], South Africa, East London. C. Dorsal view, 16 mm long [3150], Madagascar, Ambaro Bay (MNHNIM-2019-1398). D. Dorsal view, $10 \mathrm{~mm}$ long [3599], Madagascar, near Mangaoka (MNHNIM-2019-1396). E. Dorsal view, 14 mm long [3151], Ambaro Bay (MNHN-IM-2019-1399). F. Dorsal view, $22 \mathrm{~mm}$ long [6153], South Africa, East London (ELM W04108). G. Ventral view, $20 \mathrm{~mm}$ long [6149], South Africa, East London (ELM W04107). H. Ventral view, same as F. I. Ventral view, same as C. J. Ventral view, same as D. 
SOUTH AFRICA • 1 spec. (32/11 [6146] mm); East Cape, Kwelera River estuary; $32^{\circ} 54.169^{\prime} \mathrm{S}$, $28^{\circ} 03.954^{\prime}$ E; 23 Jun. 2017; M. Cole leg.; mud amongst plants in supratidal fringe; ELM W04105 • 1 spec. (23/9 [6154] mm); same collection data as for preceding; ELM W04107 • 1 spec. (22/10 [6153] $\mathrm{mm})$; same collection data as for preceding; ELM W04106 • $1 \mathrm{spec} .(20 / 10$ [6149] mm); same collection data as for preceding; ELM W04108・1 spec. $(19 / 7$ [6148] mm); same collection data as for preceding; ELM W04109.

\section{Description}

Color and morphology of live animals (Fig. 46)

The dorsal notum of live animals can be covered with mud, in which case their color may be obscured until they are washed. The dorsal notum is brown with dark brown or black markings. The hyponotum is light blue-grey and the foot is yellow. Papillae with dorsal eyes are present. Their exact number is variable, approximately from 15 to 38 were observed in specimens from South Africa and between 12 and 20 were observed in specimens from Madagascar. Each papilla bears one dorsal eye. Eyes are distributed across the notum but are absent from the margin (i.e., eyes are never $<2 \mathrm{~mm}$ from the notum edge).

Digestive system (Figs 2G, 47-48B, 53)

Radulae measure up to $3.3 \mathrm{~mm}$ in length. Examples of radular formulae are presented in Table 5. The intestinal loops are of type II, with a transitional loop oriented at approximately 7 o'clock (Figs $2 \mathrm{G}$, 48A, 53).
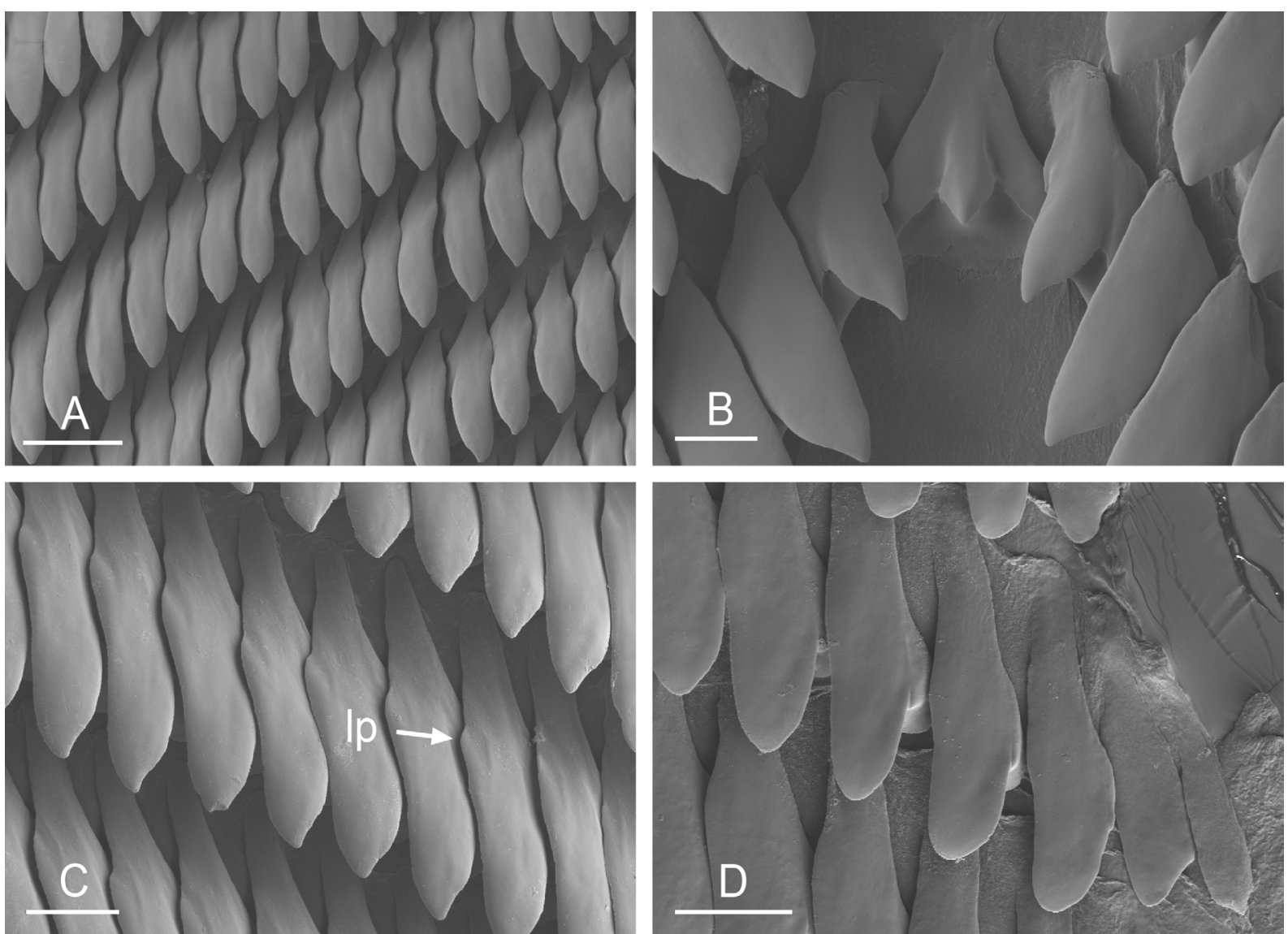

Fig. 47. Platevindex burnupi (Collinge, 1902) comb. nov., radula, South Africa. A. Left, lateral teeth [6153]. B. Rachidian tooth and innermost lateral teeth, same as A. C. Right, lateral teeth [6149]. D. Right, outermost, lateral teeth [6148]. Abbreviation: $1 \mathrm{p}=$ lateral protuberance. Scale bars: $\mathrm{A}=30 \mu \mathrm{m}$; $\mathrm{B}=10 \mu \mathrm{m} ; \mathrm{C}-\mathrm{D}=20 \mu \mathrm{m}$. 


\section{Reproductive system (Figs 49-51)}

In the posterior (female) reproductive system, the oviduct is short, wider than the deferent duct (approximately twice as wide). The length of its distal section (distal to the spermatheca) is shorter than or equal to that of its proximal section. The deferent duct is slightly longer than the oviduct, is only loosely attached to it and varies from loosely to tightly coiled (Fig. 49). The female pore is approximately 0.5 to $2 \mathrm{~mm}$ from the anus. The distal, flexible region of the penis with hooks is 1 to $1.5 \mathrm{~mm}$ long. Penial hooks are large, between 25 to $70 \mu \mathrm{m}$ long (Fig. 51A), and can be seen inside the semi-transparent penis. The retractor muscle of the penis inserts on the right side at the posterior end of the visceral cavity (from the posterior end of the heart, up to the posterior end of the visceral cavity). The length of the retractor muscle varies from half the length of the penial sheath to approximately two times its length (Fig. 50B). The deferent duct is highly convoluted.

\section{Distinctive diagnostic features (Table 4)}

Platevindex burnupi is the only known species of Platevindex from the western Indian Ocean. It can be distinguished from P. martensi and P. aptei sp. nov. by its grey hyponotum and yellow foot, and from P. amboinae and P. latus by the presence of dorsal eyes. Platevindex burnupi is similar in appearance to $P$. luteus and $P$. applanatus, but lacks distinctly raised dorsal papillae. Its dorsal surface can even be smooth. It is difficult to distinguish $P$. burnupi from $P$. coriaceus and P. tigrinus due to their similar coloration and granular dorsal appearance. Although individuals of $P$. burnupi tend to be shorter than those of $P$. coriaceus and $P$. tigrinus, animal sizes overlap and cannot be used for identification.
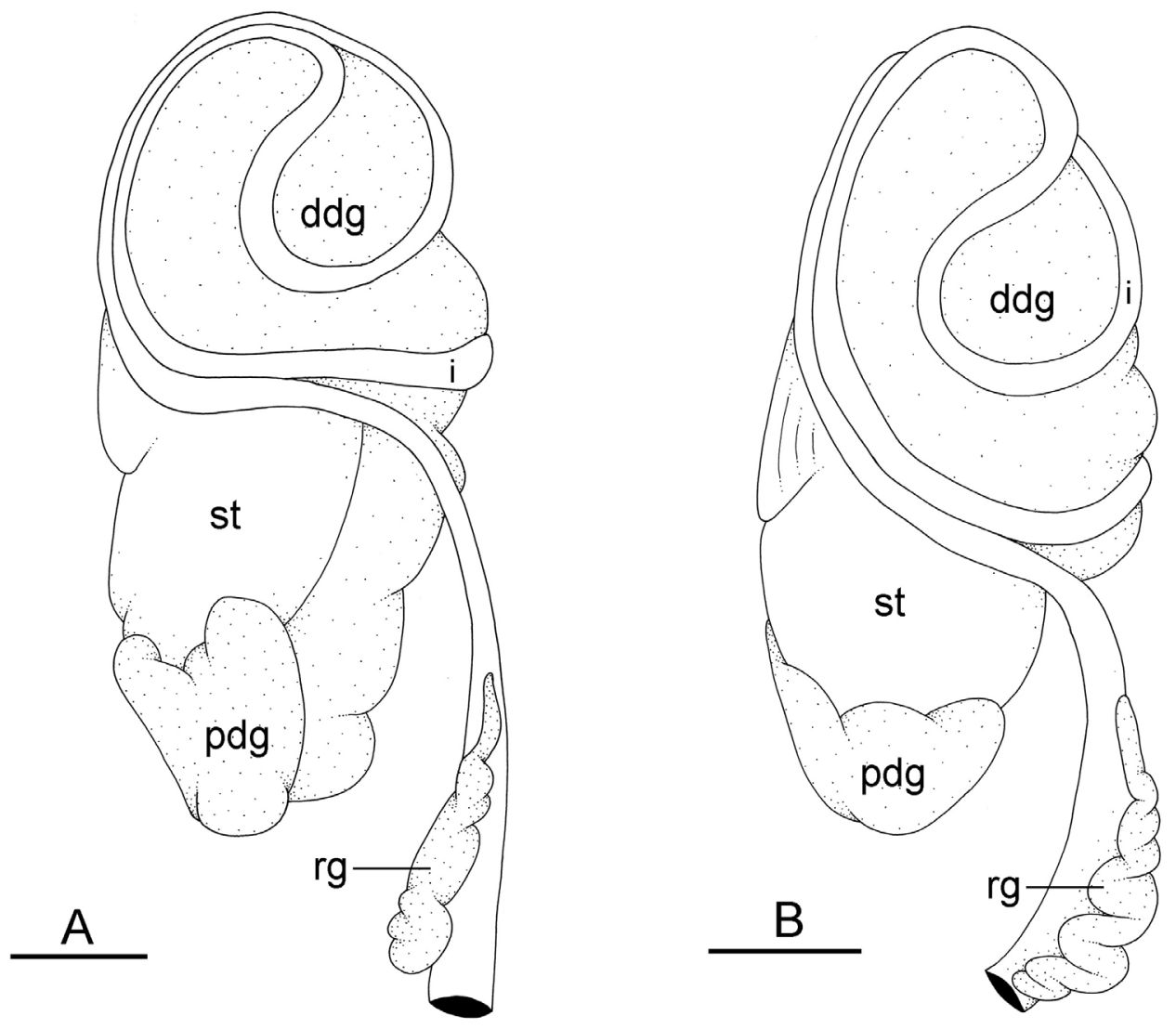

Fig. 48. Platevindex burnupi (Collinge, 1902) comb. nov., digestive system, dorsal view, intestinal loops of type II, with a transitional loop oriented at 7 o'clock. A. South Africa, lectotype (NHMUK 1905.4.12.33). B. Madagascar [3150] (MNHN-IM-2019-1398). Abbreviations: ddg = dorsal digestive gland; $\mathrm{i}=$ intestine; $\mathrm{pdg}=$ posterior digestive gland; $\mathrm{rg}=$ rectal gland; $\mathrm{st}=$ stomach. Scale bars $=2 \mathrm{~mm}$. 
Internally, the intestinal loops of type II differentiate P. burnupi from P. amboinae, P. latus, P. applanatus and some specimens (with intestinal loops of type I) of $P$. luteus. The reproductive system can be used to distinguish $P$. burnupi from all other species of Platevindex. The deferent duct in the posterior reproductive system is loosely attached to the oviduct in $P$. burnupi, which distinguishes it from $P$. coriaceus and $P$. tigrinus (deferent duct closely attached to the oviduct). The distal region of the penis with penial hooks is also much shorter in P. burnupi $(1-1.2 \mathrm{~mm})$ than in P. coriaceus $(2-8 \mathrm{~mm})$. Platevindex burnupi is very difficult to differentiate from $P$. luteus internally. They differ only slightly with respect to the insertion of the penial retractor muscle (near the heart in $P$. luteus and in the last posterior quarter of the visceral cavity in $P$. burnupi). DNA sequences are the most reliable way to distinguish Platevindex burnupi and $P$. luteus, which are more than $10.5 \%$ divergent based on COI sequences.

Distribution (Fig. 10A)

Madagascar, Mozambique and South Africa (type locality and newly-collected material).

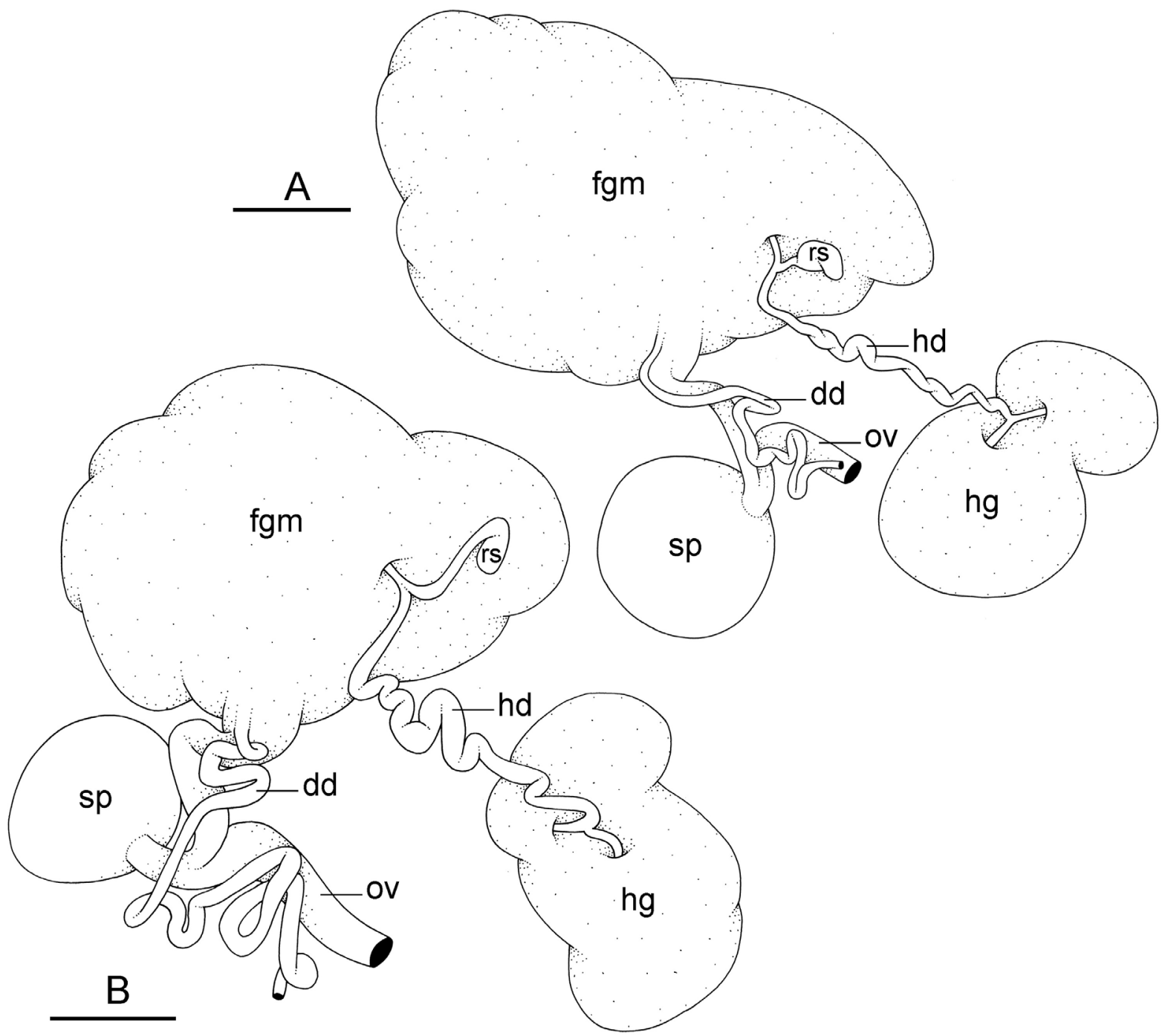

Fig. 49. Platevindex burnupi (Collinge, 1902) comb. nov., posterior reproductive system. A. South Africa, lectotype (NHMUK 1905.4.12.33). B. Madagascar [3603] (MNHN-IM-2019-1395). Abbreviations: $\mathrm{dd}=$ deferent duct; fgm = female gland mass; $\mathrm{hd}=$ hermaphroditic duct; $\mathrm{hg}=$ hermaphroditic gland; ov $=$ oviduct; $r s=$ receptaculum seminis; $\mathrm{sp}=$ spermatheca. Scale bars: $\mathrm{A}=2 \mathrm{~mm} ; \mathrm{B}=1 \mathrm{~mm}$. 
Habitat (Figs 45A-B, 52C-D)

Like other species of Platevindex, P. burnupi is found on mangrove trees but, unlike other species, it may also be found on mud. Specimens in Madagascar were found high in the intertidal on moist mud not saturated in water, and one specimen was found on a piece of wood. A specimen from Mozambique was collected on the base of a Ceriops tree, $30 \mathrm{~cm}$ above ground. All specimens in South Africa were on mud, in the supra-tidal zone of a salt marsh, a few meters away from the river.

\section{Remarks}

Onchidium burnupi must be transferred to Platevindex because of the following combination of characters in the lectotype: flattened body, rectal gland present and no penial gland. The type locality (Umlaas Lagoon, Natal, South Africa) was visited twice by our team and several times by experts from the Natal Museum (Dai Herbert, pers. com.), but no onchidiid species were ever found. This is very likely due to the fact that the Umlaas Lagoon has been developed and natural vegetation destroyed. However, onchidiids similar to the lectotype of $O$. burnupi were recently collected by Mary Cole

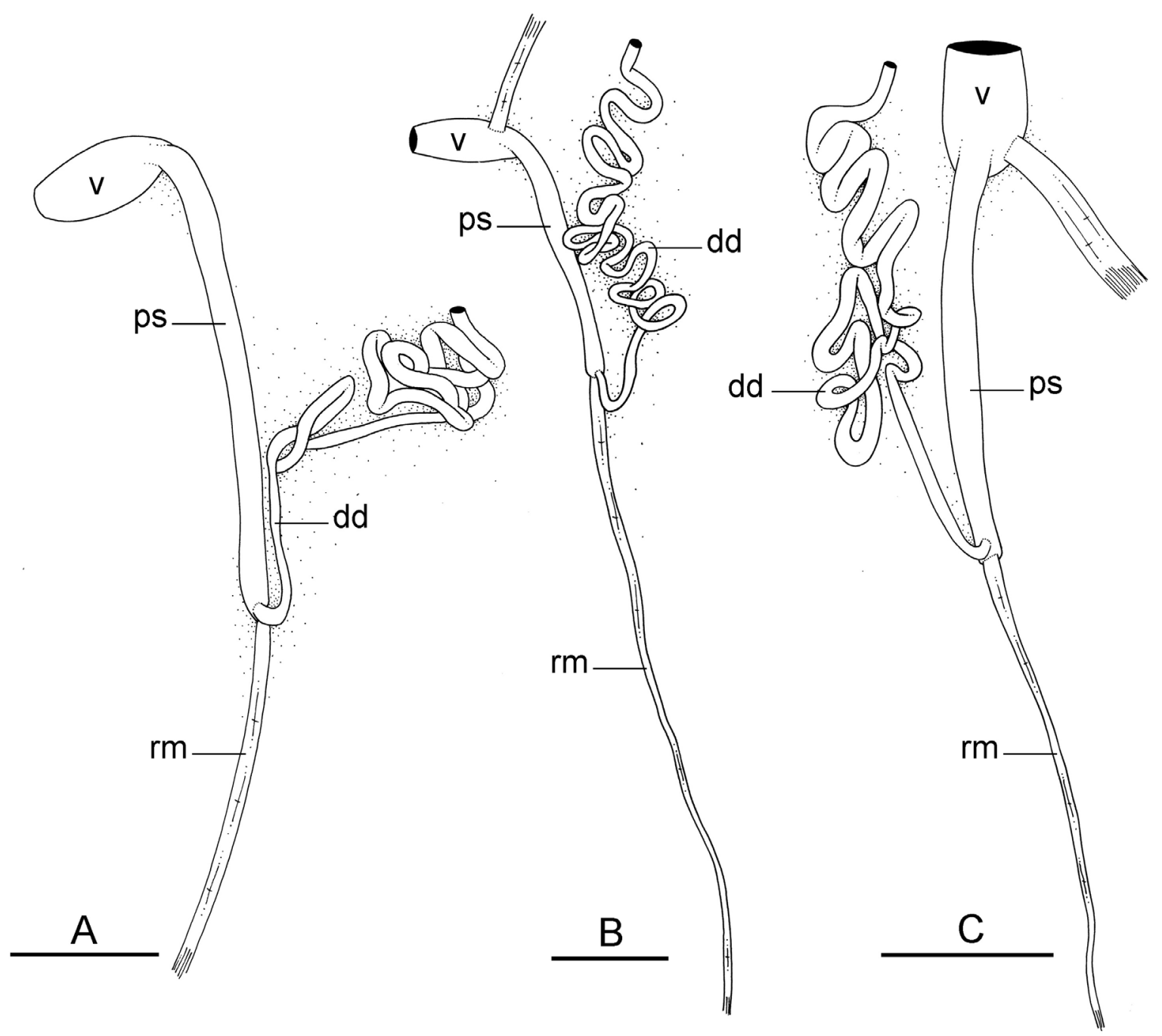

Fig. 50. Platevindex burnupi (Collinge, 1902) comb. nov., anterior, male copulatory apparatus. A. South Africa [6148] (ELM W04109). B. South Africa, lectotype (NHMUK 1905.4.12.33). C. Madagascar [3150] (MNHN-IM-2019-1398). Abbreviations: $\mathrm{dd}=$ deferent duct; $\mathrm{ps}=$ penial sheath; $\mathrm{rm}=$ retractor muscle; $\mathrm{v}=$ vestibule. Scale bars: $\mathrm{A}=1 \mathrm{~mm} ; \mathrm{B}-\mathrm{C}=2 \mathrm{~mm}$. 

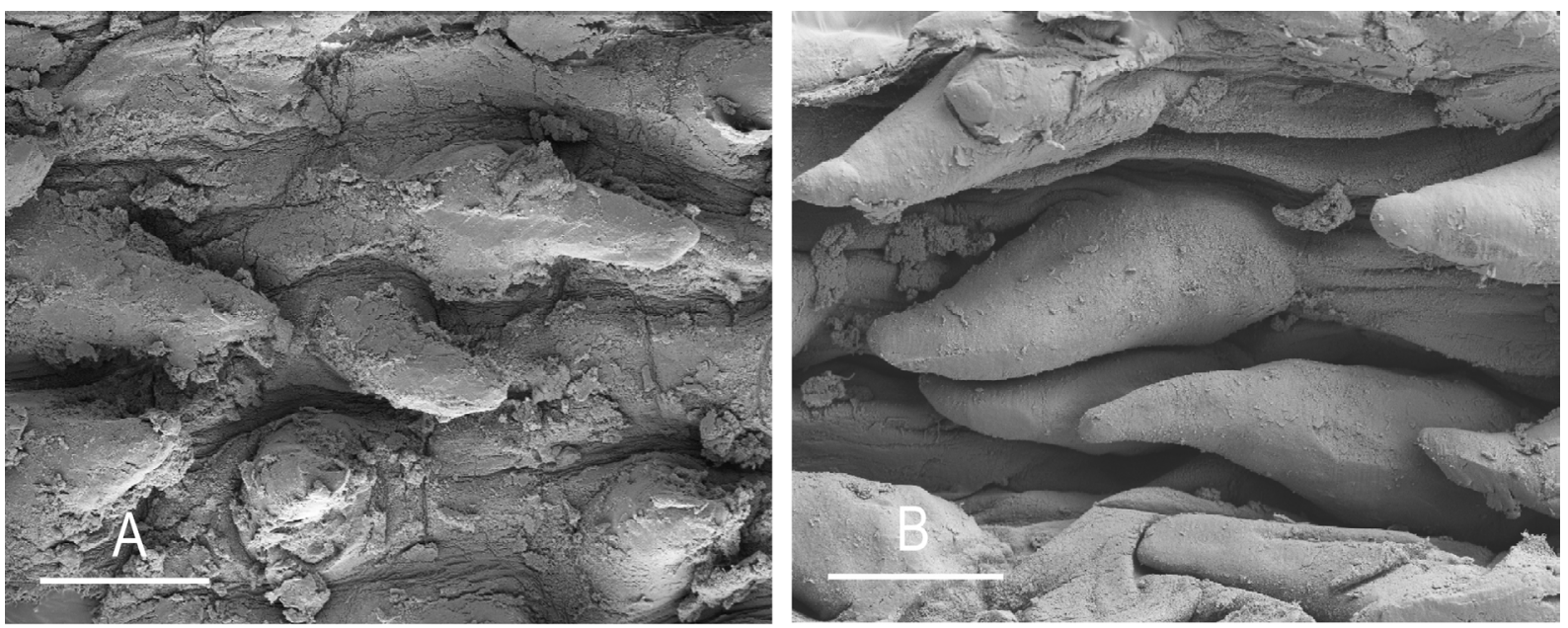

Fig. 51. Platevindex burnupi (Collinge, 1902) comb. nov., penial hooks A. South Africa [6148] (ELM W04109). B. Madagascar, Ambaro Bay [3603] (MNHN-IM-2019-1395). Scale bars: A = $30 \mu \mathrm{m}$; $\mathrm{B}=20 \mu \mathrm{m}$.

and Philippe Bouchet in the estuary of the Kwelera River, East Cape, South Africa (approximately $400 \mathrm{~km}$ south of the type locality). As of today, no other live population of $P$. burnup $i$ is known in South Africa (assuming that there is no live population at the type locality). Note that several authors have mentioned the existence of Onchidium burnupi in South Africa but exclusively based on the original
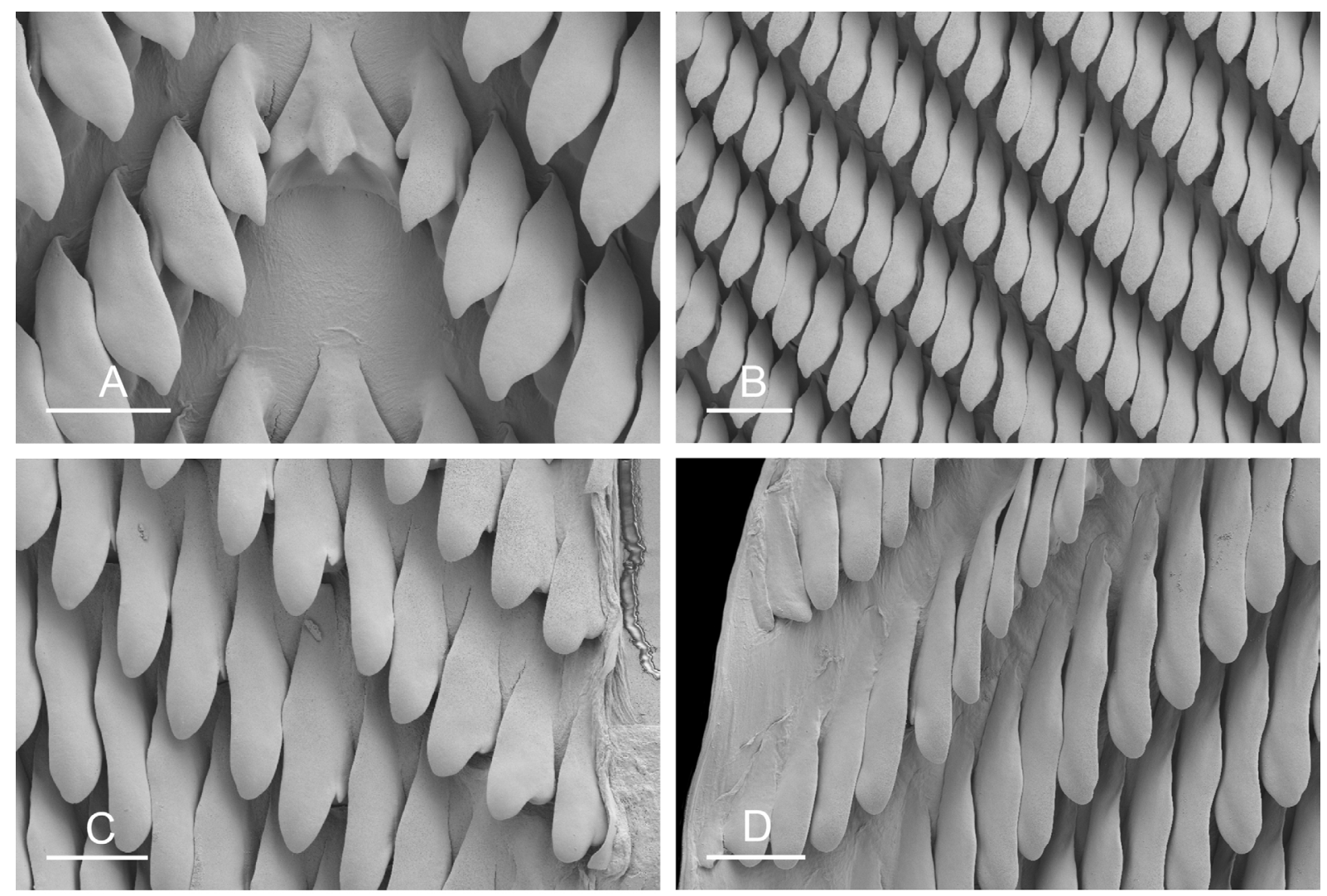

Fig. 52. Platevindex burnupi (Collinge, 1902) comb. nov., radula, Madagascar, Ambaro Bay [3603] (MNHN-IM-2019-1395). A. Rachidian and innermost lateral teeth. B. Lateral teeth. C-D. Outer lateral teeth. Scale bars: A, C-D $=20 \mu \mathrm{m} ; \mathrm{B}=30 \mu \mathrm{m}$. 
description, i.e., without providing new specimens or records (Connolly 1912, 1939; Collinge 1910; Hoffmann 1928).

Platevindex burnupi is known from two localities in South Africa, three localities in Madagascar and one locality in Mozambique. High genetic divergences between populations from Madagascar and Mozambique versus South Africa (5.4-6.0\%) as well as the fact that they are consistently recovered as
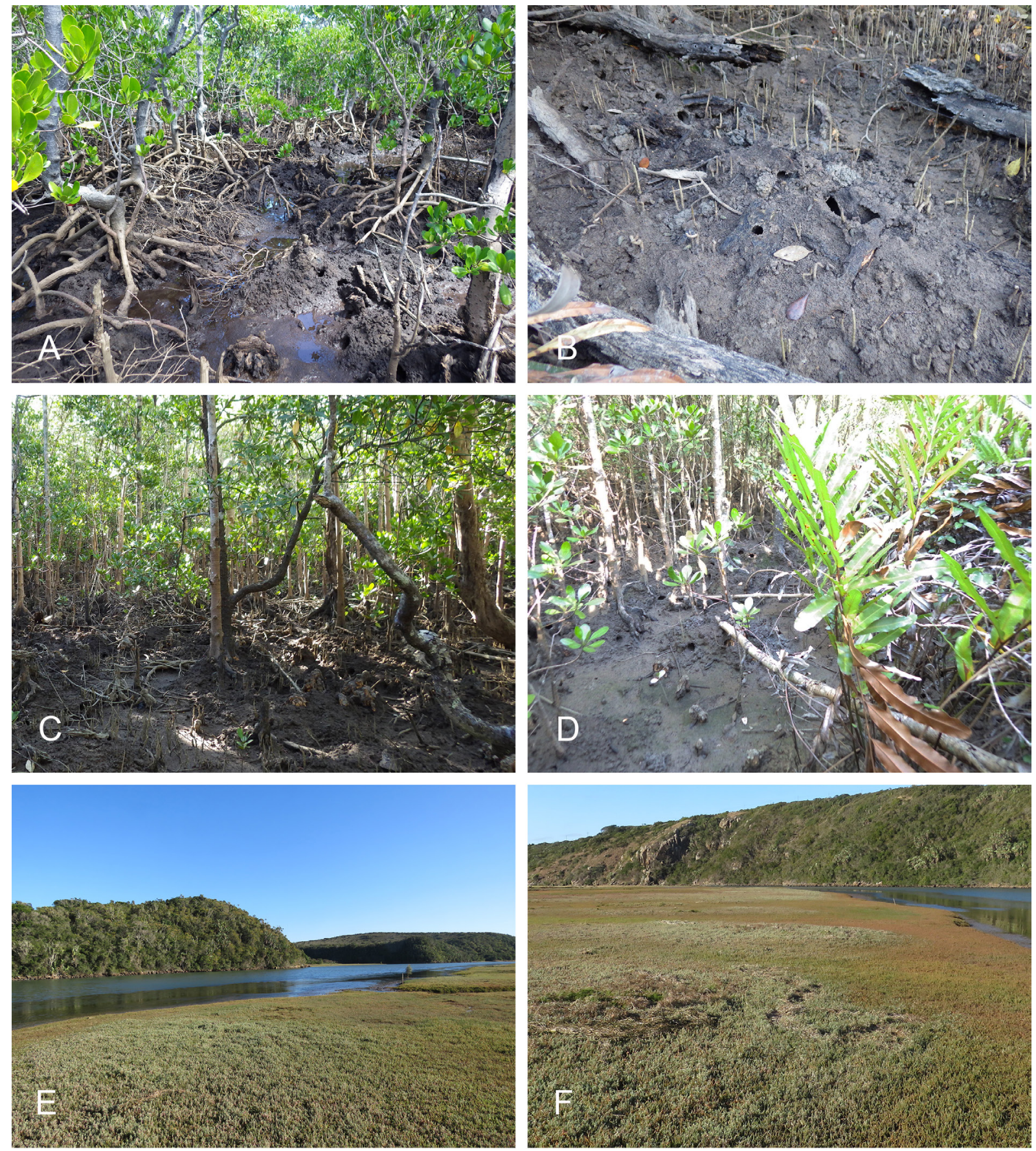

Fig. 53. Habitats of Platevindex burnupi (Collinge, 1902) comb. nov. A. Madagascar, near Mangaoka (station 160). B-D. Madagascar, Ambaro Bay, vegetation and close view of the high intertidal mud (station 164). E-F. South Africa, East Cape, Kwelera Estuary, estuarine plants in the supra-tidal fringe of salt marsh. 
reciprocally-monophyletic units (Figs 4-8) suggest that there could be more than one species. However, there is not enough evidence to justify the description of a new species in Madagascar. The anatomy of populations from South Africa and Madagascar are similar, and little is known about intraspecific variation across its distribution. The genetic divergences between Madagascar and East Africa (Mozambique and South Africa) could be the result of the large geographic distance between localities. However, there are some noticeable differences between the populations in the two regions.

The most noticeable difference between regions is animal length: individuals collected from South Africa (up to $32 \mathrm{~mm}$ ) are significantly larger than those from Madagascar (up to $16 \mathrm{~mm}$ ) and Mozambique $(13 \mathrm{~mm})$. However, intermediate sizes may be found when additional populations are discovered, or this could be due to a difference in climate. The deferent duct in the posterior (female) reproductive system is slightly longer in specimens from Madagascar than in specimens from South Africa (even though animal size is larger in South Africa), but this could also be the result of population structure (this trait is known to vary between individuals). In addition, the insertion of the retractor muscle is more posterior in specimens from Madagascar than in South Africa. Finally, Madagascan individuals were found in a different habitat (mangrove) than in South Africa (salt marsh). Salt marshes in Madagascar were not visited for this study and may need to be explored in the future.

Platevindex martensi (Plate, 1893)

Figs 54-58

Oncis martensi Plate, 1893: 196-197, pl. 7, figs 7, 23a, pl. 10, fig. 50.

Oncis inspectabilis Plate, 1893: 198-199. Syn. nov.

Onchidium coriaceum - Semper 1880: 271-273 (in part only) [non Onchidium coriaceum Semper, 1880].

Oncis martensi - Stantschinsky 1907: 395. — Hoffmann 1928: 89.

Oncis inspectabilis - Stantschinsky 1907: 395.

Platevindex martensi - Dayrat 2009: 5.

Platevindex mortoni - Zhang et al. 2017: fig. 1e (non Platevindex mortoni Britton, 1984).

\section{Material examined}

Holotype

THAILAND - holotype $(44 / 41 \mathrm{~mm})$ by monotypy; Petshaburi, Gulf of Siam [Phetchaburi, Gulf of Thailand]; ZMB/Moll 8454.

Holotype of Oncis inspectabilis

MYANMAR • holotype (28/23 mm) by monotypy; Lampee, Birma [Lampi Island, Mergui Archipelago, southern Myanmar, Andaman Sea]; Anderson leg.; ZMB/Moll 38934.

\section{Notes on type material}

Oncis martensi. The holotype was previously dissected. Internal organs are mostly missing; only a few pieces of the female (posterior) reproductive system and digestive system remain. The penial complex and buccal mass are missing.

Oncis inspectabilis. The holotype was previously dissected. Internal organs are mostly missing. The buccal mass remains, as well as pieces of the deferent duct, oviduct and spermatheca. 


\section{Other material}

AUSTRALIA - Northern Territory • 4 specs (39/26 [1711], 25/20 [1709], 25/20 [1710] and 13/12 [1707] mm); Darwin, Elizabeth Road; 12³2.893' S, 13057.642' E; 20 Aug. 2012; station 70; Ceriops and old logs in Rhizophora forest; NTM P.57611.

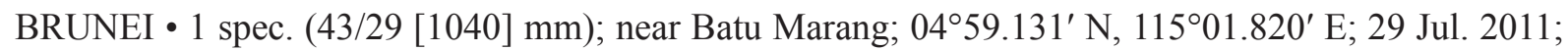
station 34; old mangrove with tall Rhizophora trees with high roots and Thalassina mounds; BDMNH.

INDONESIA - Sumatra • 1 spec. (52/19 [1767] mm); Pulau Sinaboi; 02 ${ }^{\circ} 18.145^{\prime}$ N, $100^{\circ} 59.309^{\prime}$ E; 8 Oct. 2012; station 73; some small Avicennia and Rhizophora near shore; UMIZ 00107 - 1 spec. (22/13 [1776] mm); Dumai; 01 ${ }^{\circ} 42.838^{\prime} \mathrm{N}, 1^{\circ} 1^{\circ} 23.286^{\prime}$ E; 9 Oct. 2012; station 74; mangrove just behind abandoned buildings, high intertidal; UMIZ 00108 - 1 spec. (34/19 [1748] mm); Sungai Lubuk; $05^{\circ} 40.174^{\prime}$ S, $105^{\circ} 34.097^{\prime}$ E; 19 Oct. 2012; station 79; mounds of Thalassina, Rhizophora, dead logs in the high intertidal; UMIZ 00109. - Sulawesi 2 specs (36/23 [2334] and 35/23 [2333] mm); Makassar City, Tallo; $05^{\circ} 06.117^{\prime} \mathrm{S}, 119^{\circ} 26.777^{\prime} \mathrm{E}$; 21 Mar. 2013; station 92; small mangrove with outhouse in center; UMIZ 00111.

MALAYSIA - Peninsular Malaysia • 1 spec. (30/18 [964] mm); Nibong Tebal, Pulau Burung; $05^{\circ} 12.488^{\prime} \mathrm{N}, 100^{\circ} 25.564^{\prime} \mathrm{E}$; $11 \mathrm{Jul}$. 2011; station 17; Rhizophora mangrove with a few Sonneratia and soft mud; USMMC $00029 \cdot 1 \mathrm{spec}$. (31/30 [934] mm); Balok; 0353.219' N, 103²1.978' E; $14 \mathrm{Jul}$. 2011; station 19; Rhizophora mangrove with some Avicennia and mostly hard mud; USMMC 00030 • 2 specs (37/23 [no DNA] and 36/18 [no DNA] mm); Merbok; 05³9.035' N, 100²5.782' E; $18 \mathrm{Jul}$. 2011; station 21; deep Rhizophora forest with old, tall trees, hard mud, many small creeks and dead logs; USMMC 00031 • 1 spec. (39/21 [933] mm); Merbok; 05²40.143’ N, 100²6.178' E; 19 Jul. 2011; station 22; mangrove of mostly Rhizophora, some Avicennia with soft mud near creek; USMMC 00077 • 1 spec. (37/15 [no DNA] mm); Langkawi, Tanjung Rhu; 06²5.317' N, 9950.106' E; 15 Jul. 2011; station 26; open forest of Rhizophora, Sonneratia, Bruguiera with high mounds of mud around some trees; USMMC 00032 - 1 spec. (32/24 [930] mm); Kuala Sepatang; 04 $50.434^{\prime}$ N, $100^{\circ} 38.176^{\prime}$ E; 19 Jul. 2011; station 27; old Rhizophora and Acrostichum ferns very high in tidal zone, near boardwalk; USMMC 00033.

PHILIPPINES - Bohol - 2 specs (31/16 [3342] and 14/8 [3336] mm); Mabini; 09 51.532' N, $124^{\circ} 31.685^{\prime}$ E; 17 Jul. 2014; station 194; narrow Rhizophora and Avicennia mangrove by the sea with fish ponds built on landward side, many dead logs; PNM 041250 4 specs (51/27 [3365], 34/22 [3364], 33/14 [3362] and 24/11 [3358] mm); Mabini; 09 51.402' N, 124³0.982' E; 18 Jul. 2014; station 195; narrow Rhizophora and Avicennia mangrove by the sea with fish ponds built on landward side, cement ditches between the mangrove patches and the ponds; PNM 041251.

SINGAPORE • 1 spec. (31/20 [988] mm); Pasir Ris Park; 01²2.840’ N, 1035․ $224^{\prime}$ E; 30 Mar. 2010; station 5; mud and dead logs in upper tidal; ZRC.MOL.10480 3 specs (40/22 [no DNA], 37/20 [no DNA] and 35/21 [987] mm); Lim Chu Kang; 01 $26.785^{\prime}$ N, 103 42.531' E; 5 Apr. 2010; station 9; piece of wood in Avicennia and Rhizophora mangrove; ZRC.MOL.10481.

\section{Description}

Color and morphology of live animals (Figs 54-55A)

Live animals are not usually covered with mud, and their natural color is visible without washing. The dorsal notum is brown to dark brown or black, often mottled with two colors. The notum bears small elongated (longitudinal) ridges. The ventral color varies but the hyponotum is yellow, beige or yellow-orange, with distinct darker spots of variable size (small to large) and color (faintly tan to black). When those spots are large and dark enough, the hyponotum appears nearly black (which was most common in the Strait of Malacca). The hyponotum of juvenile specimens can be marked by fewer spots. 

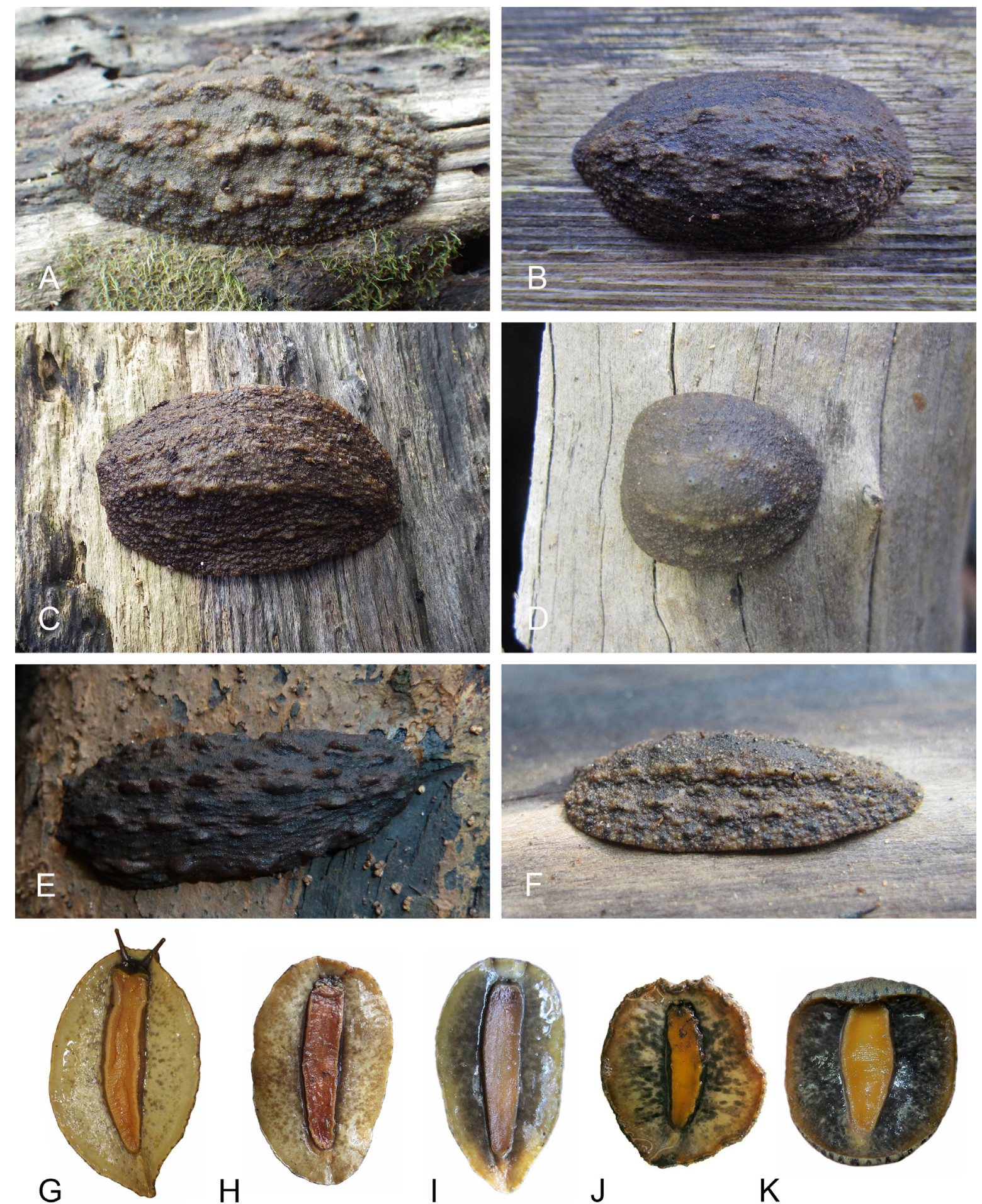

$\mathrm{H}$
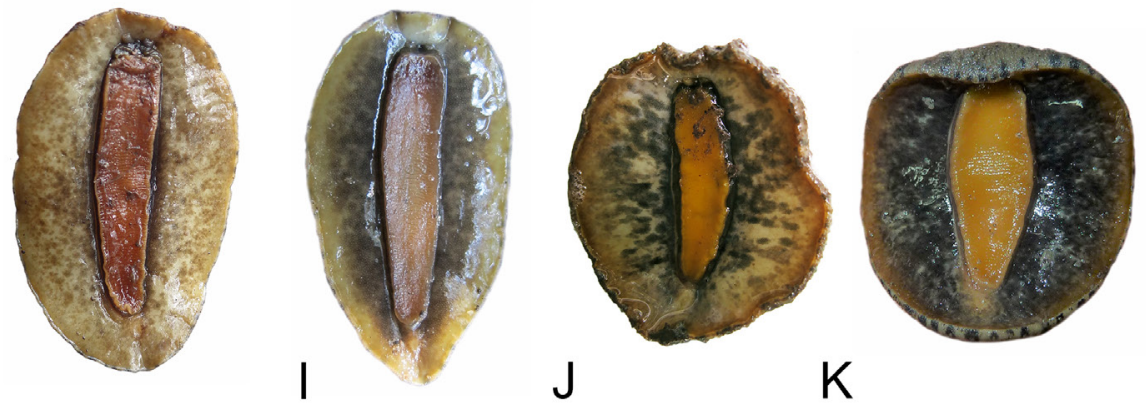

Fig. 54. Platevindex martensi (Plate, 1893), live animals. A. Dorsal view, $34 \mathrm{~mm}$ long [1748], Indonesia, Sumatra (UMIZ 00109). B. Dorsal view, $24 \mathrm{~mm}$ long [3358], Philippines, Bohol (PNM 041251). C. Dorsal view, $34 \mathrm{~mm}$ long [3364], Philippines, Bohol (PNM 041251). D. Dorsal view, $13 \mathrm{~mm}$ long [1707], Australia, Darwin (NTM P.57611). E. Dorsal view, $38 \mathrm{~mm}$ long [\#1], Peninsular Malaysia, Langkawi (USMMC 00032). F. Dorsal view, 25 mm long [1709], Australia, Darwin (NTM P.57611). G. Ventral view, $36 \mathrm{~mm}$ long [2334], Indonesia, Sulawesi (UMIZ 00111). H. Ventral view, same as C. I. Ventral view, same as F. J. Ventral view, $31 \mathrm{~mm}$ long [934], Peninsular Malaysia, Balok (USMMC 00030). K. Ventral view, 30 mm long, [964], Peninsular Malaysia, Penang (USMMC 00029). 


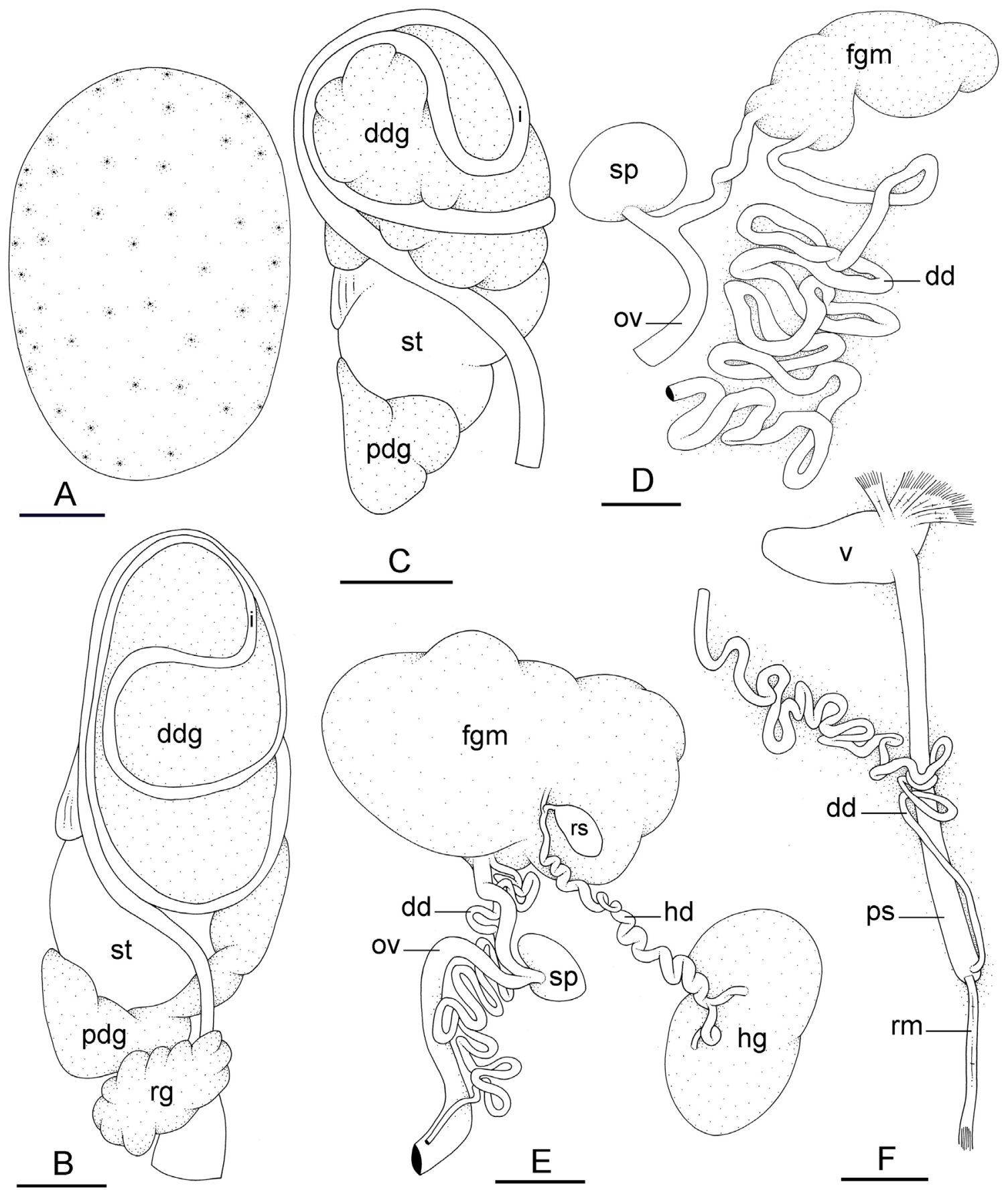

Fig. 55 Platevindex martensi (Plate, 1893), external morphology, digestive and reproductive systems. A. Dorsal notum, entire animal, Bohol, Philippines [3365] (PNM 041251). B. Digestive system, dorsal view, type II with a transitional loop oriented at 9 o'clock, Sulawesi, Indonesia [2333] (UMIZ 00111). C. Digestive system, dorsal view, type II with a transitional loop oriented at 6 o'clock, Peninsular Malaysia [964] (USMMC 00029). D. Posterior reproductive system (remaining parts), Phetchaburi, Gulf of Thailand, holotype (ZMB/Moll 8454). E. Posterior reproductive system, Darwin, Northern Territory, Australia [1711] (NTM P.57611). F. Anterior, male copulatory apparatus, same as E. Abbreviations: $\mathrm{dd}=$ deferent duct; $\mathrm{ddg}=$ dorsal digestive gland; fgm = female gland mass; $\mathrm{hd}=$ hermaphroditic duct; $\mathrm{hg}$ = hermaphroditic gland; $\mathrm{i}=$ intestine; ov = oviduct; $\mathrm{pdg}=$ posterior digestive gland; $\mathrm{ps}$ = penial sheath; $\mathrm{rg}=$ rectal gland; $\mathrm{rm}=$ retractor muscle; $\mathrm{rs}=$ receptaculum seminis; $\mathrm{sp}=$ spermatheca; $\mathrm{st}=$ stomach; $\mathrm{v}=$ vestibule. Scale bars: $\mathrm{A}=10 \mathrm{~mm}$; $\mathrm{B}-\mathrm{C}=3 \mathrm{~mm}$; $\mathrm{D}-\mathrm{F}=2 \mathrm{~mm}$. 
In Malaysia, Singapore and Brunei, the edge of the hyponotum commonly is orange, which was also occasionally observed in other populations. The foot is distinctively orange. Papillae with dorsal eyes are present. Their exact number is variable (generally between 20 and 65). Each papilla bears one dorsal eye. Eyes are distributed across the notum and many eyes are found at the margin (i.e., eyes can be $<2 \mathrm{~mm}$ from the notum edge).

Digestive system (Figs 2C-D, 55B-C, 56)

Radulae measure up to $5 \mathrm{~mm}$ in length. Examples of radular formulae are presented in Table 5. The intestinal loops are of type II, with a transitional loop oriented between 6 and 9 o'clock.

\section{Reproductive system (Figs 55D-F, 57)}

In the posterior part of the reproductive system, the oviduct is wider than the deferent duct (approximately up to twice as wide). Its distal section (distal to the spermatheca) is approximately up to twice as long as its proximal section. The deferent duct is longer than the oviduct, not attached to it, and highly coiled with tight, long, U-shaped loops. However, the deferent duct tends to be shorter in Malaysia and Northern Territory (Australia), and considerably longer in Brunei and the Philippines. The female pore is very close to the anus, between $0.5 \mathrm{~mm}$ and $2.5 \mathrm{~mm}$ apart. The distal, flexible region of the penis with hooks is approximately 2 to $2.5 \mathrm{~mm}$ long and approximately $170 \mu \mathrm{m}$ wide. Penial hooks are relatively large, approximately 35 to $55 \mu \mathrm{m}$ long (Fig. 57B), and can be seen inside the semi-transparent penis or when the penis is evaginated like the finger of a glove in the vestibule (Fig. 57A). The posterior retractor muscle of the penis inserts on the right side, within the third (posterior) quarter of the visceral cavity.
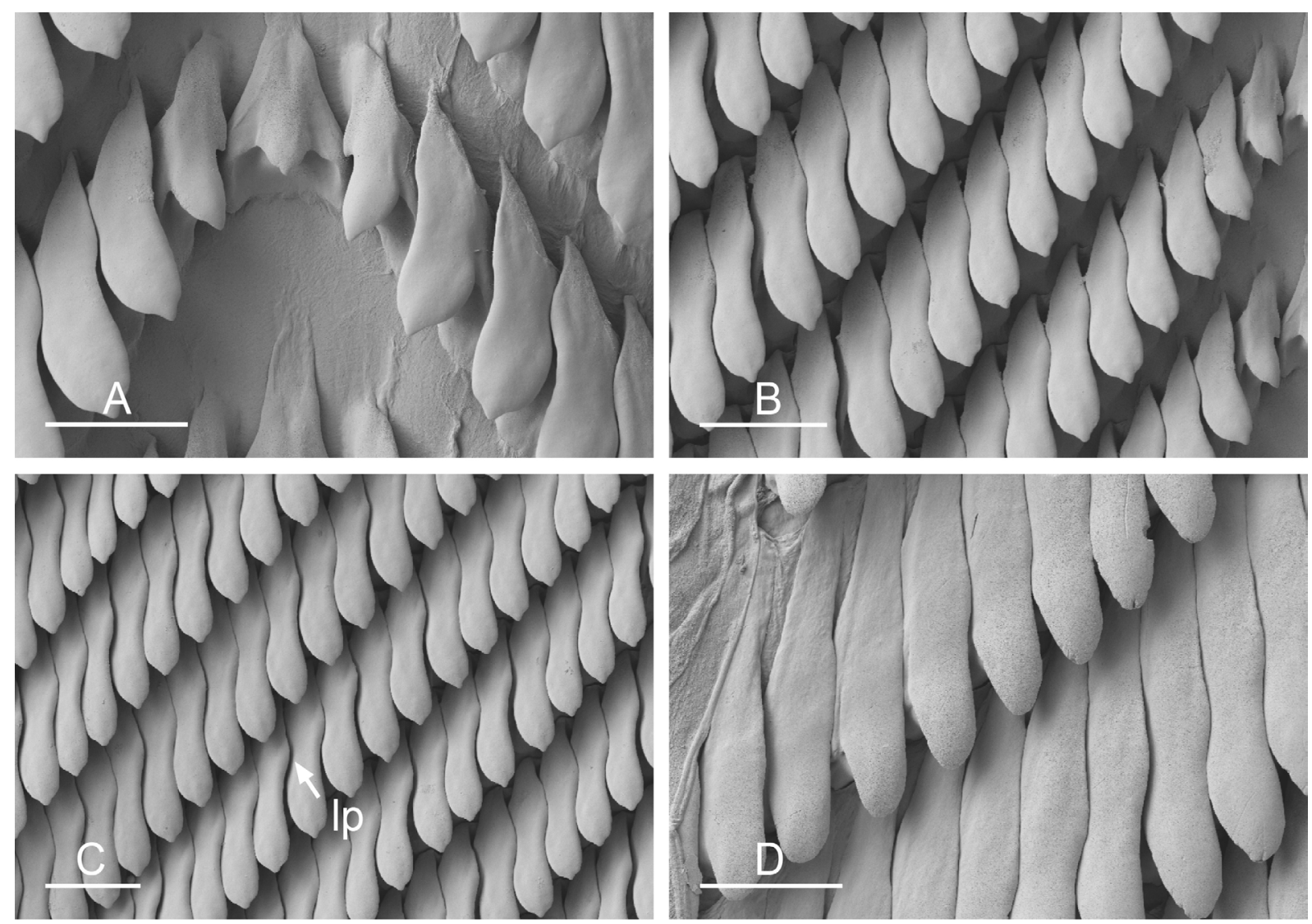

Fig. 56. Platevindex martensi (Plate, 1893), radula, Philippines, Bohol [3336]. A. Rachidian and innermost lateral teeth. B. Innermost lateral teeth. C. Lateral teeth. D. Outermost lateral teeth. Abrreviations: $1 \mathrm{p}=$ lateral protuberance. Scale bars: A, D $=20 \mu \mathrm{m} ; \mathrm{B}-\mathrm{C}=30 \mu \mathrm{m}$. 
The length of the retractor muscle varies from half the length of the penial sheath to slightly longer than the penial sheath. The deferent duct is highly convoluted (but is less convoluted in juvenile specimens).

\section{Distinctive diagnostic features (Table 4)}

Externally, the orange foot distinguishes Platevindex martensi from all other species of Platevindex. The small, elongated ridges on its dorsal notum are also present in P. aptei sp. nov., but the foot of $P$. aptei sp. nov. is black. The presence of many dorsal eyes right at the margin of the dorsal notum (within $2 \mathrm{~mm}$ from the edge) is only shared by P. martensi and P. aptei sp. nov. Internally, the long deferent duct with elongated loops in the anterior penial apparatus (which is not closely attached to the oviduct) differentiate P. martensi from other species of Platevindex. Also, the penial retractor muscle inserts between $1 / 2$ to $3 / 4$ down the length of the visceral cavity in $P$. martensi while it inserts at the posterior end of the cavity in P. aptei sp. nov.

\section{Distribution (Fig. 10C)}

Australia: Northern Territory. Brunei. Indonesia: Sulawesi, Sumatra. Peninsular Malaysia. Myanmar: Andaman Sea (type locality of $P$. inspectabilis). Philippines: Bohol. Singapore. Thailand: Gulf of Thailand (type locality of $P$. martensi). All records are new, except for the type localities.

\section{Habitat (Fig. 58)}

Platevindex martensi is typically found in or near mangroves, on tree roots and trunks as well as dead logs. It usually lives in the high intertidal only reached by the highest tides (with Acrostichum ferns). It can also be found in cement ditches nearby a mangrove. One juvenile was found on coarse-grained sand in a mangrove forest in the Philippines, but Platevindex slugs normally are not found directly on mud or sand. Platevindex martensi is not found on rocky shores.

\section{Remarks}

All of the distinctive characters of Platevindex are present in the holotype of Oncis martensi, including a flattened and hard body, a narrow foot, a male opening to the right of the midline between the two eye tentacles and no accessory penial gland. In the original description of P. martensi, Plate (1893: 196) wrote that the holotype was collected from Singapore by professor von Martens. However, von Martens (1897: 128) later wrote that "Oncis martensi Plate was not found by me at Singapore, but at Petshaburi in the Gulf of Siam," which is in the north of the Gulf of Thailand. The label of the holotype at the Berlin Museum now reads "Siam, Petehabardi" (presumably a misspelling). Hoffmann (1928: 89) considered
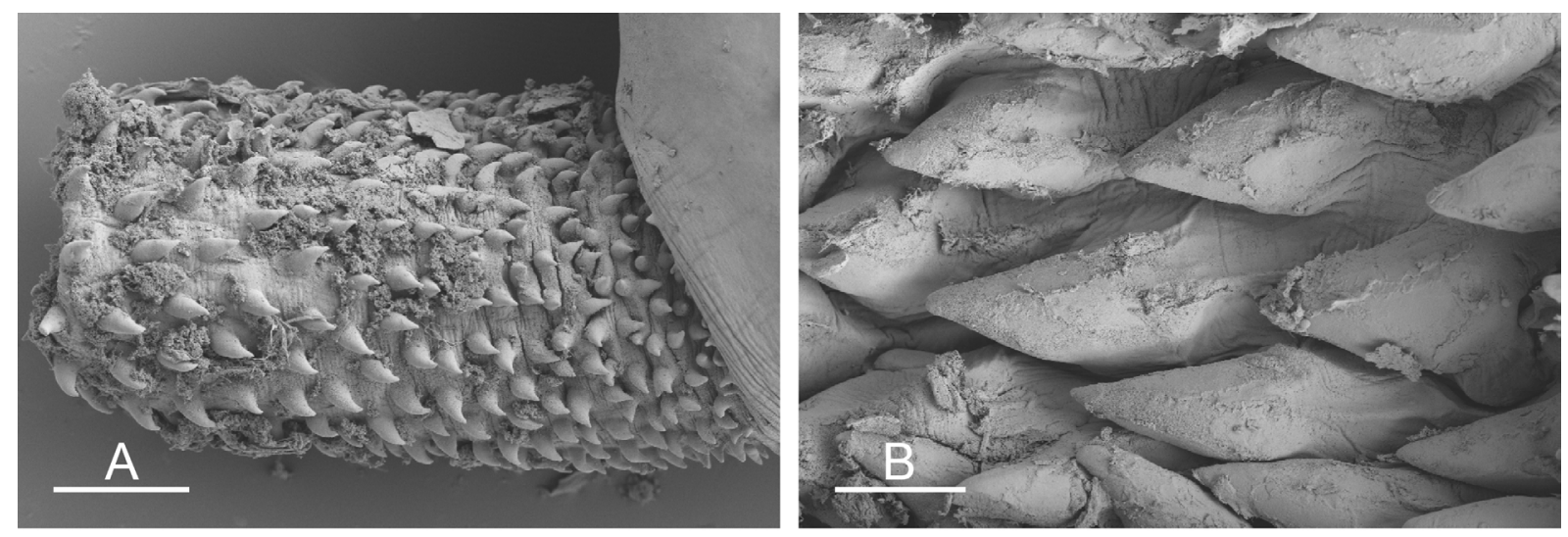

Fig. 57. Platevindex martensi (Plate, 1893), penial hooks. A. Penis everted with hooks outside, Peninsular Malaysia, Penang [964] (USMMC 00029). B. Australia, Darwin [1711] (NTM P.57611). Scale bars: $\mathrm{A}=50 \mu \mathrm{m} ; \mathrm{B}=30 \mu \mathrm{m}$. 
Petshaburi to be the type locality and even specified "Singapore, Plate, ex errore, nach Martens 1897." Also, note that the specific name appears as "martensi" in the text and in one figure caption (Plate 1893: 196, pl. 7, fig. 23a) but as "martensii" in the two other figure captions (Plate 1893: pl. 7, fig. 7, pl. 10, fig. 50).

The posterior (female) reproductive system in the holotype of $P$. martensi is largely destroyed. The hermaphroditic gland is in pieces and disconnected from the hermaphroditic duct. A large part of the female gland mass is separated from the oviduct and the deferent duct. However, the long and convoluted deferent duct is intact and is only consistent with the species described here. Plate (1893: 197) also described the color of the live animal (based on field notes from von Martens) as having an intense yellow hyponotum with black marbling as well as a light gray-brown foot. A yellow hyponotum is only found in P. martensi and P. aptei sp. nov. The color of the foot is the external trait which can distinguish these two species, and Plate's description of "light gray-brown" is a closer match to the bright orange foot of $P$. martensi than the dark black foot of $P$. aptei sp. nov. The number of dorsal eyes he described (90) is higher than what we have observed in P. martensi, but we could not check this as the dorsal eyes have lost their pigment. Plate's (1893: 197) description of the dorsal eyes that "sit alone on the big warts" is consistent with this species, but his comment that "this rule does not apply without exception, because on about 12 warts there are 2 eye spots, so that one can speak in these cases of a group" is surprising. We have found no evidence that dorsal eyes occur in groups of two in this species; Plate's statement that dorsal eyes occurred in pairs suggests that his count of dorsal eyes is likely an overestimate.

Plate's (1893: 198-199) original description of Platevindex inspectabilis from an island in southern Myanmar, in the Andaman Sea, mentioned the diagnostic characters of Platevindex. Plate indicated intestinal loops of type II, but this could not be verified because the intestine of the holotype was previously dissected. Plate's original description indicates a black-blue hyponotum (the color of the holotype has faded over time and could not be verified). Fresh specimens were not available from Myanmar, but many specimens were observed with a nearly solid black hyponotum (due to a high density of black spots) along the north-western coast of peninsular Malaysia. Despite a slight difference in the description of the hyponotum color, it can be determined that the holotype of P. inspectabilis belongs to the species described here due to the remains of its female (posterior) reproductive system. The length of the deferent duct adjacent to the oviduct is long and convoluted with elongated loops, which is indistinguishable from $P$. martensi (the deferent duct is similar in length in specimens of a similar size from Peninsular Malaysia). The length of the distal portion of the penis with hooks in P. inspectabilis $(2 \mathrm{~mm})$ also fits exactly the size range observed in P. martensi $(2-2.5 \mathrm{~mm})$. So, for all the reasons above, $P$. inspectabilis is considered here to be a junior synonym of $P$. martensi.

Semper's (1882) original description of Onchidium coriaceum was based on syntypes that are part of at least two species (see our remarks on Platevindex coriaceus coriaceus). One paralectotype of $O$. coriaceum from Penang belongs to P. martensi. Indeed, its posterior (female) reproductive system is not compatible with $P$. coriaceus, $P$. tigrinus or $P$. luteus, but displays the diagnostic feature of P. martensi (the wide, long, highly-convoluted deferent duct adjacent to the oviduct). In addition, Semper rightly noted that dorsal eyes are present across the notum including on its margin, and dorsal eyes very close to the notum edge $(<2 \mathrm{~mm})$ are only found in P. martensi and P. aptei sp. nov.

Zhang et al. (2017) recently re-described a species they identified as Platevindex mortoni based on specimens from Hong Kong, but $P$. mortoni is considered here a nomen dubium and their description is based on specimens that belong to at least two different species. One individual illustrated with a bright orange foot (Zhang et al. 2017: fig. 1e) is identified here as P. martensi.

Plate (1893: 196-199) did not comment on the very close similarity between Platevindex inspectabilis and $P$. martensi in his original descriptions, but he compared $P$. inspectabilis to P. semperi, from the 
Philippines (Plate 1893: 199). This may be due to a similarity in their hyponotum color; the preserved hyponota of both $O$. inspectabilis and $O$. semperi were described by Plate as dark blue (though, now, decades later, the hyponotum is creamish in the type specimens of both species). However, P. inspectabilis and $P$. semperi are not regarded as synonyms because Plate's (1893: 193) description of the copulatory apparatus of $P$. semperi indicates that it is a junior synonym of $P$. coriaceus. Platevindex inspectabilis was also proposed as a synonym of Oncis stuxbergi by Hoffmann (1928: 88) and Labbé (1934: 235), but Vaginulus stuxbergi Westerlund, 1883 actually belongs to the genus Onchidium (Dayrat et al. 2016).

We collected Platevindex martensi in Northern Territory, Australia, but did not find it in Queensland, Australia, though it cannot be excluded that we missed it there. An online photo (viewed at https://www.inaturalist.org/observations/14094815 on 30 Jul. 2018) from Maroochy, Mooloolaba, Queensland, shows a Platevindex slug with elongated dorsal ridges similar to those found in P. martensi and $P$. aptei sp. nov. Also, its description mentions that it is an "orange footed mangrove onch slug." Because no photograph of the ventral surface is available, the identification of that slug cannot be confirmed. Until this geographic record is confirmed by the examination of actual specimens, Queensland is not considered part of the geographic distribution for P. martensi.
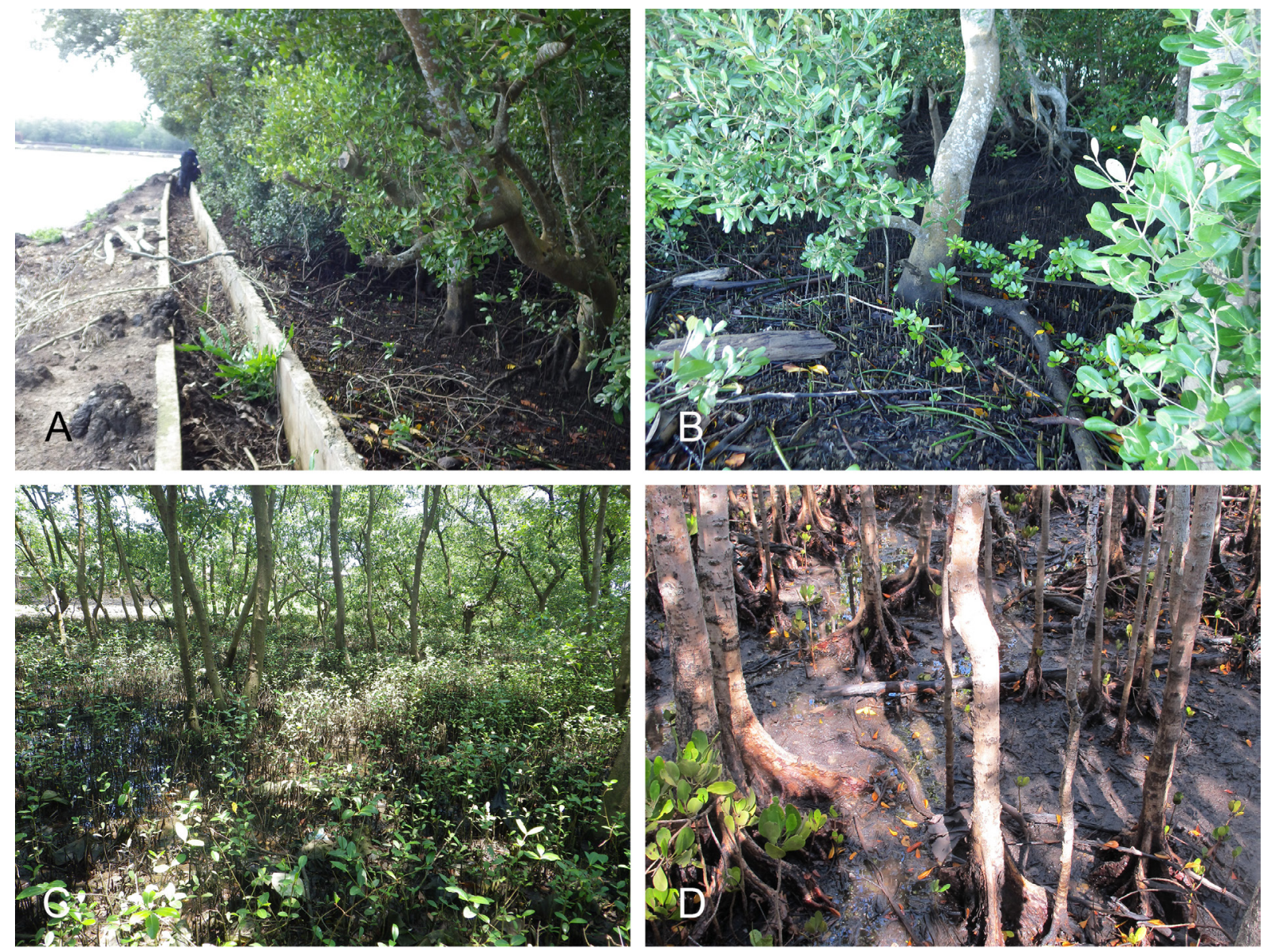

Fig. 58. Habitats of Platevindex martensi (Plate, 1893). A. Philippines, Bohol, narrow mangrove will tall trees on edge of fish ponds, cement ditches between the mangrove patches and the ponds (station 195). B. Philippines, Bohol, narrow mangrove on the edge of fish ponds, tall Rhizophora and Avicennia, many dead $\operatorname{logs}$ (station 194). C. Indonesia, Sulawesi, small mangrove used as outhouse by village, very impacted by trash (station 92). D. Australia, Darwin, Ceriops and old logs in Rhizophora forest (station 70). 
Platevindex aptei Goulding \& Dayrat sp. nov. urn:1sid:zoobank.org:act:25DECF9A-226F-40A8-BC49-99815E6B2B9D

Figs 59-63

\section{Etymology}

Platevindex aptei sp. nov. is named for Deepak Apte, a great naturalist and the Executive Director of the Bombay Natural History Society, Mumbai, India. Deepak Apte provided great help in the organization of our fieldwork in India as well as with molecular lab work at the National Centre for Cell Science in Pune. We would not have been able to explore the mangroves of India without his assistance.

\section{Material examined}

\section{Holotype}

INDIA - holotype $\left(45 / 20\right.$ [1112] mm); Andaman Islands, Shantipur, Kadamtala; $12^{\circ} 19.844^{\prime}$ N, $92^{\circ} 46.377^{\prime} \mathrm{E}$; 12 Jan. 2011; station 58, mangrove creek, open forest, lots of dead logs and trees; BNHS 3-1112.

\section{Other material}

INDIA - Andaman Islands • 1 spec. (35/20 [1092] mm); Shamkund, near Rangat; 12 $29.448^{\prime} \mathrm{N}$, $92^{\circ} 50.620^{\prime} \mathrm{E}$; $11 \mathrm{Jan} .2011$; station 57 ; ditches by road to the mangroves with high trees down to the mud on side of river; BNHS 8-1092 • 1 spec. $(35 / 20$ [1093] mm); same collection data as for preceding; BNHS 8-1093 - $3 \operatorname{specs}(55 / 35$ [\#1], 50/35 [\#2] and 25/18 [\#3] mm); same collection data as for preceding; BNHS $8 \cdot 1$ spec. (25/20 [1111] mm); Shantipur, Kadamtala; $12^{\circ} 19.844^{\prime}$ N, $92^{\circ} 46.377^{\prime}$ E; 12 Jan. 2011; station 58; mangrove creek, open forest, lots of dead logs and trees; BNHS 3-1111 1 spec.

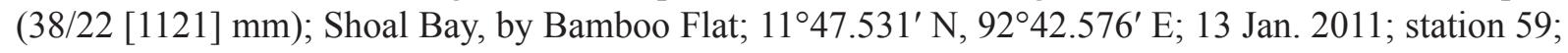
ditches and mud along the road; BNHS 14-1121.

MALAYSIA - Peninsular Malaysia - 1 spec. (28/17 [no DNA] mm); Penang; 05²3.782' N, $100^{\circ} 11.469^{\prime}$ E; 8 Jul. 2011; station 12; open Avicennia mangrove with many dead logs; USMMC

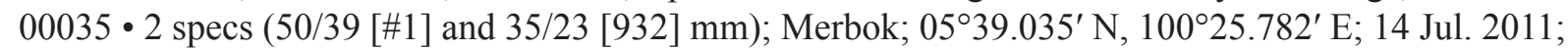
station 21; deep Rhizophora forest with old, tall trees, hard mud, many small creeks and dead logs; USMMC $00036 \bullet 1$ spec. (31/24 [917] mm); Matang; 0450.154' N, 100³6.868' E; 20 Jul. 2011; station 29; old Rhizophora mangrove with hard mud and open space between trees; USMMC $00037 \cdot 3$ specs (42/25 [5967], 37/21 [5968] and 35/22 [5955] mm); Matang; 0450.217' N, 100³6.826' E; 26 Jul. 2016; station 256; old Rhizophora mangrove with hard mud and open space between trees; USMMC 00078.

\section{Description}

\section{Color and morphology of live animals (Fig. 59)}

Live animals are not usually covered with mud, and their natural color is usually visible without washing. The dorsal notum is brown, sometimes with darker markings. The notum bears low, elongated (longitudinal) ridges. The foot is black (Malaysia) or dark brown (India). The background of the hyponotum is bright yellow (Malaysia) to light yellow or beige (India) with a varying number of spots that range from light brown (India) to dark brown or black (Malaysia). Spots tend to be more concentrated around the margin of the hyponotum, but their density is highly variable (from only around the margin to the entire hyponotum). Exceptionally, the hyponotum can be homogenously dark brown with only a small yellow band around the foot. Small or juvenile specimens tend to have fewer or no spots on the hyponotum. Papillae with dorsal eyes are present. Their exact number is variable (between 35 and 50). Each papilla bears one dorsal eye. The dorsal eyes are distributed across the notum, with numerous eyes at the margin of the notum (i.e., many eyes are $<2 \mathrm{~mm}$ from the notum edge). 

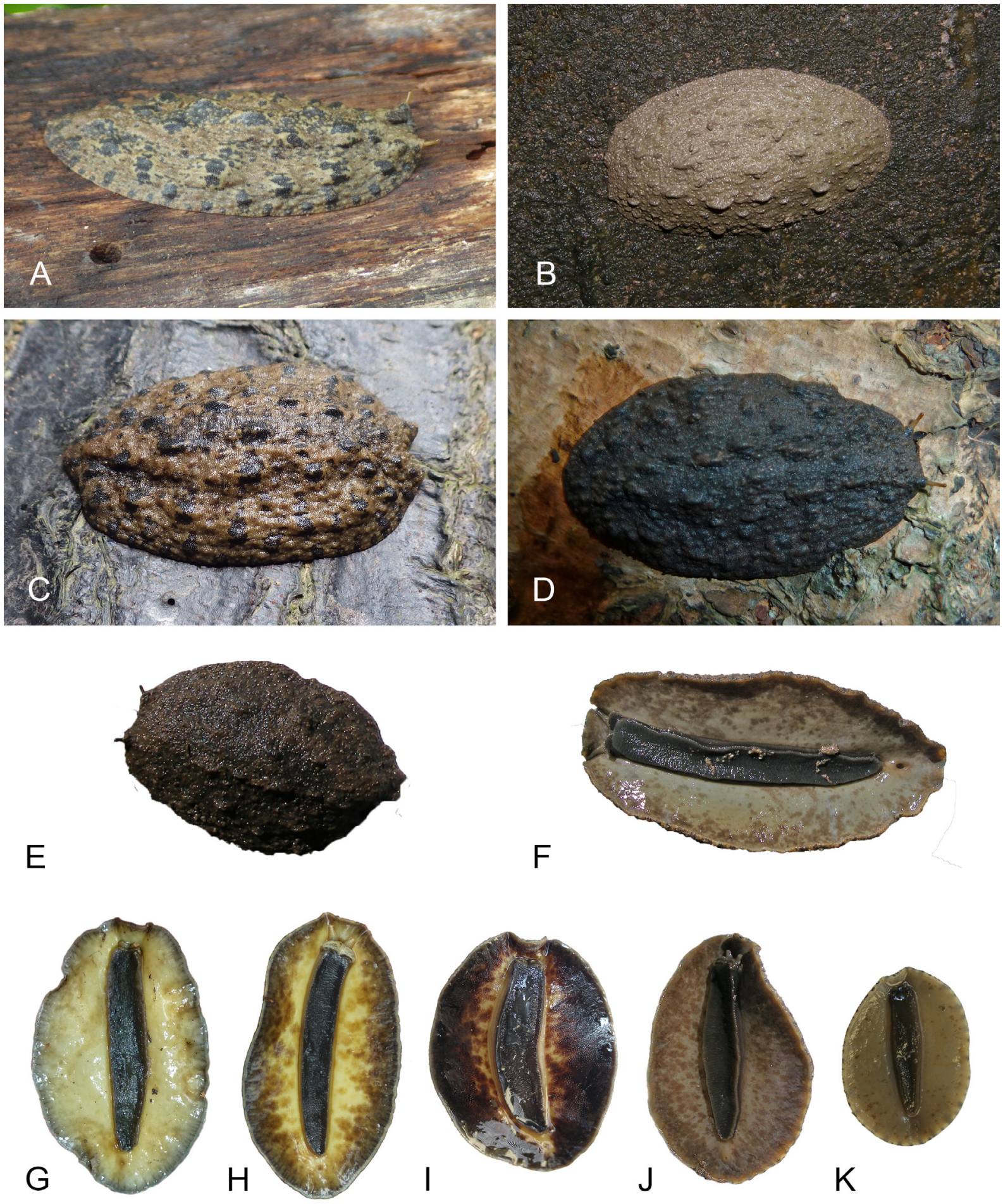

Fig. 59. Platevindex aptei Goulding \& Dayrat sp. nov., live animals. A. Dorsal view, $42 \mathrm{~mm}$ long [5967], Malaysia, Matang (USMMC 00078). B. Dorsal view, 55 mm [\#1], India, Andaman Islands, Shamkund, near Rangat (BNHS 8). C. Dorsal view, $35 \mathrm{~mm}$ long [5955], Peninsular Malaysia, Matang (USMMC 00078). D. Dorsal view, 45 mm long [\#2], Peninsular Malaysia, Merbok (USMMC 00036). E. Dorsal view, holotype, $45 \mathrm{~mm}$ long [1112], India, Andaman Islands, Shantipur (BNHS 3-1112). F. Ventral view, same as E. G. Ventral view, same as D. H. Ventral view, same as A. I. Ventral view, $50 \mathrm{~mm}$ [\#2] India, Andaman Islands (BNHS 8). J. Ventral view, $25 \mathrm{~mm}$ long [1111], India, Andaman Islands (BNHS 3-1111). K. Ventral view, 25 mm [\#3] India, Andaman Islands (BNHS 8). 
Digestive system (Figs 2F, 60, 61A-B)

Radulae measure up to $6.4 \mathrm{~mm}$ long. Examples of radular formulae are presented in Table 5. The intestinal loops are of type II, with a transitional loop oriented between 7 and 9 o'clock (Figs 2F, 61A-B).

\section{Reproductive system (Figs 61C, 62)}

In the posterior part of the reproductive system, the oviduct is wider than the deferent duct (up to twice as wide). Its distal section (distal to the spermatheca) is slightly longer than its proximal section and is sharply bent (U-shaped). The deferent duct is slightly longer than the oviduct, not attached to it, and loosely to highly convoluted (Fig. 61C). The penial sheath is very thick but the penis inside is extremely thin. The vestibule is cylindrical and attached to the anterior, dorsal wall of the visceral cavity by many short muscle fibers. The distal, flexible region of the penis with hooks is approximately 2.5 to $5 \mathrm{~mm}$ long and is very narrow, approximately $80 \mu \mathrm{m}$ wide. Penial hooks are large, approximately 30 to $40 \mu \mathrm{m}$ long, and can be seen inside the semi-transparent penis. The retractor muscle of the penis inserts at the posterior end of the visceral cavity, near the rectum. The retractor muscle varies from much shorter than the penial sheath (one-fifth its length) to approximately as long as the penial sheath. In the penial complex, the deferent duct is convoluted in small loops (Fig. 62D).

\section{Distinctive diagnostic features (Table 4)}

Externally, Platevindex aptei sp. nov. can be easily distinguished from all other known species of Platevindex by its strikingly distinctive black or dark brown foot. The bright yellow or beige hyponotum
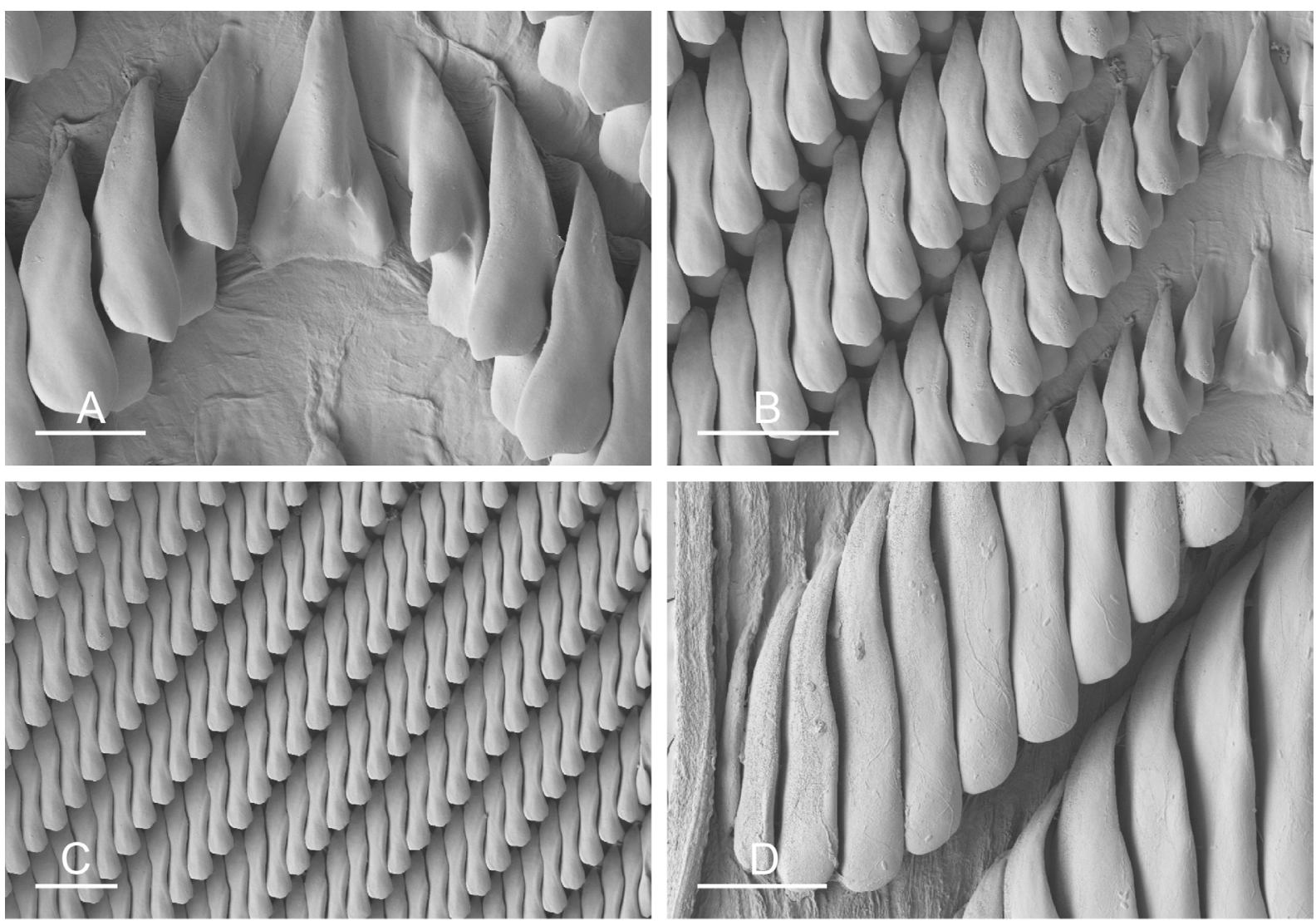

Fig. 60. Platevindex aptei Goulding \& Dayrat sp. nov., radula, Peninsular Malaysia, Matang [5967] (USMMC 00078). A. Rachidian and innermost lateral teeth. B. Innermost lateral teeth. C. Lateral teeth. D. Outermost lateral teeth. Scale bars: A, $D=20 \mu \mathrm{m} ; \mathrm{B}=50 \mu \mathrm{m} ; \mathrm{C}=60 \mu \mathrm{m}$. 
distinguishes it from most other species of Platevindex, but this also occurs in P. martensi. Low, elongated (longitudinal) ridges on the dorsal notum are diagnostic of $P$. aptei sp. nov. as well as $P$. martensi. Internally, the thick penial sheath with a very narrow penis is a distinctive characteristic of $P$. aptei sp. nov., and the flexible region of the penis bearing spines is longer in $P$. aptei sp. nov. $(2.5-5 \mathrm{~mm})$ than in P. martensi (2-2.5 mm long).
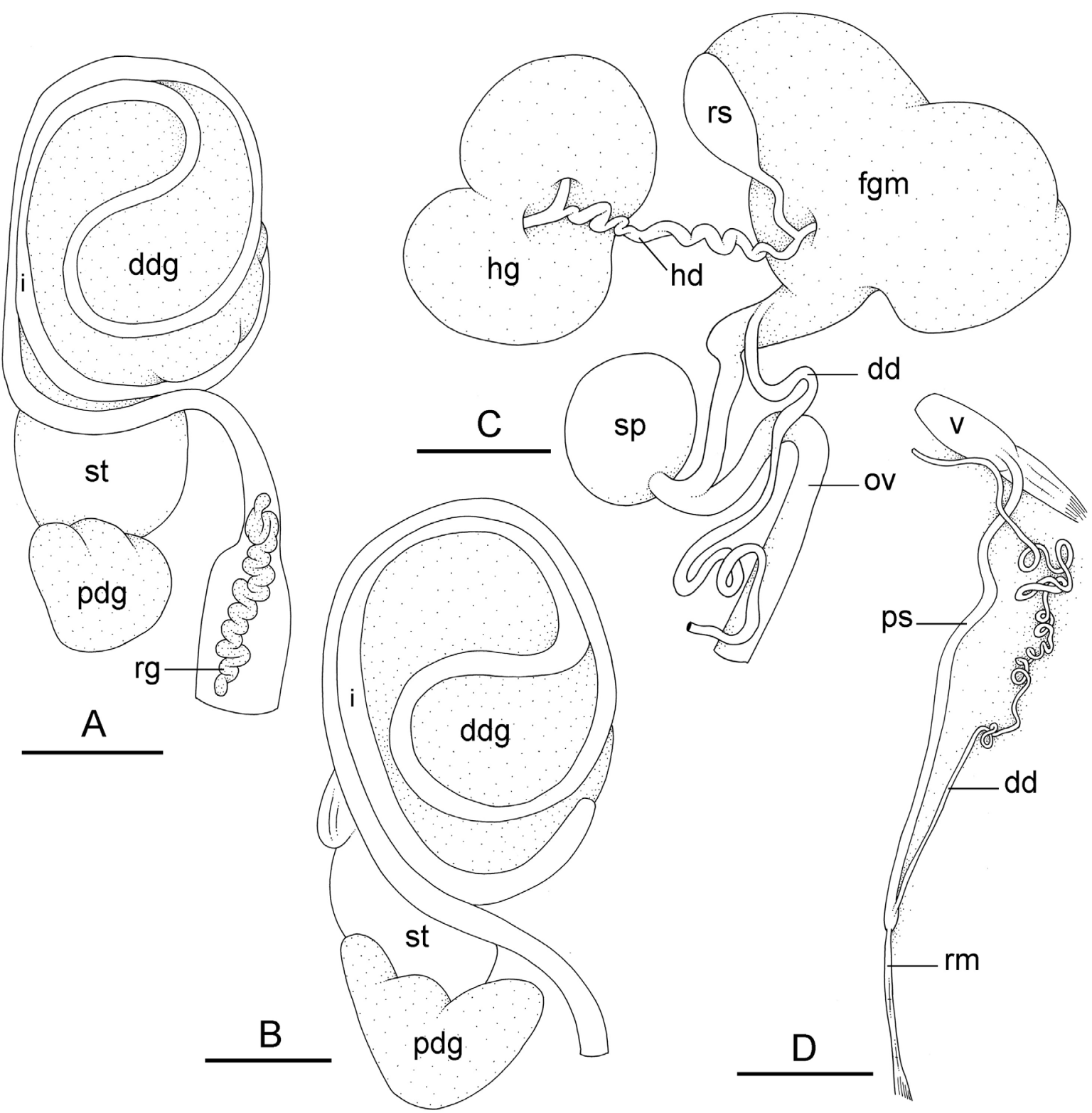

Fig. 61. Platevindex aptei Goulding \& Dayrat sp. nov., digestive and reproductive systems, Peninsular Malaysia. A. Digestive system, dorsal view, type II, with a transitional loop oriented at 8 o'clock, [5955] (USMMC 00078). B. Digestive system, dorsal view, type II, with a transitional loop oriented at 9 o'clock, [5968] (USMMC 00078). C. Posterior reproductive system, same as A. D. Anterior, male copulatory apparatus, same as A. Abbreviations: $\mathrm{dd}=$ deferent duct; $\mathrm{ddg}=$ dorsal digestive gland; fgm = female gland mass; hd = hermaphroditic duct; $\mathrm{hg}=$ hermaphroditic gland; $\mathrm{i}=$ intestine; ov = oviduct; pdg $=$ posterior digestive gland; $\mathrm{ps}=$ penial sheath; $\mathrm{rg}=$ rectal gland; $\mathrm{rm}=$ retractor muscle; $\mathrm{rs}=$ receptaculum seminis; $\mathrm{sp}=$ spermatheca; $\mathrm{st}=$ stomach; $\mathrm{v}=$ vestibule. Scale bars: $\mathrm{A}, \mathrm{D}=4 \mathrm{~mm}$; $\mathrm{B}=3 \mathrm{~mm} ; \mathrm{C}=2 \mathrm{~mm}$. 
Distribution (Fig. 10C)

India: Andaman Islands. Malaysia: Peninsular Malaysia.

\section{Habitat (Fig. 63)}

Platevindex aptei sp. nov. is found in mangroves, typically on large, dead logs, as well as on tree trunks and roots, and cement ditches adjacent to mangroves, but is not found directly on mud. It is usually found in the high intertidal. It does not live on rocky shores.

\section{Remarks}

Platevindex aptei sp. nov. may also be present in Singapore, although it was not found there during our recent visit. Many onchidiid species present in the Bay of Bengal and Peninsular Malaysia are also present in Singapore, such as Platevindex coriaceus, P. tigrinus, P. martensi, Peronina tenera (Goulding et al. 2018c), Onchidium typhae (Dayrat et al. 2016), Melayonchis siongkiati and M. eloisae (Dayrat et al. 2017). However, there are other instances of onchidiid species which have not recently been found in Singapore even though they should be there based on their known geographic distribution, such as Onchidium stuxbergi (Dayrat et al. 2016) and Melayonchis aileenae Dayrat \& Goulding, 2017 (Dayrat et al. 2017). A photo of a slug erroneously identified as Onchidium griseum, but which actually illustrates Platevindex aptei sp. nov., was found online, posted on the website WildSingapore.com with photos of P. martensi. The locality listed with the photo online is Sungei Buloh Wetland Reserve, Singapore, suggesting that $P$. aptei sp. nov. is present there. However, if $P$. aptei sp. nov. is present in Singapore, it may be at low abundance.

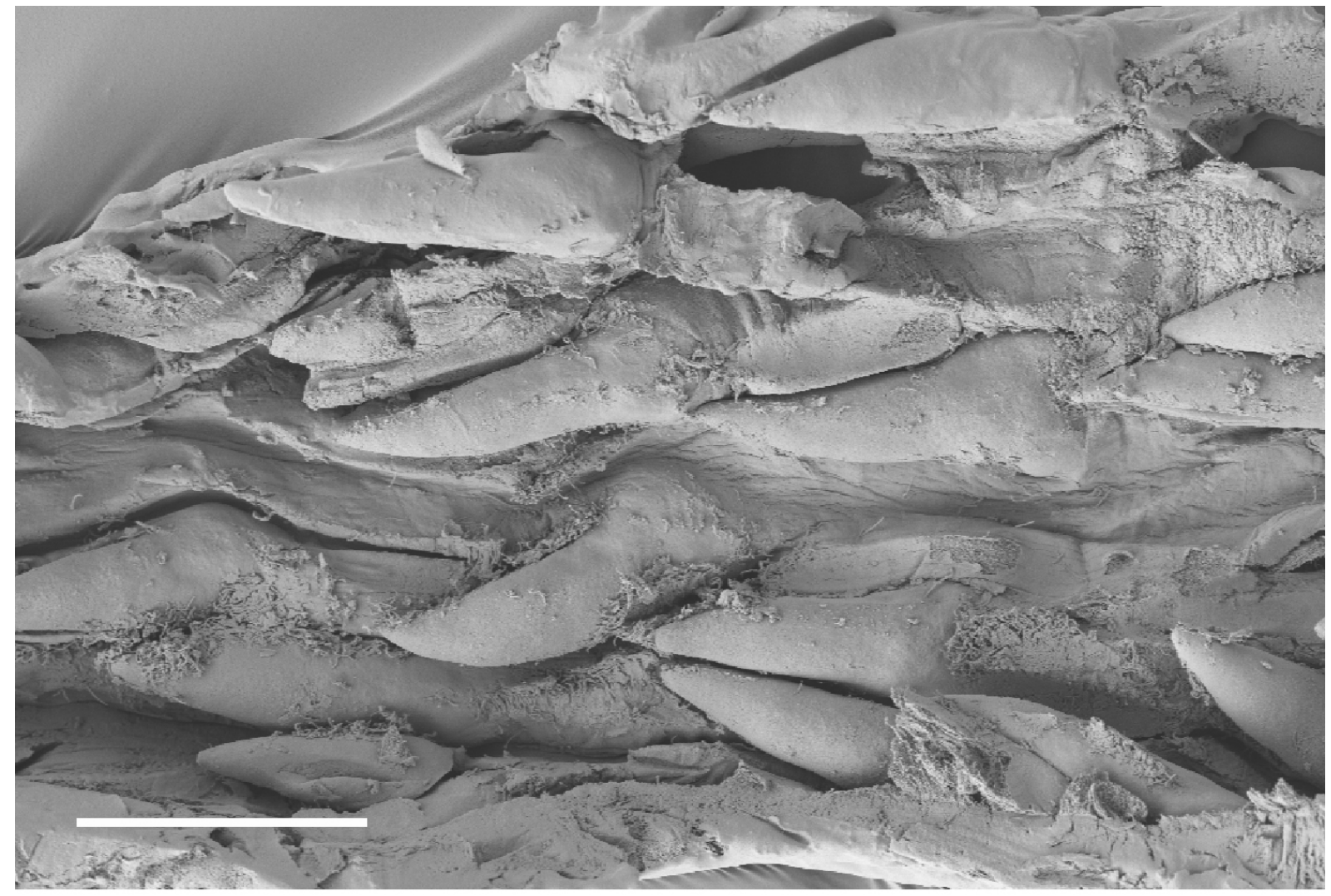

Fig. 62. Platevindex aptei Goulding \& Dayrat sp. nov., penial hooks, Peninsular Malaysia, Matang [5967] (USMMC 00078). Scale bar $=30 \mu \mathrm{m}$. 
Platevindex amboinae (Plate, 1893)

Figs 64-69

Onchidium amboinae Plate, 1893: 177-179, pl. 7, fig. 8, pl. 11, fig. 66.

Oncis coeca Plate, 1893: 199-200, pl. 7, fig. 9.

Oncis lata - von Martens 1897: 128 [non Oncis lata Plate, 1893].

Oncis coeca - Stantschinsky 1907: 395. - Hoffmann 1928: 86-87.

Oncis amboinae - Hoffmann 1928: 86-87.

Platevindex amboinae - Dayrat 2009: 5.

\section{Material examined}

Lectotype (here designated)

INDONESIA • lectotype (28/18 mm); Amboina [Ambon]; von Martens leg.; ZMB/Moll 11621a.

\section{Paralectotypes}

INDONESIA 9 paralectotypes (29/20 to $18 / 12 \mathrm{~mm})$; same collection data as for lectotype; ZMB/Moll $11621 b$.
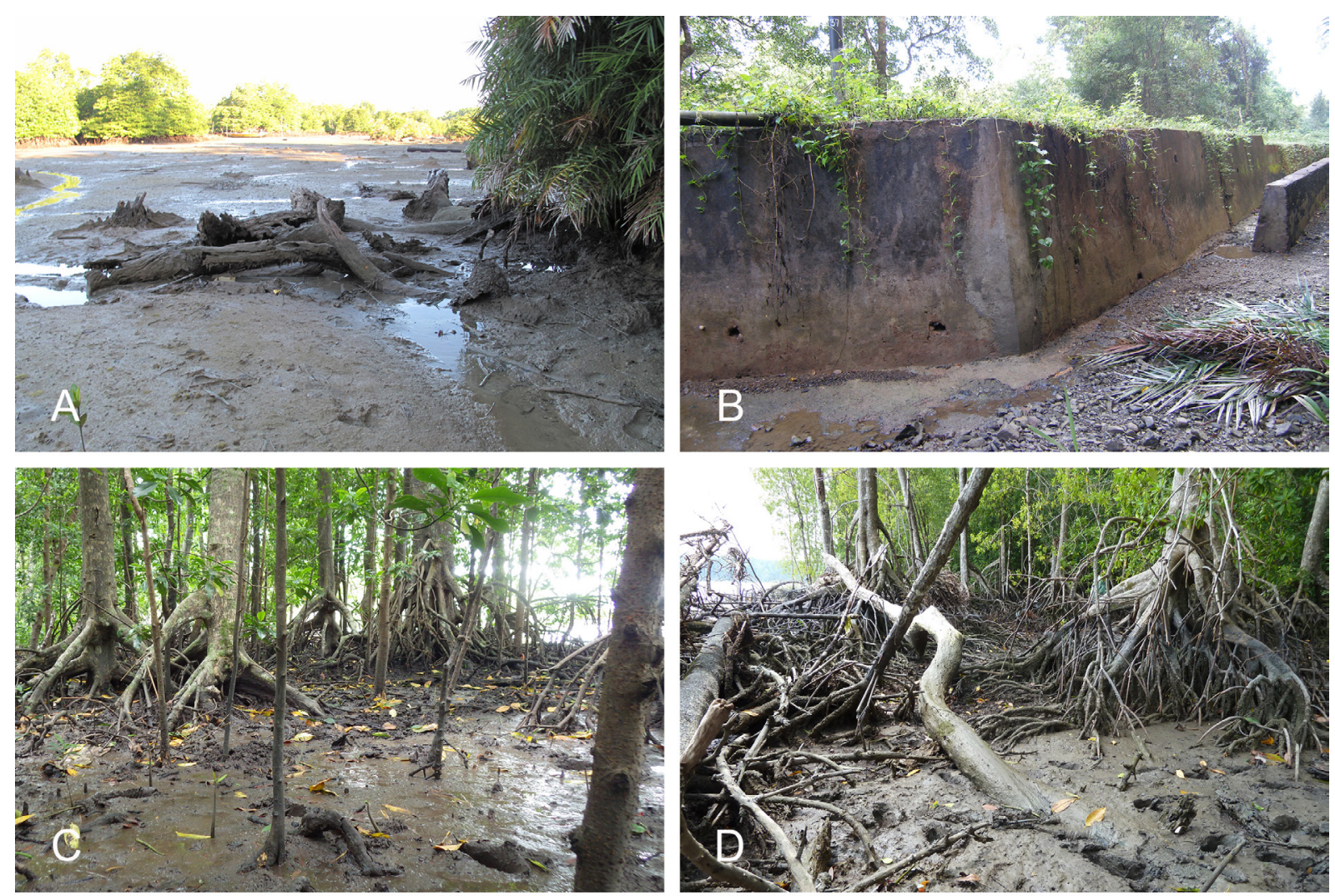

Fig. 63. Habitats of Platevindex aptei Goulding \& Dayrat sp. nov. A. India, Andaman Islands, mangrove creek, open, lots of dead logs and trees (station 58). B. India, Andaman Islands, ditches by road to the mangroves with high trees (station 57). C. Peninsular Malaysia, Matang, large, old Rhizophora forest, hard mud and open space (station 256). D. Peninsular Malaysia, Matang, large, old Rhizophora forest, hard mud and open space between trees (station 29). 


\section{Holotype of Oncis coeca}

INDONESIA - holotype (27/16 mm) by monotypy; Amboina [Ambon]; expedition Gazelle leg.; ZMB/Moll 27446.

\section{Notes on type material}

Onchidium amboinae. The notum of the lectotype was cut open for the present study to examine the internal anatomy; no internal organs were removed. Three paralectotypes (29/20, 28/21 and $27 / 23 \mathrm{~mm}$ ) are completely empty with no internal organs. Two paralectotypes $(25 / 17$ and $24 / 15 \mathrm{~mm})$ were previously dissected, with their internal organs remaining except for the male parts. Four paralectotypes $(24 / 14,23 / 20,20 / 15$ and $18 / 12 \mathrm{~mm})$ are still unopened.

Oncis coeca. Parts of the posterior (female) reproductive system and of the digestive system are still present in the holotype, although they were previously dissected into pieces, likely by Plate himself. Of the male reproductive parts, only the deferent duct remains.

\section{Other material}

INDONESIA - Seram • 1 spec. (38/28 [2883] mm); Piru; 0304.072' S, $128^{\circ} 11.362^{\prime}$ E; 19 Feb. 2014; station 136; beach of palms and Acrostichum ferns behind Sonneratia mangrove; UMIZ 00105. Halmahera • 2 specs (32/14 [5043] and 32/22 [5843] mm); Buli; 00 ${ }^{\circ} 55.367^{\prime} \mathrm{N}, 128^{\circ} 20.647^{\prime} \mathrm{E}$; 17 Mar. 2015; station 213; tall and old Rhizophora forest, high intertidal; UMIZ 00106. - Sulawesi 5 specs (30/25, 20/20, 20/15, 18/15 and 15/15 mm); Luwu; M. Weber leg.; ZMB/Moll 46314 3 specs (25/20, 22/17 [\#1] and 15/12 mm); SMF 333602/3.
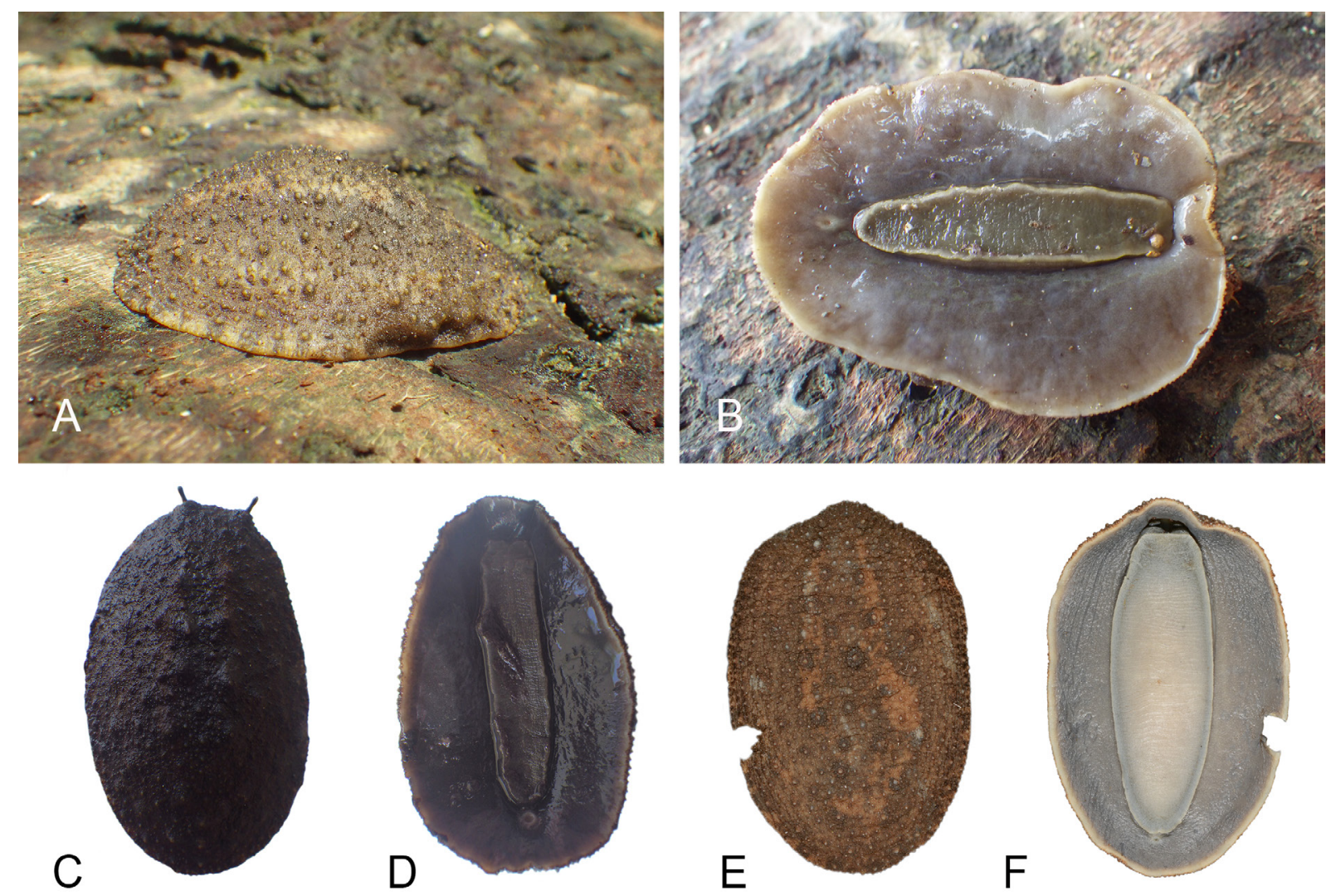

Fig. 64. Platevindex amboinae (Plate, 1893), live and preserved animals, Indonesia. A. Dorsal view, $38 \mathrm{~mm}$ long [2883], Seram (UMIZ 00105). B. Ventral view, same as A. C. Dorsal view, $32 \mathrm{~mm}$ long [5043], Halmahera (UMIZ 00106). D. Ventral view, same as C. E. Dorsal view, preserved specimen, $32 \mathrm{~mm}$ long [5843], Halmahera (UMIZ 00106). F. Ventral view, same as E. 


\section{Description}

Color and morphology of live animals (Fig. 64)

Live animals are usually not covered with mud, and their natural color is usually mostly visible without washing. The dorsal notum varies from light brown to dark brown, almost black. The hyponotum varies from grey to dark blue, almost black. The foot is yellowish-grey to dark grey (almost black). Dorsal papillae are short $(<1 \mathrm{~mm})$ and do not bear eyes. Large, thorny papillae are absent.

Digestive system (Figs 3C-E, 65-66, 67A)

Radulae measure up to $5.2 \mathrm{~mm}$ long. Examples of radular formulae are presented in Table 5. The intestinal loops are of type III, with a transitional loop oriented between 1 and 6 o'clock (Figs 3C-E, 66A-B). The intestinal loops of the lectotype (Fig. 67A) are indistinguishable from those observed in a specimen from Sulawesi (Fig. 66B).

\section{Reproductive system (Figs 67B-68)}

In the posterior part of the reproductive system, the oviduct is slightly wider than the deferent duct. Its distal section (distal to the spermatheca) is slightly shorter than its proximal section (or of the same length). The deferent duct is much longer than the oviduct, not attached to it, and highly coiled with long loops. The distal, flexible region of the penis is from 1 to $2.5 \mathrm{~mm}$ long and bears no hooks. The posterior retractor muscle of the penis inserts within the anterior half of the visceral cavity (and near the nervous system in specimens from Halmahera). The retractor muscle varies from approximately half the length of the penial sheath to as long as the penial sheath. The deferent duct is highly convoluted, with many loops around the penis. The deferent duct is twice as wide distally as proximally.
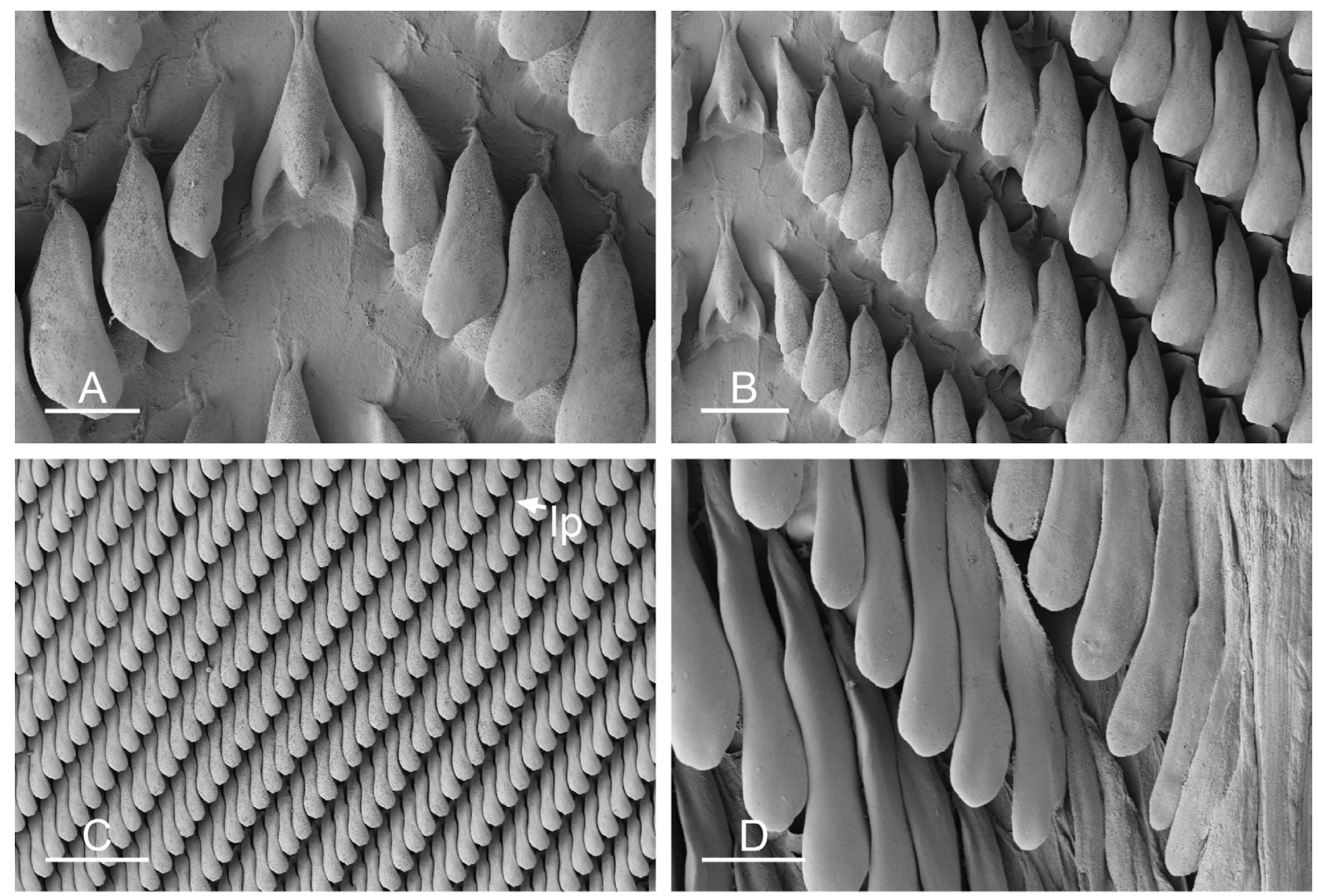

Fig. 65. Platevindex amboinae (Plate, 1893), radula, Indonesia, Seram [2883]. A. Rachidian and innermost lateral teeth. B. Lateral teeth with rachidian teeth. C. Lateral teeth. D. Outermost lateral teeth. Abbreviation: $1 \mathrm{p}=$ lateral protuberance. Scale bars: A, $\mathrm{D}=20 \mu \mathrm{m} ; \mathrm{B}=30 \mu \mathrm{m} ; \mathrm{C}=100 \mu \mathrm{m}$. 


\section{Distinctive diagnostic features (Table 4)}

Externally, the lack of dorsal eyes is shared by both Platevindex amboinae and P. latus. However, the lack of dorsal eyes should be used with caution for identification because dorsal eyes often are retracted (and thus hard to see). Platevindex amboinae can be distinguished from P. latus by the presence of smaller dorsal papillae (the papillae of $P$. latus are larger and thorny). Internally, intestinal loops of type III are found in only two species of Platevindex, P. amboinae and P. latus. Both species, however, can be distinguished by the deferent duct in the anterior reproductive system, which seems to be slightly more convoluted in $P$. amboinae than in P. latus, although this should probably be evaluated with additional individuals. Based on the available data, however, P. amboinae and P. latus do not overlap geographically (Fig. 10).
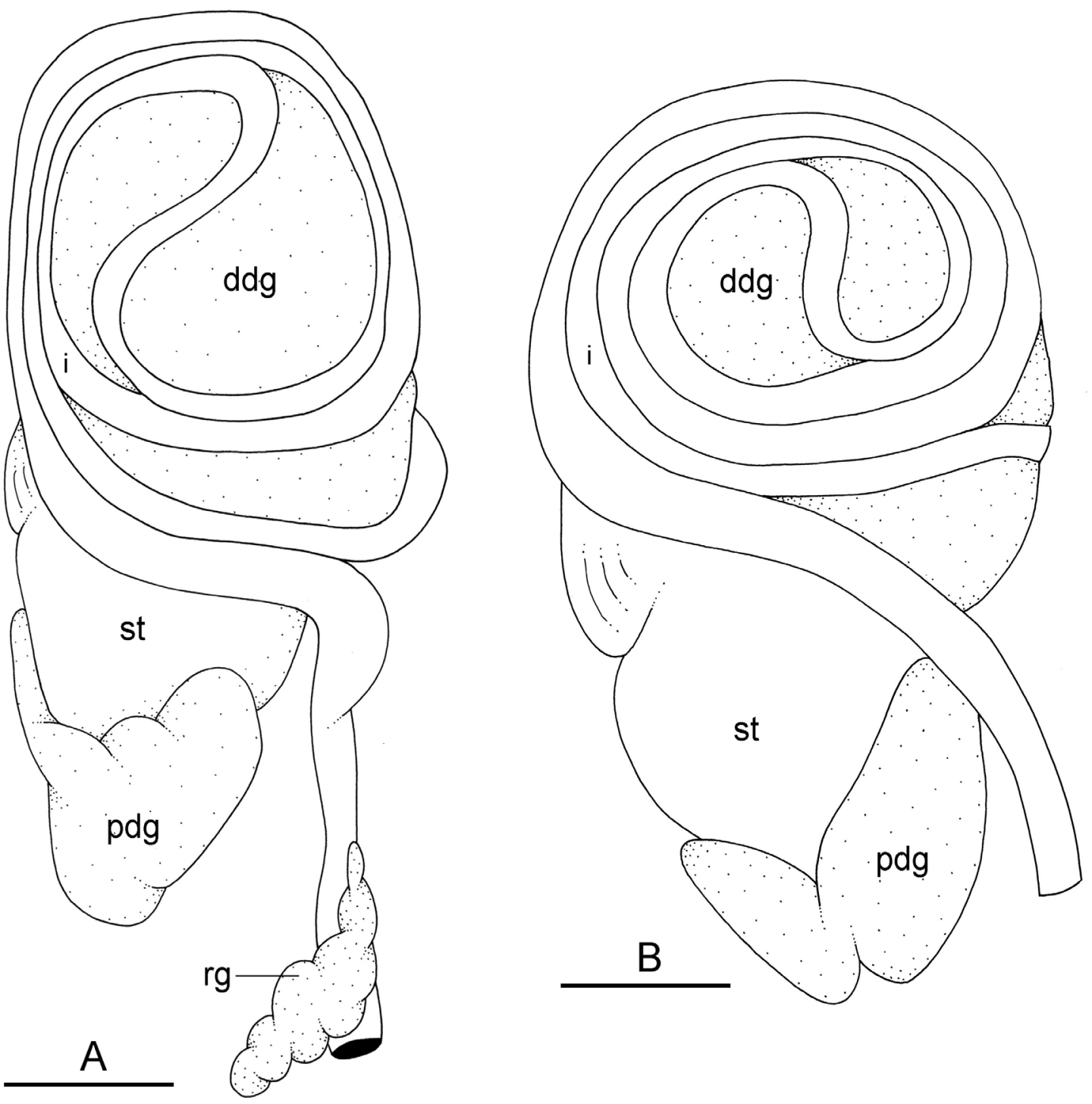

Fig. 66. Platevindex amboinae (Plate, 1893), digestive system, dorsal view, intestinal loops of type III. A. Transitional loop oriented at 2 o'clock, Seram, Indonesia [2883] (UMIZ 00105). B. Transitional loop oriented at 6 o'clock, Sulawesi, Indonesia [\#1] (SMF 333602). Abbreviations: ddg = dorsal digestive gland; $\mathrm{i}=$ intestine; $\mathrm{pdg}=$ posterior digestive gland; $\mathrm{rg}=$ rectal gland; $\mathrm{st}=$ stomach. Scale bars: $\mathrm{A}=4 \mathrm{~mm} ; \mathrm{B}=3 \mathrm{~mm}$. 

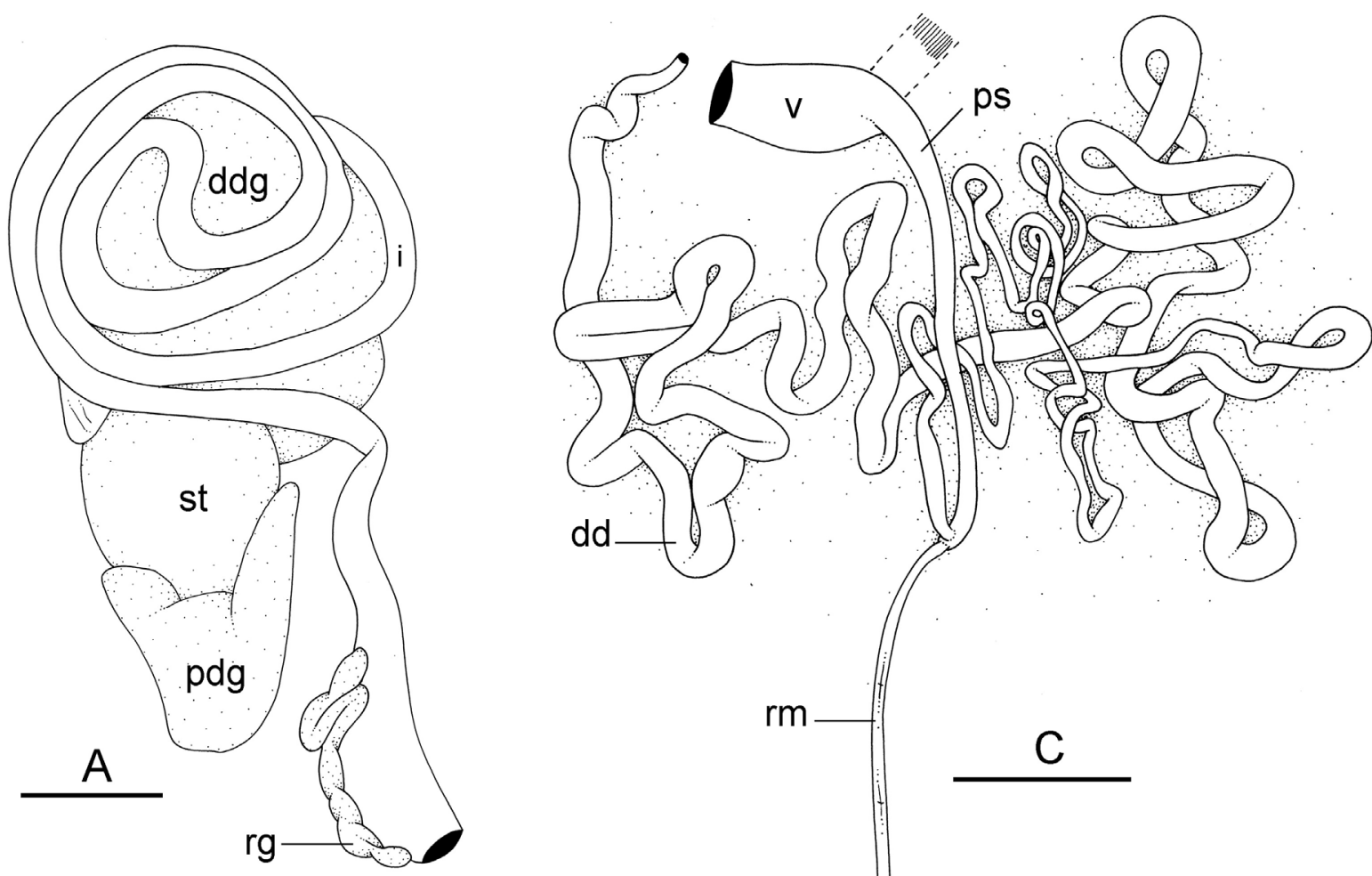

$\mathrm{B}$

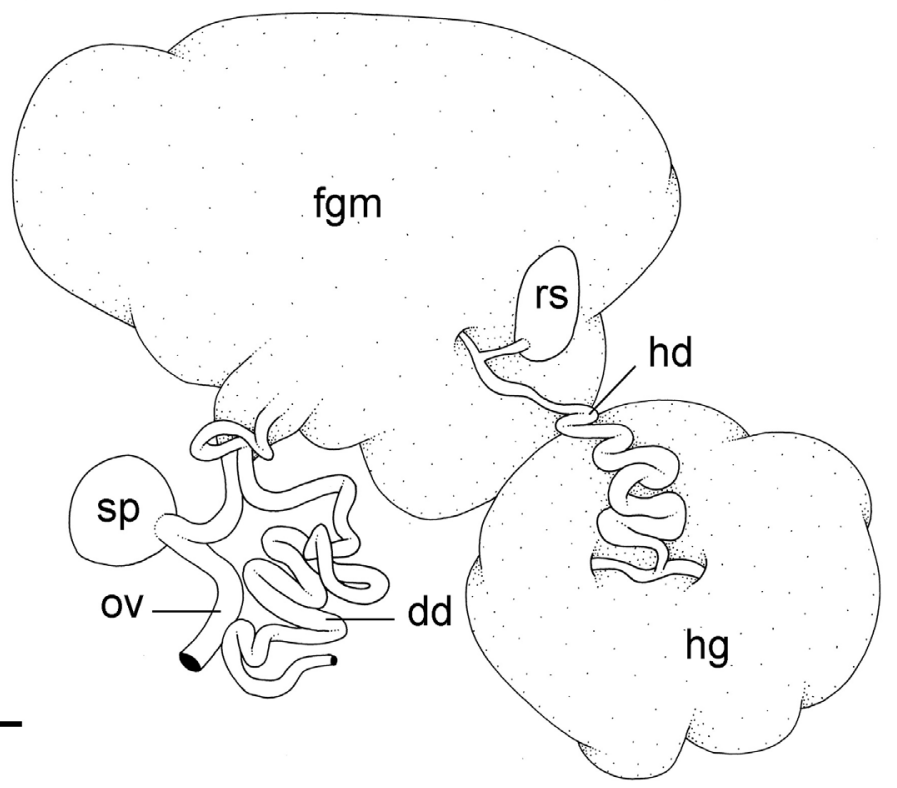

Fig. 67. Platevindex amboinae (Plate, 1893), digestive and reproductive systems, lectotype, Ambon, Indonesia (ZMB/Moll 11621a). A. Digestive system, dorsal view, type III, with a transitional loop oriented at 1 o'clock. B. Posterior reproductive system. C. Anterior, male copulatory apparatus. Abbreviations: $\mathrm{dd}=$ deferent duct; $\mathrm{ddg}=$ dorsal digestive gland; fgm = female gland mass; hd = hermaphroditic duct; $\mathrm{hg}=$ hermaphroditic gland; $\mathrm{i}=$ intestine; $\mathrm{ov}=$ oviduct; $\mathrm{pdg}=$ posterior digestive gland; $\mathrm{ps}=$ penial sheath; $\mathrm{rg}=$ rectal gland; $\mathrm{rm}=$ retractor muscle; $\mathrm{rs}=$ receptaculum seminis; $\mathrm{sp}=$ spermatheca; $\mathrm{st}=$ stomach; $\mathrm{v}=$ vestibule. Scale bars: $\mathrm{A}=4 \mathrm{~mm} ; \mathrm{B}=3 \mathrm{~mm} ; \mathrm{C}=2 \mathrm{~mm}$. 
Distribution (Fig. 10C)

Indonesia: Ambon (type locality of both Platevindex amboinae and P. coecus), Halmahera (new record) and Seram (new record).

Habitat (Fig. 69)

Platevindex amboinae is found on dead logs or tree trunks but not directly on mud, within a mangrove forest or in the higher intertidal adjacent to mangrove trees. It is not found on rocky shores.

\section{Remarks}

Onchidium amboinae needs to be transferred to the genus Platevindex due to the following combination of characters of the lectotype: flattened body, male pore slightly to the right of the midline between the ocular tentacles and no accessory penial gland. Plate (1893: 178) also indicated that there is a rectal gland in the original description, and it is clearly present in the lectotype (as in all Platevindex slugs). The absence of dorsal eyes and a short penis with no hooks mentioned by Plate (1893: 177) were confirmed by our examination of the lectotype. The hyponotum color was described as black with a white margin ( 1 to $1.5 \mathrm{~mm}$ wide), which is exactly what was observed in one of our live specimens.

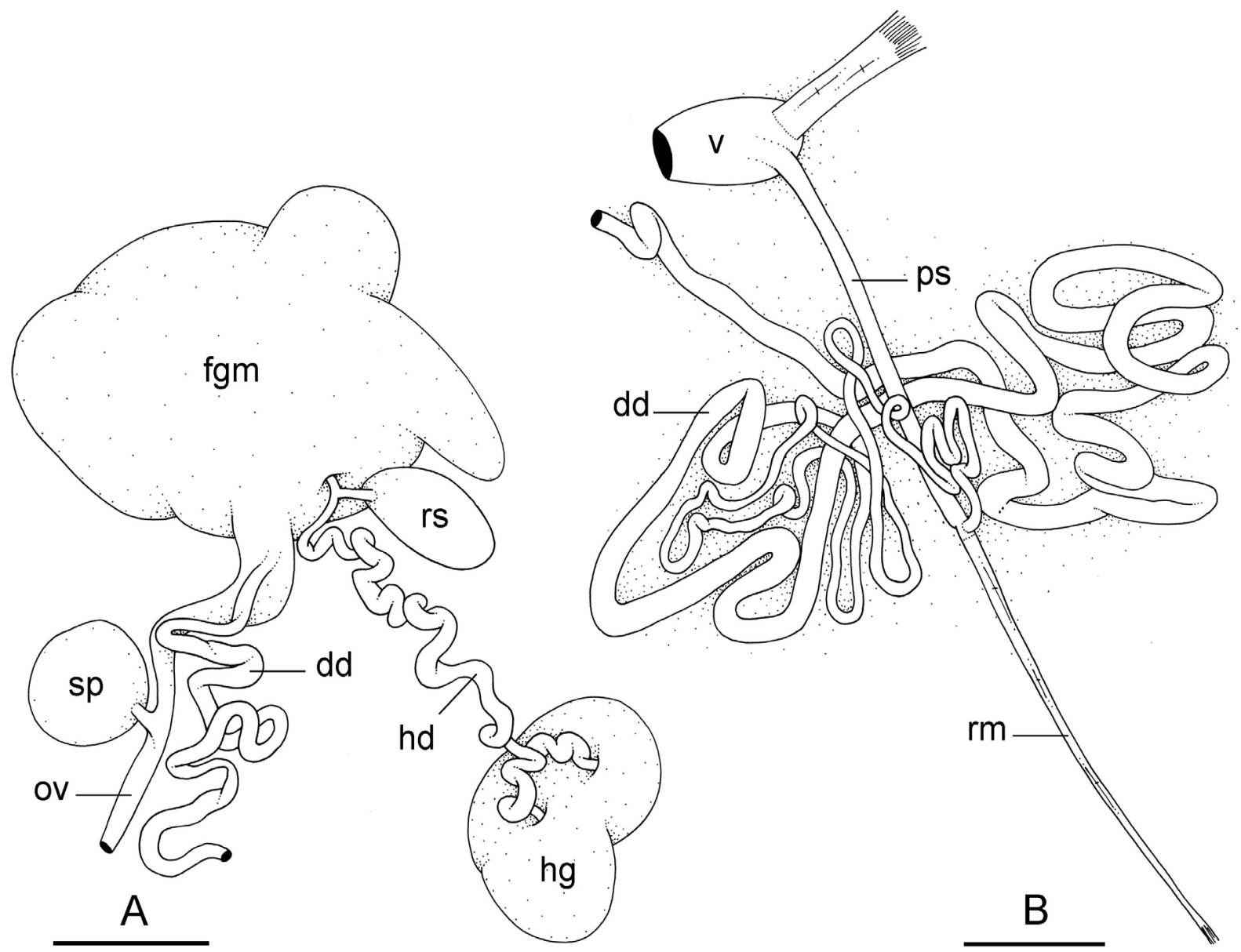

Fig. 68. Platevindex amboinae (Plate, 1893), reproductive system, Seram, Indonesia [2883] (UMIZ 00105). A. Posterior reproductive system. B. Anterior, male copulatory apparatus. Abbreviations: $\mathrm{dd}=$ deferent duct; fgm = female gland mass; $\mathrm{hd}=$ hermaphroditic duct; $\mathrm{hg}=$ hermaphroditic gland; $\mathrm{ov}=$ oviduct; $\mathrm{ps}=$ penial sheath; $\mathrm{rm}=$ retractor muscle; $\mathrm{rs}=$ receptaculum seminis; $\mathrm{sp}=$ spermatheca; $\mathrm{v}=$ vestibule. Scale bars: $\mathrm{A}=4 \mathrm{~mm} ; \mathrm{B}=2 \mathrm{~mm}$. 
However, Plate (1893: 178) described an intestine of type II in Onchidium amboinae, while the intestine of the lectotype (and of all newly-collected individuals) is clearly of type III (Fig. 67A).

The holotype of $P$. coecus (by monotypy) is characterized by a combination of traits diagnostic of species of Platevindex: a flattened body, a male opening slightly to the right of the midline between the ocular tentacles, a rectal gland and no accessory penial gland. In the original description, Plate (1893:199200) indicated a grayish-yellow sole and a black-blue hyponotum with a white margin, and also the absence of dorsal eyes. The only species in Ambon which lacks dorsal eyes is $P$. amboinae. Hoffmann (1928: 86-87) transferred Onchidium amboinae to Oncis (i.e., Platevindex) and considered Oncis coeca (i.e., Platevindex coecus) to be a synonym of Oncis amboinae (i.e., Platevindex amboinae). Labbé (1934: 234-235) agreed with Hoffmann even though he did not examine any new material. The deferent duct in the penial apparatus and in the posterior part of the reproductive system is extremely convoluted, exactly like in P. amboinae. The pieces of the intestine of the holotype were put together and are of type III, although Plate (1893: 200) described a digestive system of type II. There is no anatomical difference between the name-bearing types of Platevindex coecus and P. amboinae, both of which were described from Ambon, Indonesia. We did not find Platevindex amboinae during our mangrove survey in Ambon but we found it on the nearby island of Seram, where it seems to be rare. Platevindex amboinae was also rare in Halmahera. It may still be present in Ambon, but most likely as a rare species.

Two lots previously identified as Oncis lata from Sulawesi are re-identified here as $P$. amboinae (ZMB/Moll 46314, SMF 333602/3). The original label for ZMB/Moll 46314 indicates that the specimens were collected in Luwu by M. Weber, which means that they are very likely the specimens which von Martens (1897: 128) identified as Oncis lata. Von Martens indicated that he examined 10 specimens. Five of those are in Berlin (ZMB/Moll 46314) and three of them are in Frankfurt-am-Main (SMF 333602/3), which were originally part of the Heidelberg collections. The specimens examined here all lack dorsal eyes, a character shared by both $P$. lata and $P$. amboinae, but they also lack the large, thorny papillae that are diagnostic of $P$. lata, suggesting that they belong to $P$. amboinae.

Labbé (1934: 234-235) described a specimen $(14 / 11 \mathrm{~mm})$ from New Zealand which he identified as Oncis amboinae. However, if Labbé's description is accurate, this specimen cannot be part of Platevindex amboinae or any species of Platevindex because Labbé (1934: 235) indicated that a group of dorsal eyes was present in the middle of the notum (in Platevindex, dorsal eyes are always single). It is unclear which species Labbé examined, as Onchidella is the only onchidiid genus documented so far in New
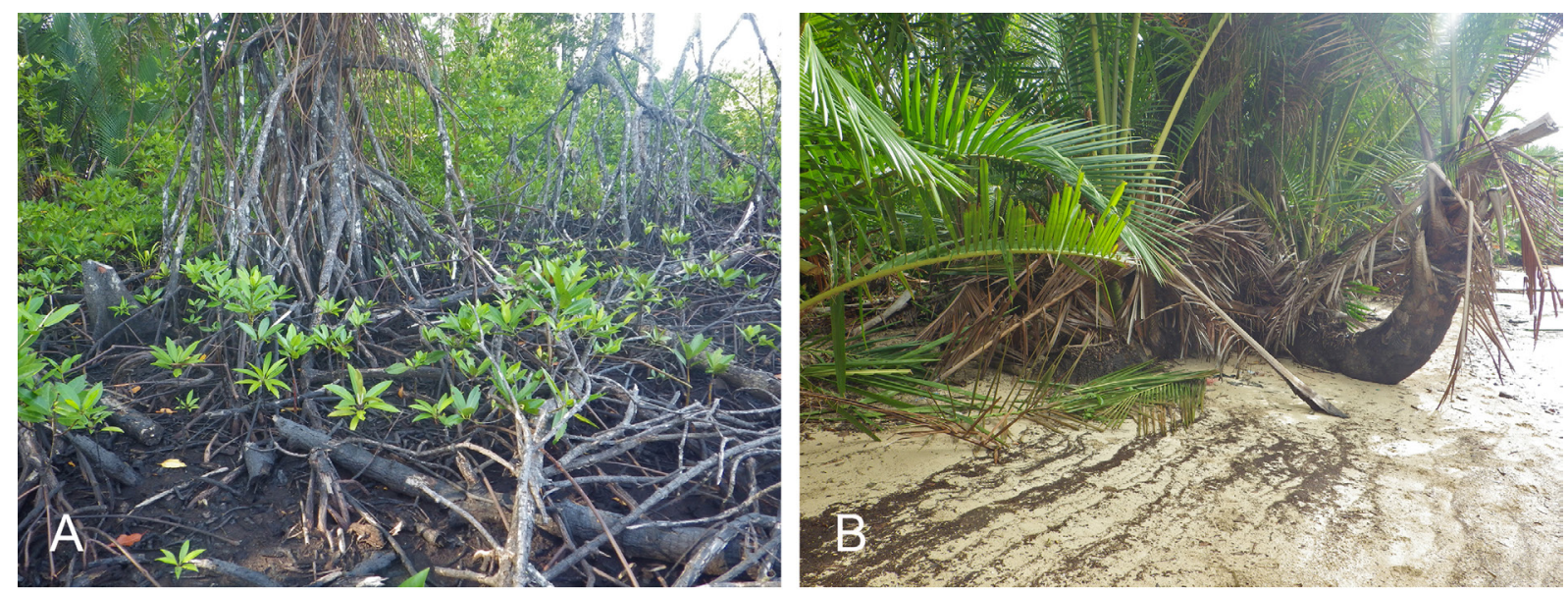

Fig. 69. Habitats of Platevindex amboinae (Plate, 1893), Indonesia. A. Halmahera, open, tall Rhizophora forest, impacted by mining (station 213). B. Seram, on base of palm tree surrounded by Acrostichum ferns behind a Sonneratia mangrove (station 136). 
Zealand. The combination of traits mentioned in the brief description (dorsal eyes, no accessory penial gland and no penial hooks), suggests it could be a Wallaconchis slug, although that is incompatible with intestinal loops of type II. Besides, Wallaconchis is not known south of New Caledonia. Most likely, as often with Labbé's work, the locality or the description, or even both, are erroneous (Dayrat et al. 2020).

Platevindex latus (Plate, 1893)

Figs 70-73

Oncis lata Plate, 1893: 191-192, pl. 7, fig. 2, pl. 11, fig. 59.

Oncis lata - Stantschinsky 1907: 395.

Platevindex latus - Dayrat 2009: 5.

\section{Material examined}

Lectotype (here designated)

PAPUA NEW GUINEA • lectotype (27/27 mm); Neu-Britannien [New Britain, Papua New Guinea]; ZMB/Moll 45656a.

\section{Paralectotypes}

PAPUA NEW GUINEA • 3 paralectotypes $(28 / 27,27 / 24$ and 23/26 mm); same collection data as for lectotype; $\mathrm{ZMB} / \mathrm{Moll} 45656 \mathrm{~b}$.

\section{Notes on type material}

The lectotype was dissected for the present study and all its internal organs were left inside except for the penial complex, which was extracted and retained in a small vial. The three paralectotypes were previously dissected and are completely empty with no internal organs. All their male parts are missing. Pieces of dorsal notum, stomach, digestive gland, intestine and female gland mass remain in the jar, all mixed together, but they cannot be assigned to a particular paralectotype.

\section{Other material}

PAPUA NEW GUINEA • 3 specs (33/28 [\#3], 32/31 [\#1] and 30/25 [\#2] mm); New Britain?; ZMH 27511.

\section{Description}

Color and morphology (Fig. 70)

The color of live slugs is unknown. The preserved dorsal surface is dark brown, occasionally with lighter brown, longitudinal stripes. The preserved hyponotum is blue-grey and the foot is light yellow. Dorsal papillae are large and thorny, and do not bear dorsal eyes.

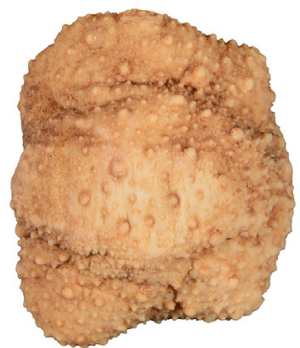

A

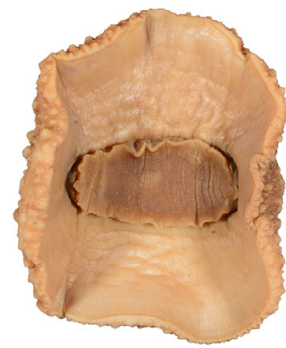

$\mathrm{B}$

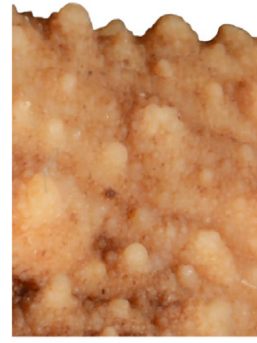

C

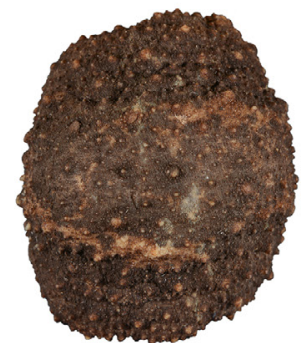

$\mathrm{D}$

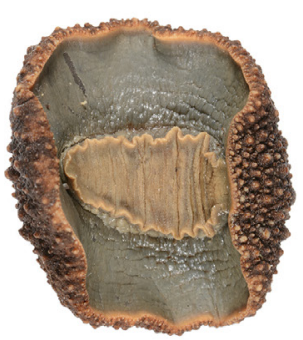

$\mathrm{E}$

Fig. 70. Platevindex latus (Plate, 1893), preserved specimens. A. Dorsal view, $24 \mathrm{~mm}$, syntype, New Britain, Papua New Guinea (ZMB/Moll 45656). B. Ventral view, same as A. C. Close-up of papillae, same as A. D. Dorsal view, 25 mm, Papua New Guinea (ZMH 27511). E. Ventral view, same as D. 
Digestive system (Figs 3B, 71-72)

Radulae measure up to $7.2 \mathrm{~mm}$ in length. Examples of radular formulae are presented in Table 5. The intestinal loops are of type III, with a transitional loop oriented between 12 and 2 o'clock (Figs 3B, 72).

\section{Reproductive system (Fig. 73)}

In the posterior reproductive system, the oviduct is short and approximately as wide as the deferent duct. Its distal section (distal to the spermatheca) is approximately as long as its proximal section. The deferent duct is longer than the oviduct, not attached to it, and is tightly coiled with a few short U-shaped loops. There are no hooks inside the distal, flexible region of the penis. The posterior retractor muscle inserts in the anterior half of the visceral cavity. The retractor muscle of the penis varies from approximately half the length of the penial sheath to $3 / 4$ its length. The deferent duct is highly convoluted.
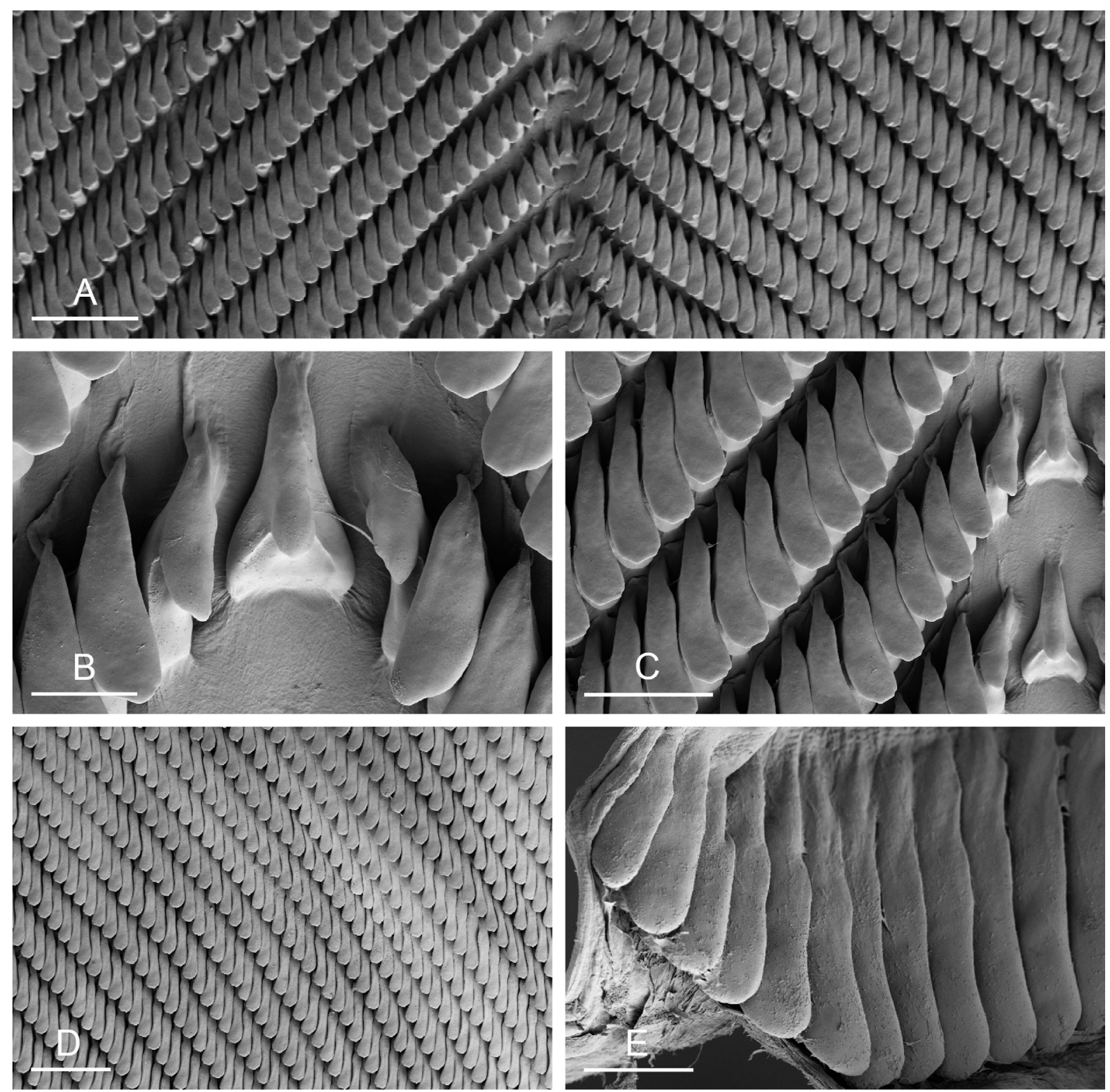

Fig. 71. Platevindex latus (Plate, 1893), radula, Papua New Guinea [\#1] (ZMB/Moll 45656). A-C. Rachidian and lateral teeth. D. Lateral teeth. E. Outermost lateral teeth. Scale bars: A, D = $100 \mu \mathrm{m}$; $\mathrm{B}, \mathrm{E}=20 \mu \mathrm{m} ; \mathrm{C}=50 \mu \mathrm{m}$. 


\section{Distinctive diagnostic features (Table 4)}

Platevindex latus and P. amboinae are the only known species of Platevindex with no dorsal eyes and no penial hooks. Platevindex latus can be distinguished from P. amboinae externally by its large and thorny dorsal papillae and internally by its anterior deferent duct, which is slightly less convoluted.

Distribution (Fig. 10C)

Papua New Guinea: New Britain (type locality and present study).

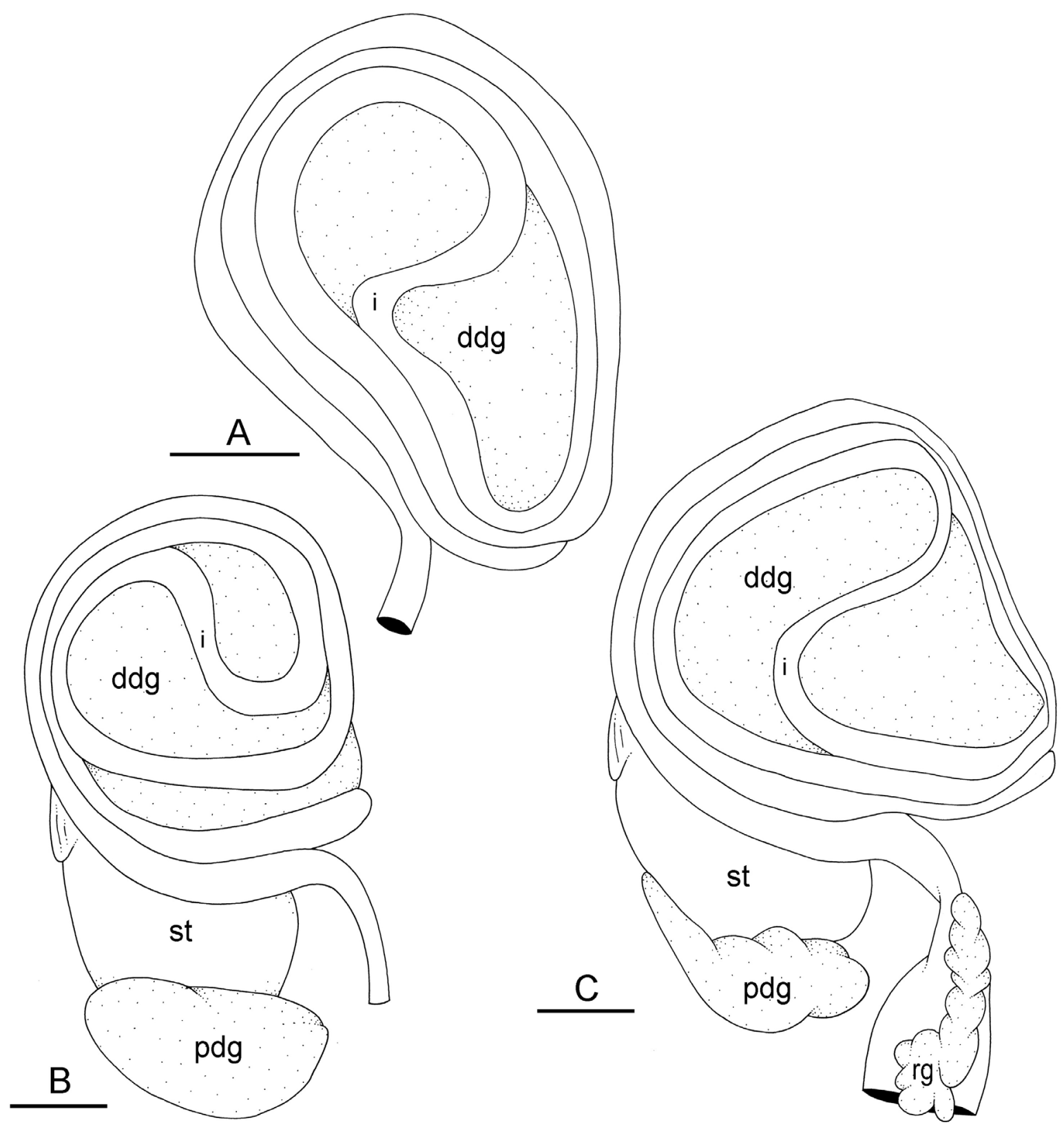

Fig. 72. Platevindex latus (Plate, 1893), digestive system, dorsal view, intestinal loops of type III. A. Transitional loop oriented at 2 o'clock, New Britain, Papua New Guinea, lectotype (ZMB/Moll 45656a). B. Transitional loop oriented at 12 o'clock, Papua New Guinea [\#1] (ZMH 27511). C. Transitional loop oriented at 2 o'clock, Papua New Guinea [\#2] (ZMH 27511). Abbreviations: $\mathrm{ddg}=$ dorsal digestive gland; $\mathrm{i}=$ intestine; $\mathrm{pdg}=$ posterior digestive gland; $\mathrm{rg}=$ rectal gland; $\mathrm{st}=$ stomach. Scale bars $=3 \mathrm{~mm}$. 

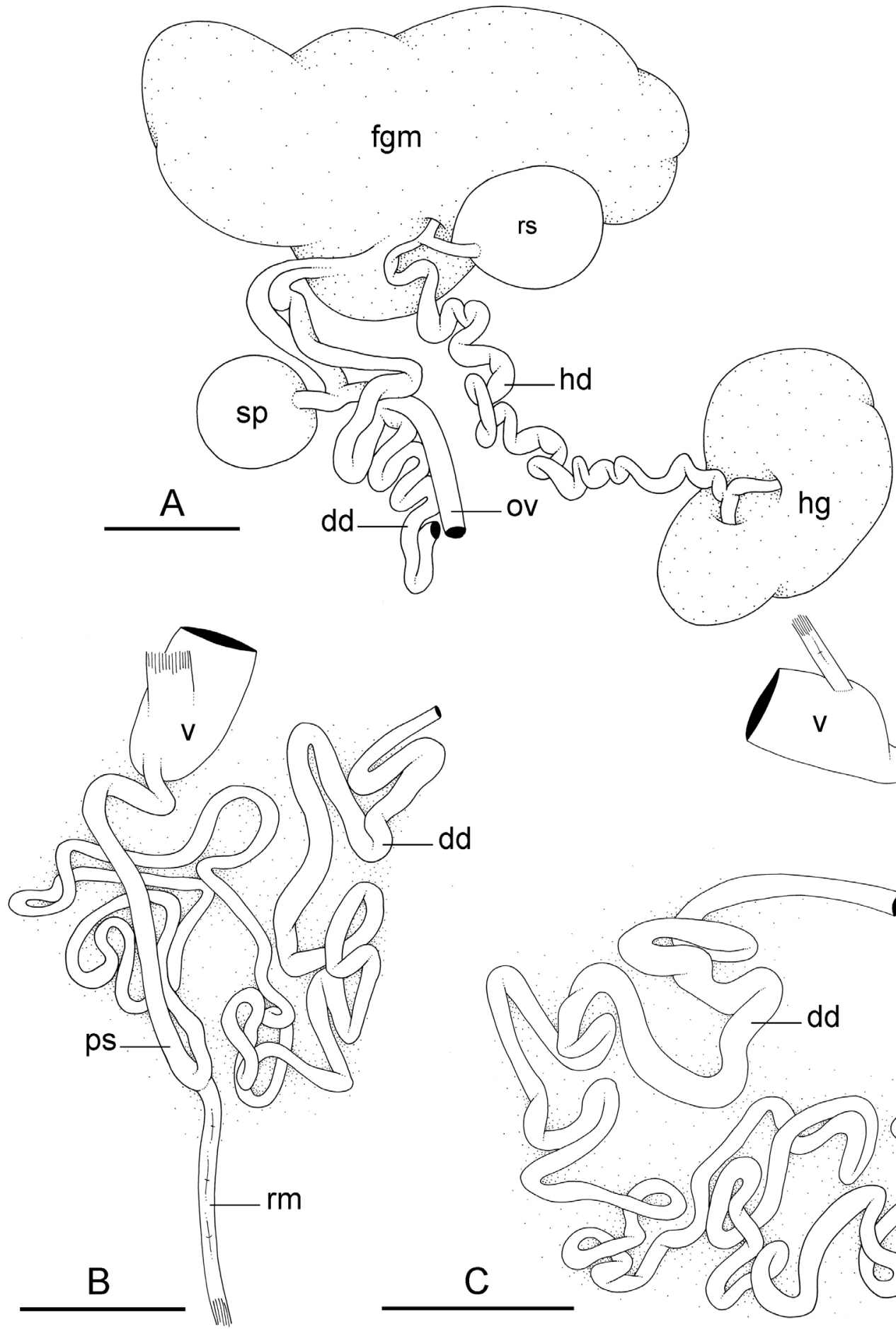

dd

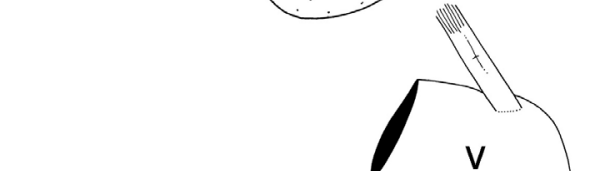




\section{Habitat}

No habitat was mentioned in the original description of $P$. latus or on the labels of the additional material. However, $P$. latus likely lives on dead logs in mangroves, like its close relative $P$. amboinae.

\section{Remarks}

The flattened body and narrow foot of the lectotype of Platevindex latus clearly indicate that it belongs to Platevindex. In the original description, Plate (1893) did not mention whether a rectal gland is present or absent, but it is present in the lectotype as well as in the non-type material (it is present in all species of Platevindex). An accessory penial gland is also absent in both the lectotype and the non-type material (it is absent in all species of Platevindex).

In the original description, Plate (1893: 191) described dorsal "conical granules" and indicated that "the mantle appears through them as if spiked with small thorns." Conical papillae are present in the lectotype and all paralectotypes of $P$. latus as well as in the additional material from Papua New Guinea. Plate (1893: 192) described the length of the penis but did not mention penial hooks, so it can be assumed that he did not see penial hooks in the types he dissected (now paralectotypes). However, because the male parts are missing from the three paralectotypes dissected by Plate, this could not be confirmed. At any rate, penial hooks are absent in the lectotype dissected for the present study. The intestinal loops of the lectotype are of type III and Plate's (1893: 192) description of a type II likely is a mistake, which would be consistent as he made the same error in the description of $P$. amboinae.

Fresh material for DNA sequencing was not available. Platevindex latus was not collected during the recent MNHN expeditions in Madang and New Ireland, Papua New Guinea. Some old material discovered at the Zoologisches Museum in Hamburg seems to be part of $P$. latus even though its locality is uncertain (the label in the jar states "Papua New Guinea. New Britain? Museum Godeffroy"). This material is externally identical to the lectotype (and paralectotypes) of P. latus. Plate (1893: 192) described a penis measuring $7 \mathrm{~mm}$ long (the proximal chondroid tube being $5 \mathrm{~mm}$ long and the distal, flexible region being $2 \mathrm{~mm}$ long). In one specimen from the Zoologisches Museum in Hamburg, the chondroid tube also measured $5 \mathrm{~mm}$, but the distal region without hooks was $0.5 \mathrm{~mm}$ long rather than $2 \mathrm{~mm}$. However, individual variation in this character occurs within species of Platevindex, and more specimens are needed to evaluate the variation for this trait within P. latus.

Hoffmann (1928: 86) suggested that Platevindex latus (as Oncis lata) was a synonym of Onchidium granulosum Lesson, 1831 (type locality New Ireland, Papua New Guinea), based on the original descriptions. Although Hoffmann acknowledged that Lesson's description was not very informative, he considered that Lesson's description of a notum being much wider than the sole indicated that Onchidium granulosum referred to a species of Oncis (Platevindex). Labbé (1934: 234) agreed with Hoffmann. However, Lesson's description is brief and leaves out many important details, such as whether dorsal eyes are present or not. The wide foot in Lesson's illustration of Onchidium granulosum (Lesson 1831: pl. 14, fig. 2) does not appear to represent a species of Platevindex. The description of the habitat as a rocky shore also strongly suggests that Onchidium granulosum does not apply to a species of Platevindex, but, instead, possibly to a species of Peronia or Wallaconchis. Adams \& Adams (1855: 234) transferred Onchidium granulosum to Onchidella with no justification. Because its type material could not be located and its internal anatomy was not described by Lesson, Onchidium granulosum is regarded here as a nomen dubium which applies to an onchidiid species of an unidentifiable genus.

Von Martens (1897: 128) indicated that M. Weber found Oncis lata in "Celebs: Mündung des Flusses Djenemaedja in Luwu" [Sulawesi: mouth of the river Djenemaedja in Luwu]. Measurements were provided for the largest and smallest specimens, and the edge of the hyponotum was described as dirty yellow-gray. Von Martens indicated that the specimens are exactly the same as Plate's (1893) 
description of $O$. lata, except for the color of edge of the hyponotum. However, when specimens from Luwu collected by M. Weber (identified as Oncis lata) were examined, they did not have the large thornlike papillae characteristic of $P$. lata. Thus, Sulawesi is not considered part of the geographic range of P. lata, and those specimens are identified here as P. amboinae (see that species).

Bretnall's (1919: 323) description of Oncis lata is merely a translation of Plate's original description, except that Plate's (1893: 191) correct statement that "eyes are missing" was changed to "eyes are present on all of the papillae." Bretnall likely assumed that Plate made a mistake because dorsal eyes are present in most other species of Platevindex and because eyes can be difficult to see when dorsal papillae are retracted. However, it is confirmed here that dorsal eyes are not present in the type material of Platevindex latus.

Labbé (1934: 234) identified two specimens (24/17 and 19/14 mm) from the Malabar coast (southwest India) collected by M. Dussumier as Oncis granulosa, but also indicated that the exterior aspect of his specimens was similar to that of Oncis lata from New Britain. However, Labbé also reported that the notum is granular with tubers that are not prominent, and that dorsal eyes are not very visible. The intestinal loops are also described as type II by Labbé, while they are of type III in Oncis lata. Due to the lack of dorsal papillae in the specimens Labbé examined, and the fact that Labbe's description suggests that dorsal eyes may have simply been retracted, the specimens he examined are not considered to be Oncis lata. It is also worth noting that the specimens Labbé examined from western India are very distant from New Britain, Papua New Guinea, and that no observations of Oncis lata have been confirmed west of New Britain.

Morphological evidence suggests that Platevindex latus is closely related to P. amboinae because both species lack penial hooks and dorsal eyes, which are present in all other species of Platevindex. They also are the only species of Platevindex with intestinal loops of type III.

\section{Discussion}

\section{Nomenclature}

Historically, 18 specific names have been originally or subsequently combined with the generic name Platevindex, though authors in the past often used Plate's (1893) generic name Oncis instead of Platevindex (see our remarks on the genus). Five of these names are regarded as valid species names of Platevindex: Onchidium amboinae, Onchidium coriaceum, Oncis lata, Onchidium luteum and Oncis martensi. Five other names are considered junior synonyms: Oncis coeca Plate, 1893, Onchidella condoriana Rochebrune, 1882, Oncis inspectabilis Plate, 1893, Oncis schneideri Hoffmann, 1932 and Oncis semperi Plate, 1893. Two other names apply to species of Platevindex but are considered nomina dubia: Oncis cinerea Odhner, 1917 and P. mortoni Britton, 1984 (see our remarks on P. coriaceus and P. tigrinus). Another name, Onchidium granulosum Lesson, 1831, was previously thought to apply to a species of Platevindex (as Oncis) by Hoffmann (1928: 86), but the original description is not informative enough and the type material could not be located, so it is also considered a nomen dubium which may apply to a species of Peronia or Wallaconchis (see our remarks on P. latus). Four other names apply to Semperoncis slugs which live in high-elevation rain forests (Dayrat 2010): Platevindex apoikistes Tillier, 1983, Onchidium glabrum Semper, 1880 (type species), Oncis montana Plate, 1893 and Onchidium ponsonbyi Collinge, 1901. Finally, it was already demonstrated that Onchidium stuxbergi does not refer to a species of Platevindex but to a species of Onchidium instead (Dayrat et al. 2016, 2019d).

In addition to the five valid species names which were historically classified in Platevindex (or Oncis), three additional existing species names are newly transferred to Platevindex and are regarded as valid: Onchidium applanatum Simroth, 1920, Onchidium burnupi Collinge, 1902 and Onchidium tigrinum 
Stoliczka, 1869. In addition to the eight species of Platevindex for which names already exist, one new species and one new sub-species are now recognized.

\section{The genus Platevindex}

The multi-locus molecular phylogeny strongly supports the monophyly of Platevindex, which is largely due to including the slower evolving nuclear loci $28 \mathrm{~S}$ and H3 (Fig. 4). species of Platevindex share a close resemblance in external appearance and internal anatomy, but two species, $P$. amboinae and $P$. latus, differ from the rest in two notable traits: they have no dorsal eyes and no penial hooks. The absence of dorsal eyes and the absence of penial hooks are synapomorphies shared by $P$. amboinae and $P$. latus with respect to other species of Platevindex. However, dorsal eyes are also absent in Onchidella and Onchidina, which means that they have been lost several times in onchidiids. As for penial hooks, it has been shown that they were lost by a few species in other genera as well, such as Wallaconchis (Goulding et al. 2018b). So, overall, the lack of dorsal eyes and penial hooks is not exclusive to $P$. amboinae and P. latus. Our results suggest that the three clades of Platevindex likely diverged long ago (Fig. 4): clade B (P. amboinae and P. latus), clade D (P. martensi and P. aptei sp. nov.), and clade C (all other known species of Platevindex).

The terrestrial slugs of the genus Semperoncis closely resemble Platevindex slugs, but there are noticeable morphological differences between them (Dayrat 2010). First, the position of the male opening is to the left of the right ocular tentacle in Platevindex, while it is on the right side of the right ocular tentacle in Semperoncis. Second, the pneumostome is approximately median in Platevindex, but it is slightly to the right in Semperoncis. Third, a central dorsal papilla with multiple dorsal eyes is present in Semperoncis and absent in Platevindex. Finally, an accessory penial gland is present in Semperoncis and absent in Platevindex.

\section{Integrating sequence data with morphology}

Based on an integrative approach, we have determined that species of Platevindex can be identified morphologically by examining a combination of characters (Table 4). Automatic Barcode Gap Discovery analysis was successful in delimiting species of Platevindex, with the exception of P. luteus and P. applanatus (Fig. 9). Mitochondrial COI and nuclear ITS2 sequences were obtained from specimens of $P$. luteus or $P$. applanatus from 19 different geographic regions. The majority of $P$. applanatus mitochondrial sequences cluster together, but mitochondrial sequences of $P$. applanatus from Mauritius, Seram and Sulawesi cluster within a clade of $P$. luteus sequences. These specimens have been identified as $P$. applanatus based on nuclear DNA sequences and morphology (e.g., the intestinal loops, Fig. 40B). Thus $P$. luteus and $P$. applanatus cannot be distinguished reliably based on mitochondrial DNA sequences. The incongruence between mitochondrial DNA and nuclear DNA may be due to mitochondrial introgression, which is increasingly recognized as causing paraphyly in mitochondrial gene trees; a survey of the literature by Funk \& Omland (2003) indicated that 23\% of the assayed species showed evidence of species-level paraphyly or polyphyly with mitochondrial loci.

High mitochondrial intraspecific divergence is found within five of the nine species of Platevindex delineated here (P. coriaceus, P. luteus, P. applanatus, P. burnupi and P. amboinae). This high divergence is not limited to species of Platevindex. High mitochondrial sequence divergence has also been observed in other onchidiids, such as Peronina zulfigari (Goulding et al. 2018c), Paromoionchis spp. (Dayrat et al. 2019a) and Peronia verruculata (Dayrat et al. 2020). Unexpectedly high mitochondrial intraspecific genetic divergence is also known in other pulmonate gastropods (e.g., Thomaz et al. 1996; Pinceel et al. 2005), which emphasizes the importance of using an integrative taxonomic approach combining both nuclear and mitochondrial markers with comparative anatomy, rather than relying exclusively on mitochondrial loci. 
Within P. coriaceus, four mitochondrial clades display substantial divergence in mitochondrial COI sequences (Fig. 9). Two subspecies are recognized here within $P$. coriaceus due to an agreement of mitochondrial data with comparative anatomy and nuclear DNA sequences. The three mitochondrial clades within P. coriaceus coriaceus cannot be distinguished anatomically and are allopatric. Given that their reciprocal monophyly is not recovered using nuclear markers (Fig. 6), they are considered part of a single subspecies (P. coriaceus coriaceus). The fourth mitochondrial clade, Platevindex coriaceus darwinensis subsp. nov., of which the reciprocal monophyly is recovered using nuclear markers (Fig. 6), differs anatomically from $P$. coriaceus coriaceus (with respect to the deferent duct in the posterior reproductive system and its hyponotum color).

Two mitochondrial clades are genetically divergent within P. burnupi: one northern clade includes all Madagascar and Mozambique sequences, and the southern clade includes all sequences from South Africa. A similar divergence is observed in nuclear ITS2 sequences (the specimen from Mozambique shares the same ITS2 haplotype as several individuals from Madagascar). Anatomically, specimens from the two units are similar, except that animals tend to be larger in South Africa than in Madagascar and Mozambique. However, only three populations were sampled, one from each country, and thus additional sampling is required to understand intraspecific variation. In the future, populations may be found in southern Mozambique or western Madagascar with unsampled haplotypes that could fall in between the two clades here from South Africa and Madagascar, which may then not be reciprocally monophyletic in phylogenetic analyses and which may no longer be separated by any barcode gap.

In P. amboinae, the mitochondrial genetic divergence did not correspond to any observed anatomical differences. However, additional samples are needed to evaluate intraspecific variation in this species (which was only found at two localities).

\section{Habitats}

Most onchidiid slugs are only found in a specific microhabitat. For instance, Melayonchis slugs are only found in mangroves, on tree roots and trunks as well as old logs (Dayrat et al. 2017), and Peronina slugs are found on mud saturated with water, in mangroves and adjacent mudflats (Goulding et al. 2018c). Nearly all Platevindex slugs live on the trunks and roots of mangrove trees and on old logs, but species are not randomly distributed across the tidal zone: Platevindex coriaceus, $P$. tigrinus, $P$. luteus and $P$. applanatus are all found in the mid-intertidal zone, and sometimes occur in close proximity; Platevindex martensi, $P$. aptei sp. nov. and P. burnupi are generally found in the high intertidal. Data on the habitat of $P$. amboinae is limited (only three specimens were found in recent surveys), but current data suggests that the species is also found in the high intertidal (there is no published information about the habitat of $P$. latus). Platevindex burnupi, P. luteus and $P$. applanatus are the only species of Platevindex that are not exclusively found in mangroves, although the presence of $P$. luteus outside mangroves is rare. Platevindex burnupi occurs in salt marshes, $P$. luteus has occasionally been found on coral rubble beaches, and $P$. applanatus is found on rocks and coral rubble. These three species are closely related (Fig. 4), and it is possible that these novel habitats outside mangroves were colonized by their common ancestral lineage.

The different microhabitats and areas of the tidal zone where species occur may contribute to the fairly high number of sympatric species of Platevindex in the South China Sea and Coral Triangle. The highest number of sympatric species of the same onchidiid genus found at one site so far is six species of Wallaconchis found at one site in Loay, Bohol, Philippines (Goulding et al. 2018b: 25). Sympatry in Melayonchis can also be high, as five species of Melayonchis live in the same mangrove forest in Matang, Peninsular Malaysia (Dayrat et al. 2019c). Five species of Platevindex (P. amboinae, P. applanatus, $P$. coriaceus, $P$. luteus and P. martensi) are recorded from Sulawesi, although they have not all been 
found in the same region of the island. The highest number of species of Platevindex in close proximity was found in Singapore (P. coriaceus, P. luteus, P. tigrinus and P. martensi).

\section{Biogeography and endemism}

With nine species recognized here, Platevindex is among the most diverse genera of onchidiids, being only slightly less diverse than Wallaconchis (10 species). Most species of Platevindex are broadly distributed, particularly P. applanatus and P. luteus. Platevindex latus is the only species with a narrow geographic range (it is only known from New Britain, Papua New Guinea). Although DNA sequences could not be obtained for P. latus, it appears to be externally distinct from P. amboinae (known from Ambon, Halmahera and Seram, in Indonesia). Fresh samples are needed from New Britain to examine the genetic divergence between $P$. amboinae and P. latus, as well as the natural history of P. latus. Platevindex amboinae could not be found during a recent survey in Ambon (type locality) despite considerable time spent exploring mangroves on the island. The habitat of $P$. amboinae was not indicated by Plate (1893) in the original description, but the individuals we found in Seram (which is very close to Ambon) and Halmahera were closely associated with mangroves, in the high intertidal. It is possible that $P$. amboinae was formerly more common in supra-tidal mangrove habitats in Ambon, where most have been lost due to urban development.

There may still be undiscovered species of Platevindex. As new populations are found in the future, because anatomical differences between species are generally subtle, it will remain critical to study them using molecular data, particularly nuclear DNA sequences, to determine whether they are distinct species or divergent populations of known species.

Although names already existed for all but one species of Platevindex described here, no species could be properly identified prior to this revision. Only one species, P. aptei sp. nov. (Strait of Malacca and the southern Bay of Bengal), had not previously been named, despite its slugs being some of the largest onchidiids (up to $6 \mathrm{~cm}$ long). It is worth noting that $P$. aptei sp. nov. has not been found in any museum collection either. Although its geographic distribution is narrower than for most other species of Platevindex, it is remarkable that it remained undiscovered until now. Given that $P$. aptei sp. nov. is one of the few onchidiid species which can easily be identified both externally and internally, its discovery is illustrative of our limited knowledge of the invertebrate fauna of mangroves in the Indo-West Pacific in general and in South-East Asia in particular.

\section{Identification key}

A key is provided to help identify the nine species of Platevindex. Because species cannot always be distinguished externally, the key also includes internal characters.

1. Dorsal eyes absent, penial hooks absent, intestinal loops of type III 2

- Dorsal eyes present, penial hooks present (in mature specimens), intestinal loops of type I or II, but never of type III

2. Dorsal surface bears large, thorny papillae .P. latus (Plate, 1893)

- Dorsal surface bears only small papillae P. amboinae (Plate, 1893)

3. Hyponotum yellow with dark spots, foot orange or black, dorsal surface bears low longitudinal ridges, dorsal eyes can be very close $(<2 \mathrm{~mm})$ to the notum edge

- Hyponotum variable (white, light to dark grey, light blue to dark blue) but not marked by distinct dark spots, foot light to bright yellow (exceptionally dark blue-grey), dorsal surface without small longitudinal ridges, dorsal eyes are not very close $(<2 \mathrm{~mm})$ to the notum edge .........5 
4. Foot bright or dark orange ...... P. martensi (Plate, 1893)

- Foot black P. aptei Goulding \& Dayrat sp. nov.

5. Notum bears distinctly-raised papillae (with or without eyes), slug frequently semi-hemispherical (especially when disturbed) .....

- Notum granular, with papillae with dorsal eyes but no distinctly-raised, prominent papillae, slugs normally remain flattened (even when disturbed)

6. No bright yellow longitudinal areas on dorsal notum, intestinal loops of types I or II with a transitional loop oriented between 3 and 8 o'clock, retractor muscle of penis inserts near heart

P. luteus (Semper, 1880)

- Bright yellow longitudinal areas present on dorsal notum, intestinal loops of type I with a transitional loop oriented between 1 and 2 o'clock, retractor muscle of penis inserts near heart or at posterior end of visceral cavity

..P. applanatus (Simroth, 1920)

7. Distal portion of oviduct (distal to spermatheca) shorter than proximal portion (from female gland mass to spermatheca)

P. burnupi (Collinge, 1902)

- Distal portion of oviduct (distal to spermatheca) much longer than proximal portion (from female gland mass to spermatheca)

8. Retractor muscle of penis inserts near heart, distal region of penis (with hooks) less than $1.5 \mathrm{~mm}$ long, deferent duct attached to oviduct (in posterior part of reproductive system) and almost straight P. tigrinus (Stoliczka, 1869)

- Retractor muscle of penis inserts near posterior end of visceral cavity, distal region of penis (with hooks) more than $2 \mathrm{~mm}$ long, deferent duct attached to oviduct (in posterior part of reproductive system) and highly coiled

P. coriaceus (Semper, 1880)

\section{Acknowledgments}

We would like to express our sincere thanks to everyone who assisted us with this project, by hosting us at their institutions, helping with logistics, or accompanying us in the field, without which this work would not have been possible. We would like to thank Vivian Ang, Don Dumale, and Marivene Manuel in the Philippines; Owen Griffiths in Mauritius, Richard Willan in Northern Territory, Niel Bruce in Queensland, Teddy Chua in Brunei, and Deepak Apte, Vishal Bhave, Reshma Pitale, Sudhir Sapre, and C.R. Sreeraj in India. We are grateful to Rahul C. Salunkhe and Yogesh Shouche (Bombay Natural History Society, Mumbai, and National Center for Cell Science, Pune) for their help with the DNA sequencing of the specimens from India, to Kenneth Hayes (Pacific Center for Molecular Biodiversity, Hawaii) for lab space and equipment to work on specimens from New Caledonia, and to Barbara Buge and Nicolas Puillandre for preparing the specimens collected during the MNHN expeditions which we used in our molecular studies. We also thank two undergraduate students, Rani Chapla and David Piperato, for their assistance with DNA extractions. We are grateful to Philippe Bouchet and Mary Cole for photographing and collecting the specimens from South Africa. We thank Philippe Bouchet for letting us study the onchidiids collected during MNHN expeditions in Papua New Guinea (Madang and Kavieng), Vanuatu, and New Caledonia. We also thank the collection managers of various institutions for accepting to host our material in their collections and who loaned us specimens for this taxonomic work: Bombay Natural History Society, Mumbai, India (BNHS); Brunei Darussalam Museum of Natural History, Brunei (BDMNH); East London Museum, East London, East Cape, South Africa (ELM); Institute of Tropical Biology, Zoology Collection, Vietnam Academy of Science and Technology, Ho Chi Minh City, Vietnam (ITBZC); Muséum national d'histoire naturelle, Paris, France (MNHN); Museum of Tropical Queensland, Townsville, Queensland, Australia (MTQ); Natural History Museum, London, United Kingdom (NHMUK); KwaZulu-Natal Museum, Pietermaritzburg, South Africa (NMSA); 
Museum and Art Gallery of the Northern Territory, Darwin, Northern Territory, Australia (NTM); National Museum of the Philippines, Manila, Philippines (PNM); Forschungsinstitut und Naturmuseum Senckenberg, Frankfurt-am-Main, Germany (SMF); Swedish Museum of Natural History, Stockholm, Sweden (SMNH); Universitas Malikussaleh, North Aceh, Sumatra, Indonesia (UMIZ); Universiti Sains Malaysia, Mollusk Collection, Penang, Malaysia (USMMC); Museum für Naturkunde, Berlin, Germany (ZMB) and Lee Kong Chian Natural History Museum, National University of Singapore (ZRC). The 'Our Planet Reviewed' - New Caledonia expedition (2016-2019) is a project of the MNHN in partnership with Conservatoire d'Espaces Naturels (CEN) de Nouvelle-Calédonie. The Koumac part of the expedition is/ was funded mainly by the Gouvernement de la Nouvelle-Calédonie, Province Nord, Agence Française de la Biodiversité (AFB), the Lounsbery Foundation, Office des Postes et Télécommunications (OPT), Maison de la Nouvelle-Calédonie, and in-kind support from Mairie de Koumac, Société Nationale de Sauvetage en Mer (SNSM), Régiment du Service Militaire Adapté (SMA) de Koumac, Base Navale de Nouméa, AirCalin, Avis Nouvelle-Calédonie, and Socalait. The expedition operated under a permit issued by Direction du Développement Economique et de l'Environnement (DDEE) of Province Nord. Our Planet Reviewed/La Planète Revisitée is a global initiative founded in 2007 by Muséum National d'Histoire Naturelle (MNHN) and Pro-Natura International (PNI). The material from Vanuatu (Santo) and Papua New Guinea (Madang, Kavieng) was collected during the MNHN-PNI-IRD Our Planet Reviewed expeditions (PI: Philippe Bouchet), funded by the Stavros Niarchos Foundation, Total Foundation, Prince Albert II of Monaco Foundation, Fondation EDF, Entrepose Contracting, and Fonds Pacifique. The expeditions operated under permits delivered by, respectively, the Environment Unit of the Government of Vanuatu, and the Papua New Guinea Department of Environment and Conservation. A research permit was awarded to Benoit Dayrat in Singapore (\#NP/RP10-020). We thank the Ministry of Research, Technology and Higher Education, Republic of Indonesia (Ristek-Dikti) that awarded a research permit to Benoît Dayrat (Ristek \#134/SIP/FRP/E5/Dit.KI/VI/2017). We also wish to thank the Universitas Malikussaleh for being our home base institution in Indonesia. We greatly benefited from conversations with Philippe Bouchet about some complicated nomenclatural cases (all errors remaining are ours). This work was supported by the Eberly College of Science at the Pennsylvania State University and by a REVSYS (Revisionary Syntheses in Systematics) award from the US National Science Foundation (DEB 1419394).

\section{References}

Adams H. \& Adams A. 1853-1858. The Genera of Recent Mollusca; Arranged According to their Organization. London, J. van Voorst. Volume 1: xl + 484 pp; Volume 2: $661 \mathrm{pp}$; Volume 3: 138 pls. [Published in parts: Vol. 1: i-xl (1858), 1-256 (1853), 257-484 (1854). Vol. 2: 1-92 (1854), 93-284 (1855), 285-412 (1856), 413-540 (1857), 541-661 (1858). Vol. 3: pl. 1-32 (1853), 33-96 (1855), 97112 (1856), 113-128 (1857), 129-138 (1858).] https://doi.org/10.5962/bhl.title.4772

Ashkenazy H., Cohen O., Pupko T. \& Huchon D. 2014. Indel reliability in indel-based phylogenetic inference. Genome Biology and Evolution 6 (12): 3199-3209. https://doi.org/10.1093/gbe/evu252

Audouin V. \& Milne-Edwards H. 1832-1834. Recherches pour servir à l'histoire naturelle du littoral de la France. Crochard, Paris. 2 volumes [Vol. 1: 406 pp.; Vol. 2: 290 pp., 8 pls.]. https://doi.org/10.5962/bhl.title.43796

Baker H.B. 1938. Nomenclature of Onchidiidae. The Nautilus 51: 85-88. https://doi.org/10.5962/bhl.part.10914

Bourke A.J. 2016. Field identification of the Platevindex mangrove slugs (Mollusca: Gastropoda: Onchidiidae) of Darwin Harbour. Northern Territory Naturalist 27: 102-105.

Bretnall W. 1919. Onchidiidae from Australia and the south-western Pacific Islands. Records of the Australian Museum 12: 303-328. https://doi.org/10.3853/j.0067-1975.12.1919.888 
Britton K.M. 1984. The Onchidiacea (Gastropoda, Pulmonata) of Hong Kong with a worldwide review of the genera. Journal of Molluscan Studies 50: 179-191.

https://doi.org/10.1093/oxfordjournals.mollus.a065863

Buchannan F. 1800. An account of the Onchidium, a new genus of the class of Vermes, found in Bengal. Transactions of the Linnean Society of London 5: 132-134. https://doi.org/10.1111/j.1096-3642.1800.tb00584.x

Cannicci S., Ruwa R.K., Giuggioli M. \& Vannini M. 1998. Predatory activity and spatial strategies of Epixanthus dentatus (Decapoda: Oziidae), an ambush predator among the mangroves. Journal of Crustacean Biology 18 (1): 57-63. https://doi.org/10.1163/193724098X00061

Colgan D.J., Ponder W.F. \& Eggler P.E. 2000. Gastropod evolutionary rates and phylogenetic relationships assessed using partial 28S rDNA and histone H3 sequences. Zoologica Scripta 29: 29-63.

https://doi.org/10.1046/j.1463-6409.2000.00021.x

Collinge W.E. 1901. On the anatomy of a collection of slugs from N.W. Borneo. Transactions of the Royal Society of Edinburgh 40: 295-312. Available from https://biodiversitylibrary.org/page/41678716 [accessed 20 Jan. 2020].

Collinge W.E. 1902. Description of a new species of Onchidium from South Africa. The Journal of Malacology 9: 17. Available from https://biodiversitylibrary.org/page/28220831 [accessed 20 Jan. 2020].

Collinge W.E. 1910. The slugs of Natal. Annals of the Natal Museum 2 (2): 159-174. Available from https://biodiversitylibrary.org/page/6322951 [accessed 20 Jan. 2020].

Connolly M. 1912. A revised reference list of South African non-marine Mollusca; with descriptions of new species in the South African Museum. Annals of the South African Museum 11: 59-306. Available from https://biodiversitylibrary.org/page/1521968 [accessed 20 Jan. 2020].

Connolly M. 1939. A monographic survey of South African non-marine Mollusca. Annals of the South African Museum 33: 1-660. Available from https://biodiversitylibrary.org/page/40865351 [accessed 20 Jan. 2020].

Cretella M. 2010. The complete collation and dating of the section Zoologie of the Coquille voyage. Bollettino Malacologico 46: 83-103. Available from https://biodiversitylibrary.org/page/51117488 [accessed 20 Jan. 2020].

Dall W.H. 1885. Notes on some Floridian land and fresh-water shells with a revision of the Auriculacea of the eastern United States. Proceedings of the U.S. National Museum 8: 255-289. Available from https://biodiversitylibrary.org/page/15383195 [accessed 20 Jan. 2020].

Dayrat B. 2009. Review of the current knowledge of the systematics of Onchidiidae (Mollusca: Gastropoda: Pulmonata) with a checklist of nominal species. Zootaxa 2068: 1-26.

https://doi.org/10.11646/zootaxa.2068.1.1

Dayrat B. 2010. Anatomical re-description of the terrestrial onchidiid slug Semperoncis montanta (Plate, 1893). Malacologia 52 (1):1-20. https://doi.org/10.4002/040.052.0101

Dayrat B. \& Goulding T.C. 2017. Systematics of the onchidiid slug Onchidina australis (Mollusca: Gastropoda: Pulmonata). Archiv für Molluskenkunde 146: 121-133.

https://doi.org/10.1127/arch.moll/146/121-133

Dayrat B., Conrad M., Balayan S., White T.R., Albrecht C., Golding R., Gomes S.R., Harasewych M.G. \& de Frias Martins A.M. 2011. Phylogenetic relationships and evolution of pulmonate gastropods (Mollusca): New insights from increased taxon sampling. Molecular Phylogenetics and Evolution 59: 425-437. https://doi.org/10.1016/j.ympev.2011.02.014 
Dayrat B., Goulding T.C., Apte D., Bhave V., Comendador J., Ngô X.Q., Tan S.K. \& Tan S.H. 2016. Integrative taxonomy of the genus Onchidium Buchannan, 1800 (Mollusca: Gastropoda: Pulmonata: Onchidiidae). ZooKeys 636: 1-40. https://doi.org/10.3897/zookeys.636.8879

Dayrat B., Goulding T.C., Apte D., Bhave V. \& Ngô X.Q. 2017. A new genus and four new species of onchidiid slugs from South-East Asia (Mollusca: Gastropoda: Pulmonata: Onchidiidae). Journal of Natural History 51: 1851-1897. https://doi.org/10.1080/00222933.2017.1347297

Dayrat B., Goulding T.C., Khalil M., Lozouet P. \& Tan S.H. 2018. Systematic revision one clade at a time: A new genus of onchidiid slugs from the Indo-West Pacific (Gastropoda: Euthyneura: Pulmonata). Raffles Bulletin of Zoology 66: 814-837. Available from https://kcnhm.nus.edu.sg/app/uploads/2018/01/66rbz814-837.pdf [accessed 20 Jan. 2020].

Dayrat B., Goulding T.C., Khalil M., Apte D., Bourke B., Comendador J. \& Tan S.H. 2019a. A new genus and three new species of mangrove slugs from the Indo-West Pacific (Mollusca: Gastropoda: Pulmonata: Onchidiidae). European Journal of Taxonomy 500: 1-77. https://doi.org/10.5852/ejt.2019.500

Dayrat B., Goulding T.C., Khalil M., Comendador J., Ngô X.Q., Tan S.K. \& Tan S.H. 2019b. A new genus of air-breathing marine slugs from South-East Asia (Gastropoda: Pulmonata: Onchidiidae). ZooKeys 877: 31-80. https://doi.org/10.3897/zookeys.877.36698

Dayrat B., Goulding T.C., Bourke B., Khalil M. \& Tan S.H. 2019c. New species and new records of Melayonchis slugs (Gastropoda: Euthyneura: Pulmonata: Onchidiidae). Raffles Bulletin of Zoology 67: 557-585. Available from https://lkcnhm.nus.edu.sg/app/uploads/2019/01/RBZ-2019-0043.pdf [accessed 20 Jan. 2020].

Dayrat B., Goulding T.C., Khalil M., Apte D. \& Tan S.H. 2019d. A new species and new records of Onchidium slugs (Gastropoda, Euthyneura, Pulmonata, Onchidiidae). ZooKeys 892: 27-57. https://doi.org/10.3897/zookeys.892.39524

Dayrat B., Goulding T.C., Apte D., Aslam S., Bourke A.J., Comendador J., Khalil M., Ngô X.Q., Tan S.K. \& Tan S.H. 2020. Systematic revision of Peronia Fleming, 1822 (Gastropoda, Euthyneura, Pulmonata, Onchidiidae). ZooKeys 972: 1-224. https://doi.org/10.3897/zookeys.972.52853

Dorenbosch M., Grol M.G.G., Christianen J.A., Nagelkerken I. \& van der Velde G. 2005. Indo-Pacific seagrass beds and mangroves contribute to fish density and diversity on adjacent coral reefs. Marine Ecology Progress Series 302: 63-76. https://doi.org/10.3354/meps302063

Ellison A.M., Farnswoth E.J. \& Merkt R.W. 1999. Origin of mangrove ecosystems and the mangrove biodiversity anomaly. Global Ecology and Biogeography 8: 95-115. https://doi.org/10.1046/j.1466-822X.1999.00126.x

Fleming J. 1822. Mollusca. In: Napier M. (ed.) Supplement to the Fourth, Fifth and Sixth Editions of the Encyclopcedia Britannica. Volume 5: 567-584. Edinburgh.

Folmer O., Black M., Hoeh W., Lutz R. \& Vrijenhoek R. 1994. DNA primers for amplification of mitochondrial cytochrome c oxidase subunit I from diverse metazoan invertebrates. Molecular Marine Biology and Biotechnology 3: 294-299.

Funk D.J. \& Omland K.E. 2003. Species-level paraphyly and polyphyly: frequency, causes, and consequences, with insights from animal mitochondrial DNA. Annual Review of Ecology, Evolution, and Systematics 34 (1): 397-423. https://doi.org/10.1146/annurev.ecolsys.34.011802.132421

Geller J., Meyer C., Parker M. \& Hawk H. 2013. Redesign of PCR primers for mitochondrial cytochrome $c$ oxidase subunit I for marine invertebrates and application in all-taxa biotic surveys. Molecular Ecology Resources 13: 851-861. https://doi.org/10.1111/1755-0998.12138 
Goulding T.C., Khalil M., Tan S.H. \& Dayrat B. 2018a. A new genus and a new species of onchidiid slugs from eastern Indonesia (Gastropoda: Euthyneura: Onchidiidae). Raffles Bulletin of Zoology 66: 337-349. Available from https://kcnhm.nus.edu.sg/app/uploads/2018/01/66rbz814-837.pdf [accessed 20 Jan. 2020].

Goulding T.C., Khalil M., Tan S.H. \& Dayrat B. 2018b. Integrative taxonomy of a new and highly-diverse genus of onchidiid slugs from the Coral Triangle (Gastropoda: Pulmonata: Onchidiidae). ZooKeys 763: 1-111. https://doi.org/10.3897/zookeys.763.21252

Goulding T.C., Tan S.H., Tan S.K., Apte D., Bhave V., Narayana S., Salunkhe R. \& Dayrat B. 2018c. A revision of Peronina Plate, 1893 (Gastropoda: Euthyneura: Onchidiidae) based on mitochondrial and nuclear DNA sequences, morphology, and natural history (Gastropoda: Pulmonata: Onchidiidae). Invertebrate Systematics 32 (4): 803-826. https://doi.org/10.1071/is17094

Gray J.E. 1850. Figures of Molluscous Animals Selected from Various Authors. Etched for the Use of Students by M.E. Gray. Volume IV. Longman, Brown, Green and Longmans, London. https://doi.org/10.5962/bhl.title.4772

Guindon S. \& Gascuel O. 2003. A simple, fast, and accurate algorithm to estimate large phylogenies by maximum likelihood. Systematic Biology 52: 696-704. https://doi.org/10.1080/10635150390235520

Hassouna N., Mithot B. \& Bachellerie J.P. 1984. The complete nucleotide sequence of mouse 28S rRNA gene. Implications for the process of size increase of the large subunit rRNA in higher eukaryotes. Nucleic Acids Research 12: 3563-3583. https://doi.org/10.1093/nar/12.8.3563

Herrmannsen A.N. 1846-1852. Index Generum Malacozoorum Primordia. T. Fischer, Cassell [Kassel, Germany]. Volume 1: 1-232 [1846], 233-637 [1847]; Volume 2: 1-352 [1847], 353-492 [1848], 493717 [1849]; Supplement: v + 1-140 [1852].

Available from https://www.biodiversitylibrary.org/page/10695423 [accessed 20 Jan. 2020].

Hoeksema B.W. 2007. Delineation of the Indo-Malayan centre of maximum marine biodiversity: the Coral Triangle. In: Renema W. (ed.) Biogeography, Time, and Place: Distributions, Barriers, and Islands: 117-178. Springer, Dordrecht, the Netherlands. https://doi.org/10.1007/978-1-4020-6374-9_5

Hill B.J. 1976. Natural food, foregut clearance-rate and activity of the crab Scylla serrata. Marine Biology 34 (2): 109-116. https://doi.org/10.1007/BF00390752

Hoffmann H. 1928. Zur Kenntnis der Oncidiiden. Zoologische Jahrbücher (Jena) 55: 29-118.

Hoffmann H. 1932. Nacktschnecken aus dem Bismarck-Archipel. Zoologischer Anzeiger, Leipzig 100: 133-149.

Hughes J.M. 1984. A note on predation by toadfish Spheroides spp. on the snail Littorina scabra. In: Coleman R.J., Covacevich J. \& Davie P. (eds) Focus on Stradbroke: 312-314. Boolarong, Brisbane.

Johnson R.I. 1969. Semper's Reisen im Archipel der Philippenen [sic], wissenshaftliche [sic] Resultate, 1867-1916. A complete collation. Journal of the Society for the Bibliography of Natural History 5: 144-147. https://doi.org/10.3366/jsbnh.1969.5.2.144

Katoh K., Misawa K., Kuma K. \& Miyata T. 2002. MAFFT: a novel method for rapid multiple sequence alignment based on fast Fourier transform. Nucleic Acids Research 30: 3059-3066.

https://doi.org/10.1093/nar/gkf436

Kearse M., Moir R., Wilson A., Stones-Havas S., Cheung M., Sturrock S., Buxton S., Cooper A., Markowitz S., Duran C., Thierer T., Ashton B., Mentjies P. \& Drummond A. 2012. Geneious Basic: an integrated and extendable desktop software platform for the organization and analysis of sequence data. Bioinformatics 28 (12): 1647-1649. https://doi.org/10.1093/bioinformatics/bts199 
Kristensen E., Bouillon S., Dittmar T. \& Marchand C. 2008. Organic carbon dynamics in mangrove ecosystems: a review. Aquatic Botany 89 (2): 201-219. https://doi.org/10.1016/j.aquabot.2007.12.005

Kumar S., Stecher G. \& Tamura K. 2016. MEGA7: Molecular Evolutionary Genetics Analysis version 7.0 for bigger datasets. Molecular Biology and Evolution 33: 1870-1874.

https://doi.org/10.1093/molbev/msw054

Labbé A. 1934. Les Silicodermés (Labbé) du Muséum d'Histoire naturelle de Paris. Première partie: Classification, formes nouvelles ou peu connues. Annales de l'Institut océanographique 14: 173-246.

Lanfear R., Calcott B., Ho S.Y. \& Guindon S. 2012. PartitionFinder: combined selection of partitioning schemes and substitution models for phylogenetic analyses. Molecular Biology and Evolution 29 (6): 1695-1701. https://doi.org/10.1093/molbev/mss020

Lee S.Y. 2008. Mangrove macrobenthos: assemblages, services, and linkages. Journal of Sea Research 59: 16-29. https://doi.org/10.1016/j.seares.2007.05.002

Lesson R.P. 1830-1831. Voyage autour du monde, Exécuté par Ordre du Roi, sur La Corvette de Sa Majesté, La Coquille, pendant les années 1822, 1823, 1824 et 1825, sous le ministère et conformément aux Instructions de S.E.M. le Marquis de Clermont-Tonnerre, Ministre de la Marine; Et publié sous les auspices de son Excellence Mgr le Cte de Chabrol, Ministre de la Marine et des Colonies, par M.L.I. Duperrey, Capitaine de Frégate, Chevalier de Saint-Louis et Membre de la Légion d'Honneur, Commandant de 1'Expédition. Zoologie, par M. Lesson. Volume 2, Part 1: 1-471, pls 1-16. Arthus Bertrand, Libraire-Editeur, Paris. [pp 241-471 published on 15 Nov. 1831; plates on mollusks published between 9 Jan. 1830 and 22 Dec. 1831; plate 14 published on 15 Nov. 1831; see Cretella 2010]. https://doi.org/10.5962/bhl.title.57936

Lloyd D.G. \& Calder V.L. 1991. Multiresidue gaps, a class of molecular characters with exceptional reliability for phylogenetic analyses. Journal of Evolutionary Biology 4 (1): 9-21. https://doi.org/10.1046/j.1420-9101.1991.4010009.x

Long J., Napton D., Giri C. \& Graesser J. 2014. A mapping and monitoring assessment of the Philippines mangrove forests from 1990 to 2010. Journal of Coastal Research 30 (2): 260-271.

https://doi.org/10.2112/JCOASTRES-D-13-00057.1

Lovelock C.E., Cahoon D.R., Friess D.A., Guntenspergen G.R., Krauss K.W., Reef R., Rogers K., Saunders M., Sidik F., Swales A., Saintilan N., Thuyen L.X. \& Triet T. 2015. The vulnerability of IndoPacific mangrove forests to sea level rise. Nature 526: 559-563. https://doi.org/10.1038/nature15538

Luther D.A. \& Greenberg R. 2009. Mangroves: A global perspective on the evolution and conservation of the terrestrial vertebrates. BioScience 59 (7): 602-612. https://doi.org/10.1525/bio.2009.59.7.11

Martens E. von. 1897. Süss- und Brackwasser-Mollusken des Indischen Archipels. Zoologische Ergebnisse einer Reise in Niederländisch Ost-Indien 4: 1-332. https://doi.org/10.5962/bhl.title.46994

Miller M.A., Pfeiffer W. \& Schwartz T. 2010. Creating the CIPRES Science Gateway for inference of large phylogenetic trees. In: Proceedings of the Gateway Computing Environments Workshop (GCE 2010): 1-8. https://doi.org/10.1109/GCE.2010.5676129

Milne I., Wright F., Rowe G., Marshal D.F., Husmeier D. \& McGuire G. 2004. TOPALi: Software for automatic identification of recombinant sequences within DNA multiple alignments. Bioinformatics 20: 1806-1807. https://doi.org/10.1093/bioinformatics/bth155

Nagy L.G., Kocsubé S., Csanádi Z., Kovács G.M., Petkovits T., Vágvölgyi C. \& Papp T. 2012. Remind the gap! Insertion-deletion data reveal neglected phylogenetic potential of the nuclear ribosomal internal transcribed spacer (ITS) of fungi. PloS One 7 (11): e49794.

https://doi.org/10.1371/journal.pone.0049794 
Odhner N.H.J. 1917. Results of Dr. E. Mjöbergs Swedish scientific expeditions to Australia 1910-1913, XVII. Mollusca. Kungliga Svenska Vetenskapsakademiens Handlingar Stockholm 52: 1-115. https://doi.org/10.5962/bhl.title.12985

Palumbi S.R. 1996. Nucleic acid II: The polymerase chain reaction. In: Hillis D.M., Moritz C., Mable B.K. (eds) Molecular Systematics. Second edition: 205-247. Sinauer Press, Sunderland, MA.

Pinceel J., Jordaens K. \& Backeljau T. 2005. Extreme mtDNAdivergences in a terrestrial slug (Gastropoda, Pulmonata, Arionidae): accelerated evolution, allopatric divergence and secondary contact. Journal of Evolutionary Biology 18: 1264-1280. https://doi.org/10.1111/j.1420-9101.2005.00932.x

Plate L.H. 1893. Studien über opisthopneumone Lungenschnecken, II, Die Oncidiiden. Zoologische Jahrbücher, Abtheilung für Anatomie und Ontogenie der Thiere 7: 93-234.

Available from https://biodiversitylibrary.org/page/11175213 [accessed 27 Sep. 2016].

Puillandre N., Lambert A., Brouillet S. \& Achaz G. 2011. ABGD, Automatic Barcode Gap Discovery for primary species delimitation. Molecular Ecology 21: 1864-1877.

https://doi.org/10.1111/j.1365-294X.2011.05239.x

Quoy J.R.C. \& Gaimard J.P. 1824-1826. Zoologie. Voyage autour du Monde entrepris par ordre du Roi, sous le ministère et conformément aux instructions de S. Exc. M. Le Vicomte du Bouchage, secrétaire d'État au Département de la Marine, exécuté sur les corvettes de S.M. l'Uranie et la Physicienne, pendant les années 1817, 1818, 1819 et 1820; publié par M. Louis de Freycinet. Pillet Aîné, Paris. 2 volumes [Volume 1: vii + 712 pp; Volume 2: 96 pls (atlas)]. https://doi.org/10.5962/bhl.title.15862

Quoy J.R.C. \& Gaimard J.P. 1832-1833. Zoologie, Tome Second. Voyage de découvertes de l'Astrolabe exécuté par ordre du Roi, pendant les années 1826-1827-1828-1829, sous le commandement de M.J. Dumont d'Urville. J. Tastu, Paris. https://doi.org/10.5962/bhl.title.2132

Rafinesque C.S. 1815. Analyse de la nature ou tableau de l'univers et des corps organisés. Self-published by the author, Palermo. https://doi.org/10.5962/bhl.title.106607

Rambaut A., Drummond A.J., Xie D., Baele G. \& Suchard M.A. 2018. Posterior summarization in Bayesian phylogenetics using Tracer 1.7. Systematic Biology 67 (5): 901-904.

https://doi.org/10.1093/sysbio/syy032

Richards D.R. \& Friess D.A. 2016. Rates and drivers of mangrove deforestation in Southeast Asia, 2000-2012. Proceedings of the National Academy of Sciences 113 (2): 344-349.

https://doi.org/10.1073/pnas.1510272113

Rochebrune A.T. de. 1882. Documents sur la faune malacologique de la Cochinchine et du Cambodge. Bulletin de la Société philomathique de Paris 6: 35-74.

Available from https://www.biodiversitylibrary.org/page/31660821 [accessed 7 Aug. 2020].

Ronquist F. \& Huelsenbeck J.P. 2003. MrBayes 3: Bayesian phylogenetic inference under mixed models. Bioinformatics 19: 1572-1574. https://doi.org/10.1093/bioinformatics/btg180

Sabri N.A. \& Singh H.R. 2018. Distribution and abundance of the Onchidiidae of the coastal mangroves of Selangor, Peninsular Malaysia. International Journal of Engineering \& Technology 7 (4.14): 67-71.

Semper C. 1880-1885. Dritte Familie, Onchidiidae. In: Semper C. (ed.) Reisen im Archipel der Philippinen. Zweiter Theil. Wissenschaftliche Resultate. Dritter Band. Landmollusken: 251-264 [1880], 265-290 [1882], pls 19-20, 22-23 [1880], pl. 21 [1882], pls 24-27 [1885]. C.W. Kreidel, Wiesbaden, Germany. Available from https://biodiversitylibrary.org/page/32630046 [accessed 22 Dec. 2018].

Simmons M.P., Ochoterena H. \& Carr T.G. 2001. Incorporation, relative homoplasy, and effect of gap characters in sequence-based phylogenetic analyses. Systematic Biology 50 (3): 454-462.

https://doi.org/10.1080/106351501300318049 
Simroth H. 1920. Über einige Nacktschnecken vom Malayischen Archipel von Lombok an ostwärts bis zu den Gesellschafts-Inseln. Abhandlungen der Senckenbergischen Naturforschenden Gesellschaft 35: 259-306. Available from https://biodiversitylibrary.org/page/48256899 [accessed 22 Dec. 2018].

Smith G.R. 1992. Introgression in fishes: significance for paleontology, cladistics, and evolutionary rates. Systematic Biology 41 (1): 41-57. https://doi.org/10.1093/sysbio/41.1.41

Soltis P.S. \& Soltis D.E. 2003. Applying the bootstrap in phylogeny reconstruction. Statistical Science 18 (2): 256-267. https://doi.org/10.1214/ss/1063994980

Spalding M.D., Blasco F. \& Field C.D. 1997. World Mangrove Atlas. International Society for Mangrove Ecosystems, Okinawa, Japan. Available from http://www.environmentalunit.com/Documentation/04\%20 Resources\%20at\%20Risk/World\%20mangrove\%20atlas.pdf [accessed 23 Feb. 2021].

Stamatakis A. 2014. RAxML version 8: a tool for phylogenetic analysis and post-analysis of large phylogenies. Bioinformatics 30 (9): 1312-1313. https://doi.org/10.1093/bioinformatics/btu033

Stantschinsky W. 1907. Zur Anatomie und Systematik der Gattung Onchidium. Zoologische Jahrbücher, Abteilung für Systematik, Geographie und Biologie der Tiere 25: 353-402.

https://doi.org/10.5962/bhl.part.11959

Starobogatov Y.I. 1976. Composition and taxonomic position of marine pulmonate mollusks. Soviet Journal of Marine Biology 4: 206-212.

Stoliczka F. 1869. The malacology of lower Bengal and the adjoining provinces. Journal of the Asiatic Society of Bengal 38: 86-111. Available from https://www.biodiversitylibrary.org/item/128669\#page/366/mode/1up [accessed 27 Sep. 2016]

Sun B., Chen C., Shen H., Zhang K., Zhou N. \& Qian J. 2014. Species diversity of Onchidiidae (Eupulmonata: Heterobranchia) on the mainland of China based on molecular data. Molluscan Research 34: 62-70. https://doi.org/10.1080/13235818.2013.868860

Swofford D.L. 2002. PAUP: Phylogenetic Analysis Using Parsimony, version 4.0b10. Sinauer, Sunderland, MA.

Takagi M., Takao Y., Mizuno K. \& Ieyama H. 2019. Genetic diversity of Onchidiidae in Japan. Fauna Ryukyuana 49: 23-37.

Tan K.S. \& Oh T.M. 2002. Feeding habits of Chicoreus capucinus (Neogastropoda: Muricidae) in a Singapore mangrove. Bollettino Malacologico 38: 43-50. Available from http://www.societaitalianadimalacologia.it/Bollettino/Supplemento\%204/Boll.\%20Mal.\%202002\%20 43-50.pdf [accessed 20 Jan. 2020].

Tapparone-Canefri C. 1883. Fauna malacologica delle Nuova Guinea e delle Isole adiacenti. Annali del Museo Civico di Storia Naturale, Genova 19: 1-313.

Available from https://biodiversitylibrary.org/page/10812600 [accessed 22 Dec. 2018].

Thomaz D., Guiller A. \& Clarke B. 1996. Extreme divergence of mitochondrial DNA within species of pulmonate land snails. Proceedings of the Royal Society B 263: 363-368.

https://doi.org/10.1098/rspb.1996.0056

Tillier S. 1983. A new mountain Platevindex from Philippine Islands (Pulmonata: Onchidiidae). Journal of Molluscan Studies Suppl. 12A: 198-202. https://doi.org/10.1093/oxfordjournals.mollus.a065743

Valiela I., Bowen J.L. \& York J.K. 2001. Mangrove forests: one of the World's threatened major tropical environments. BioScience 51 (10): 807-815.

https://doi.org/10.1641/0006-3568(2001)051\%5B0807:MFOOTW\%5D2.0.CO;2 
Vo Q.T., Kuenzer C., Vo Q.M., Moder F. \& Oppelt N. 2012. Review of valuation methods for mangrove ecosystem services. Ecological Indicators 23: 431-446. https://doi.org/10.1016/j.ecolind.2012.04.022

Vonnemann V., Schrödl M., Klussmann-Kolb A. \& Wägele H. 2005. Reconstruction of the phylogeny of the Opisthobranchia (Mollusca: Gastropoda) by means of $18 \mathrm{~S}$ and 28S rRNA gene sequences. Journal of Molluscan Studies 71: 113-125. https://doi.org/10.1093/mollus/eyi014

Wade C.M. \& Mordan P.B. 2000. Evolution within the gastropod molluscs; using the ribosomal RNA gene-cluster as an indicator of phylogenetic relationships. Journal of Molluscan Studies 66: 565-570. https://doi.org/10.1093/mollus/66.4.565

Westerlund C.A. 1883. Noch einige von der Vega-Expedition gesammelte Mollusken. Nachrichtsblatt der deutschen malakozoologischen Gesellschaft 15: 164-166.

Woodward B.B. 1894. Mollusca. Zoological Record 30: 57.

Yuri T., Kimball R.T., Harshman J., Bowie R.C., Braun M.J., Chojnowski J.L., Han K.L., Hackett S.J., Huddleston C.J., Moore W.S., Reddy S., Sheldon F.H., Steadman D.W., Witt C.C. \& Braun E.L. 2013. Parsimony and model-based analyses of indels in avian nuclear genes reveal congruent and incongruent phylogenetic signals. Biology 2 (1): 419-444. https://doi.org/10.3390/biology2010419

Zhang K., Wang D., Shen H., Qian J., Guan H., Wu H. \& Gao Y. 2017. Redescription of Platevindex mortoni (Gastropoda: Eupulmonata: Onchidiidae) from China. Molluscan Research 37: 72-78.

https://doi.org/10.1080/13235818.2016.1223535

Manuscript received: 4 April 2020

Manuscript accepted: 14 October 2020

Published on: 8 March 2021

Topic editor: Rudy Jocqué

Section editor: Thierry Backeljau

Desk editor: Danny Eibye-Jacobsen

Printed versions of all papers are also deposited in the libraries of the institutes that are members of the EJT consortium: Muséum national d'histoire naturelle, Paris, France; Meise Botanic Garden, Belgium; Royal Museum for Central Africa, Tervuren, Belgium; Royal Belgian Institute of Natural Sciences, Brussels, Belgium; Natural History Museum of Denmark, Copenhagen, Denmark; Naturalis Biodiversity Center, Leiden, the Netherlands; Museo Nacional de Ciencias Naturales-CSIC, Madrid, Spain; Real Jardín Botánico de Madrid CSIC, Spain; Zoological Research Museum Alexander Koenig, Bonn, Germany; National Museum, Prague, Czech Republic. 